\title{
DISCLAIMER
}

This repoit wis prepared as an account of work aponsored by an agency of the United States Government. Neither the United States Government nor any agency thereof, nor any of their employees, makes any warranty, expreas or implied, or asumes any legal liability or reapontibility fo: the sccuracy, completerese, or urefulness of any information, apparatus, product, or process dieckoed, or represents that its use would not infringe privately owned rights. Reference berein to any specific commercial product, procese, or ervice by trade anme, trademark, menufacturer, or otherwise does tot necessurily constitute or imply its endoriement, recommendation, of furoring by the United States Government or any agency thereof. The views and opinions of authors expressed berein do nct necessarily stete or reflect those of the United States Government or any agency theroof.

\section{Multivariable Optimization of Fusion Reactor Blankets}

Wayne Raymond Meier
Doctor of Philosophy
UCRL- -53543
in
DE84 014131

\author{
Engineering \\ University of California, Berkeley
}

Manuscript date: April 1984

\section{LAWRENCE LIVERMORE NATIONAL LABORATORY University of California - Livermore, California - 94550}


MULTIVARIABLE OPTIMLZATION OF FUSION REACTOR BLANKETS

\author{
Wayne R. Heier
}

\title{
ABSTRACT
}

The neutron blanket that surrounds the plasma in a deuteriumtritium fusion reactor is an essential component of the system. A method for optinizing the design of a fusion reactor blanket as a function of several design variables is described. The method is applied to two inertial confinement fusion reactor concepts for electilic power production.

The optimization problem consists of four key elements: a figure of merit for the reactor, a technique for estimating the neutronic performance of the blanket as a function of the design variables, constraints on the design varlables and neutronic performance, and a method for optimizing the figure of merit subject to the constraints.

The figure of merit and constraints depend on the application and design objectives of the particular reactor concept. In general, they 
may be functions of the design variables and of the neutronic performance. A variational interpolation method is used to write analytical expressions for the neutronic performance based on a 1 imited number of reference point, neitron transport calculations. This allows the figure of merit and constraints to be evaluated as a function of the design varlables. A direct search, nonlinear simplex method is used to optimize the figure of merit subject to the constraints.

The first reactor concept investigated uses a liquid lithium blanket for breeding tritium and a steel blanket to increase the fuston energy multiplication factor. The capital cost per unit of net electric power produced is minimized subject to constraints on the tritium breeding ratio and radiation damage rate. The optimal design has a 91-cm-thick 11 thium blanket denatured to $0.1 \%^{6} \mathrm{Li}$.

The second reactor concept investigated uses a BeO neutron multiplier and a $\mathrm{LiAlO}_{2}$ breeding blanket. The total blanket thickness is minimized subject to constraints on the tritium breeding ratio, the total neutron leakage, and the heat generation rate in aluminum support tendons. The optimal design consists of a 4.2-cm-thick BeO multiplier and 42-cm-thick $\mathrm{LiAlO}_{2}$ breeding blanket enriched to $34 x^{6}{ }_{L 1}$. 


\section{ACKNONLEDGEMENTS}

I would like to express my apprectation to the many people who helped make this study possible.

First of 211 , I want to thank my wife Carol. From the very start she has unselfishly supported me in the pursult of this goal. Her patience, love, and encouragement have been a great source of inspiration.

I would like to thank my committee chairman, Professor Ed Morse, for his direction and advice in this research. It has been a real pleasure to work with $\mathrm{h} t \mathrm{~m}$. I am alsu grateful to Professors Larry Grossman and Maurice Holt for serving on my dissertation committee.

I am indebted to my colleagues in the reactor studies group for thetr support and recommendations. Jack Hovingh was always ready to hear about my latest results and share his insights. John Pitts has been a continual source of encouragement. The discusstons we had on the Cascade concept and the information he supplied were most useful. I am especially grateful to Jim Blink for taking an interest in my research and taking the time to discuss it. His technical advice is greatly apprectated.

I would also like to thank the past and present leaders of the reactor studies group, Mike Monsler and B11l Hogan, and the Inertial Confinement Fusion Program Leader, John Holzrtchter, for supporting this project. 
A word of thanks also goes to Giles Peterson for helping me with some sticky graphics problems and to Ed Cheng for reviewing an early draft of Chapter 2 .

Finaliy, I am indebted to Karen Hogue for preparing this manuscript. Her skills as a typist and layout artist are evident. 


\section{CONTENTS}

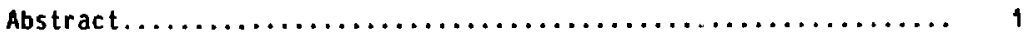

Acknow Tedgements.................................. 191

Table of Contents................................. v

List of figures................................. ix

List of Tables.................................... xiv

Chapter 1. Introduction..............................

1.1 The Importance of Optimal Blanket Design............. 1

1.2 Essential Elements of the Blanket Optimization Problem.... 5

1.2.1 The Figure of Mer1t.................... 6

1.2.2 A lechnique for Estimating Neutronic Performance... 6

1.2.3 Constraints on the Design................. 8

1.2.4 An Optimization Method.................. 8

1.3 Previous Fusion Reactor Optimization Studies............ 10

1.4 Organization of the Thesis...................... 14

Chapter 2. Estimating Neutronic Performance............... 15

2.1 Variational Estimates of Linear Functionals........... 15

2.2 Two Point Variational Interpolation for Fusion Reactors... 20

2.2.1 Two Point Variation Interpolation in Terms of Forward Fluxes......................... 20

2.2.2 Variational Interpolation for Variations in Blanket Composition..................... 23

2.2.3 Singularities of the Two Point Interpolation Formula............................. 25 
2.2.4 Multivariable Estimates Using Two Point Variational Interpolation......................... 28

2.3 Three Point Variational Interpolation for Fusion Reactors. 33 2.3.1 Three Point Variational Interpolation in Terms of Forward fluxes........................ 33

2.3.2 Singularities of the Three Point Interpolation Formula.............................. 36

2.3.3 Multivariable Estimates Using Three Point Variational Interpolation................. 44

2.4 Propagation of Error....................... 48

Chapter 3. Nonlinear Simplex Method for Optimization.......... 58

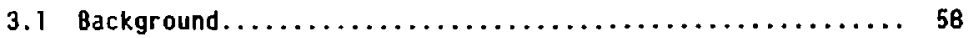

3.2 Description of the Algorithm................... 59

3.3 Convergence $\mathrm{Cr} 1$ tertion.......................... 66

3.4 Handling Constraints........................... 67

Chapter 4. Optimization of a Modified HYLIfE Chamber........... 70

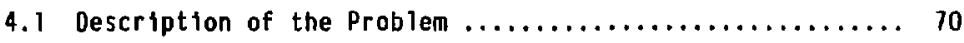

4.1.1 The HYLIfE Reactor Concept................ 70

4.1 .2 Constraints on the Design................. 75

4.1.3 Figure of Merit for HYLIFE.............. 76

4.1.4 Summary............................ 80

4.2 Reference Point Transport Calculations............. 82

4.2.1 TART Monte Carlo Transport Code............. 82

4.2.2 Neutrontcs Model of the Chamber............. 83

4.2.3 Results of the four Initial Transport Calculations. 87 
4.3 Intilal Optimization Results for HYLIFE............. 94

4.3.1 Estimated Neutronic Performance................ 94

4.3.2 Optimal Design Point.................... 108

4.3.3 Comparison to Transport Calculation at Optimal

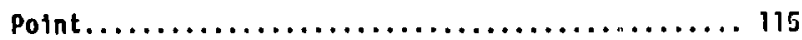

4.4 Improved Estimates of Location of Optimum 118

4.4.1 Improved Estimate Using Taylor Series Expansion

at Originar optimal Point.................. 118

4.4.2 Improved Estimate Using New Set of Four Reference

Points................................. 120

4.4.3 Improved Estimate Using Three Point Interpolation on One vartable........................ 126

4.5 Surmary of Optimization Resuits................. 132

Chapter 5. Optimization of the Cascade Chamber............. 135

5.1 0escription of the Problem.................... 135

5.1.1 The Cascade Reactor Concept............... 135

5.1 .2 Figure of Merit for Cascade............... 137

5.1 .3 Constratnts on the Design............... 138

5.2 Reference Point Transport Calculations............... 141

5.2.1 Neutronics Model of the Casc.ade Chamber.......... 141

5.2.2 Results of the Eight Initial Transport

Calculations........................... 144

5.3 Initial Optimization Results for Cascade........... 151

5.3.1 Estimated Neutrontc Performance............. 151

5.3.2 Optimal Design Point......................... 167 
5.3.3 Comparison to Transport Calculation at Optimal

Point..................................... 169

5.4 Improved Estimate of Location of Optimum........... 172

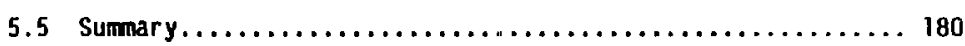

Chapter 6. Conclusion and Recommendations for future Work...... 181

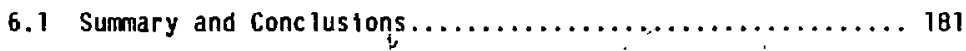

6.2 Recommendations for Future Work................. 184

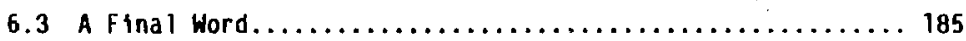

References......................................... 186

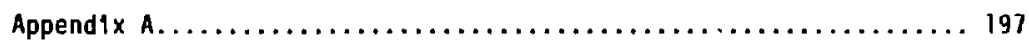

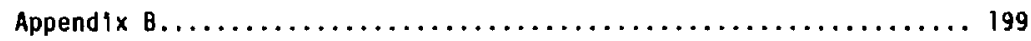




\section{LIST OF FIGURES}

Figure

Page

1.1 Cross sections for tritium producing reactions in 11 thium.. 3

2.1 Illustrative examples of two point variational

interpolation when $\Sigma(x)$ is proportional to $x \ldots \ldots \ldots \ldots .26$

2.2 Location of four reference points for two point

interpolation on two variables.................... 30

2.3 Successive two point interpolation.................. 31

2.4 Location of singularity for three point interpolation

versus $R_{b}$ for a curve with negative second derivatives.... 38

2.5 Envelope of family of curve with three poiat

interpolation for $R(0.2)=2.0$ and $R(0.6)=3.0 \ldots \ldots \ldots .39$

2.6 Location of singularity for three point interpolation

versus $R_{b}$ for a curve with positive second derivatives.... 41

2.7 Envelope of family of curves with three point

Interpolation for $R(0.2)=0.5$ and $R(0.6)=3.0 \ldots \ldots \ldots 42$

2.8 Revised envelope of famtly of curves.............. 43

2.9 Location of nine reference points for three point

interpolation on two variables.................... 45

2.10 Successive three point variational interpolation........ 46

2.11 Illustration of additional error due to successive two point interpotation............................. 50

2.12 Additional error due to successive three point

interpolation for $f_{b}=1.05 \ldots \ldots \ldots \ldots \ldots \ldots \ldots \ldots \ldots \ldots \ldots \ldots \ldots \ldots \ldots, 52$ 
2.13 Additional error due to successive three point interpolation for $f_{b}=1.00 \ldots \ldots \ldots \ldots \ldots \ldots \ldots \ldots \ldots .53$

2.14 Additional error due to successive three point interpolation for $f_{b}=0.95$.

3.1 Four basic moves in Melder and Mead's nonlinear simplex method of optimization.

3.2 Logic flow dtagram of Nelder and Mead's nonlinear simplex method.

3.3 A simple method of handing constraints.............68

3.4 Fox and Liebman's method of handling constraints........ 69

4.1 The HYLIFE concept......................... 71

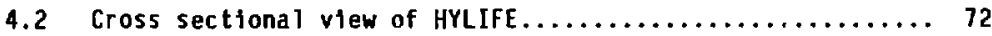

4.3 Cross sectional view of the neutronics model for the modified HYLIFE chamber....................... 84

4.4 Neutrontcs model for the modified HYLIFE chamber........ 85

4.501 splacement damage cross section for 1 ron............ 93

$4.6{ }^{6}{ }_{L I(n, T) a}$ reactions per oT reaction as a function of the ${ }^{6} \mathrm{~L} 1$ fraction and $L 1$ blanket thickness........... 95

4.7 ${ }^{2} L(n, n \cdot T) a$ reactions per oT reaction as a function of the ${ }^{6} L 1$ fraction and the $L 1$ blanket thickness......... 96

4.8 Tritium breeding ratio as a function of the ${ }^{6} \mathrm{Li}$ fraction and $L 1$ blanket thickness................. 97

4.9 Contour plot of the tritium breeding ratio for the modified HYLIFEE chamber $\ldots \ldots \ldots \ldots \ldots \ldots \ldots \ldots \ldots \ldots . \ldots \ldots$ 
4. 10 Displacement damage rate as a function of the ${ }^{6} \mathrm{Lt}$

fraction and the $L i$ blanket thickness................ 100

4.11 Contoui plot of the displacement damage rate........... 101

4.12 Energy deposited in $^{6} \mathrm{Li}$ as a function of the ${ }^{6} \mathrm{Li}$

fraction and the $L 1$ blanket thickness............... 102

4.13 Energy deposited in ${ }^{7} \mathrm{~L} 1$ as a function of the ${ }^{6} \mathrm{L1}$

fraction and the $L 1$ blanket thickness................ 103

4.14 Energy deposited in structures as a function of the

${ }^{6} \mathrm{Li}$ fraction and the $\mathrm{Li}$ blanket thickness............ 105

4.15 lotal energy deposited in the chamber per BT reacilon

as a function of the two design variables.............. 106

4.16 Energy deposited in structures as a function of the two design varlables using the neutron balance method..... 109

4.17 Total energy deposited in the chamber, per OT reaction using the neutron balance method.................. 110

4.18 Contour plot of the fusion arargy multiplication factor for the modified HYLIFE shamber................... 1 il

4.19 Figure of merit as a function of the 5 i fraction and the $L i$ blanket thickness..................... 112

4.20 Contour plot of the figure of merit for the modified HYLIFE chamber.

4.21 First estimate of the location of the optimal design point. 
4.22 Third estimate of the location of the optimal design

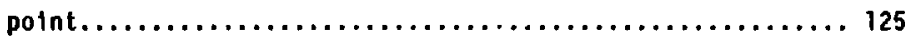

4.23 Fourth estimate of the location of the optimal design point................................ 130

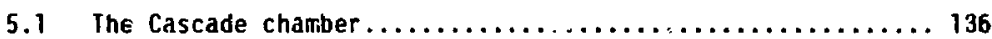

5.2 Neutrontcs model of the Cascade chamber $\ldots \ldots \ldots \ldots \ldots \ldots 142$

5.3 Tritium breeding ratio as a function of ${ }^{6} \mathrm{Li}$ fraction and $\mathrm{L}^{2} \mathrm{ALO}_{2}$ thickness with $0.05 \mathrm{~m}$ of Be0.............. 152

5.4 Contour plot of tritium breeding ratio with $0.05 \mathrm{~m}$ of Be0.. 153

5.5 Tritium breeding ratio as a function of ${ }^{6} L$ fraction and $\mathrm{LAlOO}_{2}$ thickness with 0. ij m of Be0............. 154

5.5 Contour plot of tritium breeding ratio with $0.15 \mathrm{~m}$ of Be0.. 155

5.7 Heat generation rate in Al/SiC tendons as a function. Be0 thickness and $\mathrm{LiAlO}_{2}$ thickness................ 157

5.8 Contour plot of the heat generation rate in the tendons.... 158

5.9 Total neutron leakage per OT reaction as a function of $6_{\mathrm{LI}}$ fraction and $\mathrm{L}^{1 \mathrm{AlO}_{2}}$ thickness with $0.05 \mathrm{~m}$ of $\mathrm{BeO} \ldots \ldots .159$

5.10 Contour plot of neutron leakage with $0.05 \mathrm{~m}$ of Be0....... 160 $\therefore$

5.11 Total neutron leakage per DT reaction as a function of ${ }^{6} L$ fraction and $\mathrm{L}^{1} \mathrm{AlO}_{2}$ thickness w1 th $0.15 \mathrm{~m}$ of BeO........ 162

5.12 Contour plot of neutron leakage with $0.15 \mathrm{~m}$ of BeO...... 163

5.13 Three constraints as a function of ${ }^{6} \mathrm{~L} 1$ fraction and $\mathrm{LiAlO}_{2}$ thickness with $0.05 \mathrm{~m}$ of Be0................. 164 
5.14 Three constraints as a function of ${ }^{6} \mathrm{Li}$ fraction and LiAlO 2 thickness with $0.10 \mathrm{~m}$ of $\mathrm{Be0} \ldots \ldots \ldots \ldots \ldots \ldots \ldots \ldots$

5.15 Three constraints as a function of ${ }^{6} \mathrm{Lt}$ fraction and $\mathrm{LiAlO}_{2}$ thickness with $\mathrm{c} .15 \mathrm{~m}$ of Be0................. 166 5.16 Minimum blanket thickness as a function of Be0 thickness... 168

5.17 first estimate of the location of the optima 1 design point.............................. 170

5.18 New estimate of heat generation rate in Al/Sic tendons.... 176

5.19 Contour plot of new heat generation rate............ 177

$5 . \not 0 \mathrm{Fina} 1$ estimate of location of optimal design point....... 1i8 


\section{LIST OF TABLES}

$\underline{\text { Table }}$

Page

4.1 Reference HYLIfE plant characteristics for comparison....... 79

4.2 Geometric characteristics of the modffied HYLIFE neutronics model .................................... 88

4.3 Matertal compositions of the modtfied HYiIfE neutronics mode 1

4.4 Reaction rates and neutron damage rates for the four inttial reference points.......................... 90

4.5 Energy deposition for the four inftial reference points..... 91

4.6 Comparison of neutronic performance at $x_{1}=0.27 \%$, $x_{2}=0.86 \mathrm{~m}$

4.7 Reaction rates and neutron damage rates for $x_{1}=0.07 \%$, $x_{2}=0.75$ and $1.25 \mathrm{~m}$

4.8 Energy deposition for $x_{1}=0.07 \%, x_{2}=0.75$

and $1.25 \mathrm{~m}$

4.9 Reference results used to interpolate on $x_{2} \ldots \ldots \ldots \ldots \ldots \ldots 123$

4.10 Reaction rates and neutron damage rates for $x_{1}=0.07$ and $0.50 x_{\text {with }} x_{2}=1.00 \mathrm{~m}$

4.11 Energy deposition for $x_{1}=0.07$ and $0.50 x$ with $x_{2}=1.00 \mathrm{~m}$.

4.12 Comparison of TART and estimated results at $x_{1}=0.09 \%$ and $x_{2}=0.91 \mathrm{~m}$. 
4.13 Comparison of HYLIFE and modified HYLIFE parameters at

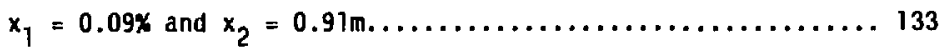

4.14 Summary of Optimal design points discussed in Chapter 4,... 134

\$.1 Geometric characteristics of the Cascade neutronics mode1.... 143

5.2 Composition of materials used in the Cascade neutronics

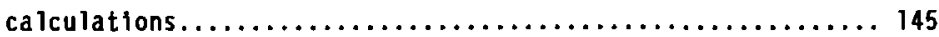

5.3 Reaction rates and neutron balance for transport

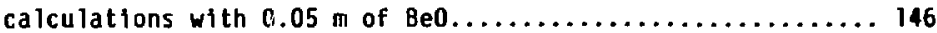

5.4 Energy deposition for the transport calculations with

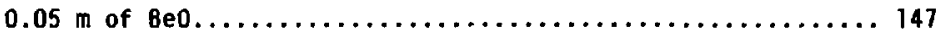

5.5 Reaction rates and neutron balance for transport calculations with $0.05 \mathrm{~m}$ of Be0...................... 148

5.6 Energy deposition for the transport calculations with

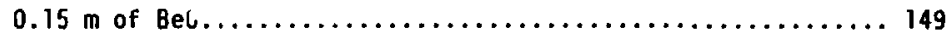

5.7 Comparison of neutronic performance at $x_{1}=63.6 \%$,

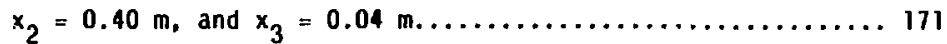

5.8 Photon energy source and deposition in Al/SiC tendons

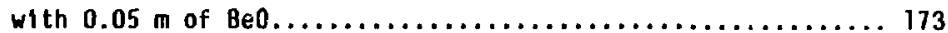

5.9 Photon energy source and deposition in Al/SiC tendons with $0.15 \mathrm{~m}$ of $8 \mathrm{e} 0$.

5.10 Comparison of neutronic performance at $x_{1}=34.2 x$, $x_{2}=0.424 \mathrm{~m}$, and $x_{3}=0.042 \mathrm{~m}$ 


\section{INTRODUCTION}

\subsection{THE IIAPORTANCE OF OPTIMAL BLANKET DESIGN}

Controlled thermonuclear fusion holds the promise of one day providing an environmentally acceptable, safe, and abundant source of energy. As national and international fusion programs progress toward the demonstration of energy breakeven, increasing attention is being given to the future applications of fusion. Conceptual design studies have been carried out for electric power plants, ${ }^{1,2}$ fusion-fission hybrids which produce fissile fuel for fission reactors, $\ddot{3}$ synthetic fue 1 producers, ${ }^{4,5}$ and other applications ${ }^{6}$ of both magnet ic and inertial confinement fusion.

The majority of current fusion research is focused on demonstrating the feasibility of fusing two heavy isotopes of hydrogen, namely, desterium $\left({ }^{2} H\right.$ or $\left.D\right)$ and tritium $\left({ }^{3} H\right.$ or $\left.T\right)$. The or fusion reaction is 7

$$
\mathrm{D}+\mathrm{T} \rightarrow{ }^{4} \mathrm{He}+\mathrm{n} \text {. }
$$

This reaction reledses $17.6 \mathrm{MeV}$; the alpha particles carries off $3.5 \mathrm{MeV}$ and the neutron kinetic energy is $14.1 \mathrm{MeV} .7$

Deuterium is a naturally occurring isotope of hydrogen with an abundance of 1 part in $\sim 6500$. Tritium, on the other hand, is radioactive and $\beta^{-}$decays with a half-life of 12.3 years. Therefore, tritium occurs only in trace quantitles in nature.

The neutron from the DT fusion reaction, however, can be used to produce tritium via reactions with*lithium. The process of producing tritium in a fusion reactor is referred to as tritium breeding: 
Natural lithium has two isotopes, $92.58 \times{ }^{7} \mathrm{~L} 1$ and $7.42 \times{ }^{6} \mathrm{~L} 1$, and both isotopes undergo tritium breeding reactions. These reactions $\operatorname{are}^{8}$

$$
n+{ }^{6} \mathrm{Li} \rightarrow \mathrm{T}+{ }^{4} \mathrm{He}+4.8 \mathrm{MeV},
$$

and

$$
n+{ }^{7} \mathrm{LI} \rightarrow \mathrm{T}+{ }^{4} \mathrm{He}+\mathrm{n}^{\prime}-2.5 \mathrm{MeV} .
$$

As indicated, the breeding reaction with ${ }^{6} \mathrm{Li}$ releases $4.6 \mathrm{MeV}$, while the breeding reaction with ${ }^{7} L_{1}$ consumes $2.5 \mathrm{MeV}$.

The cross sections for these reactions are shown in Fig. 1 (Ref. 9). The 'I.i(n, n'T)a reaction onily occurs with high-energy neutrons, while the cross section for the ${ }^{6} L I(n, T) \alpha$ reaction increases with decreasing neutron energy reaching 21000 b for thermal neutrons. The $7_{L} t$ reaction is very important since it produces a tritium atom and a lower energy neutron that can breed more tritium with ${ }^{6} L i$. As a result, the fusion reactor can achieve a tritium breeding ratio, defined as tritons bred per triton burned, greater than one. A tritlum breeding ratio greater than one is necessary because of the luss of iritium by radioactive decay, and because of losses in the recovery and recycling operations.

Surrounding the fusion plasma is a region within which the neutron kinetic energy is converted to thermal energy and tritium is bred in lithium. This region is referred to as the fusion reactor blanket, neutron blanket or. simply, the blanket. The thermal energy of the blanket is removed by a primary coolant and used to generate electricity. In fusion-fission hybrid applications, fertile materials $\left({ }^{238} \mathrm{u}\right.$ or $\left.{ }^{232} 7 \mathrm{~h}\right)$ are located in the blanket where they absorb neutrons to breed fissile fuel. 


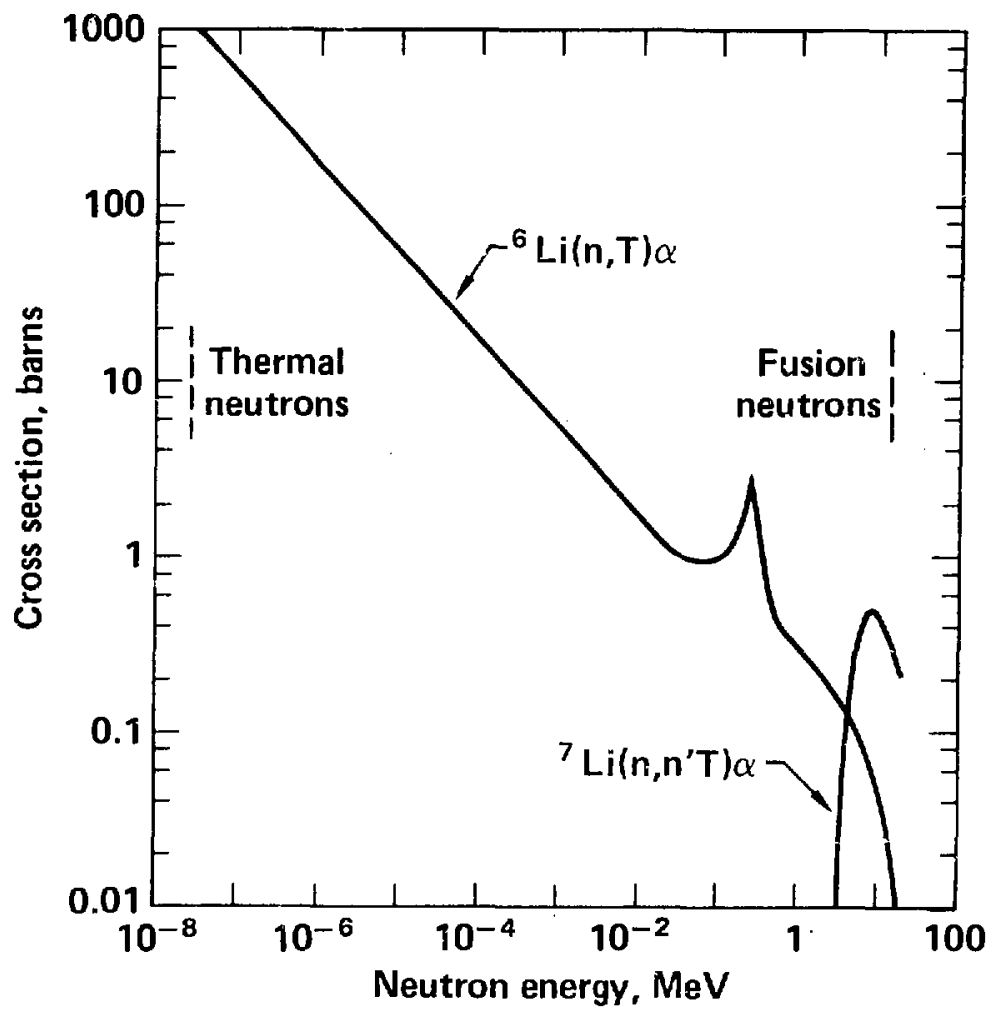

Fig. 1. Cross sections for trittum producing reactions in 1ithlum. $7_{L 1}$ breeds tritium only with high energy neutrons, wher eas the cross section for ${ }^{6} L i(n, T) \alpha$ reactions increases with decreasing neutron energy. 
Since $80 x$ of the energy released in oT fusion is carried by the fusion neutron and since efficient tritium breeding is necessary for a self-suffirlent fuel cycle, optimal blanket design is a key element in effective fusion reactor design. 


\subsection{ESSENTIAL ELEMENTS OF THE BLANKET OPTIMIZATION PROBLEM}

In the early stages of fusion reactor design, considerable latitude exists in the composition and configuration of the blanket. This is evident in reviewing the variety of designs presented in Refs. i and 2. The problem facing the design. engineer is how to select the "best" set of blanket design parameters, 1.e., the materlals, isotopic fractions and geometric factors which define the rianket.

The state of the art in blanket engineering is to develop a point design that meets the system constraints le.g., tritium breeding ratio greater than one) and then to iterate around that point in an effort to come up with a more attractive design (i.e., improve some figure of merit for the system). These modifications are often directed by intuition and experience, and the final design is not necessarily the most attractive. The optimization problem is complicated by the nonlinear interdependence of design and performance parameters and by the fact that modifications of ten produce conflicting effects, improving one system parameter while degrading another.

In this research, a methodology has been developed for systematically determining the design parameters that optimize a figure of merit for the reactor. The blanket optimization problem consists of four essential elements:

1. The figure of merit for the particular reactor design,

2. A technique for estimating the neutronic performance as a function of selected design parameters (the independent variables).

3. Constraints on both the design parameters and the neutronic 
performance, and

4. A method for optimizing the figure of merit subject to the constraints.

\subsubsection{The Figure of Merit.}

The figure of merit will depend on the application and design objectlves of the particular reactor concept. In fact several different figures of merit may be approprlate for a single concept depending on one's perspective. Consider a fuslon electric power plant for example. Minimizing the cost of electricity, minimizing the induced activation and minimizing the plant tritium invertory are each desirable design goals. Fusion-fission hybrids can also have different figures of merit. Some hybrid designs seek to maximize the energy multiplication from fast fission of the fertile material, whereas other concepts seek to suppress fission and maximize the fissile fuel produced per unit of thermal power. 3 In general, the figure of merit can be a function of the design varlabies themselves (composition and configuration) and the neutronic performance of the reactor which depends on these design varlables.

\subsubsection{A Technigue for Estimating Neutronic Performance.}

An important element in the optimization problem is the technique for estimating the neufronic performance of the blanket as a function of the design variables. Neutronic performance refers to the response of the fusion reactor blanket to incident fusion neutrons. In particular, the performance may be characterized by such things as the tritium breeding ratio, the amount of energy deposited as the result of neutron interactions, the neutron damage rate in structural materials and/or the amount of neutron activation. 
The objective of a neutrontcs calculation is to determine the neutronic performance of a reactor blanket with a specific composition and configuration, 1.e., a specific set of design parameters. Neutronics calculations for conceptual fuston reactor blankets are carried out with elther discrete-ordinate or Monte Carlo neutron transport codes. 10

In general, optimization algorithms require the evaluation and comparison of the figure of merit at many different points in the search for the most attractive point. In the case of a fusfon reactor blanket, an evaluation of the neutronic performance is required each time a new point (1.e., a new set of design parameters) is chosen for comparison. One approach would be to perform a new neutronics calculation for each point requested by the optimization algorithm. While this gives a very accurate evaluation of the neutronic performance and, hence, the figure of merit at the point, the computing time required to perform the neutron transport calculations quickly becomes prohibitive. (For example, a single typical Monte Carlo calculation takes 1-3 minutes of CRAY time. This is $~ 10 \%$ of daily time allocation (per machine) for the entire Inertial Confinement Fuston Program at Livermore.)

In this research, a vartational interpolation method is used to evaluate the neutrontc performance. 11,72 with this approach, analytical expressions can be written for the neutronics performance as a function of the design variables based on only a limited number of reference-point, neutron transport calculations. Hance, the figure of merit can be evaluated at any intermediate point without the need for additional transport calculations. 
This technique for estimating the neutronics performance as a function of the selected design varlables 15 discussed in Chapter 2 ,

\subsubsection{Constraints on the Design.}

Constraints limit the acceptable range from which blanket design variabies can be chosen in the attempt to optimize the figure of merit. Constraints can be imposed on design variables, neutronic performance, and factors which depend on the design varlables and/or the neutronic performance. An example of the first type of constraint might be a limit on the blanket thickness. Requiring a tritium breeding ratio greater than 1.05 is an example of the second type. A limit on the allowable capital cost of the fusion reactor is an 1llustration of the third type of constraint.

Clearly the constraints imposed in any optimization poblem will be specific to the system being considered. Just as there may be several interesting and approprtate figures of merit, so there may be several different constraints for the same system. That is, it may be desirable to optimize the blanket under the imposition of different constraints and compare the results.

The manner in which constraints are handled in the optimization probiem is discussed in Chapter 3 .

\subsubsection{An Optimization Method.}

There is a wide variety of potential methods of optimizing a figure of merit. 13 One of the primary considerations in selecting an appropriate method for the blanket optinization problem is the nonlinearity of the system. The neutronics performance, constraints and figure of merit can all be nonlinear functions of the design vartables. Another important consideration is that the form of the 
figure of merit may vary from one problem to another. For this reason a general purpose method is desirable, that is, one which is not dependent on the mathematical characteristics of the figure of merit. The nonlinear simplex method of Nelder and Mead ${ }^{14}$ was chosen for the blanket optimization problem. According to Walsh, ${ }^{13}$ this is one of the most efficient direct search methods available and works particularly well for up to five or six variables. The nonlinear simplex method is described in Chapter 3. 


\subsection{PREVIOLIS FUSION REACTOR OPTIMIZATION STUDIES}

Two basic types of fusion reactor optimization studies nave been carried out in the past. In the first type, a reactur figure of merit is optimized as a functicn of the plasma performance, size of the fusion chamber, and/or other plant parameters assuming that the blanket neutronic performance is fixed. In the second type, a neutronic parameter or a reactor figure of merit is optimized as a function of one or more blanket design vartables assuming that the plasma performence is fixed. Clearly the subject of this research is of the seccind type in that variations in neutronic performance as a function of the blanket design are included in evaluating the figure of merit.

References 15-20 are examples of the first type of optimization study. In each case the blanket neutronic performance was fixed or had simple scaling relationships with the parameters being investigated (i.e., in Ref. 18 the fissile-fuel production rate is proportional to the fusion power). In some cases a limited number of different blanket designs are compared, but the neutronic performance of each design is fixed.

In most of the optimization studies of the second type, a new neutron transport calculation is carried out each time the blanket composition and/or configuration is changed in attempting to optimize the chosen figure of merit. Gerstl's blanket and shield optimization was accomplished by this procedure. ${ }^{21}$ Abdou investigated options and trade-offs in the nuclear design of the blanket/shield of a Tokamak Experimental Power reactor by comparing the neutronic results 
of many dicferent cases. 22 His objective was to minimize the blanket/shield thickness subject to constraints on radiation damage and heating rates in the magnets. The authors of Ref. 23 sought to minimize the peak-to, average fissile fuel production rate across a fuel assembly in the blanket of a fusion-fission hybrid reactor. They did so by comparing this figure of merit for 13 separate cases. In Ref. 24, the cost of electrictty from an EBT power plant was evaluated as a function of several blanket design variables. Separate neutronics calculations were carried out for each modification from the baseline case. As one design variable was changed all others were held fixed. Thus, the results show the dependence of the cost of electricity on each variable independently and not as a function' of . several variables simultaneously. Gohar and Abdou carried out an extensive series of neutronics calculations to define and optimize the neutronic performance of the different solid breeder options for the STARFIRE blanket design. 25 The authors included contour plots of the tritium breeding ratio and heating rates as a function of two variables but did not specify their method. Perkins and Kulcinski reported on the economic optimization of the blanket for the Mirror Advanced Reactor. 26 Their procedure required a neutronics calculation for each iteration in the blanket design.

Some at temitis have been made to reduce the number of neutronics calculations required or io automate the iterative prosess. In their optimization of a magnet shield, Abdou and Maynard used at tenuation coefficients to estimate the heating and neutron damage rates in the magnets for various shield designs. 27 The authors of Ref. 28 studied the optimization of a Tokamak reactor. They estimated nuclear 
reaction rates and héating rates by an analytical expression involving a leading coefficient plus a sum of exponential terms related to the thickness of various blanket zones. According to their report, only a Timited number of neutron transport calculations were required to determine the coefficients of their expression. Engle and Mynatt automated their shield optimization problem by incorporating the transport calculations in the optimization process. 29 Each boundary is varied twice, and a separate neutronics calculation carried out at each position. From these results, the dose-weight derivatives are determined and used to modify the shield configuration in an effort to optimize the design.

Schwartz proposed a method to optimize an economic figure of merit for a fusion-fission hybrid. 30 starting from a reference point, each design variable was changed while holding the others fixed. Neutronics calculations were carried out at each point and the partial derivatives approximated by the finite differences. The economic figure of merit was then expressed in terms of the first order Taylor series expansions. A gradient projection algorithm was used to optimize the design.

Greenspan has developed a method for optimizing a neutronic characteristic of the blanket by varying the distribution of materials within the blanket. 31,32 It can also be used to minimize a blanket characteristic such as total cost, weight or volume. His method is based on a variational technique which uses both forward and adjoint flux calculations. Each iteration requires two transport calculations, one forward and one adjoint, and determines a new material distribution which improves the neutronic charactaristic of 
interest. The method can optimize a single characteristic subject to a single constraint. It is not applicable to problems involving the optimization of broader system parameters such as the cost of electricily.

In this research, a variational interpolation method is used to estimate the neutronic perforinance as a function of more than one varlable stmultaneously. The method provides analytical expressions for the neutronic characteristics as a function of the blanket design variables based on a limited number of neutron transport calculations. This is the subject of Chapter 2. 


\subsection{ORGANIZATION OF THE THESIS}

The remainder of this thesis is divided into five chapters. The variational interpolation method, and how it is used to make multivarlable estimates of the neutronic performance, is described in Chapter 2. The nonlinear simplex optimization method which is used to locate the optimal design point is discussed in Chapter 3 . The techniques developed in Chapters 2 and 3 ar'e applied in Chapters 4 and 5. In Chapter 4, the design of an Inertial Confinement Fusion (ICF) reactor with a liquid lithium breeding blanket is optimized. The second optimization problem, discussed in Chapter 5 , 15 also for an ICF reactor. In this case, however, the blanket contains a solid lithium compound for tritium breeding. Conclusions and suggestions for future work are given in Chapter 6. 


\section{ESTIMATING NEUTRONIC PERFORMAMCE}

In this chapter the technique used to estimate the neutronic performance as a function of the design varlables is described. The heart of the technique is the variational interpolation method described by Cheng and Conn. 11,12 Variational interpolation is a particular application of a broader category of variational methods. Background information and related applications are discussed in Ref5. 33-38 and references cited in these papers.

\subsection{VARIATIONAL ESTIMATES OF LINEAR FUNCTIONALS}

In the study of the neutronics of fusion reactor blankets, one is primarily interested in integral properties which can be written as linear functionals of the neutron flux. Examples include tritium production, nuclear heating, displacement damage, He and $H$ production, and neutron activation rates. Consider for example a reaction rate, $R$. The reaction rate can be expressed as the inner product of the macroscopic reaction cross section and the neutron flux distribution, 37

$$
R=\langle\Sigma, \phi\rangle .
$$

The inner product notation $\langle>$ indicates a sum over all discrete independent variables (e.g., various regions of the blanket) and an integral over all continuous independent variables (e.g., space, 
energy, and direction).

The neutron flux, $\phi$, is the solution to the time independent Boltzmann transport equation, 39

$$
L_{\phi}=S \text {, }
$$

where

$L$ = Transport operator such that

$$
L_{\phi}=\underline{\Omega}-\nabla_{\phi}+\Sigma_{T^{\phi}}-\iint_{\Omega^{\prime}} \int_{E^{\prime}} \Sigma_{T^{\prime}} \phi_{\phi} d \underline{\Omega}^{\prime} d E^{\prime},
$$

$\phi=\phi(\underline{r}, \underline{\underline{Q}}, E)$ the angular flux distribution at position $\underline{r}$. direction $\underline{\underline{\Omega}}$ and energy $E$,

$\Sigma_{T}=\Sigma_{T}([, E)$ the total macroscopic cross section,

$f=f\left(\underline{I}, \underline{\Omega}^{\prime} \rightarrow \underline{\Omega}, E^{\prime} \rightarrow E\right)$ is the transfer probability function

such that $\Sigma_{T}\left(\underline{r}, E^{\prime}\right)$ ff is the transfer kernal for neutron

transfer from $\underline{\Omega}^{\prime}, E^{\prime}$ to $\underline{\Omega}, E$, and

$S=S(I, \Omega, E)$ is the external or independent neutron source.

Let $x$ be a variable that characterizes the blanket. The reaction rate, $R(x)$, can be estimated using the flux, $\phi_{a}$, calculated for some reference system, $x=x_{a}$, in several ways. If we define

$$
\delta_{a} \equiv \phi-\phi_{a},
$$

then

$$
R(x)=\langle\Sigma, \phi\rangle=\left\langle\Sigma, \phi_{a}\right\rangle+\left\langle\Sigma, \delta \phi_{a}\right\rangle
$$


The estimate,

$$
R(x) \simeq\left\langle\Sigma, \phi_{a}\right\rangle
$$

is thicefore in error to first order in $\delta \phi_{a}$.

A variational estimate of $R$ yieids a result accurate to second $\operatorname{order}^{37}$ in $\delta \phi_{\mathrm{a}}$ and $\delta \phi_{\mathrm{a}}^{*}$, where

$$
\delta \phi_{\mathrm{a}}^{*}=\phi^{*}-\phi_{\mathrm{a}}^{*}
$$

The adjcint flux, $\phi^{\star}$, is the solution to

$$
L^{*} \phi^{*}=S^{*}
$$

where the adjoint operator, $L^{*}$, is defined by ${ }^{39}$

$$
\left\langle\phi^{*}, L \phi\right\rangle=\left\langle L^{*} \phi^{*}, \phi\right\rangle \text {. }
$$

Consider for example the Roussopoulos functional defined by: 7,10

$$
R_{R}\left(\phi_{a}^{*}, \phi_{a} ; x\right)=\left\langle S^{*}(x), \phi_{a}\right\rangle+\left\langle\phi_{a}^{*}, S(x)-L(x) \phi_{a}\right\rangle .
$$

In order to give this physical significance, lot $S^{*}=\sum$ so that the adjoint flux can be related to the reaction rate by

$$
\left\langle L^{*}{ }^{*}, \phi\right\rangle=\left\langle S^{*}, \phi\right\rangle=\langle\Sigma, \phi\rangle=R \text {. }
$$


Using Eqs. 2.3, 2.6, and 2.10 in Eq. 2.9 gives

$$
R_{R}=\left\langle\Sigma, \phi-\delta \phi_{a}\right\rangle+\left\langle\phi^{*}-\delta \phi_{a}^{*}, S-L\left(\phi-\delta \phi_{a}\right)\right\rangle .
$$

Expanding gives

$$
R_{R}=\left\langle[, \phi\rangle-\left\langle\left[, \delta \phi_{a}\right\rangle+\left\langle\phi \phi^{\star}-\delta \phi_{a}^{*}, S-L \phi+L \delta \phi_{a}\right\rangle\right. \text {. }\right.
$$

Noting irom Eq. 2.2 that $S-L \phi=0$, Eq. 2.12 becomes

$$
R_{R}=\langle\Sigma, \phi\rangle-\left\langle\Sigma, \delta \phi_{a}\right\rangle+\left\langle\phi^{*}, L \delta \phi_{a}\right\rangle-\left\langle\delta \phi_{a}^{*}, L \delta \phi_{a}\right\rangle .
$$

Note that using Eqs, 2.8 and 2.7 along with the fact that $s^{*}=\varepsilon$, the third term can be written as

$$
\left\langle\phi^{*}, i \delta \phi_{a}\right\rangle=\left\langle L^{*} \phi^{*}, \delta \phi_{a}\right\rangle=\left\langle\Sigma, \delta \phi_{a}\right\rangle \text {. }
$$

Hence the second and third terms of Eq. 2.13 cancel, and we are left with

$$
R_{R}=\langle\Sigma, \phi\rangle-\left\langle\delta \phi_{a}^{*}, L \delta \phi_{a}\right\rangle \text {. }
$$

This demonstrates that the variational estimate, Eq. 2.9, provides a result accurate to second order in $\delta \phi_{a}$ and $\delta \phi_{a}^{*}$ as previously stated.

The varlational interpolation method of estimating $R$ is derived from the Schwinger (fractional) functional, 2 


$$
R_{S}\left(\phi_{a}^{*}, \Phi_{a} ; x\right)=\left\langle\phi_{a}^{*}, S(x)>\left\langle\Sigma(x), \phi_{a}\right\rangle\left\langle\left\langle\phi_{a}^{*}, L(x) \phi_{a}\right\rangle .\right.\right.
$$

The Schwinger functional is derived from the Roussopoulos functional as follows. First, two scale factors are defíned for $\phi_{a}^{\star}$, and $\phi_{a}$, respectively, 37

$$
C^{*} \equiv\left\langle\mathcal{L}, \phi_{\mathrm{a}}\right\rangle /\left\langle\phi_{\mathrm{a}}^{*}, L \phi_{\mathrm{a}}\right\rangle \text {. }
$$

and

$$
C \equiv\left\langle\Phi_{a}^{*}, S\right\rangle /\left\langle\Phi_{a}^{*}, L \Phi_{a}\right\rangle \text {. }
$$

The Roussopoulos functional, Eq. 2.9, for $\mathrm{C}^{*} \Phi_{a}^{*}$ and $\mathrm{C}_{\mathrm{a}}$ becomes

$$
R_{R}\left(C^{*} \phi_{a}^{*}, C \Phi_{a} ; x\right)=\left\langle\Sigma(x), C \Phi_{a}\right\rangle+\left\langle C^{\star} \Phi_{a}^{*}, S(x)\right\rangle-\left\langle C^{\star} \phi_{a}^{*}, L(x) C \Phi_{a}\right\rangle .
$$

Substituting Eqs. 2.17 and 2.18 gives

$$
\begin{aligned}
& R_{R}=\left\langle\varepsilon, \phi_{a}\right\rangle\left\langle\phi_{a}^{*}, S\right\rangle /\left\langle\phi_{a}^{*}, L \phi_{a}\right\rangle+\left\langle\phi_{a}^{*}, S\right\rangle\left\langle\varepsilon, \phi_{a}\right\rangle /\left\langle\phi_{a}^{*}, L \phi_{a}\right\rangle \\
& -<\phi_{a}^{*}, L \phi_{a}><\varepsilon, \phi_{a}><\phi_{a}^{*}, S>/<\phi_{a}^{*}, L \phi_{a}>\left\langle\phi_{a}^{*}, L \phi_{a}>\right.\text {. }
\end{aligned}
$$

Cancelling a $<\phi_{a}^{\star}, L \phi_{a}>$ term in the numerator and denominator of the third term of Eq. 2.20 reveals tha $i$ the third term is just the negative of the first term. Hence Eq. 2.20 reduces to

$$
R_{R}=\left\langle\phi_{a}^{*}, S\right\rangle\left\langle\Sigma, \phi_{a}\right\rangle\left\langle\left\langle\phi_{a}^{*}, L \Phi_{a}\right\rangle,\right.
$$

which is Eq. 2.16. That is,

$$
R_{S}\left(\phi_{a}^{\star}, \Phi_{a} ; x\right)=R_{R}\left(C^{\star} \Phi_{a}^{\star} \cdot C_{\Phi_{a}} ; x\right) \text {. }
$$




\subsection{TWO POINT VARIATIONAL INTERPOLATION FOR FUSION REACTORS}

\subsubsection{Two Point Varlational interpolation in Terms of forward fluxes.}

In this section, the two point varfational interpolation formula is discussed, and an expression in terms of the forward fluxes at $x=x_{a}$ and $x=x_{b}$ is derived. The advantages of this formulation have been pointed out by cheng. 11 in particular since only forward fluxes are involved $\left(\phi_{a}\right.$ and $\left.\phi_{b}\right)$ no adjoint calculations are required. Calculating $\phi_{a}$ and $\phi_{b}$ allows one to interpolate in $x$ on the functional $\langle\Sigma(x), \phi\rangle$ for any $\Sigma(x)$. That 1s, estimates of several different reaction rates, damage rates, etc., can be made based on the results of two transport calculations. This is in contrast to Eq. 2.23 (below) shere an adjoint calculation is required for each $\sum(x)$ (1.e., $s^{\star}$ ) of Interest as indicated by Eq. 2.i.

The Interpolation form of Eq. 2.16 uses the forward flux calculated at $x=x_{a}$ and the adjoint $f l u x$ calculated at a different reference point, $x=x_{b}$. It is given by.

$$
R_{S I}\left(\phi_{b}^{*}, \phi_{a} ; x\right)=\left\langle\phi_{b}^{*}, S(x)>\left\langle\Sigma(x), \phi_{a}\right\rangle /\left\langle\phi_{b}^{*}, L(x) \phi_{a}\right\rangle .\right.
$$

For a fusion reactor blanket the external neutron source is flxed In most cases of interest (1.e., a fixed fusion power level). Therefore,

$$
L\left(x_{a}\right) \phi_{a}=L\left(x_{b}\right) \phi_{b}=S=\text { constant. }
$$


If the perturbation is 1 inear in $x$, then $L(x)$ can be written as

$$
L(x)=L\left(x_{a}\right)+\delta L(x),
$$

where

$$
\delta L(x)=\left[\left(x-x_{a}\right) /\left(x_{b}-x_{a}\right)\right]\left[L\left(x_{b}\right)-L\left(x_{a}\right)\right] .
$$

By substituting Eq. 2.25 into Eq 2.23 and using Eqs. 2.8 and 2.24, the variational interpolation formula can be written in terms of forward fluxes only. Consider the first term in the numerator of Eq. 2.23. Using Eq. 2.24 it can be written as

$$
\left\langle\phi_{b}^{*}, S(x)\right\rangle=\left\langle\phi_{b}^{*}, L\left(x_{b}\right) \phi_{b}\right\rangle .
$$

Then using Eq. 2.8,

$$
\left\langle\phi_{b}^{*}, S(x)\right\rangle=\left\langle L^{*}\left(x_{b}\right) \phi_{b}^{*}, \Phi_{b}\right\rangle .
$$

Using the fact that $L^{*} \phi^{*}=S^{*}=\Sigma$, gives

$$
\left\langle\Phi_{b}^{*}, S(x)\right\rangle=\left\langle\Sigma\left(x_{b}\right), \Phi_{b}\right\rangle
$$

Next consider the denominator of Eq. 2.23. First substitute Eq. 2.25,

$$
\left\langle\phi_{b}^{*}, i(x) \phi_{a}\right\rangle=\left\langle\phi_{b}^{*},\left[L_{a}+\left[\left(x-x_{a}\right) /\left(x_{b}-x_{a}\right)\right]\left(L_{b}-L_{a}\right)\right] \phi_{a}\right\rangle,
$$


where the notation $L_{a}=L\left(x_{a}\right)$ and $L_{b}=L\left(x_{b}\right)$ has been used. Expanding the right hand side of Eq. 2.29 gives

$$
\left\langle\phi_{b}^{*}, L_{a} \phi_{a}\right\rangle+\left[\left(x-x_{a}\right) /\left(x_{b}-x_{a}\right)\right]\left[\left\langle\phi_{b}^{*}, L_{b} \phi_{a}\right\rangle-\left\langle\phi_{b}^{*}, L_{a} \phi_{a}\right\rangle\right]
$$

Using Eqs. 2.24 and 2.8 this becomes

$$
\left\langle L_{b}^{*} \phi_{b}^{*}, \phi_{b}\right\rangle+\left[\left(x-x_{a}\right) /\left(x_{b}-x_{a}\right)\right]\left[\left\langle L_{b}^{*} \phi_{b}^{*}, \Phi_{a}\right\rangle-\left\langle L_{b}^{*} \phi_{b}^{*}, \Phi_{b}\right\rangle\right],
$$

or

$$
\left.<\Sigma\left(x_{b}\right), \phi_{b}\right\rangle+\left[\left(x-x_{a}\right) /\left(x_{b}-x_{a}\right)\right]\left[<\Sigma\left(x_{b}\right), \phi_{a}>-<\Sigma\left(x_{b}\right), \phi_{b}>\right] .
$$

Substituting Eqs. 2.28 and 2.32 into Eq. 2.23 gives an interpolation formula in terms of the forward fluxes $\phi_{a}$ and $\phi_{b}$.

$$
R_{S I}\left(\phi_{b}, \phi_{a} ; x\right)=\left\langle\Sigma(x), \phi_{a}><\Sigma_{b}, \phi_{b}>/ 0\right.
$$

where

$$
D=\left\langle\Sigma_{b}, \phi_{b}\right\rangle+\left[\left(x-x_{a}\right) /\left(x_{b}-x_{a}\right)\right]\left[\left\langle\Sigma_{b}, \phi_{a}\right\rangle-\left\langle\Sigma_{b}, \phi_{b}\right\rangle\right] .
$$

Here the notation $\Sigma\left(x_{a}\right)=\Sigma_{a}$ and $\Sigma\left(x_{b}\right)=\Sigma_{b}$ has been used. Note that at $x=x_{a}, R_{S I}=\left\langle\Sigma_{a}, \phi_{a}\right\rangle$, and at $x=x_{b}$, $R_{S I}=\left\langle\Sigma_{b}, \Phi_{b}\right\rangle$. Hence, Eq. 2.33 provides the exact solution at the two reference points and an estimate for other values of $x$. (Exact means the same result as from the transport calculation.) It has been shown that for $x_{a}<x<x_{b}$ varlational interpolation relies on cancellation of error. 11 That is, as $x$ approaches $x_{b}$ from $x_{a}$, $\delta \phi_{a}$ is growing while $\delta \phi_{b}$ is tending 
to zero. For values of $x$ that do not lie between $x_{a}$ and $x_{b}$ both $\delta \phi_{a}$ and $\delta \phi_{b}$ increase as the distance from the reference point increases. Therefore, great accuracy is not expected in using Eq. 2.33 to extrapolate.

The magnitude of the error will depend both on the proximity of the reference points and on the sensitivity of the reaction rate to the design variable. In general, the farther apart $x_{a}$ and $x_{b}$ are, the greater the error in the estimated value of $R$ at intermiediate values of $x$ will be. Also, if $R$ is very sensitive to $x$, the error will be larger than if $R$ is a weak function of $x$. To determine what the error actually is requires a transport calculation at the intermediate point of interest.

\subsubsection{Variational Interpolation for Variations in Blanket Composition.}

of particular interest in the study of fusion reactor blankets, is how reaction rates change as the isotopic composition of the blanket (or a region of the blanket) is changed. For reactions with 15otope-j, the macroscoptc cross-section is

$$
\Sigma_{j}=N_{j} \sigma_{j}=f_{j} \rho N_{0} \sigma_{j} / M
$$

where

$f_{j}=$ atom fraction of isotope-j in the blanket material,

$N_{\mathrm{j}}=$ number density of isotope-j,

$\sigma_{\mathbf{j}}=$ microscopic reaction cross section with isotope-j,

$\rho=$ material density,

$N_{0}=$ Avagadro's number, and

$M=$ effective atomic weight of the material. 
To investigate the effects of varying the fraction of isotope-g in the blanket, $x$ is set equal to $f$; hence, the macroscopic cross-sections for reactions with 1sotope-j are proportional to $x$. As a result, varying $x$ gives a 11inear perturbation in $L$ and Eq. 2.33 can thus be applied.

In this case, Eq. 2.33 can be simplified by noting that

$$
\Sigma(x)=x \Sigma_{a} / x_{a}
$$

Substituting gives

$$
R_{S I}\left(\phi_{b}, \phi_{a} ; x\right)=\left(x / x_{a}\right)<\Sigma_{a}, \phi_{a}><\Sigma_{b}, \phi_{b}>/ 0,
$$

there

$$
0=\left\langle\varepsilon_{b}, \phi_{b}\right\rangle+\left[\left(x-x_{a}\right) /\left(x_{b}-x_{a}\right)\right]\left[\left(x_{b} / x_{a}\right)<\varepsilon_{a}, \phi_{a}\right\rangle-\left\langle\Sigma_{b}, \phi_{b}>\right] .
$$

In terms of the reaction rates obtained from the transport calculations at the two reference points, i.e.,

$$
R_{a}=\left\langle\varepsilon_{a}, \phi_{a}\right\rangle \text {, }
$$

and

$$
R_{b}=\left\langle\varepsilon_{b}, \phi_{b}\right\rangle
$$

Eq. 2.36 becomes

$$
R_{S I}\left(R_{a}, R_{b} ; x\right)=\left(x / x_{a}\right) R_{a} R_{b} / 0
$$

where

$$
D=R_{b}+\left[\left(x-x_{a}\right) /\left(x_{b}-x_{a}\right)\right]\left[\left(x_{b} / x_{a}\right) R_{a}-R_{b}\right] .
$$


Equation 2.38 is exact at $x=x_{a}$ and $x=x_{b}$ and gives a nonlinear interpolation for intermediate values of $x$. That is, $R_{S I}=R_{a}$ at $x=x_{a}$, and $R_{S I}=R_{b}$ at $x=x_{b}$. Also note that since $\Sigma(x)$ is proportional to $x, R=0$ at $x=0$, and in this case Eq. 2.38 is also exact at $x=0$.

To 11 lustrate the nature of Eq. 2.38, two cases are shown in Fig. 2.1; the lower curve has reference values $R(0.2)=0.5$ and $R(0.6)=3.0$ while the upper curve is for $R(0.2)=2.0$ and $R(0.6)=3.0$. The untts are arbitrary.

\subsubsection{Singularities of the Two Point Interpolation formula.}

Equation 2.38 has a singularity when $D=0$. Setting $D=0$ and sclving for the location of the singularity, $x_{s}$, gives

$$
x_{s}=x_{a}-\left(x_{b}-x_{a}\right) R_{b} /\left[\left(x_{b} / x_{a}\right) R_{a}-R_{b}\right] .
$$

This is of concern only if $x_{5} \geq 0$ (since negative atom fractions are meaningless! which occurs if $R_{a} \geq R_{b}$, assuming $a<b$. For $R_{a}<R_{b}$, Eq. 2.38 is well behaved and gives a nonlinear estimate of $R(x)$ which is monotonically increasing with $x$. If the reference point calculations give $R_{a} \geq R_{b}$, then Eq. 2.38 is inadequate. In this case a 3-point variational interpolation formulation may be usef:1. The 3-point interpolation formula is developed later in this chapter.

In the case where the bieiket is composed of only two isotopes the atom fraction of each is related to $x$ by 
$-26-$

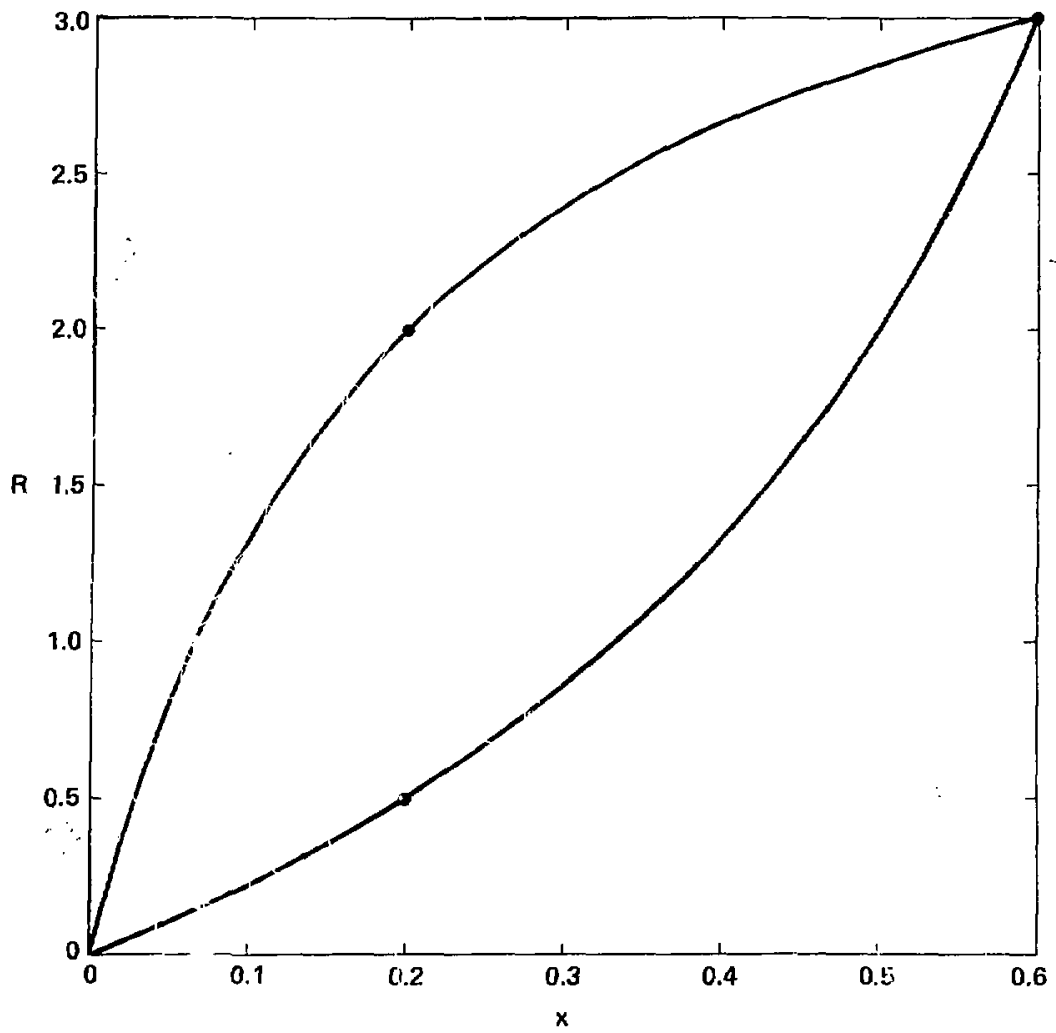

Fig. 2.1 Illustrative examples of tin point variational interpolation when $I(x)$ is proportional to $x$ (Eq. 2.38). The reference points for the lower curve are $R(0.2)=0.5$ and $R(0.6)=3.0$. The upper curve has reference points $R(0.2)=2.0$ and $R(0.6)=3.0$. 


$$
r_{1}=x_{1}
$$

and

$$
f_{2}=1-x .
$$

Then for isotope-2, Eq. 2.35 becomes

$$
\Sigma(x)=(1-x) \Sigma_{a}\left(1-x_{a}\right),
$$

and Eq. 2.38 becomes

$$
R_{S I 2}\left(R_{a}, R_{b} ; x\right)=(1-x) R_{a} R_{b} /\left[\left(1-x_{a}\right) 0\right],
$$

where

$$
D=R_{b}+\left[\left(x-x_{a}\right) /\left(x_{b}-x_{a}\right)\right]\left[\left(1-x_{b}\right) R_{a} /\left(1-x_{a}\right)-R_{b}\right] .
$$

Note that $R_{a}$ and $R_{b}$ are the reaction rates with isotope-2 derived from the reference point calculations at $x=x_{a}$ and $x=x_{b}$, respectively. For isotope-2, Eq. 2.42 is exact at $x=x_{a}, x=x_{b}$ and also at $x=1$. It is not exact at $x=0$.

To summarize, in the case of blanket composed of only two isotopes where the design variable of interest is the atom fraction of the first isotope, the two point variational interpolation formula gives exact values for reaction rates with isotope-1 at $x=0, x_{a}$ and $x_{b}$, and gives exact values for reaction rates with isotope-2 at $x=x_{a}, x_{b}$ and 1 .

If the atom fraction of an 1sotope is unaffected by the variation of $x$, then

$$
\Sigma(x)=\Sigma_{a}=\Sigma_{b}=\text { constant }
$$


In this case Eq. 2.33 becomes

$$
R_{S I C}\left(R_{a}, R_{b} ; x\right)=R_{a} R_{b} / 0 \text {, }
$$

where

$$
0=R_{b}+\left[\left(x-x_{a}\right) /\left(x_{b}-x_{a}\right)\right]\left[R_{a}-R_{b}\right] .
$$

One example where this holds is in a blanket containing 3 or more isotopes with one or more specified as constant. In particular, 3 isotopes could be specified as $f_{1}=x, f_{2}=1-c-x$, and $f_{3}=C=$ constant. Another example where Eq. 2.44 holds is in regions of the blanket other than the region where $x$ is yaried. In these cases, the varlational estimate reflects the charige in the flux due to a change in $x$.

Generalizing Eqs. $2.38,2.42$, and 2.44 , the two point varlational interpolation formula becomes

$$
R_{S l}\left(R_{a}, R_{b} ; x\right)=\left(\Sigma(x) / \Sigma_{a} / R_{a} R_{b} / D,\right.
$$

where

$$
D=R_{b}+\left[\left(x-x_{a}\right) /\left(x_{b}-x_{a}\right)\right]\left[\left(\Sigma_{b} / \Sigma_{a}\right) R_{a}-R_{b}\right] .
$$

\subsubsection{Multivariable Estimates Using Two Point Variational Interpolation.}

The previous section shows how variational interpolation can be used to estimate neutronic characteristics as a function of a single design varlable. In practice it is desirable to evaluate tine effects of variations in several design variables simultaneously. By successive application of the varlational interpolation procedure discussed in the previous section, one can estimate the neutronic 
characteristics of interest at any point in an $n$-dimensional space, based on a limited number of reference point transport calculations.

Consider the problem of estimating reaction rates as a function of two design varlables $x_{1}$ and $x_{2}$. To do this using the variational interpolation scheme requires four reference point transport calculations. These four points are most conveniently chosen to define a rectangle in Cartesian coordinates as shown in Fig. 2.2. The reference points are denoted $\left(x_{1 a}, x_{2 a}\right),\left(x_{1 b}, x_{2 a}\right),\left(x_{1 a}, x_{2 b}\right)$ and $\left(x_{1 b}, x_{2 b}\right)$. The corresponding reaction rates at these four points are denoted $R_{a a}, R_{b a}, R_{a b}$ and $R_{b b}$, respecitively.

The procedure used to estimate the reaction rate at some point $\left(x_{1 d}, x_{2 d}\right)$ is thlustrated in Fig. 2.3. First, the result $R_{d a}$ is found by interpolating on $x_{1}$ with $x_{2}=x_{2 a}$. Next, the result $A_{d b}$ is found by interpolating on $x_{1}$ with $x_{2}=x_{2 b}$. The two results are then used to interpolate on $x_{2}$ with $x_{1}=x_{1 d}$, to find the result $R_{d d}$. As suin, 3 interpolations are required to estimate the reaction rate.

In terms of the prevtous expressions for Schwinger Interpolation, the successive interpolation approach can be written as

$$
\begin{aligned}
& R_{S S I}\left(R_{a a}, R_{b a}, R_{a b}, R_{b b} ; x_{1}, x_{2}\right) \\
& =R_{S I}\left(R_{S I}\left(R_{a a}, R_{b a} ; x_{1}\right), R_{S I}\left(R_{a b}, R_{b b} ; x_{1}\right) ; x_{2}\right)
\end{aligned}
$$

(C) learly one could just as easijy interpolate on $x_{2}$ first and then on $\left.x_{1}\right)$.

To extend the approach to a third varlable, $x_{3}$, requires four additional reference point transport calculations. Assuming the first 


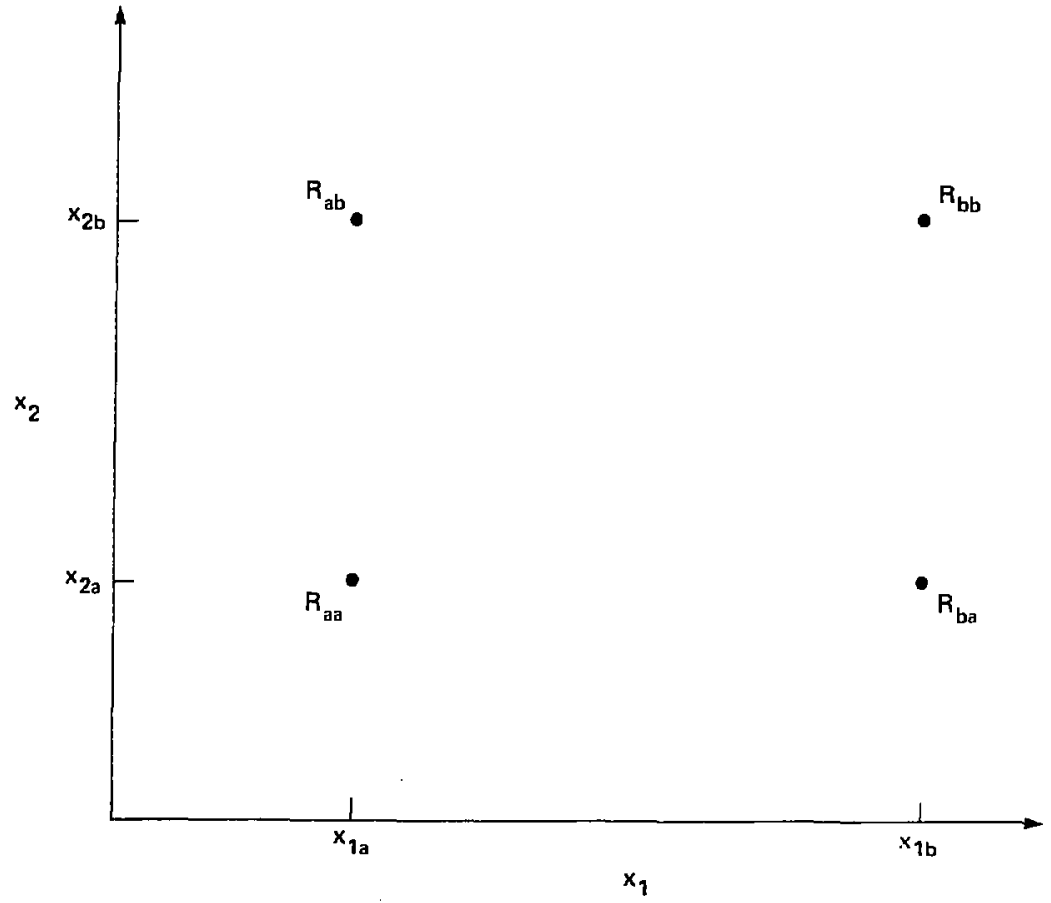

Fig. 2.2 Location of four reference points for two point interpolation on two variables. Neutron transport calculations are carrled out at these four points. The resulting reaction rates are denoted by $R$ with two subscripts corresponding to the $x_{1}$ and $x_{2}$ coordinates, respectiveiy. 
$-31-$

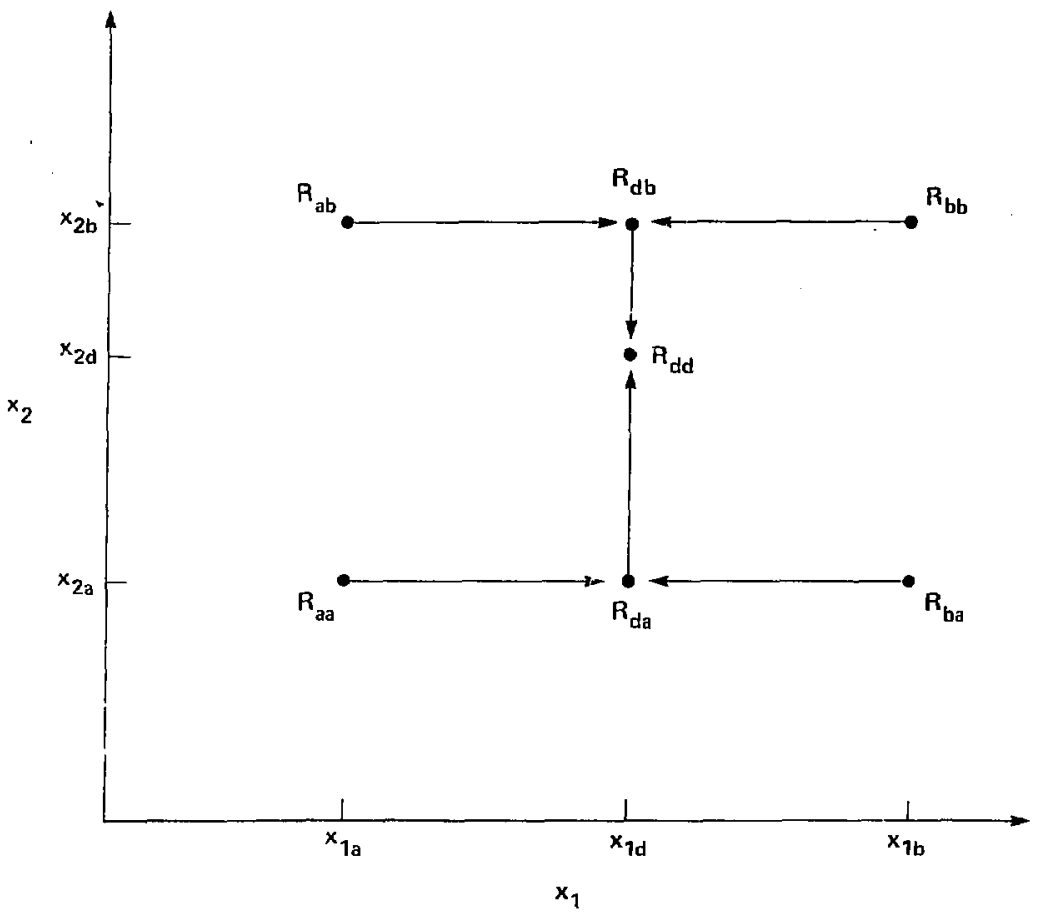

fig. 2.3 Successive two point variational interpolation. To $f$ ind the reaction rate at the point $\left(x_{1 d}, x_{2 d}\right)$ requires three interpolations; one to find $R_{d a}$, a second to find $R_{d b}$, and a third to find $R_{d d}$. 
$-32-$

four are in the plane $x_{3}=x_{3 a}$, the four additional points would be in the plane $x_{3}=x_{3 b}$. Applying Eq. 2.46 in the plane $x_{3}=x_{3 a}$ gives the result $R_{d d a}$. A second application of Eq. 2.46 with $x_{3}=x_{3 b}$ gives $\mathbf{R}_{\mathrm{ddb}}$. These are then used to interpolate on $x_{3}$ to give the desired result $R_{\text {gd }}$ In this case a total of 7 interpolations are required.

Generalizing, in order to span $n$-space with this technique requires $2^{n}$ reference point transport calculations and $\left(2^{n}-1\right)$ successive interpolations for each reaction of interest at each point of interest. 


\subsection{THREE POINT VARIATIONAL INTERPOLATION FOR FUSION REACTORS}

The three point vartational interpolation formula based on the Schwinger functional is given by, 11

$$
\begin{aligned}
& R_{S I 3}\left(\phi_{a}, \phi_{b}, \phi_{c}^{*} ; x\right)=\left\langle\Sigma(x), \phi_{a}\right\rangle \\
& \quad+\left\langle\phi_{c}^{*}, S(x)-L(x) \phi_{a}>\left\langle\Sigma(x), \phi_{b}-\phi_{a}>\left\langle\left\langle\phi_{c}^{*}, L(x)\left(\phi_{b}-\phi_{a}\right)\right\rangle\right.\right.\right.
\end{aligned}
$$

where $s^{*}(x)$ has been set equal to $\Sigma(x)$. The subscripts $a, b$ and $c$ refer to conditions at $x=x_{a}, x=x_{b}$ and $x=x_{c}$, respectively, where $x_{a}<x_{b}<x_{c}$.

\subsubsection{Three Point Variational Interpolation In Terms of Forward Fluxes.}

For a fixed external source and linear perturbations, a formula in terms of forward fluxes only can be derived. For a fixed external source,

$$
L_{a} \phi_{\lambda}=L_{b} \phi_{b}=L_{c} \phi_{c}=S=\text { constant } .
$$

If the perturbation is 1 inear in $x$, then $L(x)$ can be written as

$$
L(x)=L_{a}+\lambda_{c a}\left(L_{c}-L_{a}\right),
$$

where

$$
\lambda_{c a}=\left(x-x_{a}\right) /\left(x_{c}-x_{a}\right)
$$

or as,

$$
L(x)=L_{b}+\lambda_{c b}\left(L_{c}-L_{b}\right) \text {. }
$$

where

$$
\lambda_{c b}=\left(x-x_{b}\right) /\left(x_{c}-x_{b}\right) .
$$


Consider the term,

$$
\left\langle\phi_{c}^{*}, S(x)-L(x) \phi_{a}\right\rangle
$$

in the numerator of the second term in Eq. 2.47. Substituting Eqs. 2.48 and 2.49 and expanding gives

$$
\left\langle\Phi_{c}^{*}, L_{c} \phi_{c}\right\rangle-\left\langle\Phi_{c}^{*}, L_{a} \phi_{a}\right\rangle-\lambda_{c a}\left\langle\phi_{c}^{*},\left(L_{c}-L_{a}\right) \phi_{a}\right\rangle
$$

Noting that the first two terms of (2.52) cancel, we are left wth,

$$
-\lambda_{c a}\left[\left\langle\phi_{c}^{*}, L_{c} \Phi_{a}\right\rangle-\left\langle_{c}^{*}, L_{a} \phi_{a}\right\rangle\right]
$$

Using Eqs. 2.8 and 2.48 this can be rewritten as,

$$
-\lambda_{c a}\left[\left\langleL_{c}^{*} \phi_{c}^{*}, \phi_{a}>-\left\langle\phi_{c}^{*}, L_{c} \phi_{c}>\right]\right.\right.
$$

Using Eq. 2.8 again gives,

$$
-\lambda_{c a}\left[<\Sigma_{c}, \phi_{a}>-<\Sigma_{c}, \phi_{c}>\right]
$$

Hence, $\phi_{c}^{\star}$ has been ellminated from this term.

Next, consider the denominator of the second term in Eq. 2.47,

$$
\left\langle\phi_{c}^{\star}, L(x)\left(\phi_{b}-\phi_{a}\right)\right\rangle .
$$


Expanding gives,

$$
\left\langle\phi_{c}^{*}, L(x) \phi_{b}\right\rangle-\left\langle\phi_{c}^{*}, L(x) \phi_{a}\right\rangle
$$

Using Eq. 2.50, the first term of $(2.57)$ becomes,

$$
\left.\left\langle\phi_{c}^{*} \cdot L_{b} \phi_{b}\right\rangle+\lambda_{c b}<\phi_{c}^{*},\left(L_{c}-L_{b}\right) \phi_{b}\right\rangle
$$

Using Eqs. 2.8 and 2.48 gives,

$$
\left\langle\phi_{c}^{*}, L_{c} \phi_{c}\right\rangle+\lambda_{c b}\left[\left\langle L_{c}^{*} \phi_{c}^{*}, \phi_{b}\right\rangle-\left\langle\phi_{c}^{*}, L_{c} \phi_{c}\right\rangle\right]
$$

and then

$$
\left\langle\varepsilon_{c}, \phi_{c}>+\lambda_{c b}\left[<\Sigma_{c}, \phi_{b}>-\left\langle\Sigma_{c}, \phi_{c}>\right] .\right.\right.
$$

Similarly ine second term of $(2.57)$ reduces to

$$
-\left\langle\Sigma_{c}, \phi_{c}>-\lambda_{c a}\left[\left\langle\Sigma_{c}, \phi_{a}\right\rangle-\left\langle\Sigma_{c}, \phi_{c}\right\rangle\right] .\right.
$$

Using Eqs. 2.49, 2.50, 2.55, 2.60, and 2.61, Eq. 2.47 can be written as

$$
\begin{aligned}
& { }_{S I 3}\left(\phi_{a}, \phi_{b}, \phi_{c} ; x\right)=\left\langle\Sigma(x), \phi_{a}\right\rangle \\
& \quad-\left[\left(x-x_{a}\right) /\left(x_{c}-x_{a}\right)\right]\left[\left\langle\Sigma_{c}, \phi_{a}>-\left\langle\Sigma_{c}, \phi_{c}>\right]<I(x), \phi_{b}-\phi_{a}>/ 0,\right.\right.
\end{aligned}
$$

where

$$
\begin{aligned}
0= & {\left[\left(x-x_{b}\right) /\left(x_{c}-x_{b}\right)\right]\left[<\varepsilon_{c}, \phi_{b}>-\left\langle\Sigma_{c}, \phi_{c}>\right]\right.} \\
& -\left[\left(x-x_{a}\right) /\left(x_{c}-x_{d}\right)\right]\left[<\varepsilon_{c}, \phi_{d}>-\left\langle\varepsilon_{c}, \phi_{c}>\right] .\right.
\end{aligned}
$$


In terms of the reaction rates at the reference points

$$
\begin{aligned}
& R_{a}=\left\langle\varepsilon_{a}, \phi_{a}\right\rangle, \\
& R_{b}=\left\langle\Sigma_{b}, \phi_{b}\right\rangle \text {, and } \\
& R_{c}=\left\langle\Sigma_{c}, \phi_{c}\right\rangle \text {, }
\end{aligned}
$$

Eq. 2.62 becomes,

$$
\begin{aligned}
& R_{S I 3}\left(R_{a}, R_{b}, R_{c} ; x\right)=\left(\Sigma(x) / \Sigma_{a}\right) R_{a} \\
& -\left[\left(x-x_{a}\right) /\left(x_{c}-x_{a}\right)\right]\left[\left(\Sigma_{c} / \Sigma_{a}\right) R_{a}-R_{c}\right]\left[\left(\Sigma(x) / \Sigma_{b}\right) R_{b}-\left(\Sigma(x) / \Sigma_{a}\right) R_{a}\right] / 0,
\end{aligned}
$$

where

$$
\begin{aligned}
0= & {\left[\left(x-x_{b}\right) /\left(x_{c}-x_{b}\right)\right]\left[\left(\Sigma_{c} / \Sigma_{b}\right) R_{b}-R_{c}\right] } \\
& -\left[\left(x-x_{a}\right) /\left(x_{c}-x_{a}\right)\right]\left[\left(\Sigma_{c} / \Sigma_{a}\right) R_{a}-R_{c}\right] .
\end{aligned}
$$

Note that Eq. 2.64 is exact at $x=x_{a}, x_{b}$ and $x_{c}$ gtving the results $R_{a}$, $R_{b}$ and $R_{c}$, respectively.

\subsubsection{Sinqularitles of the Three Point Interpolation Formula.}

This three point interpolation formula has singularities when the denominator of Eq. 2.64 equals zero. This occurs when

$\left[\left(x-x_{b}\right) /\left(x_{c}-x_{b}\right)\right]\left[\left(\Sigma_{c} / \Sigma_{b}\right) R_{b}-R_{c}\right]=\left[\left(x-x_{a}\right) /\left(x_{c}-x_{a}\right)\right]\left[\left(\Sigma_{c} / \Sigma_{a}\right) R_{a}-R_{c}\right]$.

The value of $x$ at whtch Eq. 2.65 holds is,

$$
x_{s}=\left\{x_{b}\left[\left(\varepsilon_{c} / \varepsilon_{b}\right) R_{b}-R_{c}\right] /\left(x_{c}-x_{b}\right)-x_{a}\left[\left(\varepsilon_{c} / \Sigma_{a}\right) R_{a}-R_{c}\right] /\left(x_{c}-x_{a}\right)\right] / D,
$$

where 
$D=\left[\left(\Sigma_{c} / \Sigma_{b}\right) R_{b}-R_{c}\right] /\left(x_{c}-x_{b}\right)-\left[\left(\Sigma_{c} / \Sigma_{a}\right) R_{a}-R_{c}\right] /\left(x_{c}-x_{a}\right)$.

For the case where $\Sigma(x)$ is proportioral to $x$, 1.e., $\Sigma_{c} / \Sigma_{a}=x_{c} / x_{a}$ and $\Sigma_{c} / \Sigma_{b}=x_{b} / x_{a}, E q \cdot 2.66$ reduces to

$$
x_{s}=\left\{\left(x_{c} R_{b}-x_{b} R_{c}\right) /\left(x_{c}-x_{b}\right)-\left(x_{c} R_{a}-x_{a} R_{c}\right) /\left(x_{c}-x_{a}\right)\right\} / 0,
$$

where

$$
D=\left(x_{c} R_{b}-x_{b} R_{c}\right) /\left[\left(x_{c}-x_{b}\right) x_{b}\right]-\left(x_{c} R_{a}-x_{a} R_{c}\right) /\left[\left(x_{c}-x_{a}\right) x_{a}\right] .
$$

In using the three point interpolation one must check to see if the singularity lies in the range of interest. Consider a specific exampie where

$$
R_{a}=2.0 \text { at } x_{a}=0.2 \text {, }
$$

and

$$
R_{c}=3.0 \text { at } x_{c}=0.6 \text {. }
$$

Figure 2.4 shows the location of the singularity, $x_{5}$, as a function of the reaction rate, $R_{b}$, at $x_{b}=0.4$. If $R_{b} \leq 2.5$, there is a singularity between 0 ano $0 \cdots$ If $R_{b} \geq 4.0$, there is a singularity at a point less than 0.60 . Hence, Eq. 2.63 can be used to interpolate between 0.2 and 0.6 and extrapolate down to $x=0$ only if $2 . .5<R_{b}<4.0$.

The envelope of the famlly of curves which the three point interpolation can $f: t$ through the points $R(0.2)=2.0$ and $R(0.6)=3.0$ is shown in Fig. 2.5. Note that, unlike the two point internolation, the three point interpolation can generate a curve which goes through 


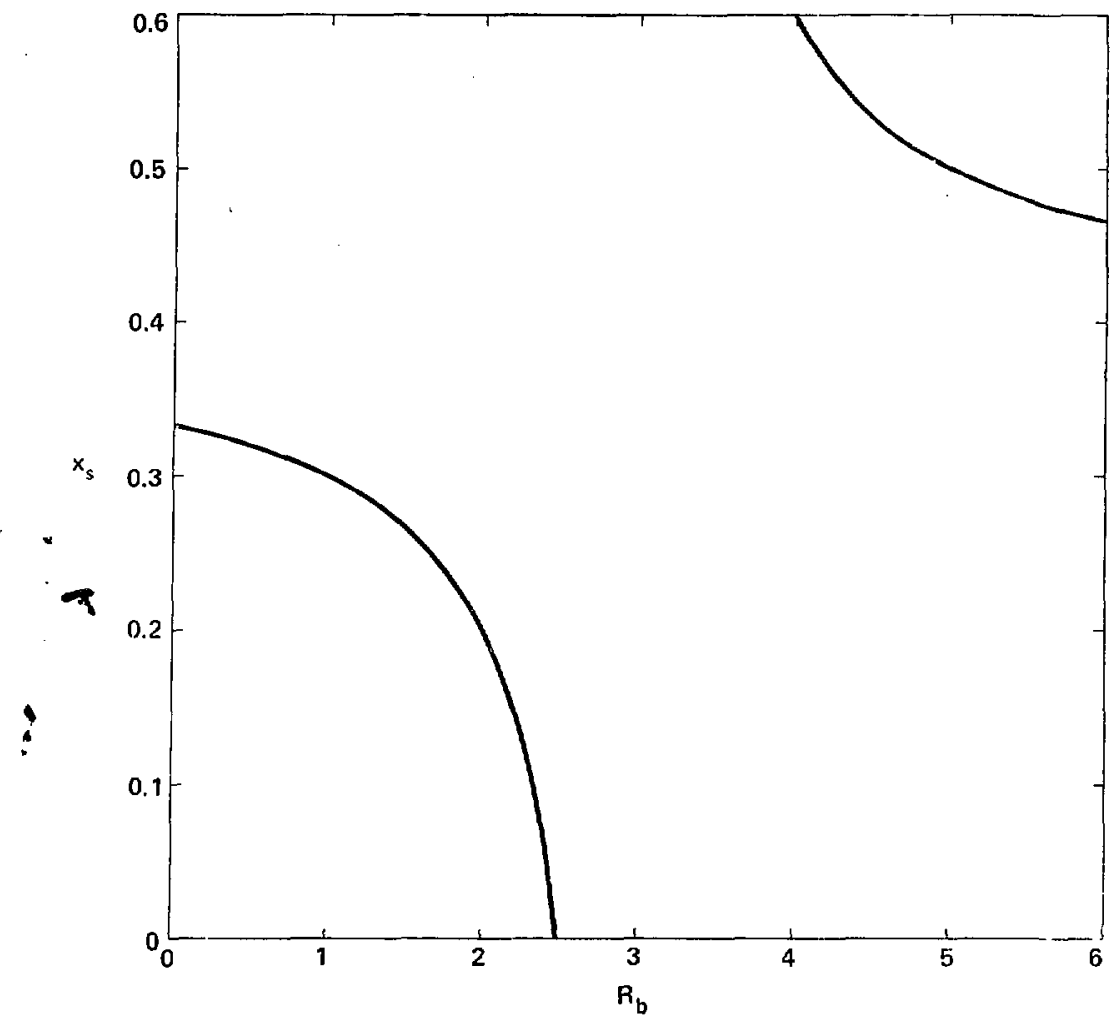

Fig. 2.4 Location of singularity for three point interpolation versus $R_{b}$ for a curve with negative second derivatives. The reference point results are $R_{a}(0.2)=2.0$ and $R_{c}(0.6)=3.0$. If the result $R_{b}$ at $x_{b}=0.4$ is not between 2.5 and 4.0 , the location of the singularity, $x_{b}$, will 11e if the range of interest, $0 \leq x \leq 0.6$. 


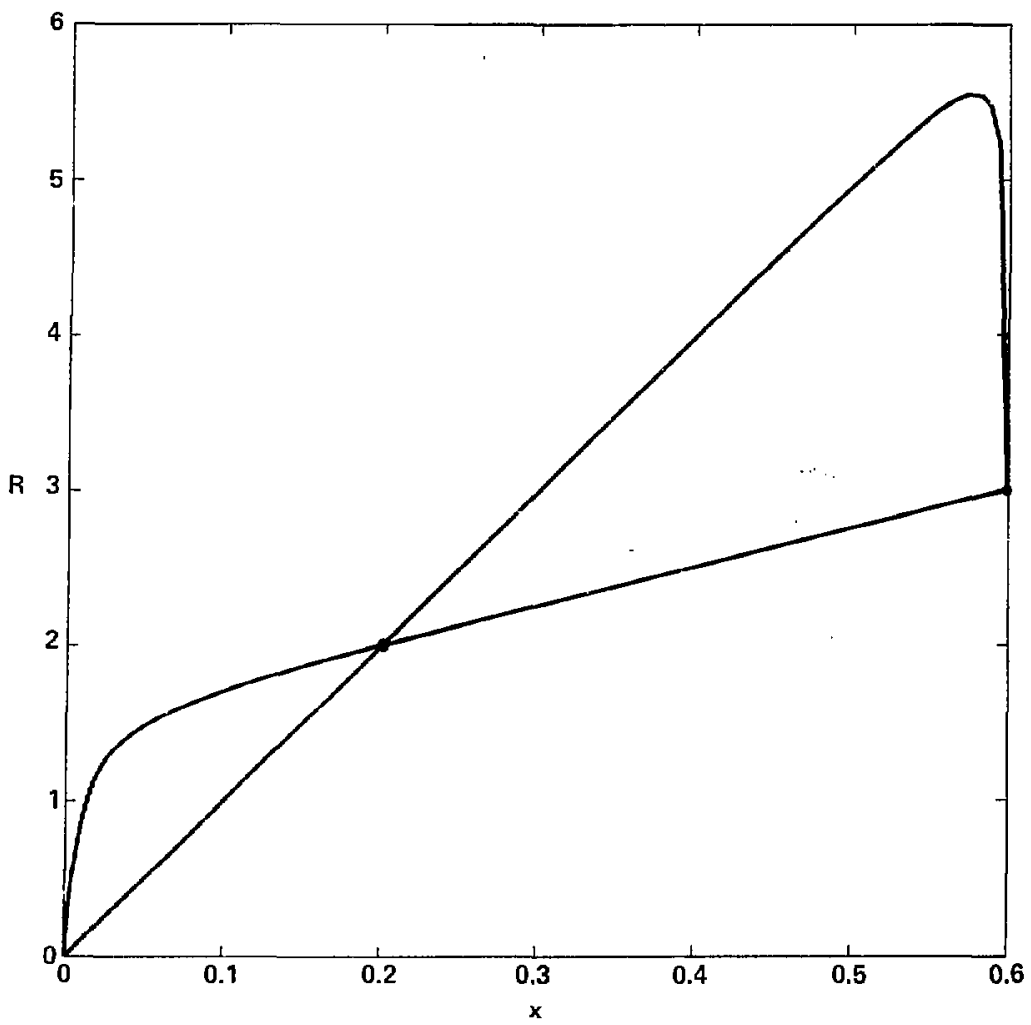

Fig. 2.5 Envelope of famlly of curves with three point interpolation for $R(0.2)=2.0$ and $R(0.6)=3.0$. Compare to the upper curve in fig. 2.1 obtained with two point interpolation. 
a maximum. Figure 2.5 should be compared to the upper curve in Fig. 2.1.

Figures 2.4 and 2.5 11lustrate the nature of the three point interpolation for $R_{a} / x_{a}>R_{c} / x_{c}$, $1 . e$. , curves which are concave down. Now consider the opposite case where $R_{a} / x_{a}<R_{c} / x_{c}$. Let

$$
R_{a}=0.5 \text { at } x_{a}=0.2 \text {, }
$$

and

$$
R_{c}=3.0 \text { at } x_{c}=0.6 \text {. }
$$

Figure 2.6 shows the location of the singularity as a function of $R_{b}$, where $x_{b}=0.4$ as before. In this case $R_{b}$ is 1 imited to values between 1.0 and 1.75 in order to avoid singularity in the range $0 \leq x \leq 0.6$.

Figure 2.7 shows the envelope of the famlly of curves obtained for $1.0<R_{b}<1.75$. Here we see another 1 imitation of the three point interpolation. If the formula is used to extrapolate between 0.2 and 0 , negative reaction rates are predicted. Obviously this is meaningless. In order to assure that $R>0$ in the extrapolated region, the derivative of Eq. 2.64 as $x$ approaches zero must be $\geq 0$. The derivative of Eq. 2.64 for the case of $\Sigma(x)=x \Sigma_{a} / x_{a}=x \Sigma_{b} / x_{b}$ and the limit as $x$ approaches zero is given in Appendix $I$. For this specific example (1.e., $R(0.2)=0.5$ and $R(0.6)=3.0$ ) the condition $R_{b} \leq 1.6$ is required to prevent negative values of $R$ near $x=0$. The revised envelope of possible curves is shown in Fig. 2.8, See the lower curve of Fig. 2.1 for comparisorl. 
$-41-$

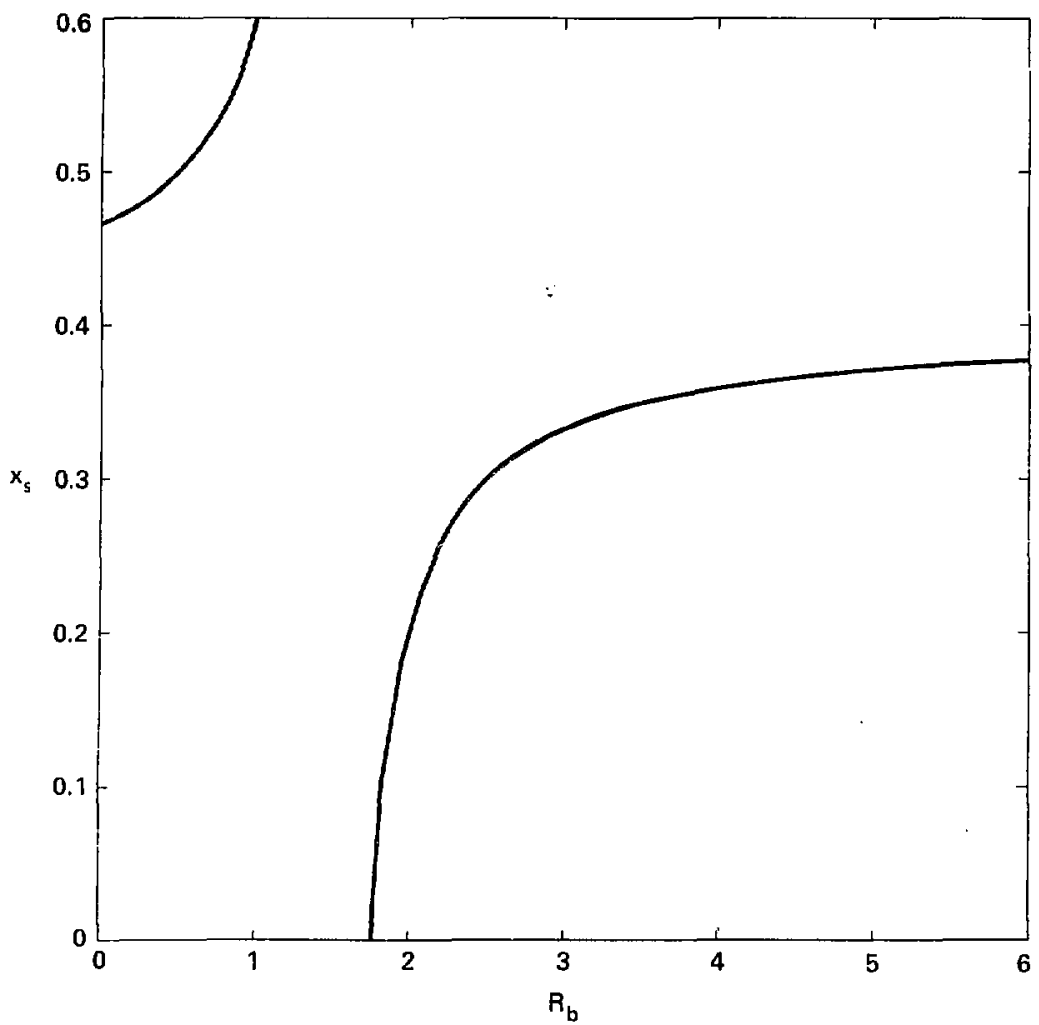

fig. 2.6 Location of singularity for three point interpolation versus $R_{b}$ for a curve with positive second derivatives. The reference point results are $R_{a}(0.2)=0.5$ and $R_{c}(0.6)=3.0$. If the result $R_{b}$ at $x_{b}=0.4$ is not between 1.0 and 1.75 , the location of the singularity, $x_{b}$, will lie in the range of interest. 


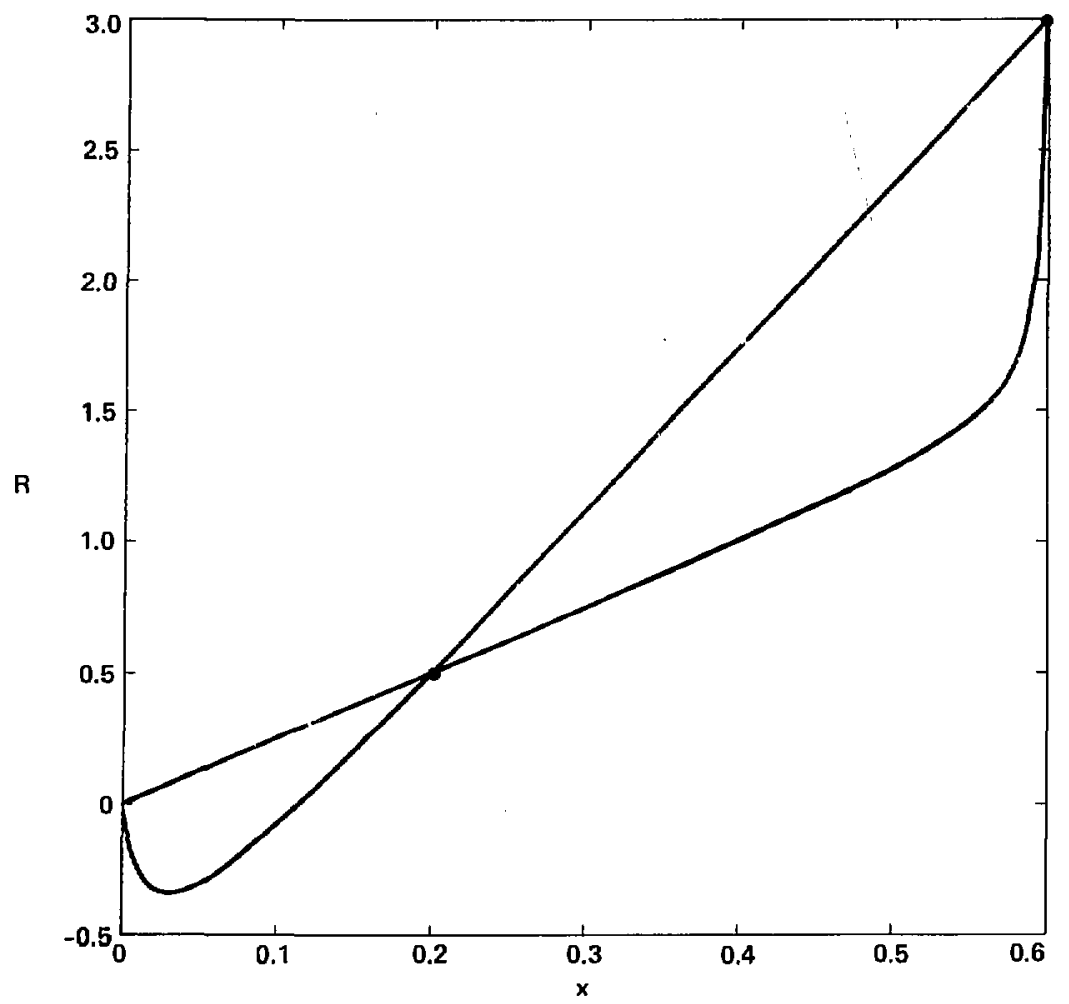

fig. 2.7 Envelope of famtly curves with three point interpolation for $R(0.2)=0.5$ and $R(0.6)=3.0$. In some cases, negative values of $R$ are predicated as $x$ approaches zero. 


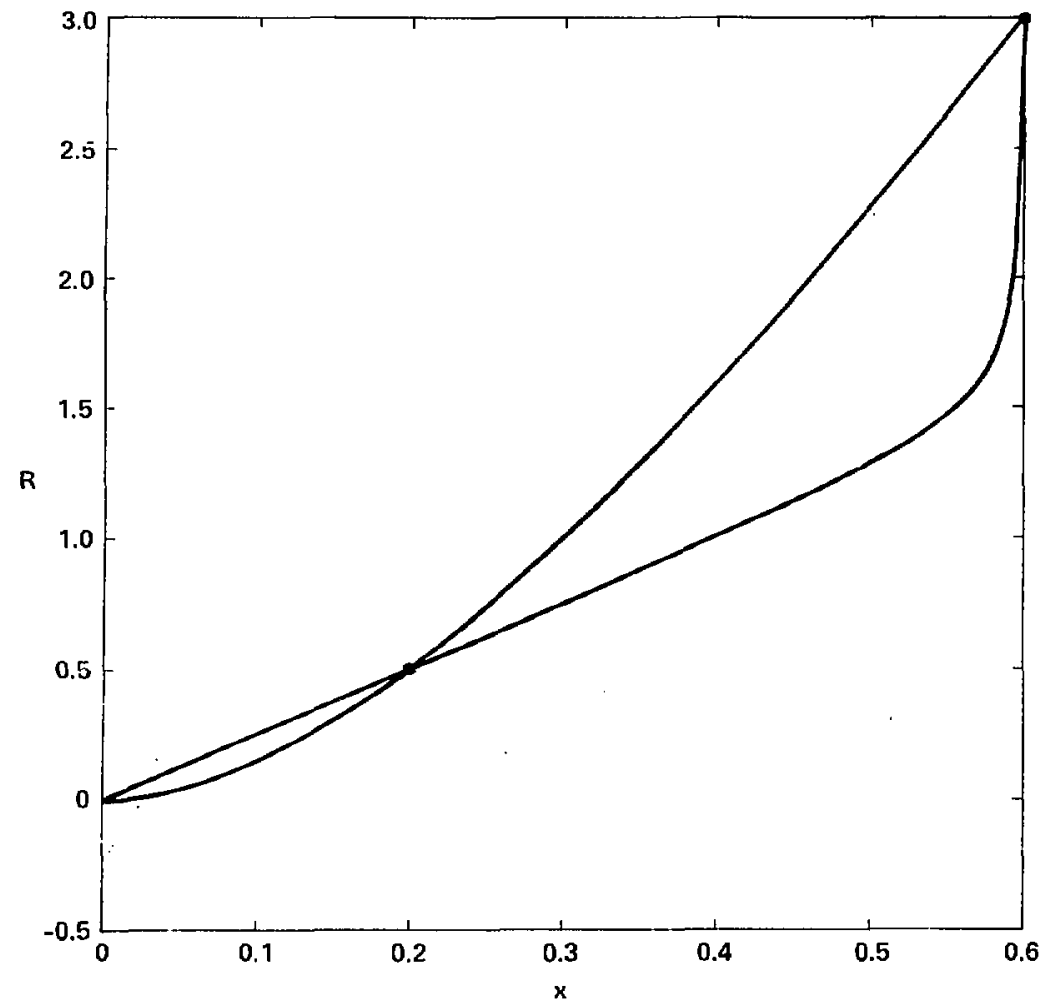

Fig. 2.8 Revised enve lope of famlly of curves. Excluding the curves which give negative values of $R$ changes the envelope shown in fig. 2.7 to the envelope shown here. Compare to the lower curve in Fig. 2.1 obtained with two point interpolation. 


\subsubsection{Multivarlable Estimates Using Three Point Variational} Interpolation.

As with two point interpolation, by successive application of three point variational interpolation, neutronic characteristics can be estimated as a function of more than one variable.

Consider the problem of estimating a reaction rate as a function of two varlables $x_{1}$ and $x_{2}$. Three point interpolation on both varlables requires a grid of 9 reference point neutronics calculations as shown in Fig. 2.9. The reference points are denoted $\left(x_{1 a}, x_{2 a}\right),\left(x_{1 b}, x_{2 a}\right),\left(x_{1 c}, x_{2 a}\right),\left(x_{1 a}, x_{2 b}\right),\left(x_{1 b}, x_{2 b}\right),\left(x_{1 c}, x_{2 b}\right)$, $\left(x_{1 a}, x_{2 c}\right),\left(x_{1 b}, x_{2 c}\right)$, and $\left(x_{1 c}, x_{2 c}\right)$. The corresponding reaction rates at the reference points are denoted $R_{a a}, R_{b a}, R_{c a}, R_{a b}, R_{b b}, R_{c b}$, $R_{a c}, R_{b c}$, and $R_{c c}$, respectively.

The procedure to estimate $R$ at some point $\left(x_{1 d}, x_{2 d}\right)$ is 17 lustrated in Fig. 2.10. First, the result $R_{\text {da }}$ is found by interpolating on $x_{1}$ with $x_{2}=x_{2 a}$. Next, the result $R_{d b}$ is found by interpolating on $x_{1}$ with $x_{2}=x_{2 b}$. Thirdly, $R_{d c}$ is Found by interpolating on $x_{1}$ with $x_{2}=x_{2 c}$. These three results are used to interpolate on $x_{2}$ with $x_{1}=x_{1 d}$.

In terms of the three point variational interpolation formula, Eq. 2.64, the successive three point interpolation can be written as

$$
\begin{aligned}
& R_{S I 33}\left(R_{a a}, R_{b a}, R_{c a}, R_{a b} ; R_{b b}, R_{c b}, R_{a c}, R_{b c}, R_{c c} ; x_{1}, x_{2}\right) \\
&= R_{S I 3}\left(R_{S I 3}\left(R_{a a}, R_{b a}, R_{c a} ; x_{1}\right), R_{S I 3}\left(R_{a b}, R_{b b}, R_{c b} ; x_{1}\right),\right. \\
&\left.R_{S I 3}\left(R_{a c}, R_{b c}, R_{c c} ; x_{1}\right) ; x_{2}\right) .
\end{aligned}
$$




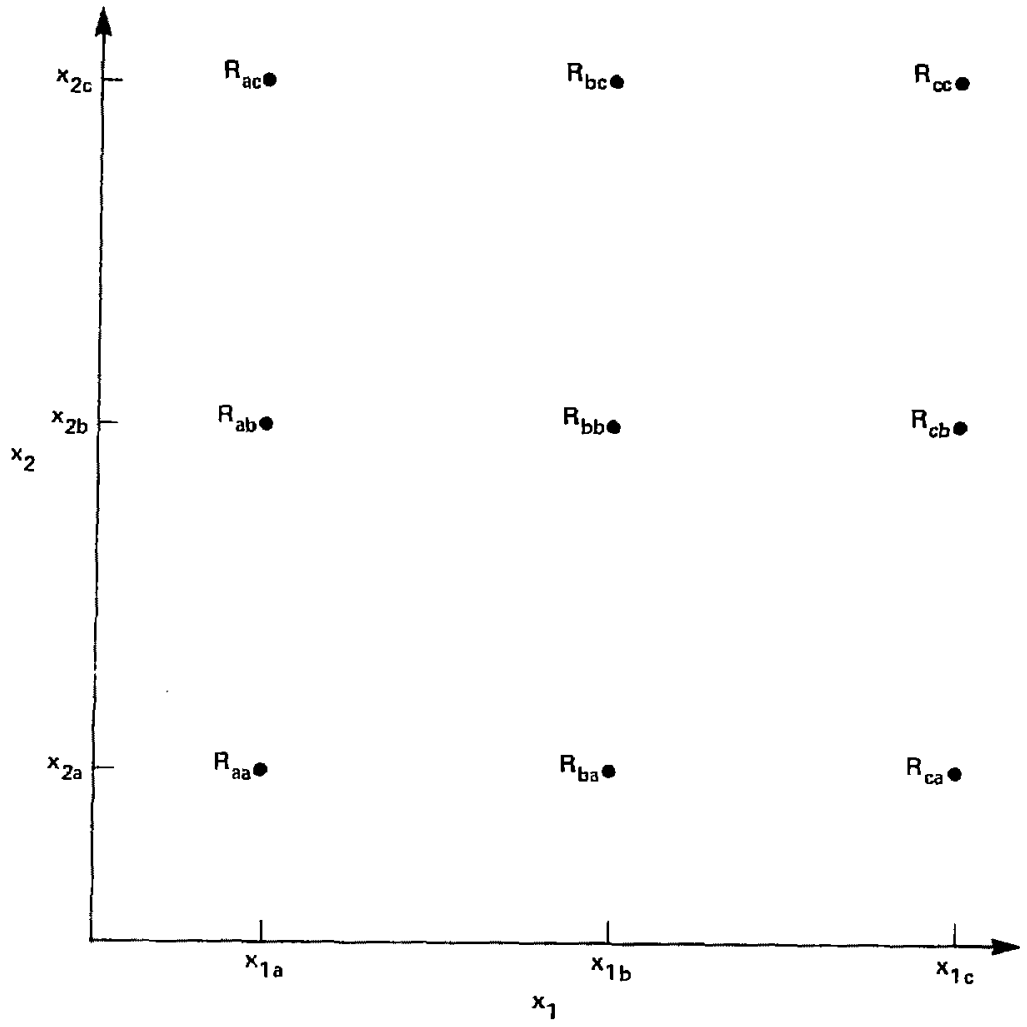

Fig. 2.9 Location of nine reference points for three point interpolation on two varlables. Neutron transport calculations are carrled out at these nine points. The resulting reaction rates are denoted by $R$ with two subscripts corresponding to the $x_{1}$ and $x_{2}$ coordinates, respectively. 


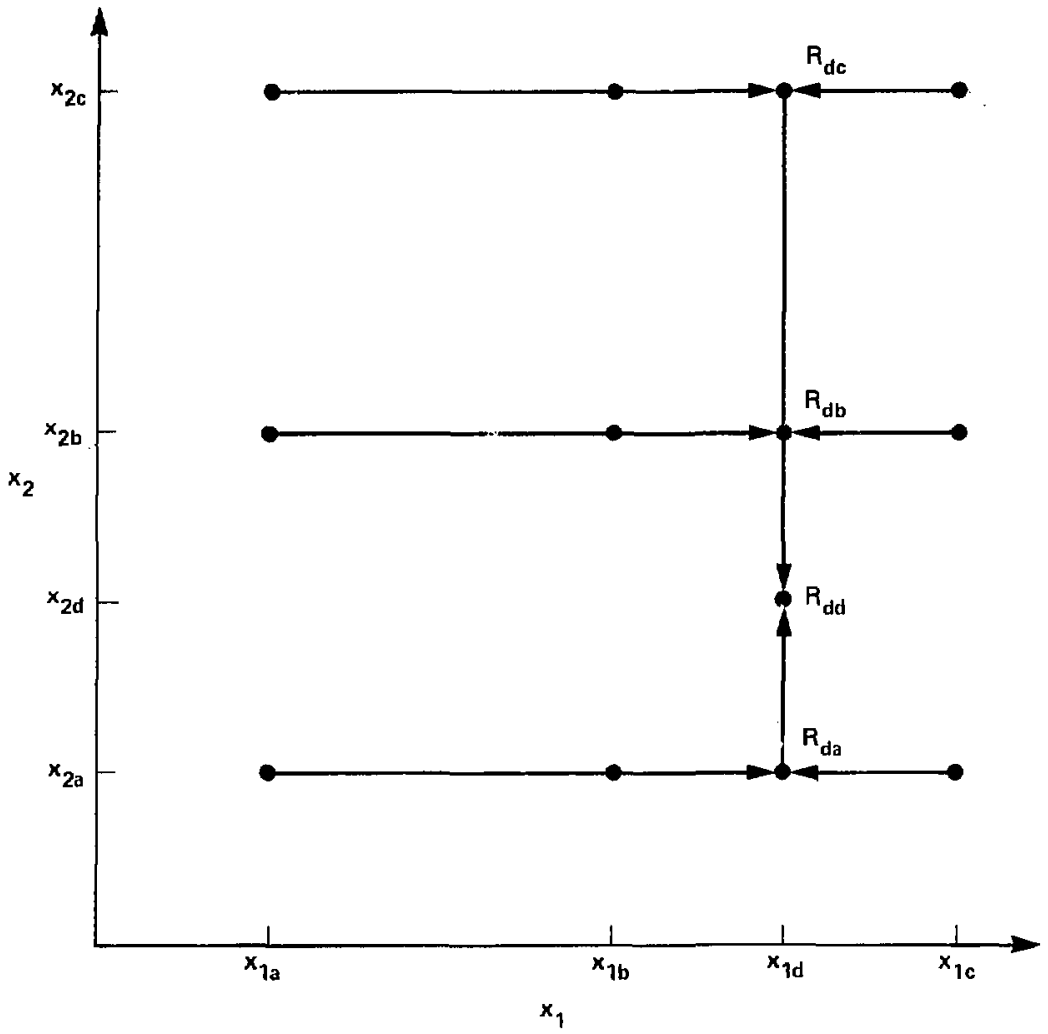

Fig. 2.10 Successive three point variational interpolation. To find the reaction rate at the point $\left(x_{1 d}, x_{2 d}\right)$ requires four interpolations; one to find $R_{d a}$, a second to find $R_{d b}$, a third to find $R_{d c}$, and a fourth to find $R_{d d}$. 
To extent the three point interpolation to a third variable, $x_{2}$, would require 18 more reference transport calculations, and as such gets quite cumbersome. We can, however, combine successive two point and three point interpolations. For two variables, a three point interpolation could be used for one dimension and a two point interpolation for the second. That is,

$$
\begin{aligned}
& R_{S I 32}\left(R_{a d}, R_{b a}, R_{c a}, R_{a b}, R_{b b}, R_{c b} ; x_{1}, x_{2}\right) \\
& =R_{S I 2}\left(R_{S I 3}\left(R_{a a}, R_{b a}, R_{c a} ; x_{1}\right), R_{S I 3}\left(R_{a b}, R_{b b}, R_{c b} ; x_{1}\right) ; x_{2}\right) .
\end{aligned}
$$

This requires 6 reference point transport calculations as indicated. To extend to a third dimension using another two point interpolation requires 6 more transport calculations. 


\subsection{PROPAGATION OF ERROR}

Consider Eq. 2.46 which is the formula for successive, two point interpolation to determine a reaction rate as a function of two vartables, $x_{1}$ and $x_{2}$.

$$
\begin{aligned}
& R_{S S I}\left(R_{a a}, R_{b a}, R_{a b}, R_{b b} ; x_{1}, x_{2}\right) \\
& =R_{S I}\left(R_{S I}\left(R_{a a}, R_{b a} ; x_{1}\right), R_{S I}\left(R_{a b}, R_{b b} ; x_{1}\right) ; x_{2}\right)
\end{aligned}
$$

Note that the "reference values" for interpolation on $x_{2}$ are actually estimates based on the previous interpolations on $x_{1}$. Refer to Fig. 2.3. The question arises, "How does using these estimates as the basis for interpolation on $x_{2}$ affect the accuracy of the result?" Let us compare the result at $x_{1}=x_{1 d}$ and $x_{2}=x_{2 d}$ obtained by two methods. The first is by using Eq. 2.46. The second method assumes that two more transport calculations are carried out to determine the exact results at $\left(x_{1 d}, x_{2 a}\right)$ and $\left(x_{1 d}, x_{2 b}\right)$, denoted $R_{\text {dae }}$ and $R_{d b e}$, respectively. That 15 , in method 2 the reference values for interpolation on $x_{2}$ are exact. Assume that the reference results obtained by variational interpolation on $x_{1}$ are related to these exact values by

$$
R_{d a}=f_{a} R_{d a e} \text {. }
$$

and

$$
R_{d b}=f_{b} R_{d b e} .
$$


The difference in the result at $\left(x_{1 d}, x_{2 d}\right)$ is given by

$$
\Delta=R_{S I}\left(f_{a} R_{d a e} ; f_{b} R_{d b e} ; x_{2}\right)-R_{S I}\left(R_{d a e}, R_{d b e} ; x_{2}\right) .
$$

The magnitude of this additional error (1.e., in addition to the error from using vartational interpolation to begin with) depends on the relative magnitude and sign of $\left(f_{a}-1\right)$ and $\left(f_{b}-1\right)$. Referring to Eq. 2.45, note that $R_{a}$ and $R_{b}$ terms appear in both the numerator and denominator. If $f_{a} \sim f_{b}$, then

$$
\Delta \sim\left(f_{\mathrm{a}}-1\right) R_{\mathrm{SI}}\left(R_{\mathrm{dae}} \cdot R_{\mathrm{dbe}} ; x_{2}\right) .
$$

The fractional difference is $\left(f_{a^{-1}}\right)$. If $\left(f_{a^{-1}}\right)$ and $\left(f_{b^{-1}}\right)$ are opposite in sign; that is, an over estimate of $R_{d a}$ ard underestimate of $R_{d b}$ or vise versa, then the fractional difference will be less than or equal to $\{f-1\rangle$. Near $x_{2}=y_{<a}$ it $v 111$ be $\sim\left(f_{a}-1\right)$, and near $x_{2}=x_{2 b}$ it will be $\sim\left(f_{b}-1\right)$.

Figure 2.11 shows the relative difference as a function of $x_{2}$ for three fllustrative cases:

$$
\begin{aligned}
& f_{a}=f_{b}=1.05, \\
& f_{a}=1.05 \text { and } f_{b}=1.00, \\
& f_{a}=1.05 \text { and } f_{b}=0.95 .
\end{aligned}
$$

The example is based on the exact reference points $(0.2,2.0)$ and $(0.6,3.0)$. Note how the magnitude of the addition error is less than $5 \%$ in all cases. 


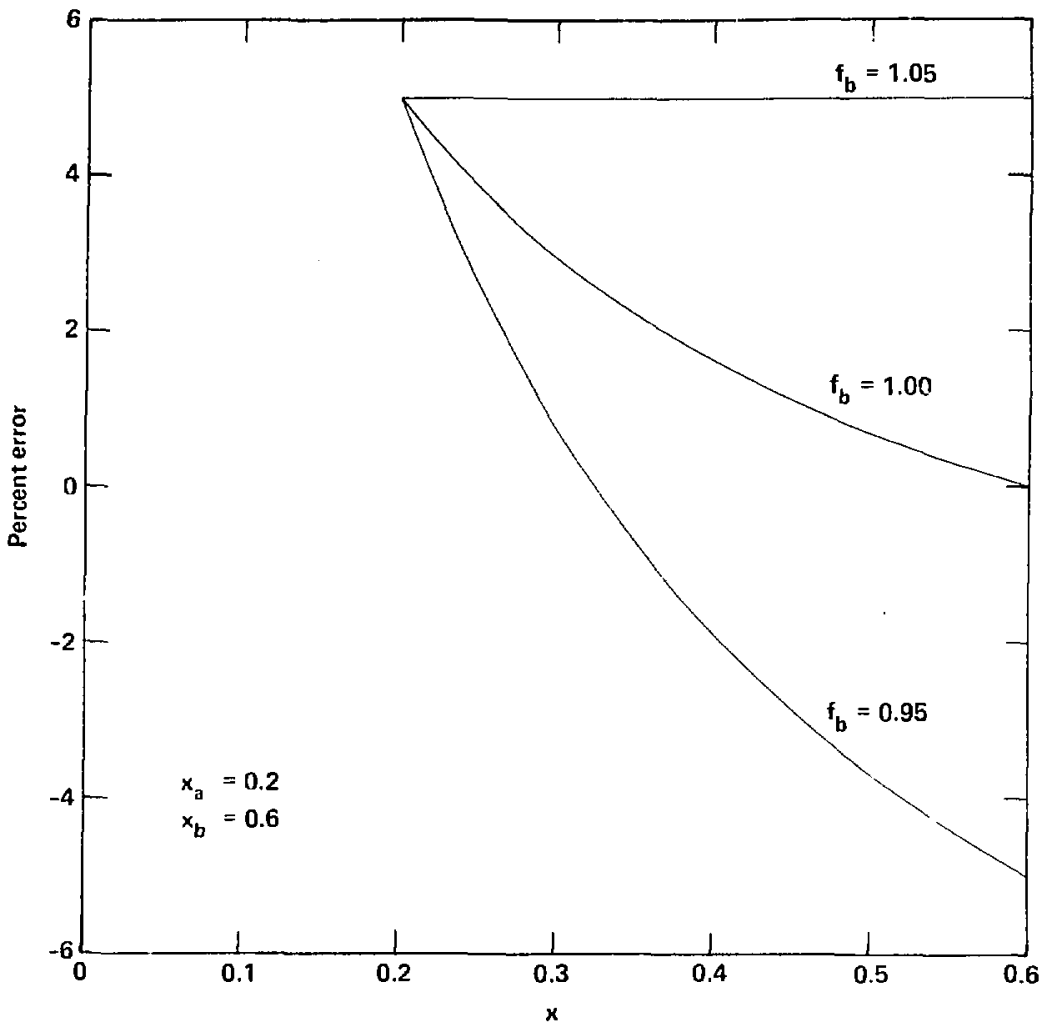

fig. 2.11 Illustration of additional error due to successive two point interpolation. Refer to Fig. 2.3. The ratios of the interpolated results $R_{d a}$ and $R_{d b}$ to the exact results at $\left(x_{1 d}, x_{2 a}\right)$ and $\left(x_{1 d}, x_{2 b}\right)$ are denoted $f_{a}$ and $f_{b}$ ' iespectively. Here, $f_{a}=1.05$ and $f_{b}$ ranges from 0.95 to 1.05. The magnitude of the additional error is less than $5 \%$ in the range of interpolation, $0.2 \leq x \leq 0.6$. 
For the three point interpolation the additional fractional eriar can, in some cases, exceed the magnitude of $\left(f_{a}-1\right),\left(f_{b}-1\right)$ or $\left(1 c^{-1}\right)$. Here $f_{a}, f_{b}$ and $f_{c}$ are the ratios of the results obtained by three point interpolation on $x_{1}$ at $x_{2}=x_{2 a}, x_{2 b}$ and $x_{2 c}$. respectively, to the exact results if additional transport calculations had been carried out at $\left(x_{1 d}, x_{2 a}\right),\left(x_{1 d}, x_{2 b}\right)$ and $\left(x_{1 d}, x_{2 c}\right)$, respectively. See Fig. 2.:0.

The additional fractional error is shown in figs. 2.12-2.14. In each case $f_{a}=1.05$ and $f_{c}$ takes on three values 1.05, 1.00, and 0 95. Figure 2.12 is for $f_{b}=1.05, F i g .2 .13$ fo: $f_{b}=1.00$ and Fig. 2.14 for $f_{b}=0.95$. The exact reference results are $(0.2,2.0)$, $(0.4,2.67)$ and $(0.6,3.0)$. Note that in Fig. 2.12, the error exceeds $5 \%$ in the range $0.2<x_{2}<0.4$ for $f_{c}=1.00$ and 0.95 . In Fig. 2.13, the magnitude of the error is less than $5 \%$ in all cases. In Fig. 2.14, the magnitude of the error exceeds $5 \%$ for $f_{c}=1.05$ when $0.28<x<0.4$ and exceeds $5 \%$ for $f_{b}=0.05$ when $0.4<x<0.6$.

In the previous examples, the error due to the first interpolation was assumed to be less than or equal to $5 \%$. Cheng has evaluated the error due to the Schwinger functional (Eq. 2.16) as well as the two point interpolation form of this functional (Eq. 2.33) by comparing the results to those obtained with transport calculations at various points. ${ }^{12.36}$ For the examples he chose, the errors were on the order of 2-5* over a relatively large variation in the design varlable.

An expression for the error can be developed in terms of a serles solution for the neutron flux. The relationship of the variational principles to perturbation theory has been shown. ${ }^{36,37}$ Consider the neutron transport equation 


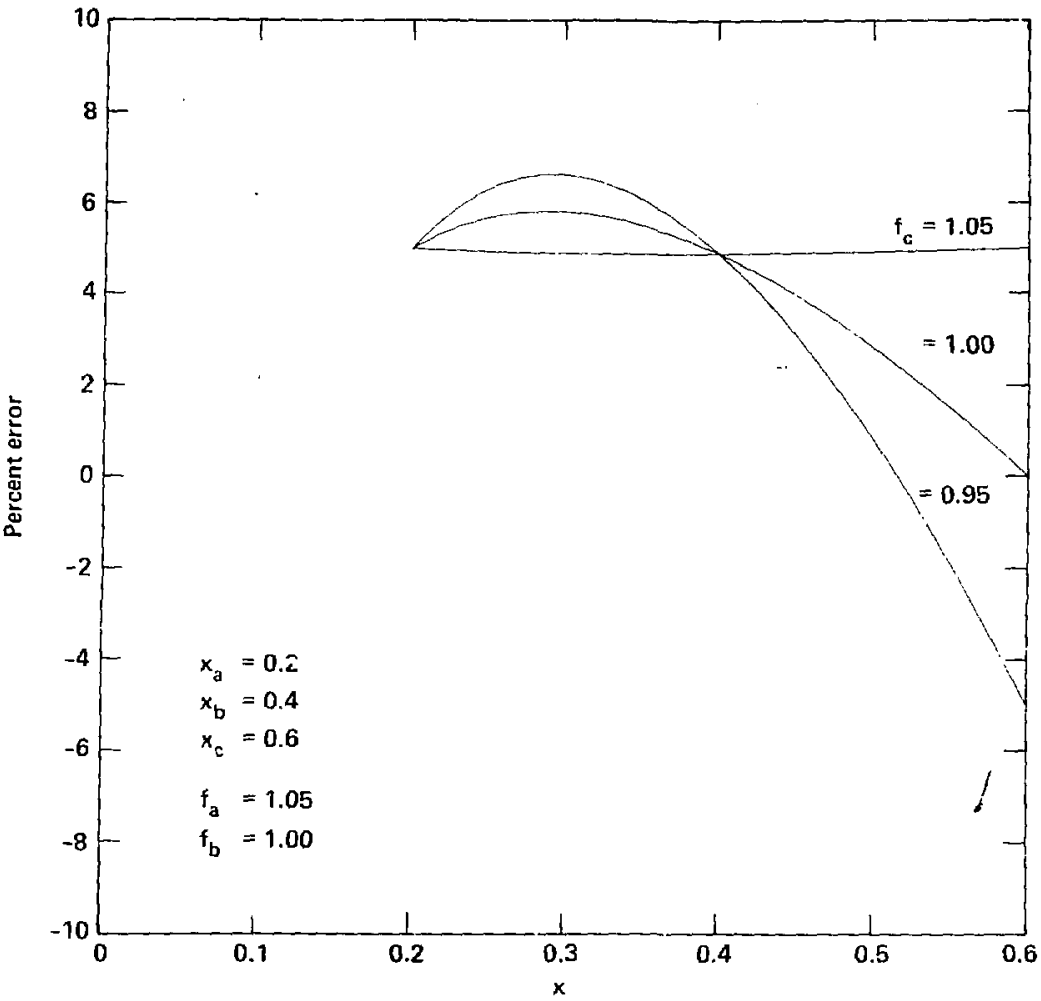

fig. 2.12 Additional error due to successive three point interpolation for $f_{b}=1.05$. Refer to Fig. 2.10. The ratios of the inierpolated results $R_{d a}, R_{d b}$ and $R_{d c}$ to the exact results at these points are denoted $f_{a}, f_{b}$ and $f_{c}$, respectively. $f_{a}=1.05$ and $f_{c}$ ranges from 0.95 to 1.05 . The magnitude of the error exceeds $5 \%$ in some cases. 


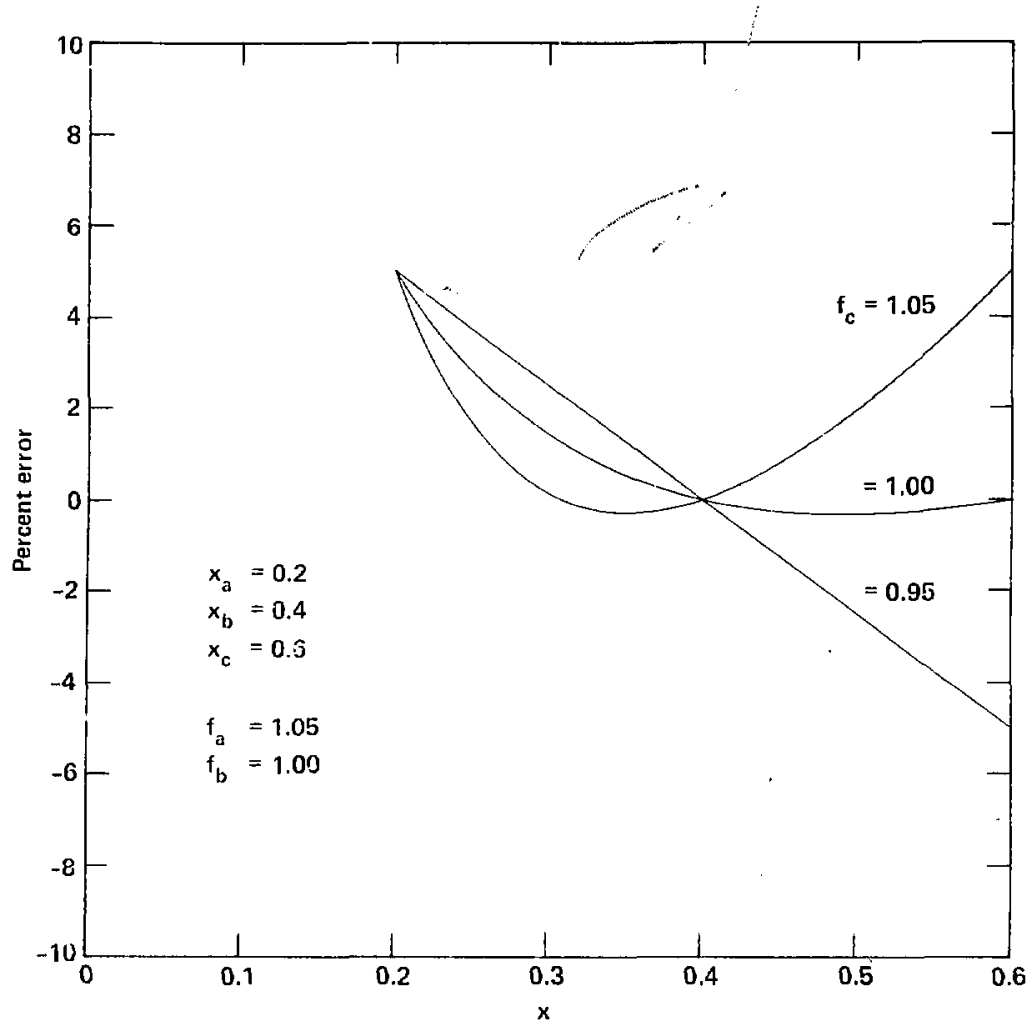

fig. 2.13 Adutional error due to successive three point interpolation for $f_{b}=1.00$. 


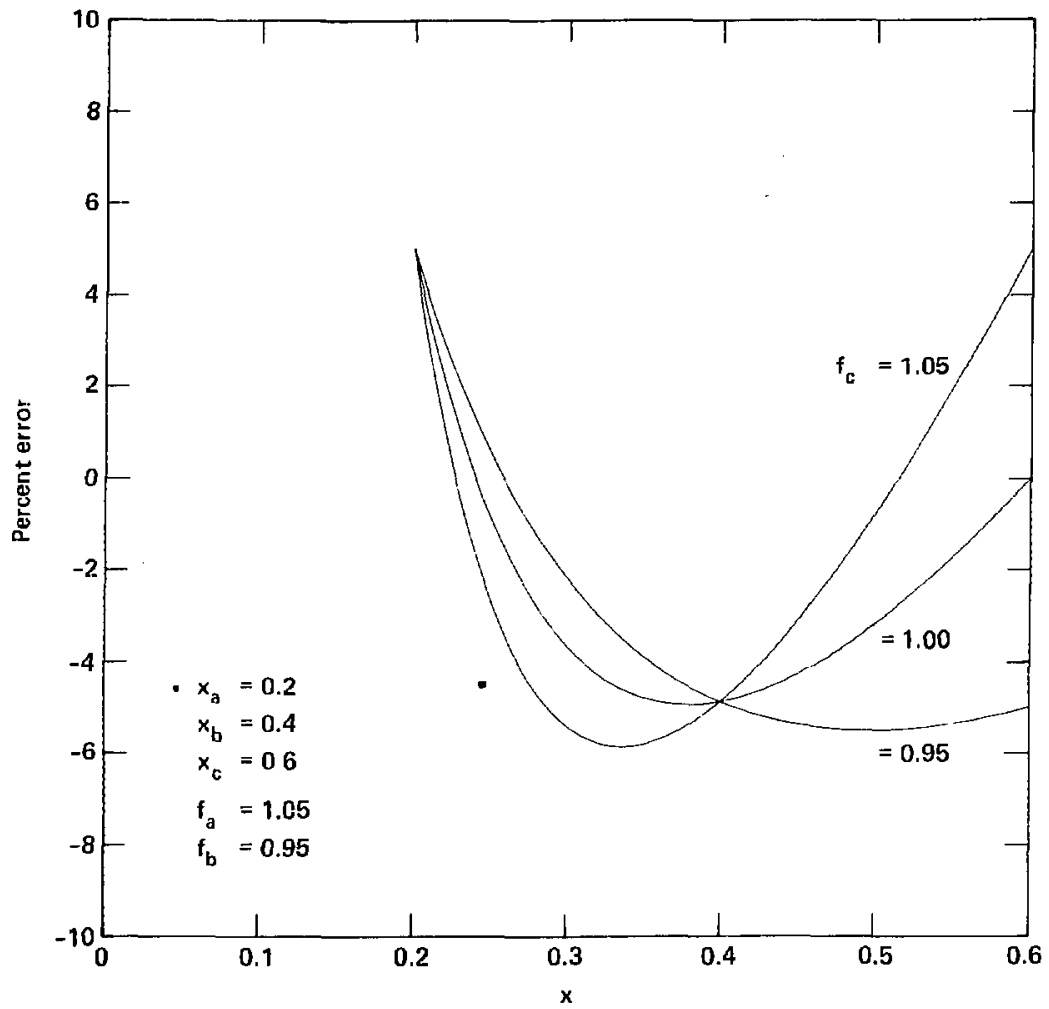

Fig. 2.14 Additional error due to successive three point interpolation for $f_{b}=0.95$. 


$$
L \phi=S \text {, }
$$

and the associated adjoint equation

$$
L^{*} \phi^{*}=S^{\star}=\delta .
$$

If the reference system, $L_{0}$, is perturbed, the altered system, $L$, can be related to it by

$$
L=L_{0}+\alpha \delta L
$$

where $\alpha$ is a perturbation parameter. The serles solution for $\phi$ is

$$
\varphi=\sum_{i=0}^{\infty} \alpha^{i} \Phi_{i} .
$$

The reaction rate, $\langle[, \phi\rangle$, can thus be determined exactly by an infinite series of the solutions, $\Phi_{1}$, to the higher order equations

$$
L_{0} \phi_{1}=-\delta L_{1-1} .
$$

That 15,

$$
R=\sum_{i=0}^{\infty} \alpha^{\left.1<\Sigma, \phi_{1}\right\rangle} .
$$


The vartational functionals are given in terms of both forward and adjoint solutions. The adjoint flux can similarly be written as

$$
\phi^{*}=\sum_{1=0}^{\infty} \alpha^{\dagger} \phi_{1}^{*},
$$

where $\phi_{1}^{*}$ is the solution to

$$
L_{0}^{*} \phi_{1}^{*}=-\delta L^{*} \phi_{1-1}^{*}
$$

If the exact solutions, $\phi$ and $\phi^{*}$, given by Eqs. 2.76 and 2.79 are used in the variational expressions the resultant reaction rate is exact. Truncating the serles with the first term gives the Roussopoulos and Schwinger functions described in section 2.1. That 1s, these estimates are based on the solutions $\phi_{0}$ and $\phi_{0}^{*}$ at the reference point.

The error of the fractional variational functionals, $\Delta F_{m n}$, is given by 36

$$
\Delta F_{m n}=\sum_{j=0}^{n} \sum_{i=0}^{m} \sum_{k=m+1}^{\infty} N \div \sum_{j=0}^{n} D,
$$

where

$$
N=\alpha^{j+j+k+1}\left[\left\langle\varepsilon, \phi_{1}>\left\langle\phi_{j}^{*}, \delta L \phi_{k}\right\rangle-\left\langle\Sigma, \phi_{k}\right\rangle\left\langle\phi_{j}^{*}, \delta L \phi_{1}\right\rangle\right],\right.
$$

and

$$
D=a^{j}\left[\left\langle\phi_{j}^{*}, S\right\rangle+\sum_{i=0}^{m} a^{i+1}\left\langle\phi_{j}^{\star}, \delta L_{i}\right\rangle\right] .
$$


$-57-$

Here $m$ is the number of terms retained in the solution for

(Eq. 2.76), and $n$ is the number of terms retained in the solution for \$ (Eq. 2.79).

For the Schwinger functional, $m=n=0$, and Eq. 2.81 reduces to

$$
\begin{aligned}
\Delta f_{00} & =\sum_{k=1}^{\infty} \alpha^{k+1}\left[\left\langle\varepsilon, \phi_{0}>\left\langle\phi_{0}^{*}, \delta L \phi_{k}\right\rangle-\left\langle\left[, \phi_{k}>\left\langle\phi_{0}^{*}, \delta L \phi_{0}>\right]\right.\right.\right.\right. \\
& \div\left[\left\langle\phi_{0}^{*}, S>+\alpha<\phi_{0}^{*}, \delta L \phi_{0}>\right] .\right.
\end{aligned}
$$

Hence the error can be evaluated if the solutions, $\phi_{k}$, are calculated. 


\section{NONLINEAR SIMPLEX METHOO FOR OPTIMIZATION}

\subsection{BACKGROUND}

As previously mentioned, the nonlinear simplex method of Nelder and Mead ${ }^{14}$ was chosen for the blanket optimization problem. It is a direct search method which relles on evaluating a function at a sequence of points and comparing values in order to reach the optimal point. The method is based on a geometrical design known as a simplex. An $n$-divienstonal simplex is defined by $n+1$ points which are the points at which the function is compared. This should not be confused with the simplex algorithms of linear programing.

Nelder and Mead's method is an improvement on the algorithm proposed by Spendley, et a1. ${ }^{42}$ Spendley's method uses a I gular simplex. A regular simplex is one in which the vertices are equally spaced. An equilateral trlangle is an example of a regular simplex. Nelder and Mead's method allows the simplex to become nonregular. It is one of the most efficlent direct search methods avallable and works well if the number of variables is not more than five or six. ${ }^{13}$

While other modifications to Melder and Mead's method have been proposed, 43,44 they have not been incorporated in the algorithm used in this study. The optimization subroutine used in the blanket optimization problem was previously coded and used by 3 . Trenholme to opt Imize the design of experimental lasers at Lawrence Livermore National Laboratory. 15 


\subsection{DESCRIPTION OF THE ALGORITHM}

The objective is to minimize a function $F$, where $F$ is a function of $n$ variables $x_{1}, x_{2}, \ldots, x_{n}$. The simplex consists of $n+1$ points, $P_{j}$.

The following notation will be used. Let

$$
\begin{aligned}
& P_{h}=\text { point with the highest function value, } \\
& P_{s}=\text { point with the second highest function value, } \\
& P_{Q}=\text { point with the lowest function value, and } \\
& \bar{P}=\text { centroid of all points except } P_{h} .
\end{aligned}
$$

That is,

$$
P=\frac{1}{n} \sum_{\substack{j=1 \\ j \neq h}}^{n+1} P_{j} .
$$

Also let

$$
\begin{aligned}
& F_{h}=F\left(P_{h}\right) . \\
& F_{s}=F\left(P_{s}\right) . \\
& F_{l}=F\left(P_{2}\right) .
\end{aligned}
$$

The method of Nelder and Mead is a follows: 13,14

1. Choose the points of the initial simplex. In the optimization subroutine used in this work, a singie starting 
point is specified in the input file. the routine then chooses the initial points of the simplex so that they surround the starting point. It is advantageous, although not required, to choose the starting point from within the feasible region. In general, a feastble starting point can eastly be detemined by examining the results of the reference point transport calculations. It is also advisable to run the problem starting at several different points which will help determine if the optimum is unique.

2. Evaluate $F$ at each point and determine the highest point, $P_{h}$.

3. Calculate the centrold, $\bar{P}$, of the remaining points.

4. Reflection. The highest point, $P_{h}$, is reflected through the centroid of the remaining points, $F$. The reflected point is denoted $P_{r}$. The value of $F$ at $P_{r}$ is calculated and denoted $F_{r}$. The reflection factor, $a>0$, is the ratio of the distance between $\bar{P}$ and $P_{r}$ to the distance between $P_{h}$ and $P$. That is,

$$
p_{r}-\bar{p}=\alpha\left(\bar{p}-p_{n}\right) \text {. }
$$

or

$$
P_{r}=(1+\alpha) P=\alpha P_{h} .
$$

If $a=1$, the reflected point is as for on the other side of the centrold as the high point is from tine near side. The 
reflection move is lllustrated in fig. 3.1a for a two dimensional case.

5. If $F_{Q} \leq F_{r} \leq f_{s}$, replace $P_{h}$ by $P_{r}$ and return to Step 2. That is, if the value of the function at the reflected point falls between the low value and second to highest value, the old high point is replaced by the reflected point.

6. Extens 3n. If $F_{r}<F_{Q}$, extend the simplex using an extension factor $Y>1$. That is, find the extended point, $P_{e}$, such that

$$
P_{e}-P=Y\left(P_{r}-P\right)
$$

or

$$
P_{e}=(1-Y) P+Y P_{r} .
$$

The value of the function at this point is $F_{e}$. In this case a new low value has been found $\left(F_{r}<F_{\ell}\right)$ so the reflected point is moved farther in the same direction to see If $f$ continues to decrease. There are two possible results:

a) If $F_{e}<r_{\ell}$, replace $P_{h}$ by $P_{e}$ and return to Step 2.

b) If $F_{e} \geq F_{Q}$, replace $P_{h}$ by $P_{r}$ and return to Step 2. In this case the extension has falled. It can be viewed as moving into a valley $\left(F_{r}<F_{\ell}\right)$ but the extension produces a result $f_{e}$ that is up the slope on the opposite side. The extension move is illustrated in Fig. 3.1b. 
A) Reflection

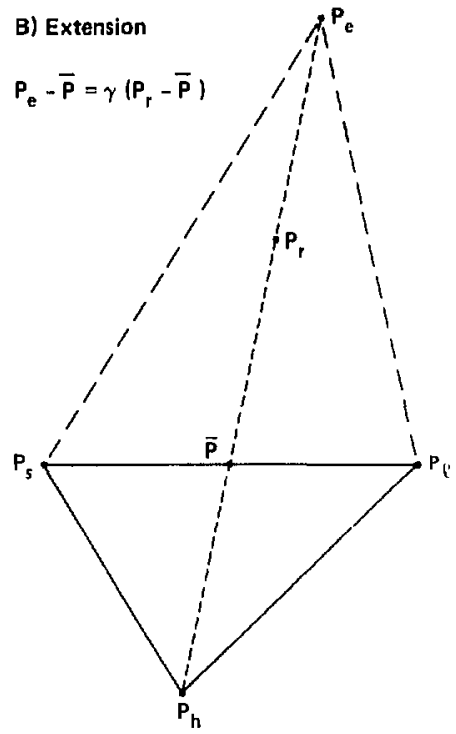

$P_{p}-\bar{P}=\alpha\left(\bar{P}-P_{h}\right)$
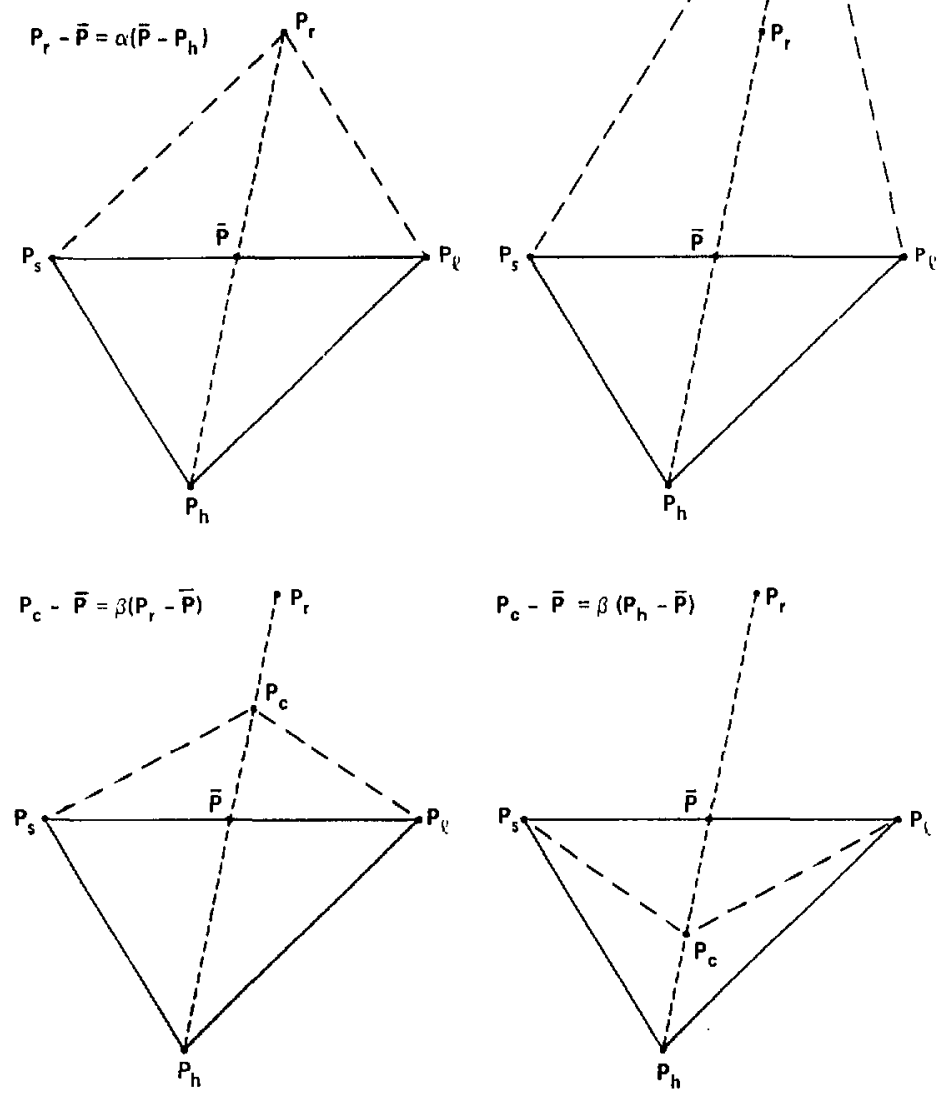

c) Contraction, $F_{r} \leqslant F_{h}$

D) Contraction, $F_{r}>F_{h}$

Fig. 3.1 Four basic moves in Nelder and Mead's nonlinear simplex method of optimization. 
7. Contraction. If $F_{r}>F_{s}$, contract the simplex using a contraction factor $\beta$, where $0<\beta<1$. There are two cases:

a) If $F_{r} \leq F_{h}$, find the contracted point $P_{c}$ defined by

$$
P_{c}-\overline{\mathbf{P}}=B\left(P_{r}-\bar{P}\right) \text {. }
$$

or

$$
P_{C}=(1-P) \vec{P}+B P_{r} .
$$

This is illustrated in Fig. 3.1c.

b) If $F_{r}>F_{h}$, find the contracted point $P_{c}$ defined by

$$
P_{c}-P=B\left(P_{h}-P\right) \text {, }
$$

or

$$
P_{c}=(1-\beta) \bar{P}+\beta P_{h} \text {. }
$$

This is lllustrated in Fig. 3.1d. Note that Step 6a is the equivalent of replacing $P_{h}$ by $P_{r}$ and then finding $P_{c}$ defined by Eq. 3.4. For etther $7 a$ or $7 b$ there are again two cases to consider:

c) If $F_{c}<F_{h}$ and $F_{c}<F_{r}$, replace $P_{h}$ by $P_{c}$ and return to Step 2 .

d) If $F_{c} \geq F_{h}$ or $F_{c} \geq F_{r}$, reduce the size of the simplex by halving the distance from $P_{2}$ and return to Step 2. That 1s, replace all $P_{j}$ by $\left(P_{j}+P_{R}\right) / 2$. This last move is referred to 
as a huddle.

We see that in Meider and Mead's method, each iteration begins with a reflection move. Subsequent steps depend on the value of the function at the reflected point with respect to the highest, second-to-highest and lowest values of function evaluated at the vertices of the 5 implex (1.e., how $F_{r}$ compares to $F_{h}, F_{s}$, and $F_{Q}$ ). The authors recomend the values $\alpha=1, \beta=0.5$, and $Y=2$ as the best strategy. ${ }^{14}$ A flow diagram is given in Fig. 3.2 . 


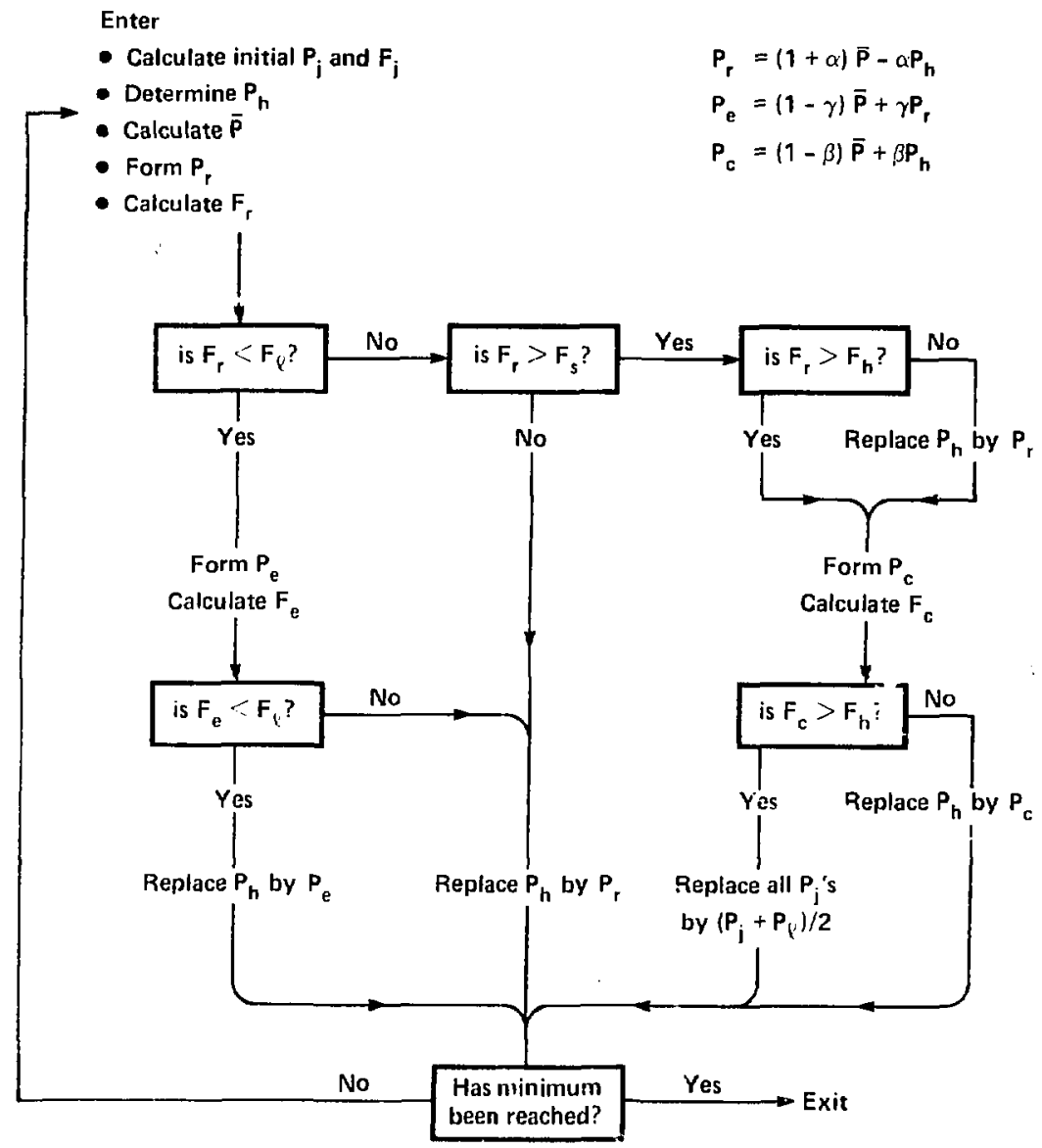

F1g. 3.2 Loglc flow dlagram for Nelder and Mead's nonlinear simplex method (after Ref. i4). 


\subsection{CONVERGENCE CRITERION}

After exth iteration, twe convergence criterla are checked to see if the search should be halted, 1.e.: if the minimum has been located. The first criterion compares the highest function value in the simplex, $F_{h}$, to the lowest, $F_{q}$. If these two values differ by less than some small number, $\varepsilon$, the searih is halted. That is, if

$$
F_{h}-F_{y}<\varepsilon .
$$

The second criterion is based on the distance between the location of highest and lowest value of the current simplex. If the distance is less than $\delta$, the subroutine terminates. Let $\left[P_{h} P_{Q}\right]$ represent the distance between $P_{h}$ and $P_{\ell}$. If

$$
\left[P_{h} P_{Q}\right]<\delta,
$$

the search is halted. Both $\varepsilon$ and $\delta$ are input parameters for the optimization subroutine. Clearly the optimal point is $P_{\ell}$, and the value of the function is $F_{\ell}$ at the time when either criteria is met 


\subsection{HANDLING CONSTRAINTS}

Constraints limit the acceptable range from which points can be chosen in searching for the minimun value of $F$. With Nelder and Mead's method constraints are handled in the definition of the function to be minimized. That is, if a constraint is violated, $F$ is set equal to an arbitrarily large number. As such, If a point in the simplex results in a violated constraint, contraction moves will be made until all points of the simplex are inside the feasible region. See fig. 3.3. A problem can arlse if the search is started in the unfeasible region. If all points of the initial simplex lle in the unfeasible region, they all have the same value, and the first convergence criterion, Eq. 3.5, is satisfied. As a result the search terminates. This difficulty can easily be corrected.

Fox and Liebman proposed a modified method of handling constraints. $^{43}$ It is 1llustrated in Fig. 3.4. Here the value of the function in the infeasible region slopes down toward the feasible region like a funnel. In this way, if the search is begun in the infeasible region, it will proceed until it falls into the "well" of the feasible region.

In the next chapter, the method of estimating neutronic performance is combined with the optimization algoritinm described in this chapter to optimize the blanket of an inertlal confinement fusion reactor. 


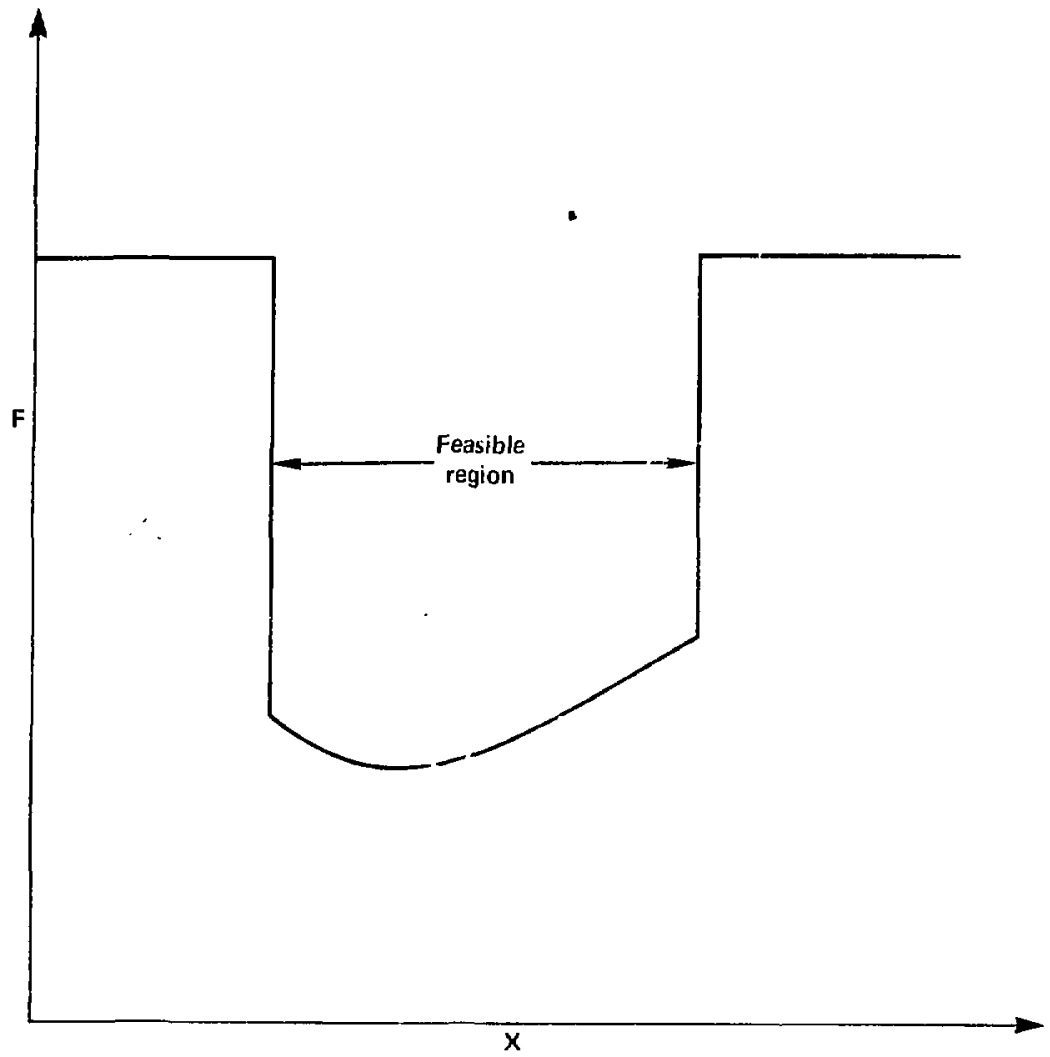

fig. 3.3 A simple method of handing constralnts. The figure of merit, $F$, is defined to be an arbitrarily large number outside the feasible region. 
$\cdot$

$-69-$

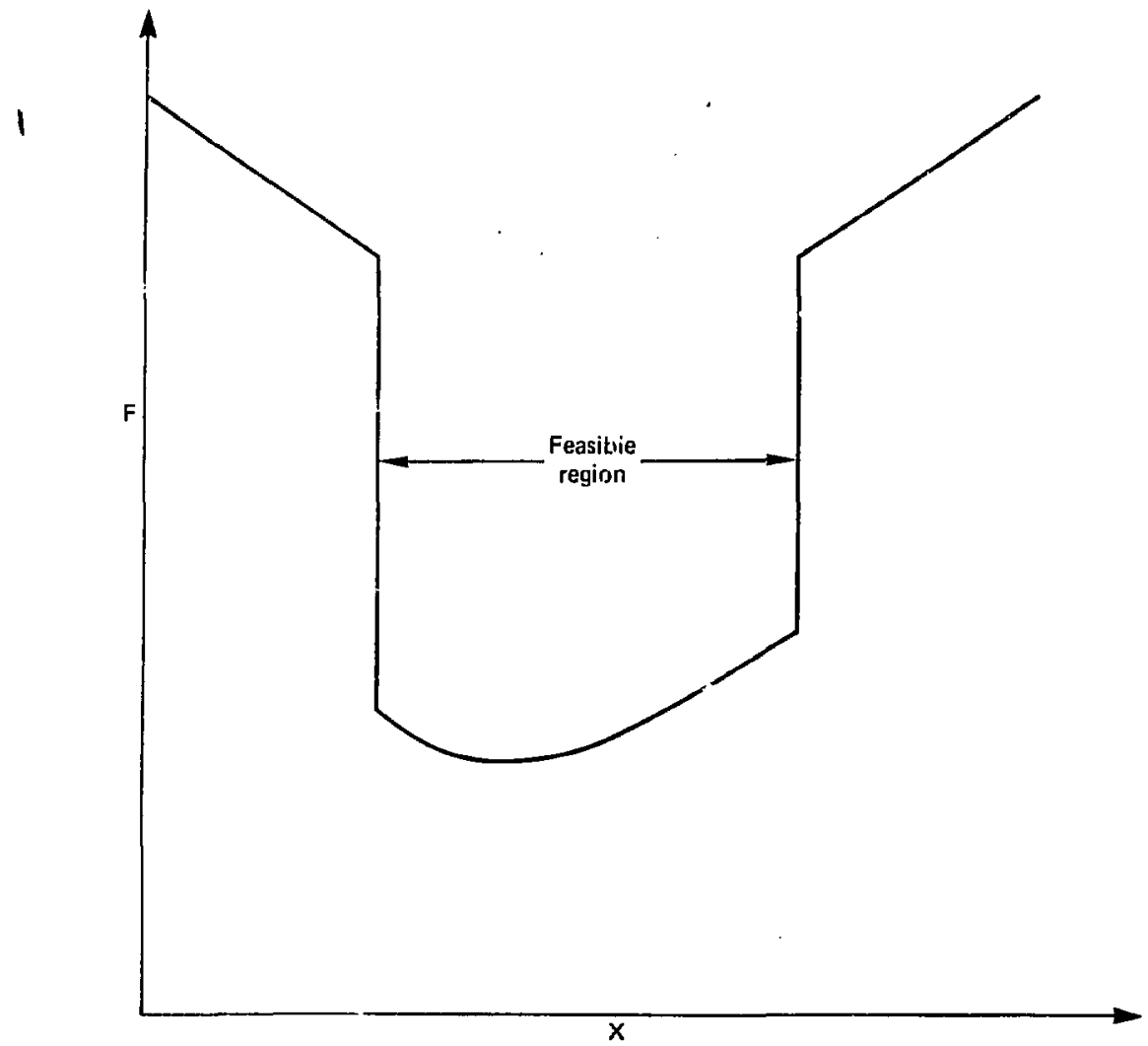

Fig. 3.4 Fox and Llebman's method of handling constraints. The search is directed toward the feasible region. 


\section{OPTIMIZATION OF A MODIF IEO HYL IFE CHAMBER}

\subsection{DESCRIPTION OF THE PROBLEM}

\subsubsection{The HYLIFE Reactor Concept.}

The High Yield Lithium Injection Fusion Energy (HYLIFE) chamber for inertial confinement fusion (ICF) has been described in detatl in the ifterature. ${ }^{1,46-51}$ The HYLIFE Concept is illustrated in Fig. 4.1, and a cross sectional view is shown in fig. 4.?

In the HYLIFE chamber, an array of lithium jets is injected into the chamber between fusion pulses to provide the equivalent of a 1 -m-thick blanket between the fusion target and the first structural wall. Thts energy conversion blanket shtelds the chamber structural matertals from direct exposure to the $x$-rays, debris, and high-energy neutrons emitted by the fuston pellet. The $14 \mathrm{MeV}$ neutron flux is reduced by more than a factor of 200 , and neutron damage levels are low enough to allow the 5 -m-radtus chamber wall to operate for more the 30 years without replacement. ${ }^{52,53}$ with a $1.0 \mathrm{~m}$ thick blanket of natural 11thium $\left(7.42 \%{ }^{6} \mathrm{~L} .1\right.$ and $92.58 \%{ }^{7}$ L.1), HYLIFE achieves a tritium breeding ratio of 1.75 .54

The subject of this first blanket optimization problem is a modification of the HYLIFE chamber. The modified design is an attempt to increase the energy deposited in the chamber per fusion reaction. The ratto of total energy deposited to the fusion energy released per DT reaction is defined as the fusion energy multiplication. uctor, $M_{f}$. It is given by 


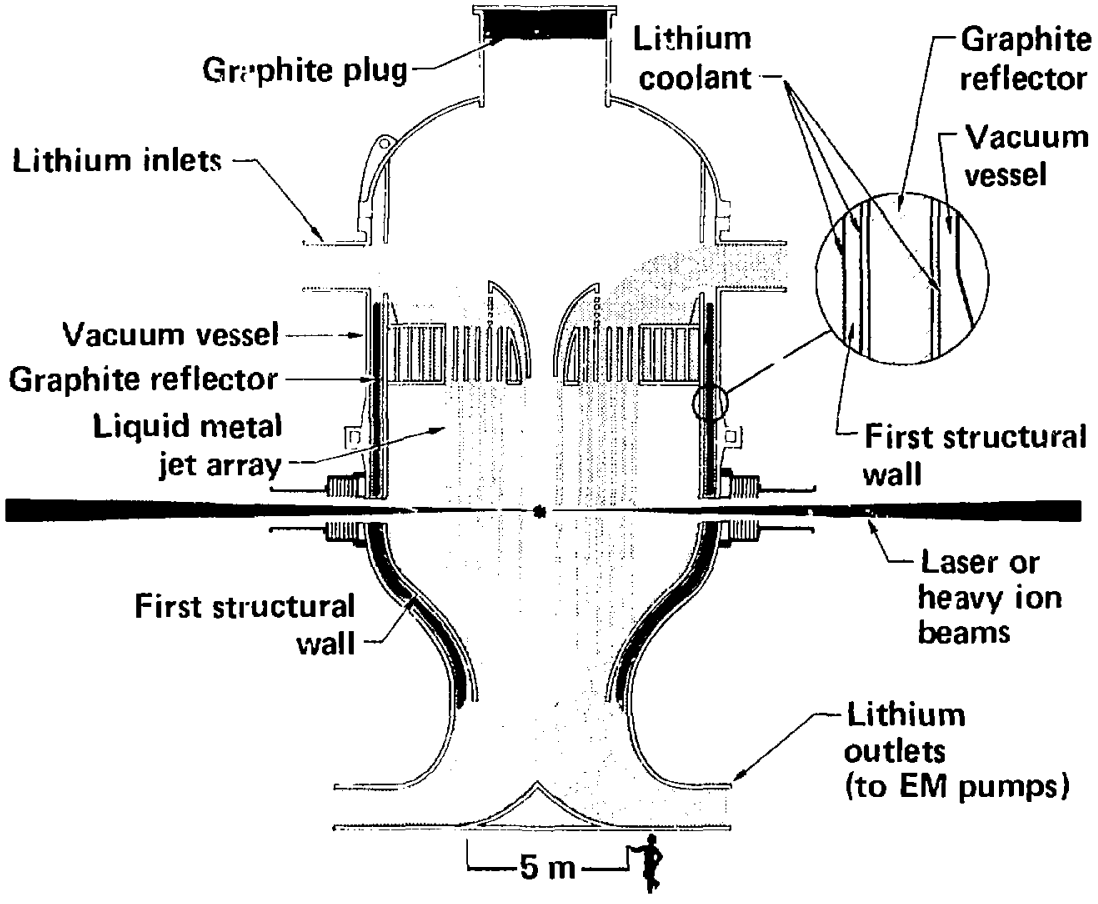

Fig. 4.1 The HYLIFE concept. 


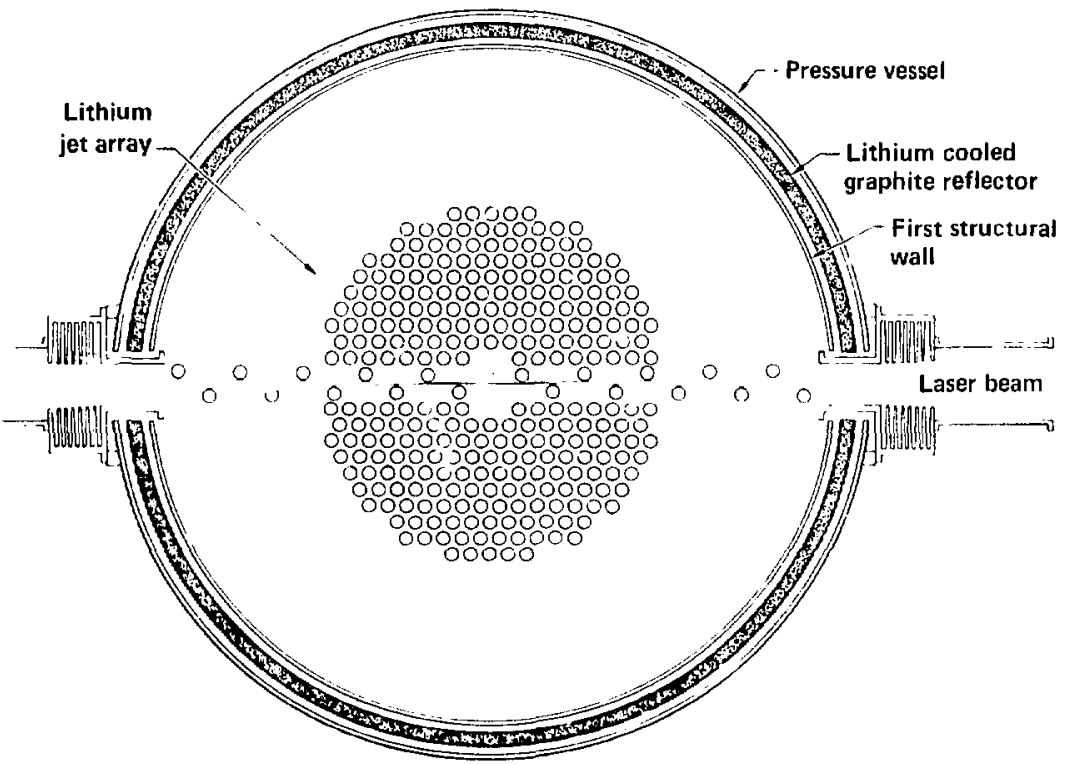

fig. 1.2 Cross sectional view of HYLIFE. 


$$
H_{f}=\left(E_{n}+3.5\right) / 17.6,
$$

where

$$
\begin{aligned}
E_{n}= & \text { the total energy (MeV) deposited as a result } \\
& \text { of neutron reactions within the chamber. It } \\
& \text { includes the neutron energy deposited in the } \\
& \text { compressed fuel region of an ICF target. }
\end{aligned}
$$

The factor 3.5 is the fuston alpha particle energy in MeV and $17.6 \mathrm{MeV}$ Is the total fusion energy released per OT reaction. In general, $M_{f}$ will be slightly greater than one due to exoergic neutron reactions with blanket materials, e.g., the ${ }^{6} \operatorname{Li}(n, T) a$ reaction which releases 4.8 MeV. For HYLIFE, $M_{f}$ is 1.16 .

The approach in the modifted HYLIFF design is to reduce the tritium breeding ratio and capture the excess neutrons in ${ }^{55} \mathrm{Mn}$. Each capture in ${ }^{55} \mathrm{Mn}$ adds 9.8 tiel to the energy balance. The ${ }^{55} \mathrm{Mn}\{\mathrm{n}, Y\}$ reaction releases $7.3 \mathrm{MeV}$ whlle the decay of the product, ${ }^{56}$ Mn, releases an additional $2.5 \mathrm{MeV}$ of recoverable energy. 55 The half-11fe for the $B^{-}$decay is 2.6 hours.

Increasing $M_{f}$ by capturing neutrons in structural material has been previously proposed. ${ }^{56}$ The authors of Refs. 57 and 58 suguested a 14\% Mn steel called Fe-1422 for the purposes of increasing $M_{f}$. In this work, a $20 \%$ Mn steel, known as Nippon Steel Alloy NH-1, is ued. 59 The composttion of NM-1 by weight percent is $77.5 \% \mathrm{Fe}$, $20.0 \% \mathrm{Mn}, 2.0 \times \mathrm{Cr}$ and $0.5 \% \mathrm{C}^{59}$

The potential auvantage of lncreasing the fusion energy multiplication factor is a lower cast of electricity from a fusion-electric power plart. This follows since more power is 
avallable for a given investment in the laser ofiver and target factory in the case of ICF (or for a given investment in the magnets for magnetic fusion reactors). That is, fixing the size of the laser and the characteristics of the target, fixes the fusion energy released per puise. If this energy can be increased as a result of neutron reactions in the blanket, more thermal energy wil be avallable for conversion to electricity. In the blanket optimization problem, the characteristics of the driver and target are fixed, as is the chamber pulse repetition rate. The variables relate only to the design of the blanket itself as discussed below.

There are two simole ways to reduce the tritlum breeding ratio in HYLIFE; one is to reduce the fraction of $6_{L 1}$ in lithium and the other is to reduce the effective thickness of the 11 thlum blanket, 1.e.. the 11 thium jet array. ${ }^{60}$ In addition, the Li cooled graphite reflector (see Fig. 4.? and 4.2) is replaced by a sodium cooled Mn-steel blanket in the modifled design. Hence all the trittum breeding must occur in the lithlum blanket. The two design varlable for this problem are

$$
x_{1}={ }^{6} L_{1} \text { fraction in } L 1 \text {, }
$$

and

$$
x_{2}=\text { effective LI blanket thickness, } m \text {. }
$$

Note that the actual thickness of the $L 1$ blanket is heid constant whlle the packing fraction of liquid lithlum jets within that region is varted. This is, in essence, a variation of the materlal density and thus qualifies 35 a linear perturbation as seen from Eq. 2.34. 


\subsubsection{Constraints on the Design.}

Reducing the blanket thickness is advantageous in that it reduces the Li flow rate resulting iri savings in pumping power and capttal costs for liquid metal $r$ imps and piping. There is a lower 1 imit, however, set by a constra: it on the maximum allowable radiation damage rate in the first structurd wall. For HYLIfE the rate was 1 imited to the point where the wall was expected to malntain its structural integrity for the 30 year $11 \mathrm{fe}$ of the power plant. 1 The $11 \mathrm{fe}$ 11miting radtation damage mechanism for HYLIFE was found to be the o1splacement of atoms from their lattice positions. ' 01splaced atoms leave vacancies which can conglomerate to forn. volds within the steel, and this leads to a phenomena known as vold swelling. 61 After some total amount of damage, expressed in terms of displacements per atom or dpa, the structural naterlal is deformed, and/or its properties are degraded to the point where it loses its integrity.

Currently there is insufficient data to set absolute damage 11 mits for structures in fusion reactors. It is known, however, that ferritic steels are less susceptible to the effects of displacement danage than austenitic steels, ${ }^{62}$ and a damage limit of $\sim 200 \mathrm{dpa}$ was recently suggested as a reasonable estimate for high $\mathrm{Cr}$ ferritic steels. ${ }^{63}$ A low-alloy, ferritic steel, $2.25 \mathrm{Cr}-1 \mathrm{Mo}$, was specifled for HYLIfE due to its low cost, resistance to liqutd-metal corrosion and resistance to the effects of radiation damage. ${ }^{51}$

For the purposes of this study, the total disp?acement damage in the first structural wail of the modified HYLIFE chamber is $11 \mathrm{mited}$ to 200 dpa over an operating perlod of 30 years at $70 x$ plant capacity factor. This gives a constraint on the displacement damage rate of 
9.5 dpa per full-power-year. The dpa rate is expected to depend primarlly on the blanket thickness, $x_{2}$, but may also depend somewhit on the ${ }^{6} \mathrm{LI}$ fraction.

finother constraint in the optimization problem is the requirement for a tritium breeding ratio high enough to assure a scif-sufficlent fuel cycle. A tritlum breeding ratio $\geq 1.05$ has been chosen to satisfy this criterla, Clearly the tritium breeding ratio will be a function of both design variables.

\subsubsection{Figure of Merit for HYLIFE.}

The figure of merit for this optimization problem is the captal cost of the power plant divided by the net electric power production. That is.

$$
F=C_{T} / P_{n} \text {. }
$$

where

$$
\begin{aligned}
& C_{T}=\text { total plant capital cost including the } \\
& \text { cost of the reactor, laser and target } \\
& \text { factory, } \$ \text {, and } \\
& \rho_{n}=\text { net electric power produced and avatlable } \\
& \text { for sale, } k W_{e} .
\end{aligned}
$$

The cost of electricity (1.e..,e/kW $\mathrm{h}$ ) from a fusion electric power pizat is expected to be dominated by the carrying charges un the capital investment. 47 The capital cost portion of the cost af eleciricity is given by

$$
c_{e}=1 C_{T} / 8760 \mathrm{fP}{ }_{\mathrm{n}}
$$


where

$$
\begin{aligned}
t & =\text { f }\left\{\text { xed charged rate. } y^{-1} \text { (typically } 15 \%\right. \text { per year). } \\
f & =\text { plant capacity factor (typtcal1y } 70 \% \text { ), and } \\
8760 & =\text { number of hours per year. }
\end{aligned}
$$

Since to first order, 1 and $f$ are independent of the blanket design, the cost of electricity is proportional to $C_{T} / P_{n}$. Hence minimizing the plant capital cost per unit of net electric power is equivalent to minimizing the cost of electricity under these assumptions.

The total capital cost is broken into four components,

$$
c_{T}=c_{R}+c_{P}+c_{L}+c_{T F} \text {, }
$$

where

$$
\begin{aligned}
& C_{R}=\text { cost of the reactor including the balance of } \\
& \text { plant required for heat transfer and conversion } \\
& \text { to electririty. } \\
& C_{P}=\text { cost of } 11 \text { thium recirculating } p \text {,ps and piping } \\
& \text { required to maintain the flowing lithium blanket, } \\
& C_{L}=\text { cost of the laser driver, and } \\
& C_{Y}=\cos t \text { of the target factory. }
\end{aligned}
$$

The cost of the reactor scales as the plant thermal power, $P_{t}$, ralsed th the 0.8 power, ${ }^{64}$

$$
C_{R} \propto P_{t}^{0.8}
$$


The thermal power is simply the fusion power, $P_{f}$. times the fusion energy multiplication factor. $M_{f}$. Hence

$$
C_{R} \times\left(M_{f} P_{f}\right)^{0.8}
$$

As previously stated, $P_{f}$ is flixed but $M_{f}$ will be a function of both the ${ }^{6}{ }_{1}$ fraction, $x_{1}$, and the Li blanket thickness, $x_{2}$.

The cost of the pumps will be proportlonal to the total ifthium flow rate through the chamber. The flow rate is taken to be proportional to the effective blanket thickness $x_{2}$, hence

$$
c_{p} \propto x_{2}
$$

The cost of the laser and target factory are fixed and independent of the two design varlables.

The actual costs are referenced to those 1 isted in Table 4.1 for HYLIFE. ${ }^{47}$ Using these vaiues, the direct capltal cost of the modif led HYLIFE chamber in $\$ B$ is,

$$
c_{T} \quad 0.96\left(H_{f} / 1.16\right)^{0.8}+0.16 x_{2}+0.43
$$

The net electric power is given by

$$
p_{n}=p_{g}-p_{Q}-p_{a}-p_{p}
$$

where

$$
\begin{aligned}
& P_{g}=\text { gross electric power, } W_{e^{\prime}} \\
& P_{2}=\text { laser power requirement, } W_{e^{*}}
\end{aligned}
$$




\section{Table 4.1}

Reforence HYLIFE plant characteristics for comparison

Tritium breeding ratto

Neutron energy deposition

Fustion power

Fusion energy multiplication factor

Thermal power

Thermis conversion eff 1 clency

Gross electrical power

Laser power consumption

Auxiliary power requirements

Lithium pimping power (a)

Net eiectrical power

Direct capital costs

Reactor (b)

Lithlum puinps

Laser (c)

Target factory

TOTAL

$$
\begin{aligned}
& T=1.75 \\
& E_{n *}=16.9 \mathrm{MeV} \\
& P_{f}=2700 \mathrm{MW} \\
& M_{f}=1.16 \\
& P_{t}=3130 \mathrm{ww}_{f} \\
& n_{t}=39 \% \\
& P_{g}=1220 W_{e} \\
& P_{Q}=135 W_{Q} \\
& P_{\mathrm{a}}=75 \mathrm{w}_{\mathrm{e}} \\
& P_{p}=30 w_{e} \\
& P_{n}=980 \mathrm{NW}
\end{aligned}
$$

$$
\begin{aligned}
& C_{R}=\$ 960 M \\
& C_{P}=\$ 160 M \\
& C_{L}=\$ 330 M
\end{aligned}
$$$$
C_{\text {TF }}=\$ 100 \mathrm{~m}
$$

$C_{T}=\$ 1.55 \mathrm{~B}$

(a) based un a lithlum blanket thickness of $1.0 \mathrm{~m}$ and $~ 50 \%$ efflclent EM pumps.

(b) reactor includes the chamber and balance of plant required for heat transfer and converston to electrictity; it excludes the $L i$ recirculating pumps.

(c) half the estimated cost of $4.5 \mathrm{~mJ}$ laser; it is assumed that the laser drives two full sized reactors by switching beams. 


$$
\begin{aligned}
& P_{a}=\text { plant aux } 11 \text { lary power requirements, } M W_{e} \text {, and } \\
& P_{p}=11 \text { thium pumplng power, } M W_{e} .
\end{aligned}
$$

The gross electric power is equal to the thermal conversion efficiency times the thermal power and, therafore, is proportional to the fusion energy multiplication factor $M_{f}$. The laser and alixiliary power requitements are independent of the blanket design. The 11 thium pumping power is taken to be proportional to the 1 ithium flow rate and hence to the blanket thickness, $x_{2}$. Again, the values are based on the HYLIFE parameters 11 sted in table 4.1 . Hence

$$
P_{n}=1220\left(m_{f} / 1.16\right)-135-75-30 x_{2} \text {, }
$$

or

$$
P_{n}=1220\left(M_{f} / 1.16\right)-30 x_{2}-210 \text {, }
$$

where $x_{2}$ is in meters.

Combining Eqs. 4.8 and 4.10 and normalizing to the HYLIFE cost of $\$ 1.55 \mathrm{~B}$ and net power of $980 \mathrm{MW}_{\mathrm{e}}$ gives the figure of merit as

$$
F=\left[0.62\left(m_{f} / .16\right)^{0.8}+0.10 x_{2}+0.28\right] / 0 \text {. }
$$

where

$$
0=1.24\left(m_{f} / 1.16\right)-0.03 x_{2}-0.21
$$

\subsubsection{Summary.}

In sumary, the optimization problem is to minimize $F$ given by Eq. 4.11 subject to the constraint on the dispiacement damage rate, 
and the constraint on the tritium breeding ratio,

$$
T \geq 1.05
$$

The methods of Chapter 2 are used to write analytical expresstons for the fusion energy multiplication factor, the tritium breeding ratio, and the displacement damage rate, as a function of the two design variables, $x_{1}$ and $x_{2}$. Hence the figure of merit can be calculated at any point $\left(x_{1}, x_{2}\right)$. The methods of Chapter 3 are then applied to optimize the figure of merit subject to the constraints.

The first calculation of the optimal design point for the modified HYL IfE chamber is based on the two point variational interpolation method for estimating the neutronic performance. As such, four reference point neutron transport caiculations are required. The neutronics model and results for these initlal reference point calculations are discussed in the next section. 


\subsection{REFERENCE POINT tRansport CALCULATIONS}

\subsubsection{TART Monte Car lo Transport Code.}

All neutronics calculations were carried out with TART, a coupled neutron-photon Monte Carlo transpert code. ${ }^{65}$ Cross sections are der Ived from TART's data base, the Evaluated Nuclear Data Library which includes neutron data from $10^{-9} \mathrm{MeV}$ to $20 \mathrm{MeV}$ and photon data from $1 \mathrm{keV}$ to $20 \mathrm{MeV} .^{9}$ It is a multigroup code utilizing 175 energy groups.

An input file is created by the user which describes the geometry of the problem, composition of each zone, the characteristics of the neutron source and the type of output desired. Geometry refers to the boundary functions of a problem. Combining a number of boundary functions creates a unique and unambiguous volume called a zone. The boundarles are either planes or quadradic. TART is capable of handling three dimensional problems. The composition of each zone is described by specifying the isotopes, the isotopic fraction and density of the material represented by the zone. For fusion reactor problems a monoenergetic source of $14.1 \mathrm{MeV}$ neutrons is generally specified. Many different kinds of output can be ottained from the same TART prob'em. Of particular interest for this study are reaction rates, snergy dependent neutron $f l u x$, and energy deposition as a result of neutron interactions. ATl output is normalized to one source neutron. A typical probiem will track 20,000 neutrons $(20$ groups of 1000) and take 1-3 minutes of CRAY time. In addition to Ref. 65, a TART users manual is avallable on the MFECC computer network (see Appendix II). 


\subsubsection{Neutrontcs Model of the HYLIFE Chamber.}

The neutronics model of the modified HYLIFE chamber is shown in Figs. 4.3 and 4.4. Figure 4.3 represents a horizontal slice through the midplane of the chamber. Note that it has been subdivided into two halves and Fig. 4.4 shows only the right half. This was necessary since the current version of TART does not allow the user to output reaction rates and neutron flux for the same zone. A new version of TART will correct this difficulty. 66

Zone 1 represents the compressed DT in which the $14.1 \mathrm{MeV}$ fuston neutrons are born. The neutron source is distributed uniformly throughout this hemispherical zone. The target has a density radius product, $\rho R$, of $3 \mathrm{~g} / \mathrm{cm}^{2}$. Zone 2 is essentially void, containing L1 vapor at a very low density.

Zones 3 and 4 represent the Li jet array where all the tritium breeding occurs in this modified HYLIFE concept. The effective density and isotopic fraction of ${ }^{6} L y$ is varied in these zones. The inner radius of these zones in $0.5 \mathrm{~m}$ and they are $2.0 \mathrm{~m}$ thick. The density of $L\}$ in zones 3 and 4 is less than normal density in order to represent the packing fraction of 11 quid Li jets within the jet array. Using density multipliers of 0.375 and 0.625 give effective thicknesses of $0.75 \mathrm{~m}$ and $1.25 \mathrm{~m}$ for the $L 1$ blanket. These are the two reference values for $x_{2}$. That is, $x_{2 a}=0.75$ and $x_{2 b}=1,25$. The reference values for ${ }^{6} L 1$ concentration in the $L f$ are $0.50 \%$ and $7.42 \%, 1 . e, x_{1 a}=0.0050$ and $x_{1 b}=0.0742$. The combinations of these values define the four reference point calculations for the two point interpolation on two varlables. 


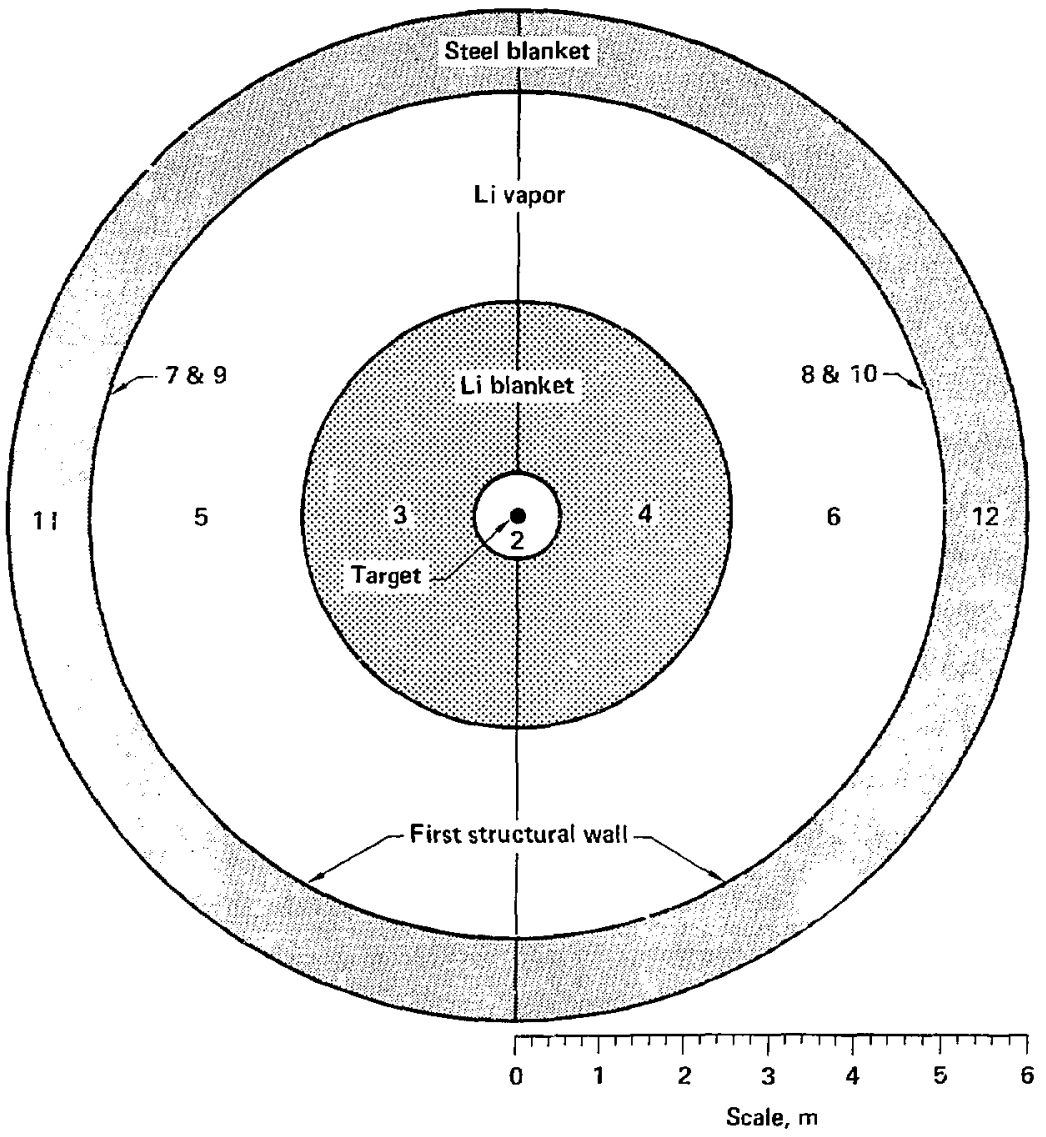

Fig. 4.3 Cross sectional view of the neutronics model for the modified HYLIFE chamber. Zone numbers are indicated. 


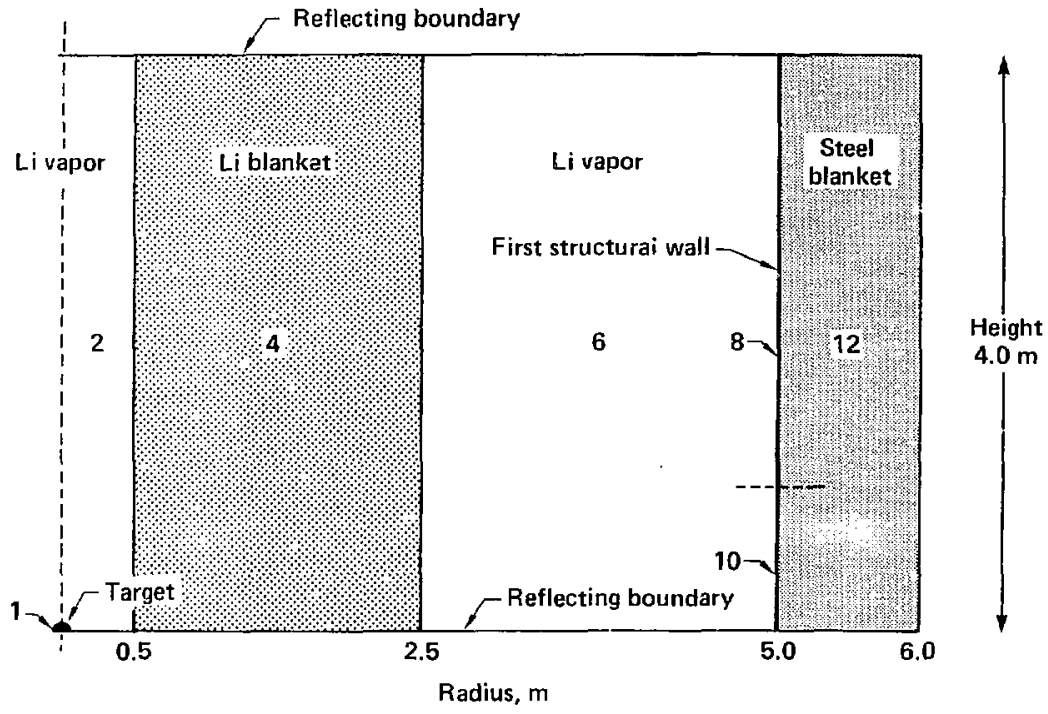

fig. 4.4 Neutronics model of the modified HYLIfE chamber. 
Returning to figs. 4.3 and 4.4, zones 5 and 6 are again LI vapor regions. Zones 7-10 represent a low-alloy, ferritic steel, first structural wall for the chamber. The inner radius is $5.0 \mathrm{~m}$ and the wall is $2 \mathrm{~cm}$ thick. The neutron flux in the $1-m-h$ igh zone 10 is used to determine the peak neutron damage rate in the first structural wal1. It gives a peak damage rate since it is nearer to the neutron source and protected by less $L 1$ than the wall as a whole. Zones 11 and 12 represent the energy multiplying stee 1 blanket. These 1 -m-thick zones contain 80 vol\% An stee 1 and 20 vol\% Na coolant.

Figure 4.4 is a vertical slice through the neutronics model. The top and bottom boundaries are reflecting planes. That is, if a neutron's path iricersects one of these planes, it is "reflected" back into the problem at the point of intersection. The bottom plane represents the symmetry of the HYL.IFE chamber.

The top (and the bottom) of the HYLIFE chamber contain thick pools of Li. Witi a top reflecting plane in the neutronics model, neutrons are reflected back into the $L i$ jet array and the effect is essentially the same as if a $L i$ pool would have been added at the top. This was verified by comparing the results of a TART calculation with a model such as this to the results reported in Ref. lij which modeled the HYLIFE chamber in detail. Both the tritium breeding ratio and neutron energy deposition were very close. With the reflected model, the tritium breeding ratio and neutron energy deposition were 1.74 and $17.0 \mathrm{MeV}$, respectively, compared to the Ref. 54 results of 1.75 and 16.9 $\mathrm{HeV}$. Hence it is felt that the simple model qllustrated in Figs. 4.3 and 4.4 adequately represents the chamber being considered 
in this study.

A detalled description of the geometry and composition of the neutronics model is given in Tables 4.2 and 4.3 .

\subsubsection{Results of the Four Initial Transport Calculations.}

The results of the reference polnt neutrontcs calculations are glven in Tables 4.4 and 4.5. With a few exceptions a 11 parameters listed are output directly by TART. The exceptions are discussed be low.

The energy deposition by isotope in the $L i$ blanket required a modification of the standard method that TART uses to calculate energy deposition. Normally, energy-dependent energy deposition factors are determined for the mixture of isotopes making up the material in a zone. These factor times the expected number of collisions per energy group, summed over a 11 energy groups gives the total energy'deposited in the zone.

To get the energy deposition by isotope requires the order of summations to be changed. By determining energy deposttion factors for each isotope in the material, multiplying it by the number of collisions with that isotope, and summing over all energy groups gives the energy deposition by isotope in the zone.

The other calculated parameter is the displacement damage rate. Using the neutron fluence in zone 10 calculated by TART, the displacement damage rate (dpa per full power year) is calculated as follows:

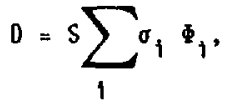


Table 4.2

Geometric characteristics of the modified HYLIFE neutronics model

\begin{tabular}{|c|c|c|c|c|}
\hline Zone & Descrintion & $\begin{array}{c}\text { Inner } \\
\text { Radius } \\
\text { (cm) }\end{array}$ & $\begin{array}{l}\text { Outer } \\
\text { Radius } \\
\text { (cm) }\end{array}$ & $\begin{array}{l}\text { He ight } \\
\text { (cm) }\end{array}$ \\
\hline
\end{tabular}

$\begin{array}{llrrrr}1 & \text { Target } & 0 & 0.03 & - & 1 \\ 2 & \text { Li Vapor } & 0 & 50 & 400 & 2 \\ 3,4 & \text { Li Blanket } & 50 & 250 & 400 & 3 \\ 5,6 & \text { Li Vapor } & 250 & 400 & 400 & 2 \\ 7,8 & \text { Steel Wal1 } & 500 & 502 & 300 & 4 \\ 9,10 & \text { Steel Wal1 } & 500 & 502 & 100 & 4 \\ 11,12 & \text { Steel Blanket } & 502 & 600 & 400 & 5\end{array}$




\section{Table 4.3}

Material compositions of the modified HYLIFE neutronics model

\begin{tabular}{|c|c|c|c|c|c|}
\hline \multirow{2}{*}{$-\frac{\text { Matertal }}{1}$} & \multicolumn{2}{|c|}{$\begin{array}{l}\text { Composition } \\
\left(V_{0} \mid \%\right)\end{array}$} & \multirow{2}{*}{$\frac{\begin{array}{l}\text { Dens ity } \\
\left\langle\mathrm{g} / \mathrm{cm}^{3}\right\rangle\end{array}}{100}$} & \multicolumn{2}{|c|}{$\begin{array}{c}\text { Isotopic Fractions } \\
(x)\end{array}$} \\
\hline & ot & 100 & & $\begin{array}{l}0 \\
\mathrm{~T}\end{array}$ & $\begin{array}{l}50 \\
50\end{array}$ \\
\hline 2 & $\mathrm{Li}$ & 100 & $10^{-8}$ & $\begin{array}{l}6_{L 1} \\
7_{L 1}\end{array}$ & $\begin{array}{r}7.42 \\
92.58\end{array}$ \\
\hline $3 a$ & Li & 100 & 0.490 & $\begin{array}{l}\sigma_{L 1} \\
7 L_{1}\end{array}$ & $\begin{array}{r}7.42 \\
92.58\end{array}$ \\
\hline $3 b$ & $\mathrm{Li}$ & 100 & 0.495 & $\begin{array}{l}6 \\
7_{L 1}\end{array}$ & $\begin{array}{r}0.50 \\
99.50\end{array}$ \\
\hline $4^{\star}$ & $\mathrm{Fe}$ & 100 & 7.86 & $\mathrm{Fe}$ & 100.00 \\
\hline $5^{\star \star}$ & $\begin{array}{l}\mathrm{NM}-1 \\
\mathrm{Na}\end{array}$ & $\begin{array}{l}80 \\
20\end{array}$ & 6.49 & $\begin{array}{l}\mathrm{Na} \\
\mathrm{Cr} \\
\mathrm{Mn} \\
\mathrm{Fe}\end{array}$ & $\begin{array}{r}5.97 \\
2.01 \\
19.03 \\
72.99\end{array}$ \\
\hline
\end{tabular}

* The first structural wall is $2.25 \mathrm{Cr}-1$ Ho steel. For the purposes of these calculations, it is represented by $100 \%$ natural Fe.

* The steel b Tanket is $80 \mathrm{Vo} 1 \%$ NH-1 steel 177.5 wt\% Fe, 20.0 wt\% Hn, 2 wt. $\mathrm{Cr}$ ) and 20 vol\% Na as the coolant. 
Table 4.4

Reaction rates and neutron damage rates for the four initlal reference points

Reference Point

6 Li fraction, $x$

Li Thickness, m

1
0.50
0.75

2

7.42

0.75

3

0.50

4

1.25

7.42

1.25

Reactions ${ }^{a}$

\begin{tabular}{|c|c|c|c|c|}
\hline${ }^{6} L 1(n, r) \alpha$ & $\begin{array}{l}0.440 \\
(1.2)^{\mathrm{C}}\end{array}$ & $\begin{array}{l}0.797 \\
(1.2)\end{array}$ & $\begin{array}{l}0.733 \\
(1.0)\end{array}$ & $\begin{array}{l}1.004 \\
(1.1)\end{array}$ \\
\hline${ }^{7} \operatorname{Li}\left(n, n^{\prime} T\right) \alpha$ & $\begin{array}{l}0.604 \\
(1.2)\end{array}$ & $\begin{array}{l}0.628 \\
(0.8)\end{array}$ & $\begin{array}{l}0.718 \\
(i .1)\end{array}$ & $\begin{array}{l}0.663 \\
(1.2)\end{array}$ \\
\hline$\gamma_{L}(n, Y)$ & $\begin{array}{l}0.004 \\
(i .2)\end{array}$ & -- & $\begin{array}{l}0.007 \\
(1.5)\end{array}$ & $\cdots$ \\
\hline $\operatorname{Mn}(n, Y)$ & $\begin{array}{l}0.331 \\
(1.9)\end{array}$ & $\begin{array}{l}0.156 \\
(2.3)\end{array}$ & $\begin{array}{l}0.185 \\
(1.5)\end{array}$ & $\begin{array}{l}0.057 \\
(4.1)\end{array}$ \\
\hline $\operatorname{Fe}(n, Y)$ & $\begin{array}{l}0.343 \\
(1.8)\end{array}$ & $\begin{array}{l}0.159 \\
(2.1)\end{array}$ & $\begin{array}{l}0.193 \\
(1.5)\end{array}$ & $\begin{array}{l}0.057 \\
(3.8)\end{array}$ \\
\hline
\end{tabular}

Displacement Damage Rate

15.5

13.5

3.95

2.92

(3)

(3)

(8)

(8)
a) per OT fusion reaction.
b) dpa per full-power-year based on $2700 \mathrm{MH}$ of fusion power.
c) percent standarid deviation. 
Table 4.5

Energy deposition for the four inftial reference points

$\begin{array}{lcccc}\text { Reference Point } & 1 & 2 & 3 & 4 \\ \text { Gi Fraction, } \% & 0.50 & 7.42 & 0.50 & 7.42 \\ \text { Li Thickness, m } & 0.75 & 0.75 & 1.25 & 1.25\end{array}$

Energy Deposition

$\begin{array}{lllll}\text { Target } & \begin{array}{l}1.83 \\ (0.4)(c)\end{array} & \begin{array}{l}1.85 \\ (0.4)\end{array} & \begin{array}{l}1.83 \\ (0.5)\end{array} & \begin{array}{l}1.84 \\ (0.4)\end{array} \\ 6 \mathrm{Lt} & 2.09 & 4.66 & 3.61 & 5.72 \\ & (1.2) & (1.0) & (0.9) & (1.0) \\ T_{\mathrm{Li}} & 8.96 & 8.21 & 9.64 & 8.73 \\ & (1.7) & (3.0) & (2.3) & (4.7) \\ \text { First wal1 } & 0.73 & 0.35 & 0.40 & 0.09 \\ & (1.7) & (3.0) & (2.3) & (4.7) \\ \text { Stee1 blanket } & 5.29 & 2.94 & 2.57 & 0.89 \\ & (1.5) & (2.1) & (1.7) & (3.5) \\ \text { Mn decayb } & 0.83 & 0.39 & 0.46 & 0.14 \\ \text { Alpha particle } & \underline{3.52} & \underline{3.52} & \underline{3.52} & \underline{3.52} \\ \text { TOTAL } & & & & \\ & 23.25 & 21.92 & 22.03 & 20.93\end{array}$
a) MeV per DT fusion reaction.
b) energy released from decay of $56_{M n}$ equals $2.5 \operatorname{MeV} \operatorname{per} \operatorname{Mn}(n, Y)$
reaction.
c) percent standard deviation. 
where

$$
\begin{aligned}
S= & \text { neutron source, } n / y r, \\
\sigma_{1}= & \text { energy dependent displacement cross section, } b, \\
\Phi_{1}= & \text { energy dependent neutron fluence, } r \mathrm{~cm}^{2} \text { per source } \\
& \text { neutron, and } \\
1= & \text { energj group index for the multigroup calc"lation. }
\end{aligned}
$$

The source of DT neutrons is related to the fuston pcwer, $P_{f}$, by

$$
S=11.2 \times 10^{24} \mathrm{P}_{\mathrm{f}} \text {. }
$$

where $P_{f}$ is in $\mathrm{MW}$.

The displacement damage cross section for iron is shown in Fig. 4.5. This cross section was calculated by Doran and Graves 67 and is somewhat higher than a previously publisited version. ${ }^{68,69}$ It is based on an effective displacement energy of $40 \mathrm{eV}$, which is recomnended for iron. For low energy ieutrons, the displacement cross section varies as $\Xi^{-0.5}$ from a value of $17 \mathrm{~b}$ at $0.025 \mathrm{ev} .^{68}$ 


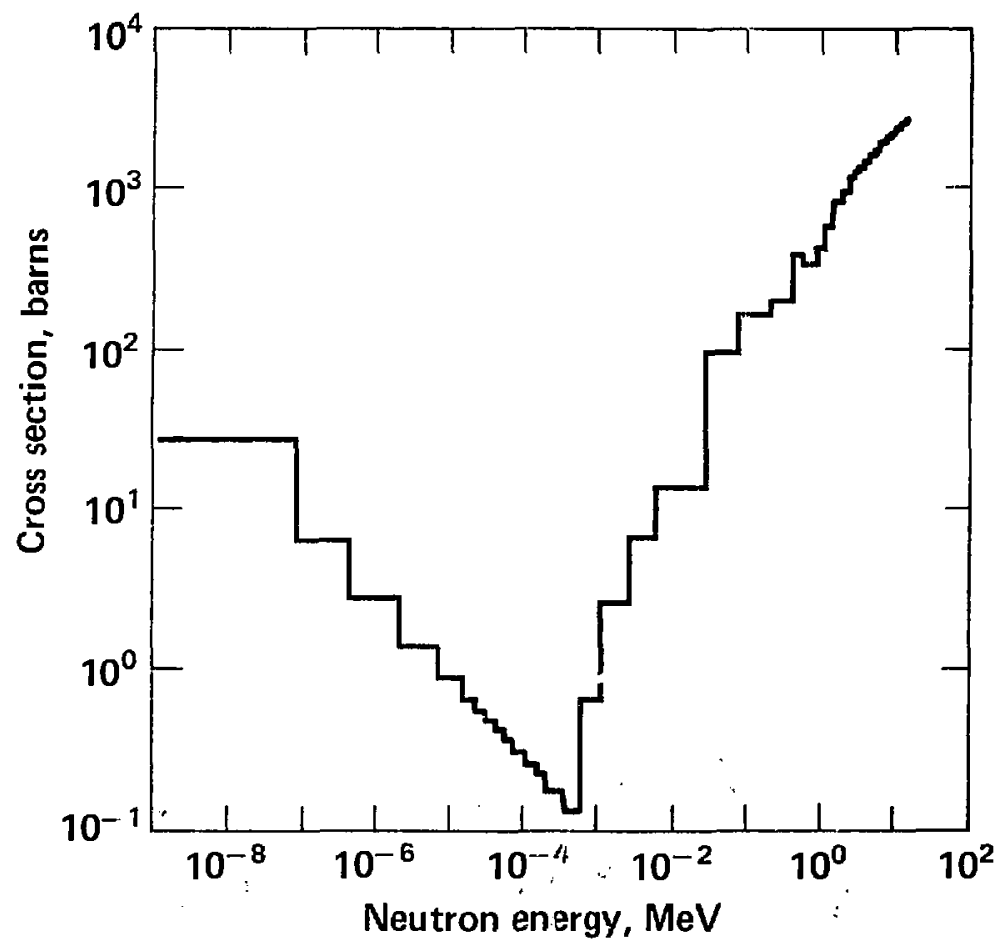

Fig. 4.5 lisplacement damage cross section for iron. 


\subsection{INITIAL OPTIMIZATION RESULTS FOR HYYLIFE}

\section{Estimated Neutronic Performance.}

Based on the results of the four reference point neutronics calculations, the tritium breeding ratio, displacement damage rate and neutron energy deposited in the chamber are estimated using successive two point interpolation (Eq. 2.46).

The results for tritium breeding are shown in Figs. 4.6-4.9. Figure 4.6 shows the number of ${ }^{6} L i(n, T) \alpha$ reactions per oT reaction, denoted $T_{6}$, as a functioi of the two design variables, ${ }^{6}{ }_{L}$ fraction in the Li blariket and the Li blanket thickness. (Note that those portions of the surface outside the range $0.5 \% \leq x_{1} \leq 7.42 \%$ are extrapolations not interpolations.) As seen in Fig. 4.6, T6 increases with increasing ${ }^{6} \mathrm{~L}$ fraction and also with increasing blanket thickness. The rise in To is very sharp at low ${ }^{6} \mathrm{Li}$ concentrations.

The number of ${ }^{L}\left(i\left(n, n^{\prime} T\right) \alpha\right.$ reactions per DT fusion reaction, denoted $[7$, as a function of the two design variables is shown in Fig. 4.7. Note the change in the vertical scale from the previous figure. fis indicated, T7 decreases with increasing ${ }^{6} L i$ fraction. Thits is as expected since the ${ }^{L}{ }_{L}$ concentration decreases as the 6 if concentration increases. Also, T7 increases with increasing blanket thickness.

The sum of $T 6$ and $T 7$ gives the tritium breeding ratio, denoted $T$, as shown in Fig. 4.8. Since the variation in $T 7$ over this range of - varlables is relatively small, the tritium breeding ratio surface essentially mimics the features of the T6 surface. Some difference, 


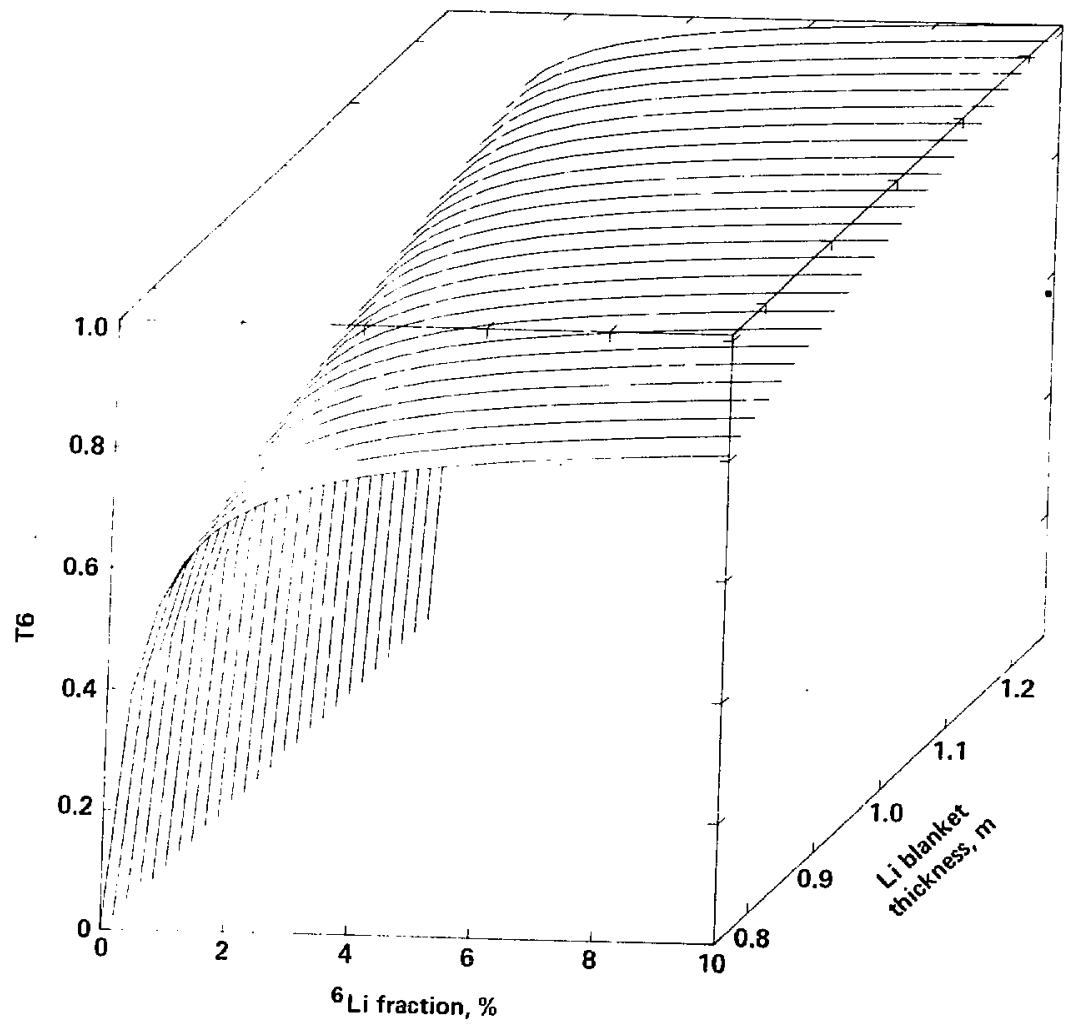

Fig. $4.6^{6}{ }_{L 1}(n, T) \alpha$ reactions per OT reaction as a function of the $6 L 1$ fraction and $L 1$ blanket thickriess. 


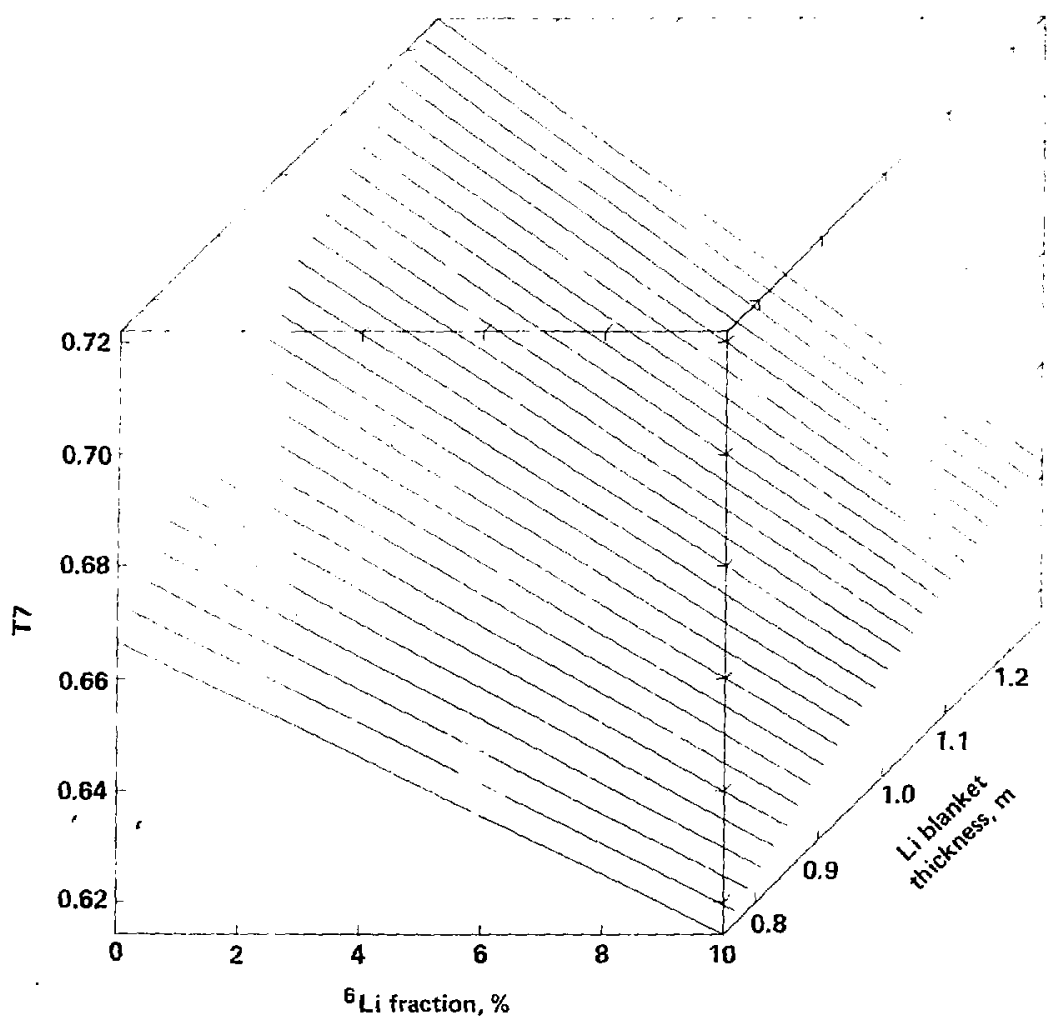

Fig. 4.7 ${ }^{7} \mathrm{~L}\left(n, n^{\prime} T\right) \alpha$ reactions per DT reaction as a function of the ${ }^{6} 1$ fraction and the $L 1$ blanket thicksess. 


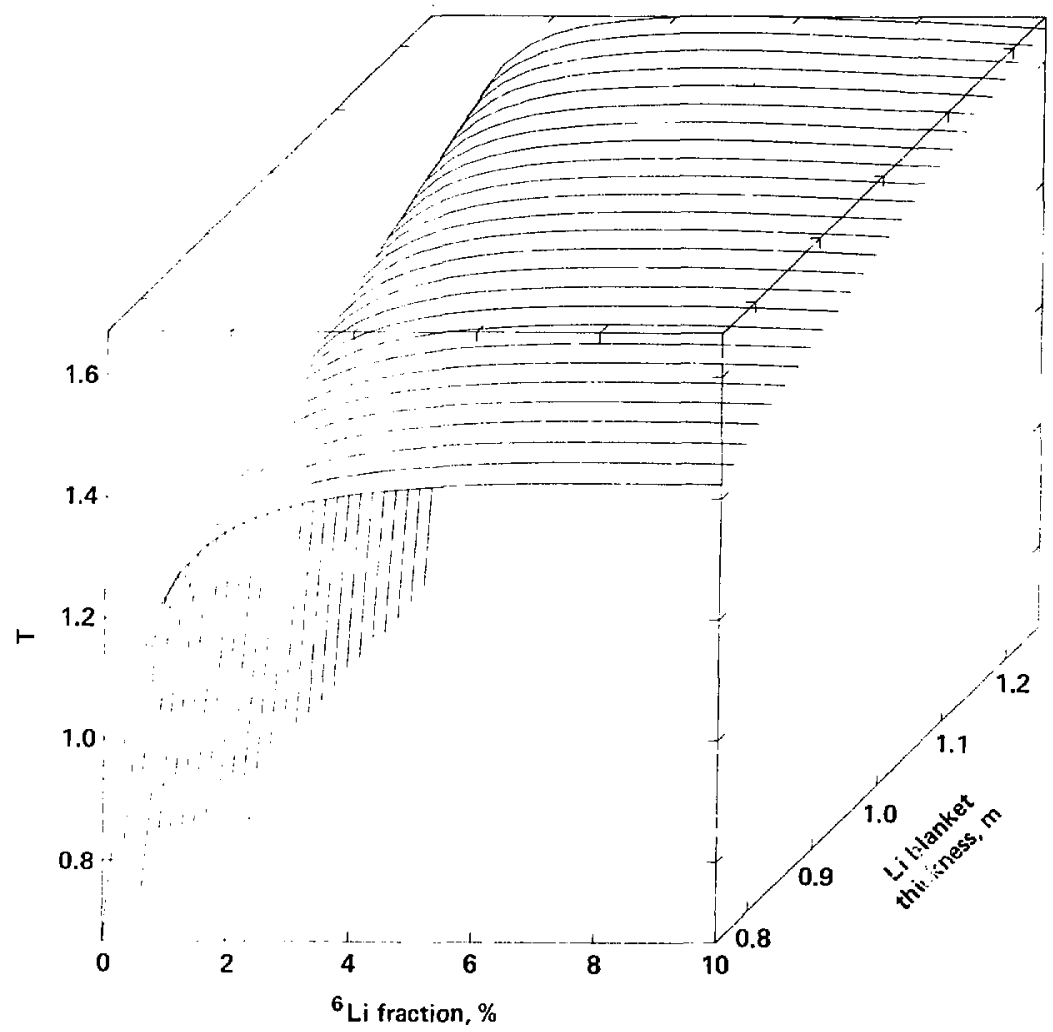

Fig. 4.8 Tritium breeding ratio as a function of the ${ }^{6} i$ fraction and the LI blanket thickness. 
however, are visible. Note how at $x_{2}=1.25 \mathrm{~m}, \mathrm{~T}$ goes through a broad maximum as $x_{1}$ increases, indicating that $T 7$ is falling faster than T6 is rising in this region.

A contour plot of the tritlum breeding ratio is shown in Fig. 4.9. The first solid line is $T=1.05$, the constraint on the breeding ratio. At low ${ }^{6} \mathrm{Li}$ fractions $T$ is primarily a function of the ${ }^{6} L 1$ fraction whereas above $\sim 5 \%{ }^{6} L, T$ is primar 1 ly dependent on the blanket thickness.

The displacement damage rate, dpa per full-power-year, is shown in Fig. 4.10 as a function of the two design variables. As indicated, the dpa rate decreases with increasing ${ }^{6} q$ fraction and increasing blanket thickness. The contour plot, Fig. 4.11. gives a better Indication of the nature of the dependence of damage rate on the two design variables. It is clear that the dpa rate depends primarily on the blanket thickness. This is due to the nature of the displacement damage cross section. Most of the displacement damage resulis from high energy neutrons. Hence simply moderating the fusion neutrons is sufficient to decrease the dpa rate significantly. Increasing the ${ }^{6}{ }_{L i}$ fraction attenuates the neutron flux reaching the first wall by absorbing neutrons in ${ }^{6} \mathrm{Li}(\mathrm{n}, \mathrm{T}) \alpha$ reactions. Since ${ }^{6} \mathrm{Li}$ more readily captures lower energy neutrons, the dpa rate decreases only slightly with increasing ${ }^{6} \mathrm{LI}$ fraction. The dashed line is the displacement damage rate constraint of $9.5 \mathrm{dpa} / \mathrm{yr}$.

Next, consider the energy deposited in the chamber. Figures 4.12 and 4.13 show the neutron energy deposited in ${ }^{6} \mathrm{Li}$ and ${ }^{7} \mathrm{Li}$. The features of these surfaces are similar to those for T6 and 17 . The energy deposited in the first structure wall and the $\mathrm{Na}$ cooled steel 


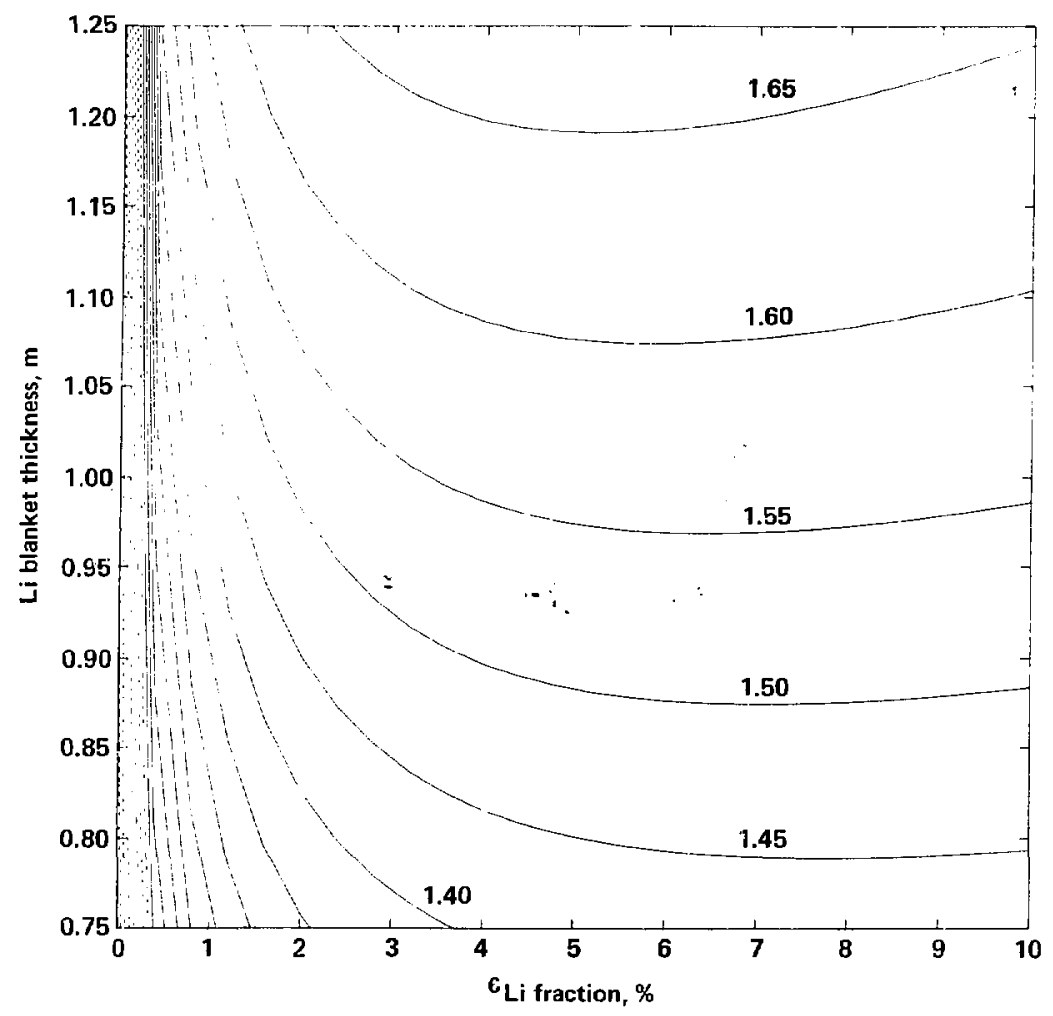

Fig. 4.9 Contour plot of the tritium breeding ratio for the modifled HYL IFE chamber. 


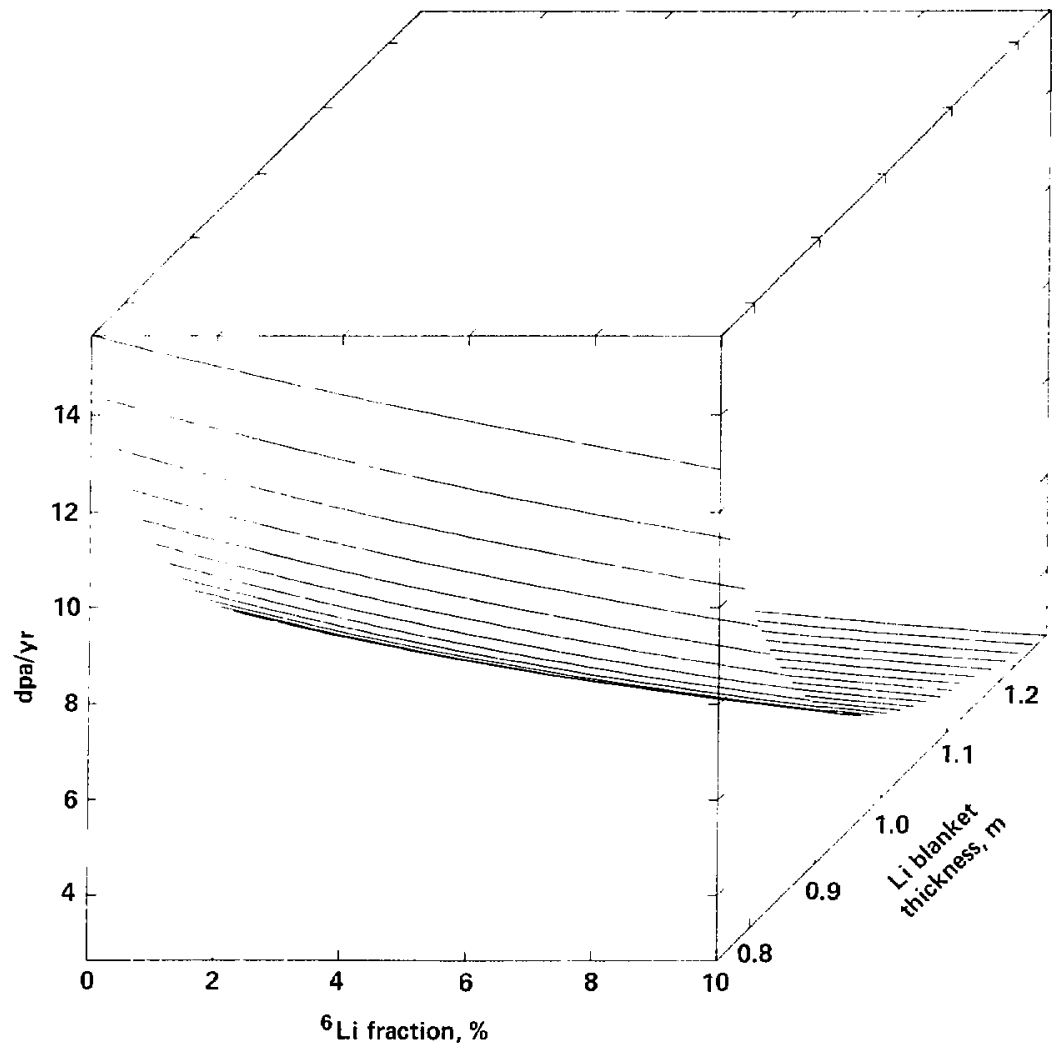

Fig. 4.10 Displacement damage rate in dpa per full-power-year as a function of the ${ }^{6} \mathrm{~L}$ fraction and the Li blanket thickness. 


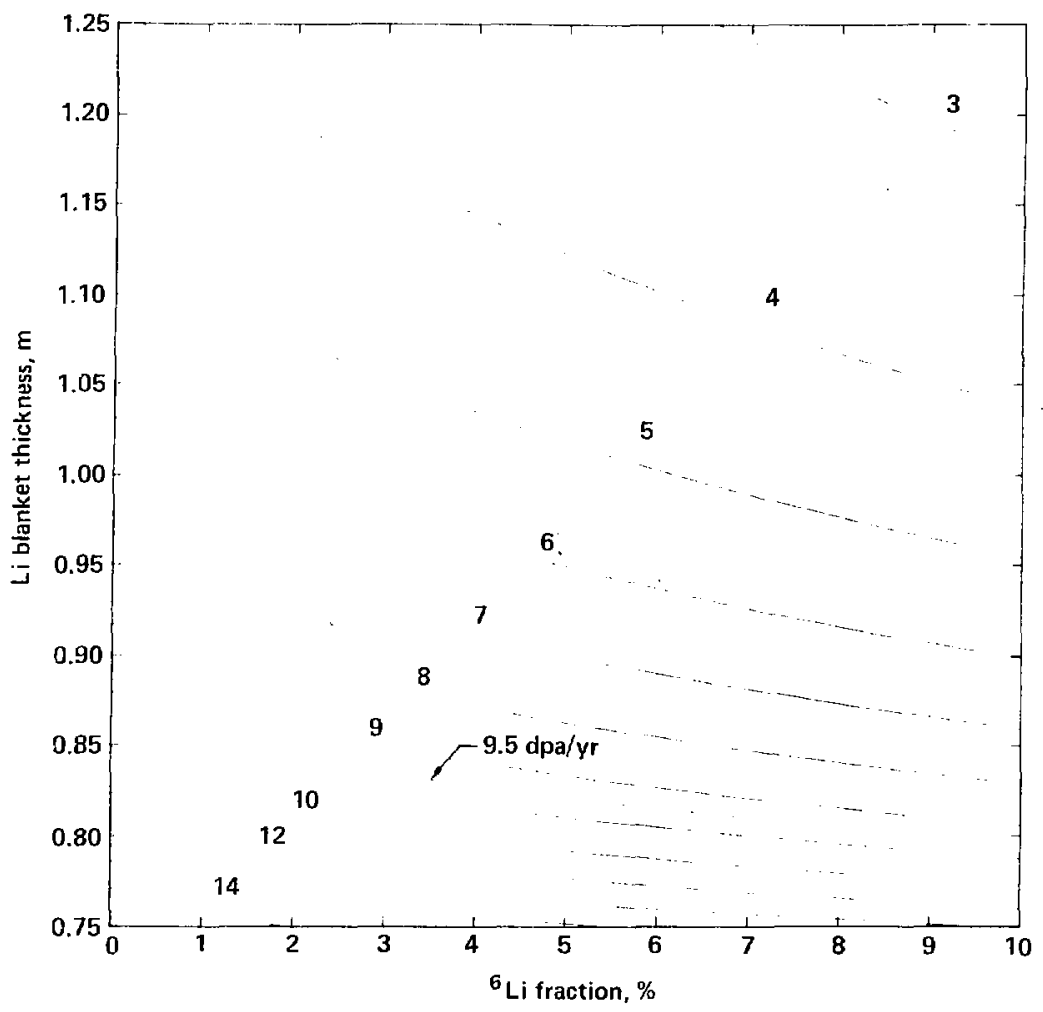

Fig. 4.11 Contour plot of the displacement damage rate. For a 30 year wall life, the damage rate must be less than $9.5 \mathrm{dpa} / \mathrm{yr}$. 


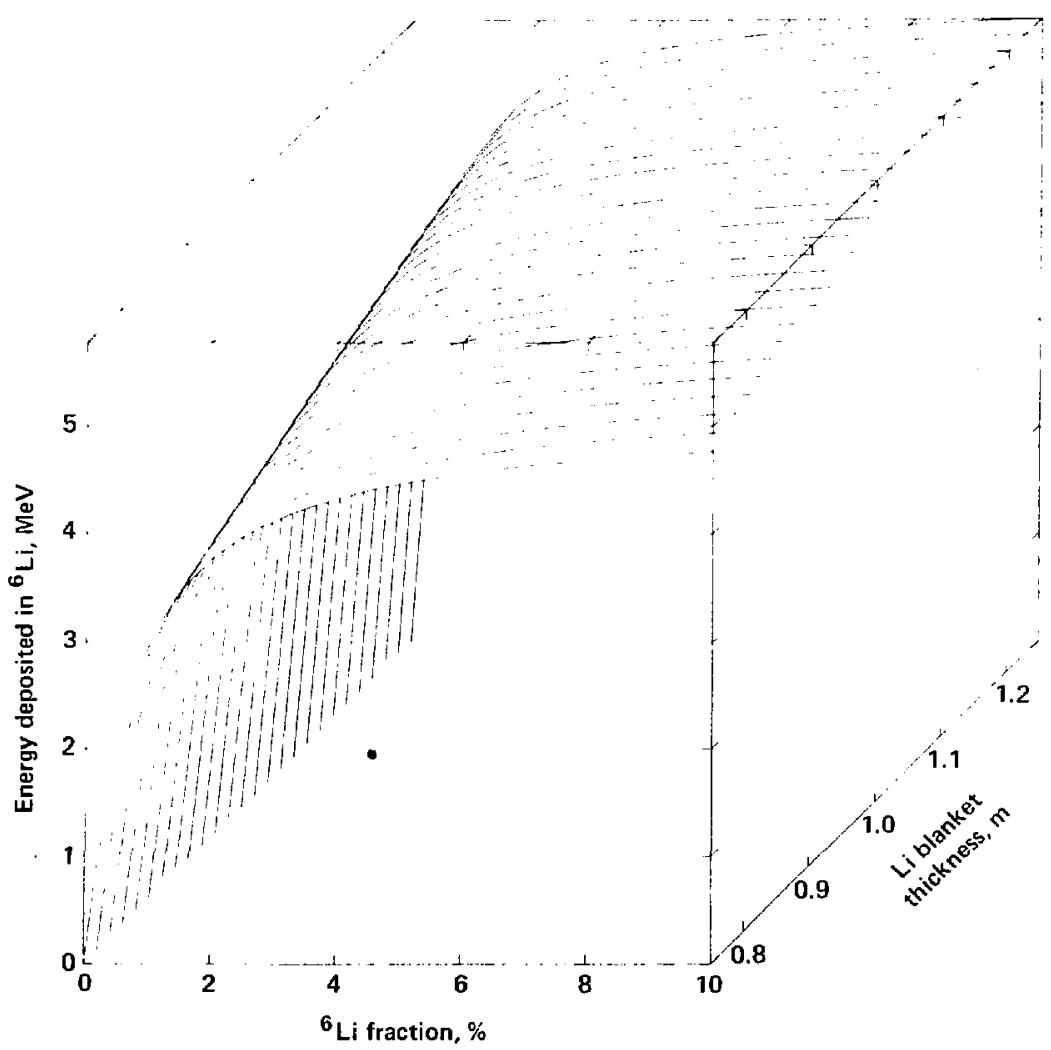

Fig. 4.12 Energy deposited in ${ }^{6} \mathrm{Li}$ as a function of the ${ }^{6} \mathrm{Li}$ fraction and the Li blanket thickness. 


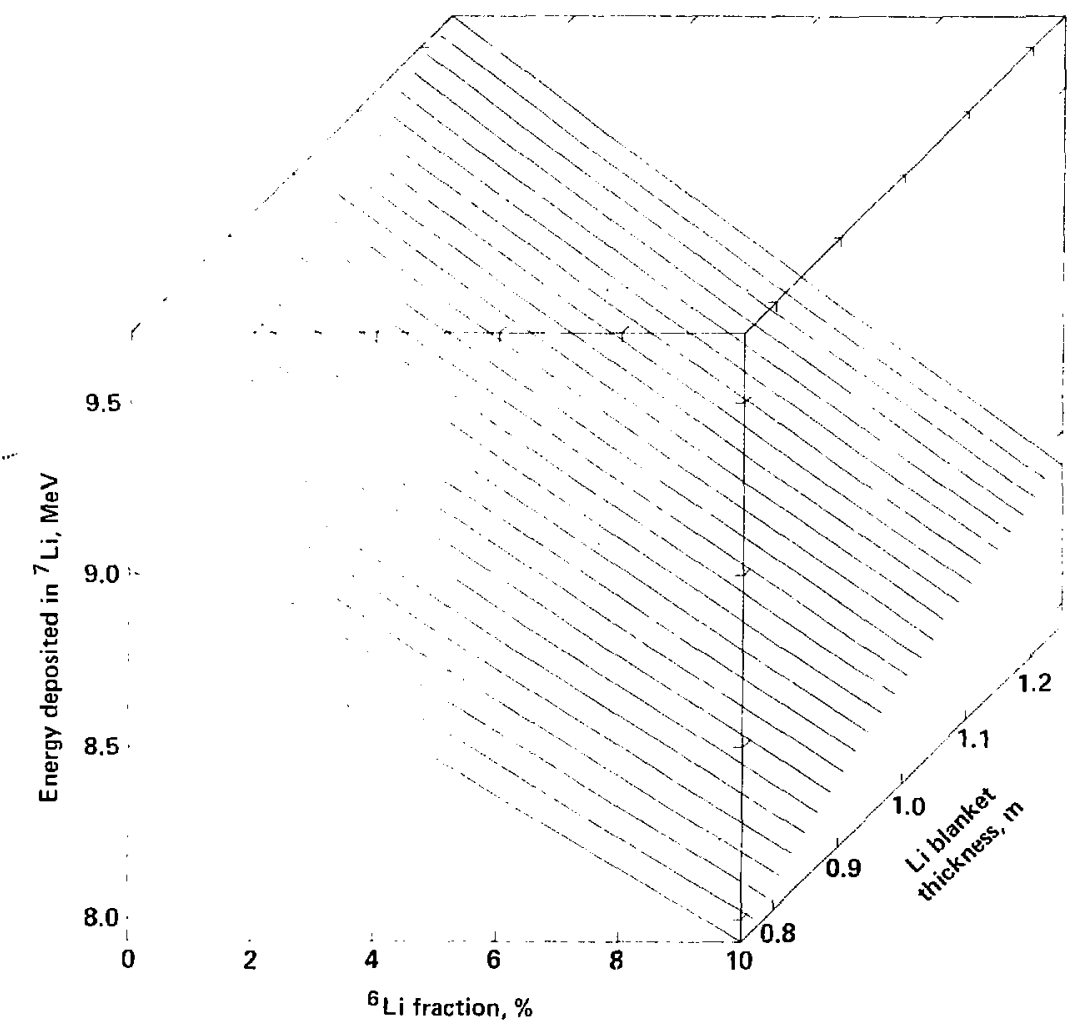

Fig. 4.13 Energy deposited in $7_{L 1}$ as a function of the $6_{L 1}$ fraction and the Li blanket thickness. 
blanket is shown in Fig. 4.14. The energy deposited in these regions is primarily due to the energy released in neutron capture reactions In $\mathrm{Fe}$ and $\mathrm{Mn}$. As indicated, the energy deposition in these regions increases with decreasing ${ }^{6} \mathrm{Li}$ fraction and with decreasing $\mathrm{LI}_{1}$ blanket thickness. This follows since decreasing the ${ }^{6} L$ fraction and the LI blaiket allows more neutrons to penetrate the LI blanket and be captured in structures.

The total energy deposited in the chamber is shown in Fig. 4.15. It includes the neutron energy deposited in the compressed fue 1 of the target (1.84 MeV), the fusion alpha particle energy (3.52 Mels), and the ${ }^{56} \mathrm{Mn}$ decay energy. The ${ }^{56} \mathrm{Mn}$ decay energy is $2.5 \mathrm{MeV}$ per ${ }^{55}{ }_{M n(n, Y)}$ capture reaction. In general, the total energy deposition increases with decreasing ${ }^{6} L i$ and $L i$ blanket thickness.

At very low ${ }^{6} L 1$ concentrations, however, the energy depostition begins to fall off. This is due to the nature of the varlational estimates in the extrapolated region $\left(x_{1}<0.5 \%\right)$ and is not based on the physical situation. The variation interpolation estimate for the energy depasition in ${ }^{6} L i$ must go to zero as - the ${ }^{6} L i$ fraction goes to zero. The vartational estimate of the energy deposition in structures, however, has no additional boundary condition at low ${ }^{6}{ }^{7}$ fractions, and hence the extrapolation to values below $x_{1}=0.5 \%$ does not rise as steeply as would be expected based on the number of neutrons penetrating the $L 1$ blanket as the number of $L i(n, T) \alpha$ reactions falls to zero.

To get a more accurate estimate of the total energy deposition, especially at low $6_{L 1}$ fractions, a neutron balance approach is used. The number of avallable neutrons per DT fusion reaction is 1.00 


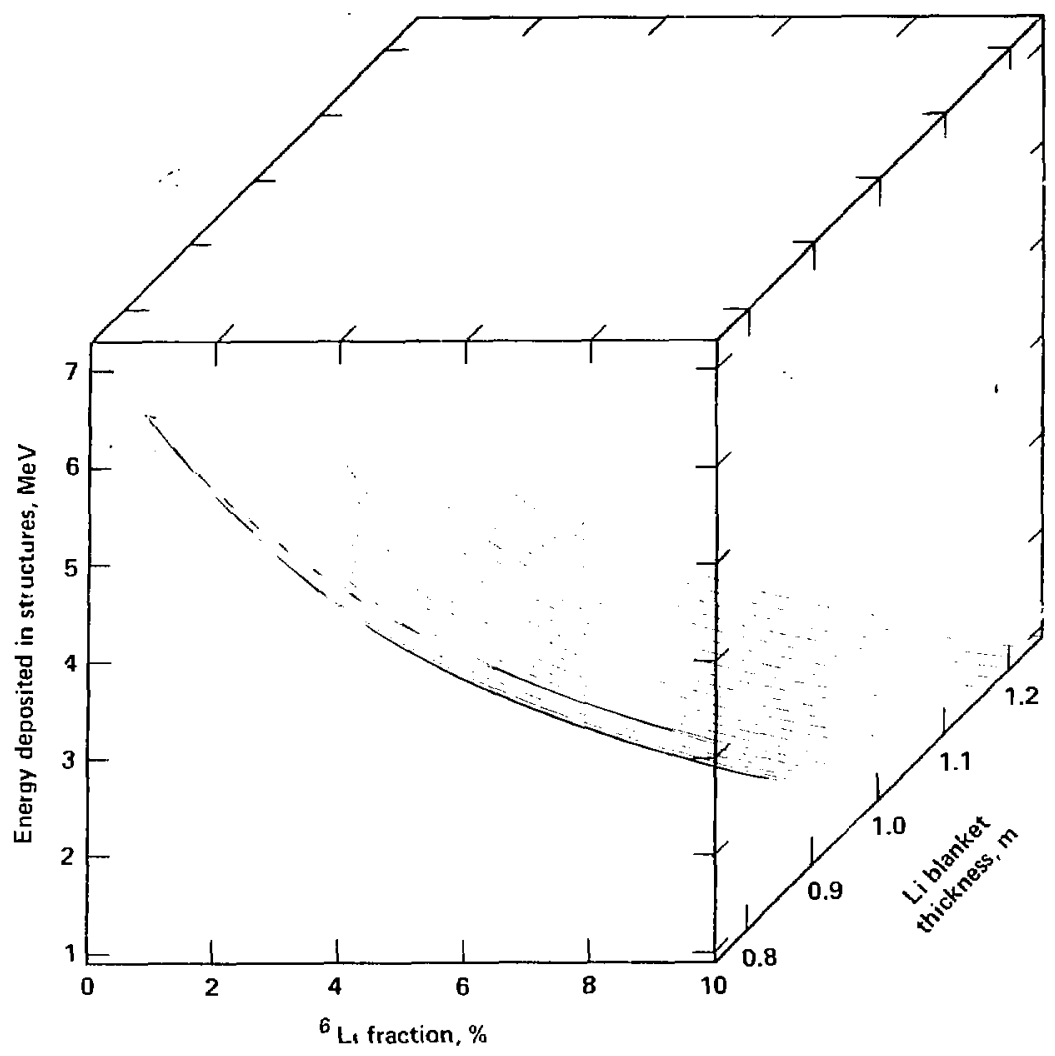

Fig. 4.14 Energy deposited in structures as a function of the ${ }^{6}{ }_{11}$ fraction and LI blanket thickness. 


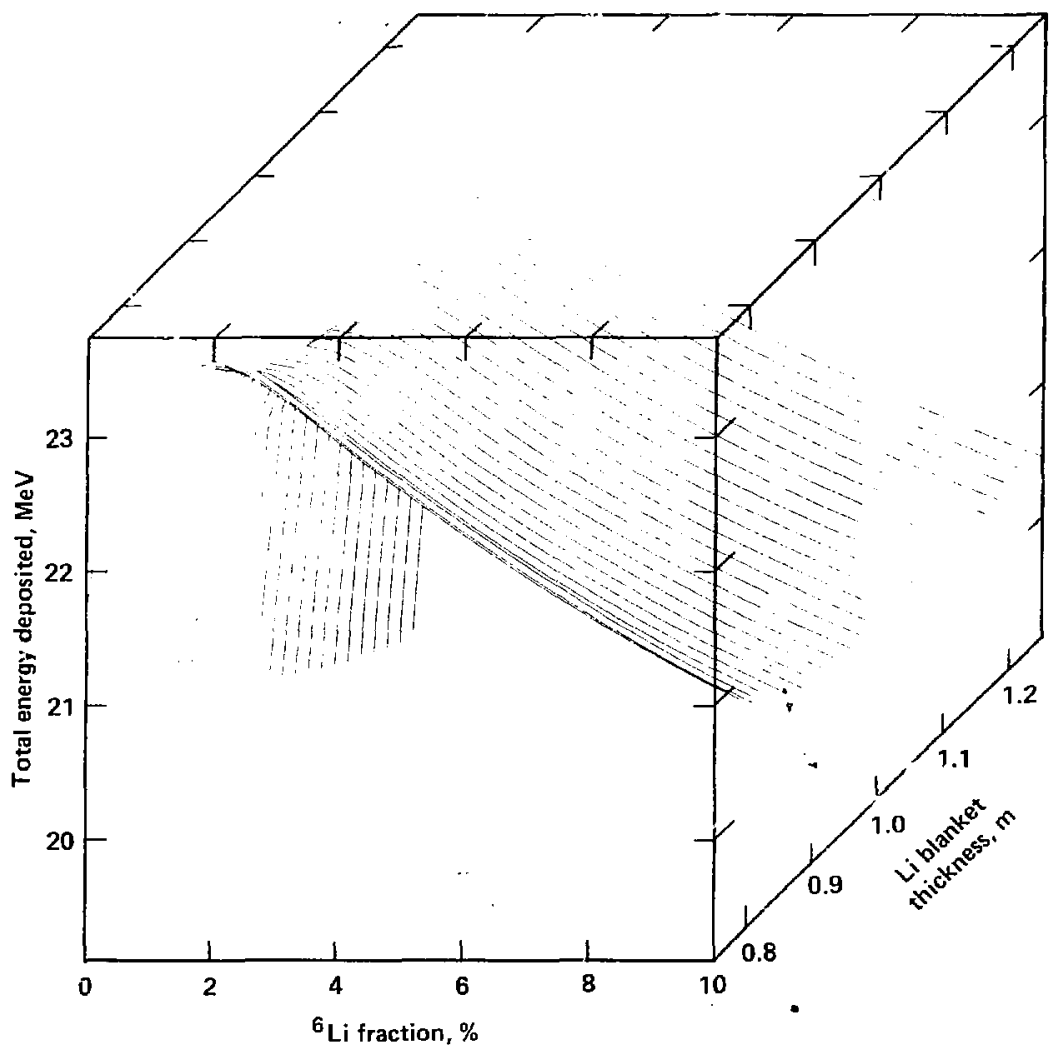

Fig. 4.15 Total energy deposited in the chamber per OT reaction as a function of the two design vartables. The $3.5 \mathrm{MeV}$ a pha partic le energy and Mn decay energy are included. 
from the fusion reaction, plus 0.05 from $(n, 2 n)$ reactions with 0 and $T$ in the compressed fue 1 of the target, plus 0.06 from $(n, 2 n)$ reactions with ${ }^{7}{ }_{1}$ in the $L 1$ blanket for a total of 1.11 .

There are three primary neutron sinks in the chamber; neutrons can be captured in ${ }^{6} L i(n, T) \alpha, F e(n, Y)$ and $M n(n, Y)$ reactions. The sum of these three reactions for the four reference point transport calculations 11 sted in Table 4.4 is essentially constant (to within 1\%) with an average value of 1.114 .

In the neutron balance method, the number of ${ }^{6} L i f, i j \alpha$ reactions is estimated using variational interpolation and then the number of neutrons avallable far capture in Fe or Mn is calculated from,

$$
N=1.114-. T 6 .
$$

Also note from Table 4.4 that Mn capture reactions are always $\sim 49 \%$ of the total capture in $\mathrm{Fe}$ and $\mathrm{Mn}$. Eact $\mathrm{Fe}(\mathrm{n}, \mathrm{Y})$ reaction releases $\sim 7.7 \mathrm{MeV}$ and each $\mathrm{Mn}(n, Y)$ reaction releases $\sim 7.3 \mathrm{MeV}$. In addition, each Mn capture leads to a $\beta^{-}$decay which releases 2.5 MeV of recoverable energy. Therefore, the energy deposited in structures due to neutron capture and ${ }^{56}$ Mn decay is

$$
E_{c}=7.7(0.51) \mathrm{N}+9.8(0.49) \mathrm{N},
$$

or

$$
E_{C}=8.73 N \text {. }
$$

Summing the energy deposited in the first wall, stee 1 blanket and Mn decay listed in Table 4.5 gives a total energy deposition which is 
scinewhat higher than predicated by Eqs. 4.16 and 4.17 when the value of T6 from Table 4.4 is used. This additional energy, which can be viewed as deposition due to scattering reactions in these regions, must be added to $E_{c}$ to get the correct total energy deposition in the structures. The additional energy for reference point cases 1-4 are $0.96,0.92,0.09$, and $0.16 \mathrm{MeV}$, respectively.

The neutron balance estimate of the energy deposited in the first wall and steel blanket is shown in fig. 4.16. This surface shows the sharp rise in energy deposition as the ${ }^{6} \mathrm{Li}$ approaches zero as expected. The improved estimate of the total energy deposited in the chamber is shown in Fig. 4.17. It increases with decreasing ${ }^{6} \mathrm{~L}$ fraction and decreasing $L i$ blanket thickness over the entire range of $x_{1}$ and $x_{2}$.

A contour plot of the fusion energy multiplication factor, $M_{f}$, is given in Fig. 4.18. This figure clearly shows the sharp rise at low ${ }^{6} L 1$ concentrations.

\subsubsection{Optimal Design Point.}

Based on the previous results the figure of merit is calculated as a function of the two design varlables as shown in Fig. 4.19. Recall that low values of $F$, the normalized capital cost per net electric power production, are desirable. As seen in fig. 4.19, $F$ decreases with decreasing ${ }^{6} L i$ fraction and $L i$ blanket thickness. A contour plot of $F$ is shown in Fig. 4.20 .

The constraints on the tritium breeding ratio and displacement damage rate 1 imit the degree to which the ${ }^{6} \mathrm{Li}$ fraction and blanket thickness can be decreased in the attempt to decrease $F$. Figure 4.21 shows these two constraints overlaid on the cantour plot of $F$. Note 


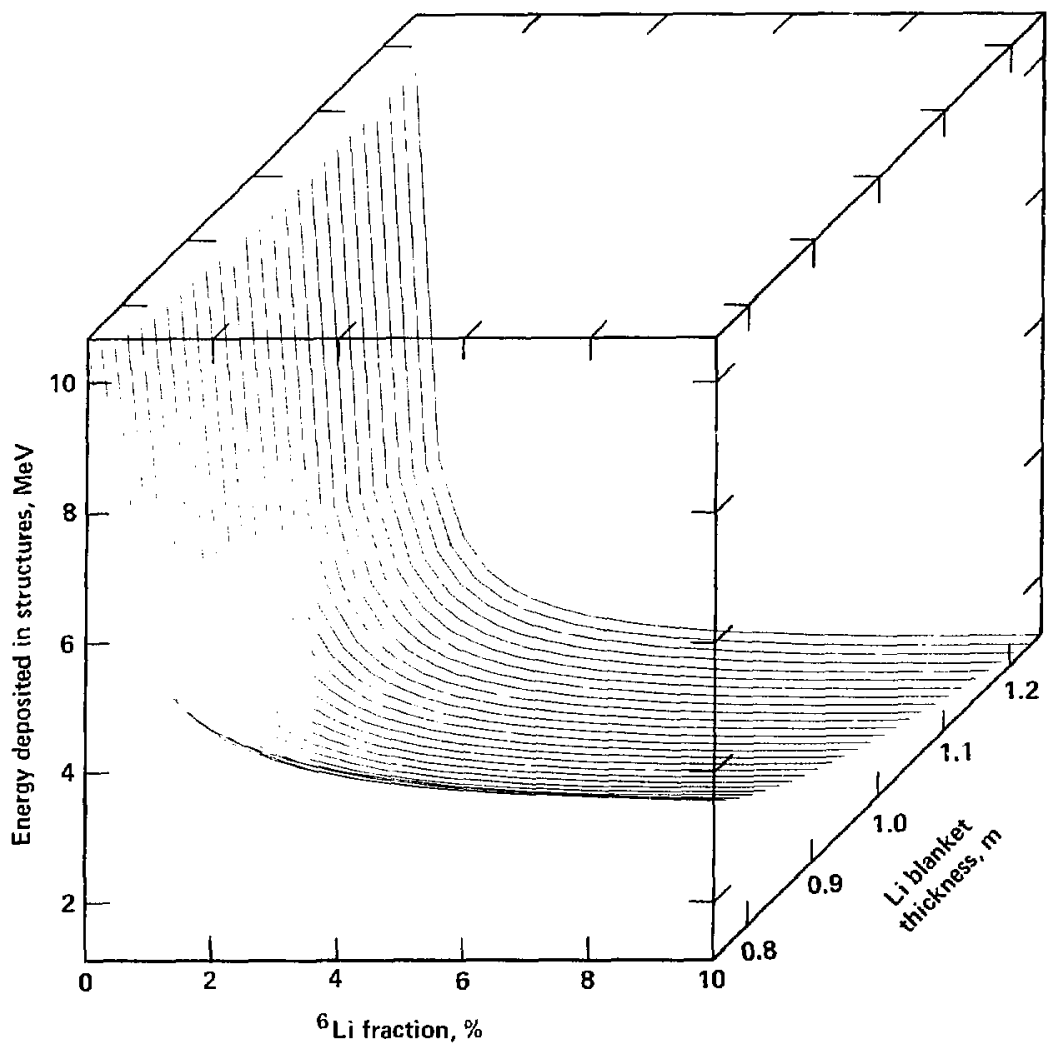

Fig. 4.16 Energy deposited in structures as a function of the two design varlatiss using the neutron balance method. 


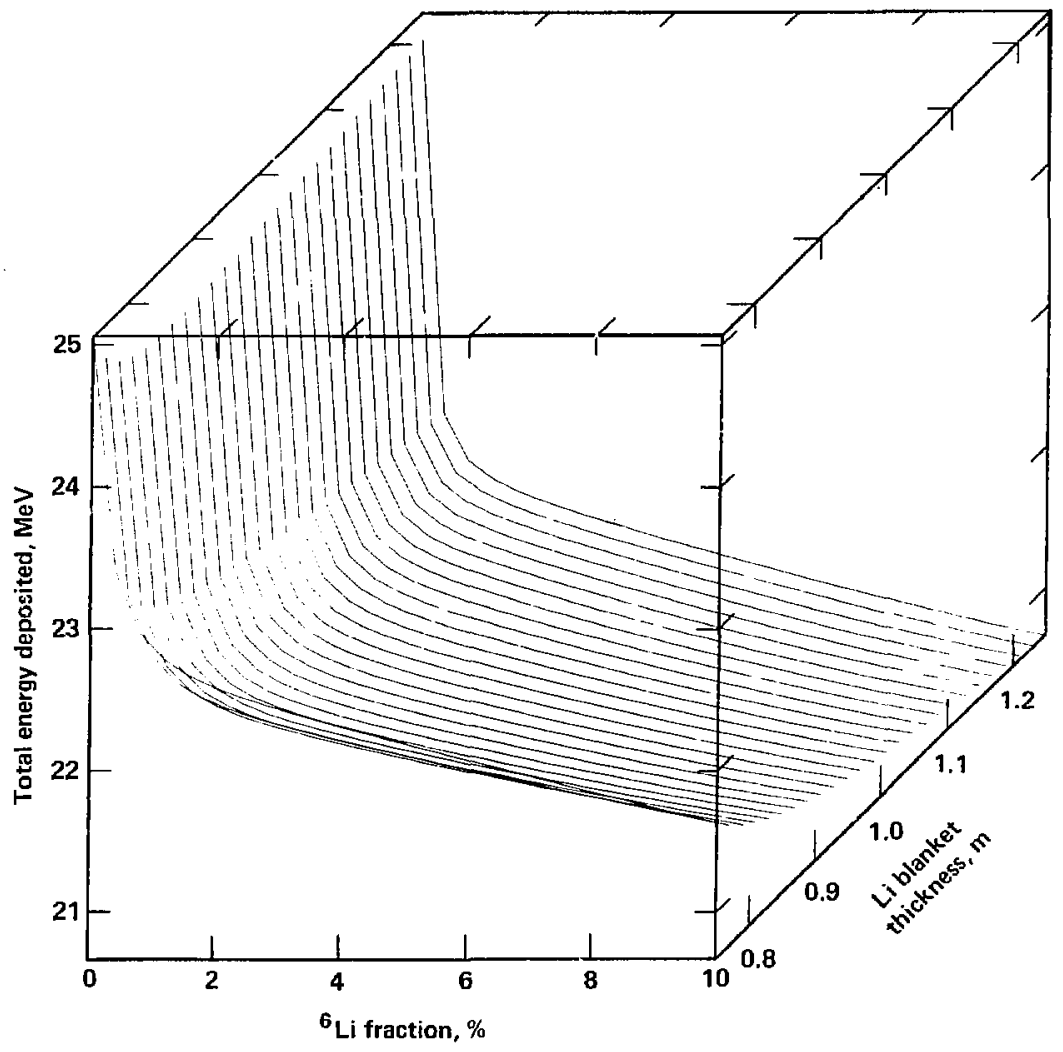

Fig. 4.17 Total energy deposited in the chamber per DT reaction using the neutron balance method. 


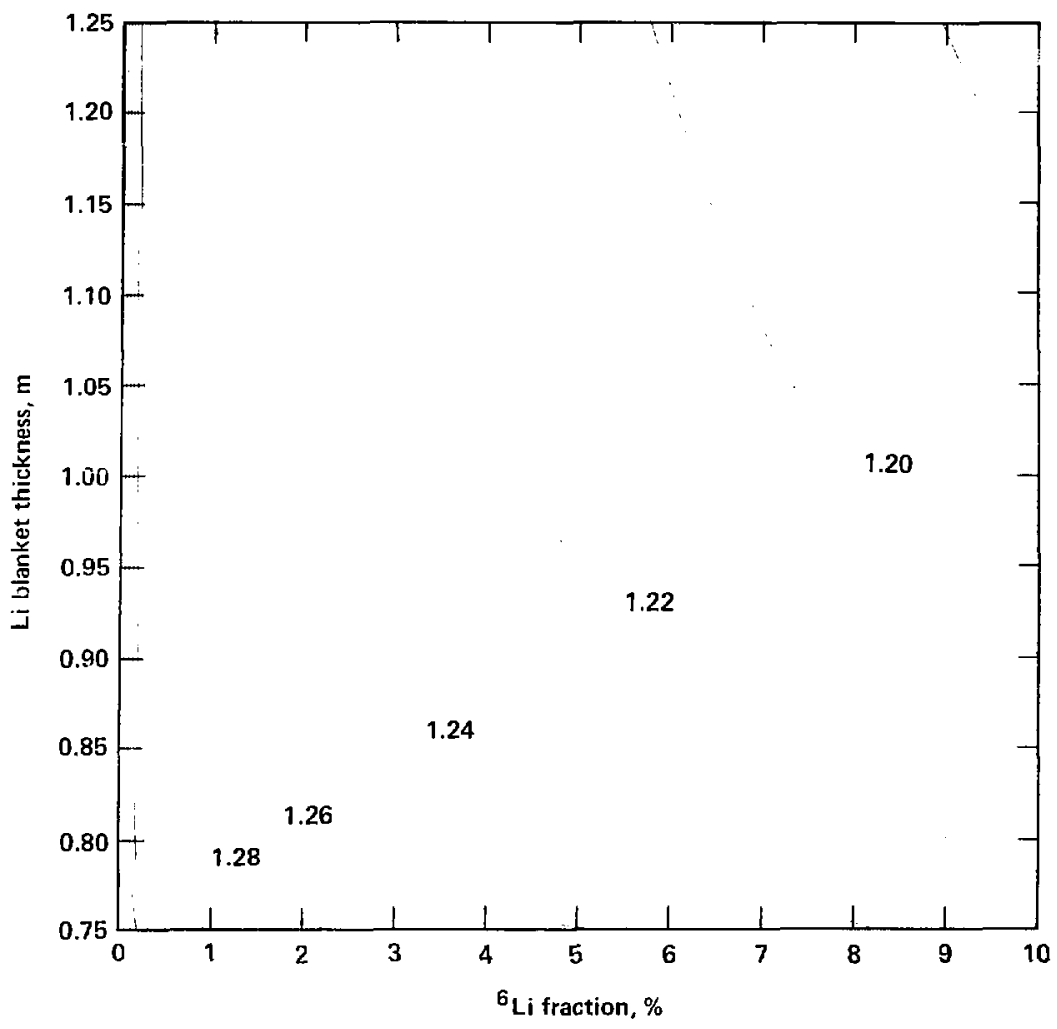

Fig. 4.18 Contour plot of the fusion energy multiplication factor for the modified HYLIFE chamber. 


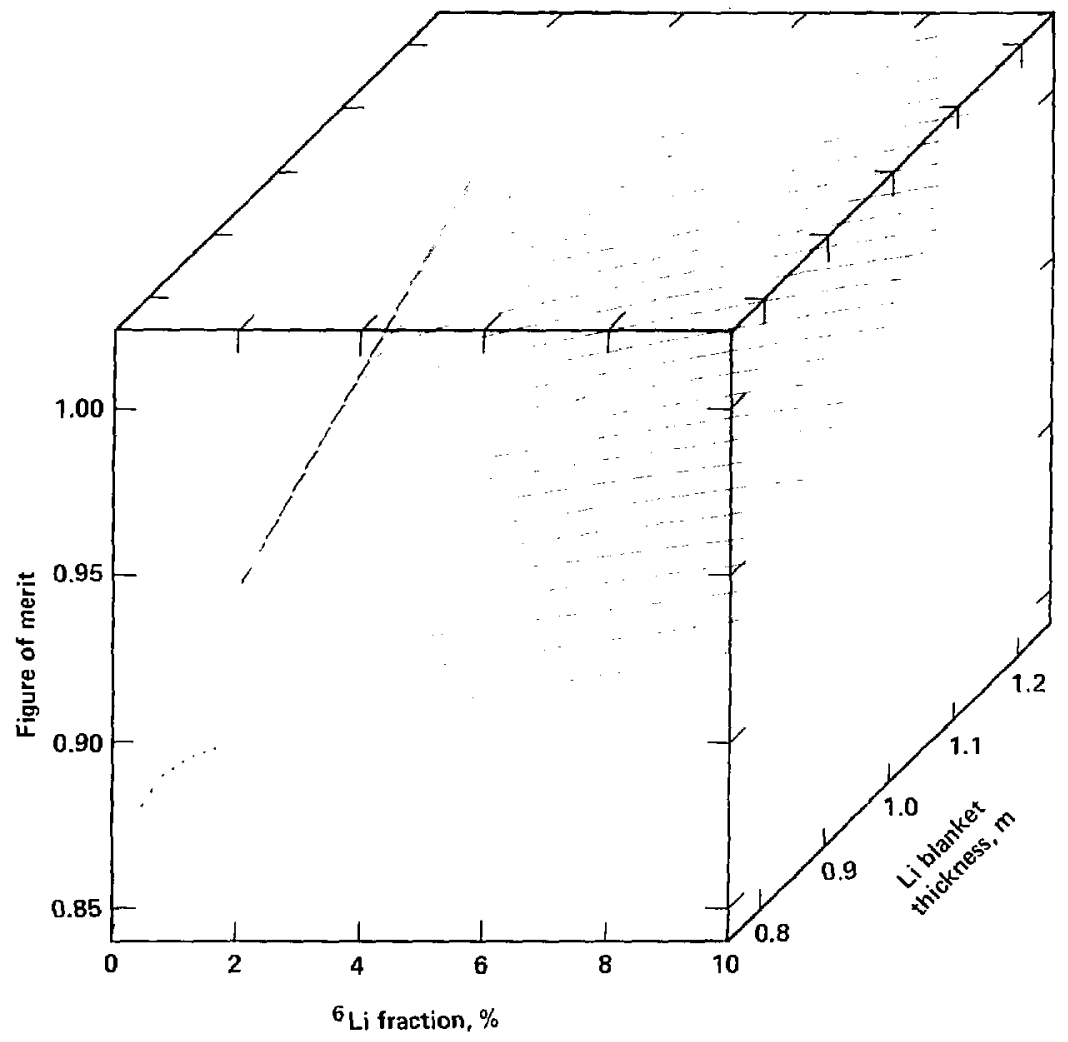

Fig. 4.19 Figure of mer 4 t as a function of the ${ }^{6} \mathrm{Lt}$ fraction and the Li blanket thickness. The figure of merit is a normalized capital cost per unit of net electric power production. 


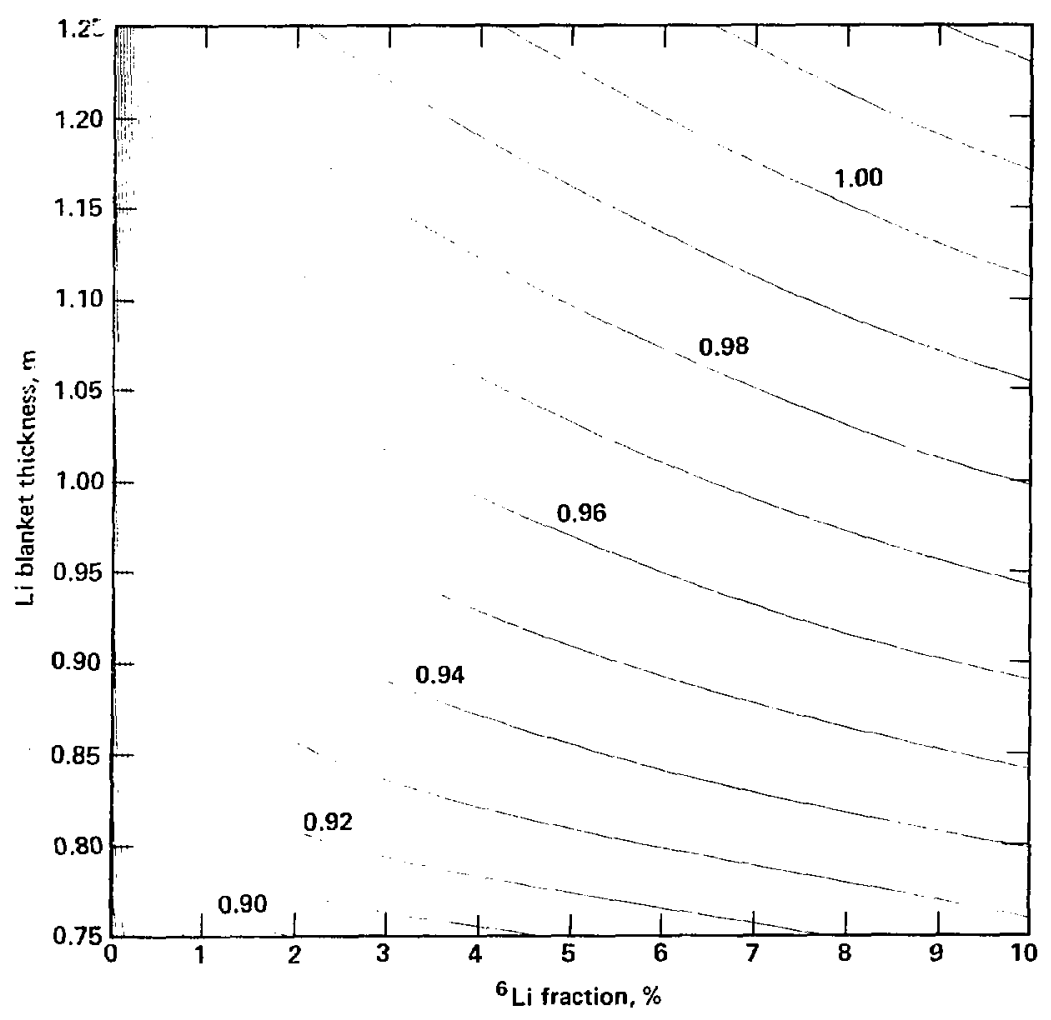

Fig. 4.20 Contour plot of the figure of merit for the modified HYLIFE chamber. 


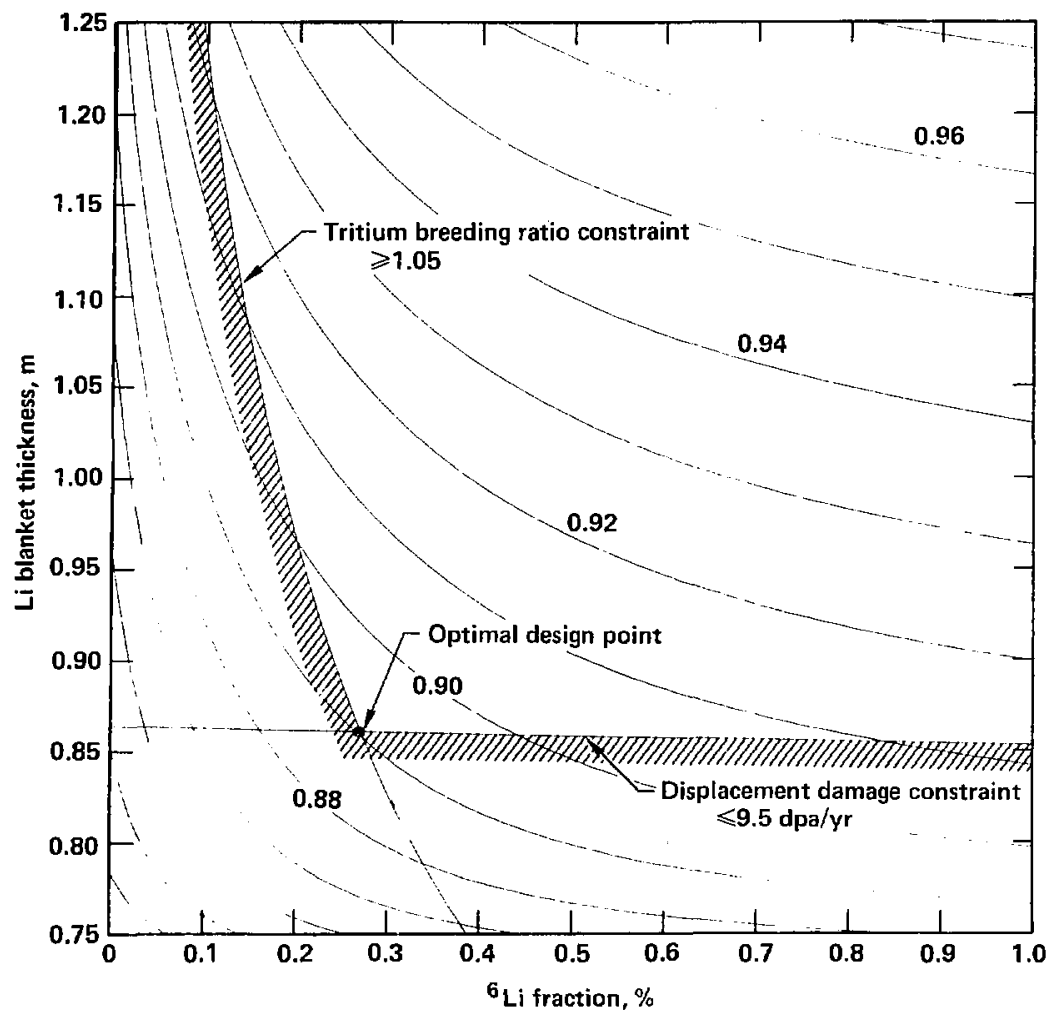

Fig. 4.21 First estimate of the location of the optimal design point. The point lies the intersection of the tritium breeding and displacement damage constraints. 
the scale of the horizontal axis has been changed in order to focus on the region of interest. The optimal design point lies at the intersection of the two constraints. The optimal ${ }^{6} \mathrm{Li}$ concentration is $0.27 \%$ and the optimal Li blanket thickness if $0.86 \mathrm{~m}$. At this point the modified HYLIFE plant costs $4.8 \%$ more than HYLIFE but produces $16 \%$ more electric power. The power plant cost per unit of net electric power is, therefore, reduced by $10 \%$, and the figure of merit is 0.90 .

\subsubsection{Comparison to Transport Calculation at Optimal Point.}

In order to check the accuracy of the result an additional neutron transport calculation was carried out for these conditions, i.e., $x_{1}=0.27 \%$ and $x_{2}=0.86 \mathrm{~m}$. The results of the neutron transport calculation are compared with the estimated parameters in Table 4.6.

The variational estimate of the number of ${ }^{6} L i(n, T) \alpha$ reactions is low by $\sim 17 \%$. This relatively large error is not totally surprising considering the steepness of the T6 surface at such low $6_{L i}$ concentrations (see Fig. 4.6). In particular. T6 increases by 0.8 per $1 \%$ increase in ${ }^{6} \mathrm{~L} t$ fraction in this region. On the other hand the number of tritium breeding reactions with ${ }^{7} L i$ is predicted quite accurately. The actual tritium breeding ratio thus exceeds the required 1.05 by 0.074 and the breeding ratto constraint is satisfied.

The neutron capture rate in $\mathrm{Mn}$ and $\mathrm{Fe}$ is overestimated. This is a direct result of underestimating T6 since the neutron balance method is used to calculate these rates.

The underestimate of the energy deposited in ${ }^{6} L$ is consistent with underestimating $T 6$. The estimated energy deposition in ${ }^{7} L_{i}$ is very close to the transport calculation result. The energy deposited 
Table 4.6

Comparison of neutronic performance at $x_{1}=0.27 \%, x_{2}=0.86 \mathrm{~m}$

\section{$\underline{\text { TART }}$}

\section{Estimated}

Reactions ${ }^{\mathbf{a}}$

$\begin{array}{lll}\sigma_{L\{! n, T) \alpha} & 0.441(1.2)^{2} & 0.368 \\ T_{L Y\{n, n\} T) \alpha} & 0.683(1.2) & 0.682 \\ T & 1.124 & 1.050 \\ M n(n, Y) & 0.318(1.2) & 0.366 \\ F e(n, Y) & 0.336(1.4) & 0.380\end{array}$

Energy Deposition, ${ }^{a}$ MeV

$\begin{array}{lll}\text { Target } & 1.85(0.4) & 1.84 \\ { }^{6}{ }_{\mathrm{L} 1} & 2.12(1.2) & 1.64 \\ 7_{\mathrm{Li}} & 9.22(0.8) & 9.19 \\ \text { Structures }^{\mathrm{b}} & 6.48(1.4) & 6.81 \\ \text { Alpha particle } & 3.52 & \underline{3.52} \\ \text { TOTAL }^{23.19} & 23.00 \\ \text { placement damage rate }^{c} & 10.82 & 9.50\end{array}$
a) per DT fusion reaction.
b) Energy deposited in first structural wall and steel blanket including Mn decay energy.
c) opa per full-power-year based on $2700 \mathrm{MW}$ of fusion power.
d) percent standard devlation. 
in the first structural wall and steel blanket including ${ }^{56}$ Wn decay is overestimated by $\sim 5 \%$. The errors in estimating the energy deposition nearly cancel and the total is low by less than $1 \%$. The final parameter is the displacement damage rate. It is underestimated by $\sim 12 \%$. This means that the displacement damage rate constraint is not really met at this point.

Based on this comparison some conclusions can be drawn with respect to the location of the optimal design point. Since the tritium breeding ratio is sigher than required, the ${ }^{6} \mathrm{Li}$ concentration could in fact by lowered below $0.27 \%$. Also since the displacement damage rate is not met, the Li blanket must be made somewhat thicker than $0.86 \mathrm{~m}$. This then will allow an even greater reduction in the ${ }^{6} \mathrm{~L}$ concentration. A better estimate of the location of the optimal design point is made in the next section. 


\subsection{IMPROVED ESTIMATES OF LOCATION OF OPTIMUM}

\subsubsection{Improved Estimate Using Tay'or Expansion : $t$ Original Optimal}

Point.

An improved estimate of the location of the optimal design point can be made by making use of the results of the additional transport calculation discussed in the previous section and tabulated in Table 4.6. Since the location of the optimal design point is at the intersection of the two constraints, the objective is to produce a better estimate of point at which $T=1.05$ and $D=9.50$. This can be done by expanding $T$ and $D$ in first order Taylor Series in the two destgn variables. 70 The required partial dertvatives are approximated by fintte differences between points bounding the original optimal design point, t.e. $x_{1}=0.27 \%$ and $x_{2}=0.86 \mathrm{~m}$. The values of $T$ and $D$ at these adjacent points are calculated using successive variation interpolation as in the previous section.

The Taylor Serles expansions for $T$ and $D$ are 70

$$
T\left(x_{1}, x_{2}\right)=T\left(x_{10}, x_{20}\right)+T_{x 1^{\prime}}^{\prime} \Delta x_{1}+T_{x 2}^{\prime} \Delta x_{2},
$$

and

$$
D\left(x_{1}, x_{2}\right)=0\left(x_{10}, x_{20}\right)+D_{x 1}^{\prime} \Delta x_{1}+D_{x 2}^{\prime} \Delta x_{2},
$$

where,

$$
\begin{aligned}
& \left(x_{1}, x_{2}\right)=\text { New optimal design point, } \\
& \left(x_{10}, x_{20}\right)=(0.0027,0.86)=\text { or iginal optimal design point, } \\
& T\left(x_{1}, x_{2}\right)=1.05=\text { tritium breeding ratio constraint, } \\
& D\left(x_{1}, x_{2}\right)=9.50=\text { displacement damage rate constraint, } \\
& T\left(x_{10}, x_{20}\right)=1.124=\text { TART result, }
\end{aligned}
$$




$$
\begin{aligned}
& 0\left(x_{10}, x_{20}\right)=10.82=\text { TART result, } \\
& T_{x 1}^{\prime} \text { and } D_{x 1}^{\prime}=\text { partial derivatives of } T \text { and } 0 \text { with respect } \\
& \text { to } x_{1} \text { at the point }\left(x_{10}, x_{20}\right) \text {. } \\
& T_{x 2}^{\prime} \text { and } D_{x 2}^{\prime}=\text { partia } 1 \text { derivatives of } T \text { and } D \text { with respect } \\
& \Delta x_{1}=\left(x_{1}-x_{10}\right) \text {, and the point }\left(x_{10}, x_{20}\right) . \\
& \Delta x_{2}=\left(x_{2}-x_{20}\right) .
\end{aligned}
$$

The partin) derivatives at $\left(x_{10}, x_{20}\right)$ are

$$
\begin{aligned}
& T_{x 1}^{\prime}=79.8, \\
& D_{x 1}^{\prime}=-35.7, \\
& T_{x 2}^{\prime}=0.645, \text { and } \\
& D_{x 2}^{\prime}=-33.7 .
\end{aligned}
$$

These were calculated from the varlations in $T$ and 0 between $x_{1}=0.24$ and $0.30 \%$ with $x_{2}=0.86$, and between $x_{2}=0.85$ and 0.87 with $x_{1}=0.27 \%$.

Substituting the above partials and the known values for $T$ and $D$, Eqs. 4.18 and 4.19 reduce to

$$
-0.074=79.8 \Delta x_{1}+0.645 \Delta x_{2}
$$

and

$$
-1.32=-35.7 \Delta x_{1}-33.7 \Delta x_{2} .
$$

Solving for $\Delta x_{1}$ and $\Delta x_{2}$ gives $\Delta x_{1}=-0.00136$, and $\Delta x_{2}=0.041$.

The new optimal desigr. point is, therefore, $x_{1}=0.14 \%$, ancs $x_{2}=0.90 \mathrm{~m}$. 


\subsubsection{Improved Estimate Using Hew Set of Four Reference Points.}

As prevlously noted, the original estimate of the optimal design point, 1.e., $x_{1}=0.27 \%$ and $x_{2}=0.36 \mathrm{~m}$, did not fall between the reference values for the ${ }^{6} \mathrm{Lt}$ fraction, $1 . e ., 0.5$ and $7.42 \%$. Hence the neutronic performance in the vicinity of the optimal point was estimated based on extrapolations on $x_{1}$. An improved estimate of the location of the optimal design point is obtained if it falls within the rectangle defined by the four reference points. In this section the two reference value for $x_{1}$ are $0.07 \%$ and $0.5 \%$, which, based on the results of the previous section, i.e., $x_{10}=0.14 \%$, should bound the optimal ${ }^{6}{ }_{L i}$ fraction.

The results of the two new reference point transport calculations are tabulated in Tables 4.7 and 4.8. Comparing these results to the results given in Tables 4.4 and 4.5 reveals that the ${ }^{7} L i\left(n, n^{\prime} T\right) a$ reaction rate, the energy deposited in ${ }^{7} \mathrm{Li}$, and tine displacement damage rate are independent of $x_{1}$ in this range. That 15 , the vartations are less than one standard deviation for the Monte Carlo result. Hence in evaluating the figure of merit and constraints, these parameters are only functions of $x_{2}$ and are estimated using two point interpolation on $x_{2}$. In each case, the average of the results at $x_{1}=0.07$ and $0.5 \%$ serves as the reference value for interpolation on $x_{2}$. These average reference values are listed in lable 4.9.

The neutron balance method described in section 4.3 is also used here to estimate the energy deposition in structures. In this case, however, the average number of avaliable neutron is 1.101 compared to 


\section{Table 4.7}

Reaction rates and neutron damage rates for

$$
x_{1}=0.07 \%, x_{2}=0.75 \text { and } 1.25 \mathrm{~m}
$$

Reference Point

$6_{L 1}$ fraction, $\%$

Li Thickness, m
5

0.07

0.75

0.07

1.25

Reactions per DT reaction

$\sigma_{L i(n, T) \alpha}$

0.229

$(1.9)^{\mathrm{a}}$

0.503

(1.6)

$T_{L i}\left(n, n^{\prime} T\right) \alpha$

0.680

(0.8)

0.709

(1.0)

$T_{L i(n, Y)}$

0.013

(1.7)

0.029

(1.5)

$M n(n, Y)$

0.403

(1.3)

0.253

(1.8)

$\operatorname{Fe}(n, Y)$

0.444

(1.2)

0.297

(1.7)

Displacement Oamage Rateb

15.6

(3)

3.97

(8)
a) percent standard deviation.
b) dpa per fuli-power-year based on $2700 \mathrm{MW}$ of fusion power. 


\section{Table 4.8}

Energy deposition for $x_{1}=0.07 \%, x_{2}=0.75$ and $1.25 \mathrm{~m}$

Reference Point

6 Li Fraction, $\%$

0.07

0.07

Li Thickness, m

0.75

1.25

Energy Depositiona

Target

$(0.4)^{\mathrm{b}}$

1.84

(0.4)

6 L1

1.12

(1.9)

2.43

(1.6)

$7_{\text {Li }}$

8.99

(0.5)

9. 62

(0.6)

First wall

1.12

$\{1.6\}$

0.81

(1.7)

Steel blanket

6.37

3.62

(1.4)

(1.8)

Mn decay

1.01

0.63

Alpha particle

3.52

3.52

TOTAL

23.96

22.47

a) MeV per DT reaction.

b) percent standard deviation. 


\section{Table 4.9}

Reference results used to interpolate on $x_{2}$

Parameter

$0.75 \mathrm{~m}$

$1.25 \mathrm{~m}$

7 Lin, n'T)e reactions

0.672

0.713

Energy deposition in ${ }^{2} 1$, MeV

8.98

9.63

Displacement damage rate, dpa/yr

15.52

3.96 
1.114 used previously. Also at $0.07 x^{6} \mathrm{~L} 1$, neutron capture in ${ }^{7} \mathrm{Li}$ becomes significant (1.e., > $1 \times$ ) and is therefore included as a sink In the neutron balance. Finally Mn accounts for 48\% of the captures in Mn and Fe compared to $49 \%$ in the previous case.

The expression for energy deposition in structures due to neutron capture and ${ }^{56}$ Mn decay is

$$
E=8.71(1.101-\mathrm{T} 6-(7), \mathrm{MeV},
$$

where

$$
C 7=\text { nestron capture in }{ }^{7} L(n, Y) \text { reactions. }
$$

Compare this to Eqs. 4.16 and 4.17. As before, T6 and $\mathrm{C7}$ are estimated using variational interpolation.

The direct neutron energy deposition is equal to the difference between the result obtained with Eq. 4.22 and the sum of the tabulated energy deposition in the steel wall, in the steel blanket, and due to Mn decay.

The resulting contour plot of the figure of merit is shown in Fig. 4.22. The displacement damage rate and tritium breeding constraints have been overlaid. In this case, the optimal design point is located at $x_{1}=0.13 \%$ and $x_{2}=0.86 \mathrm{~m}$. The ${ }^{6} L_{1}$ concentration agrees more closely with the Improved estimate obtained in the previous section, i.e., $0.14 \%$. The optimal Li blanket thickness however, is the same as the original estimate. This is as expected since the blanket thickness is Ifmited by the displacement damage rate which in this range is independent of the ${ }^{6} L i$ fraction. Hence, the two new transport calculations at different values of ${ }^{6} \mathrm{Li}$ 


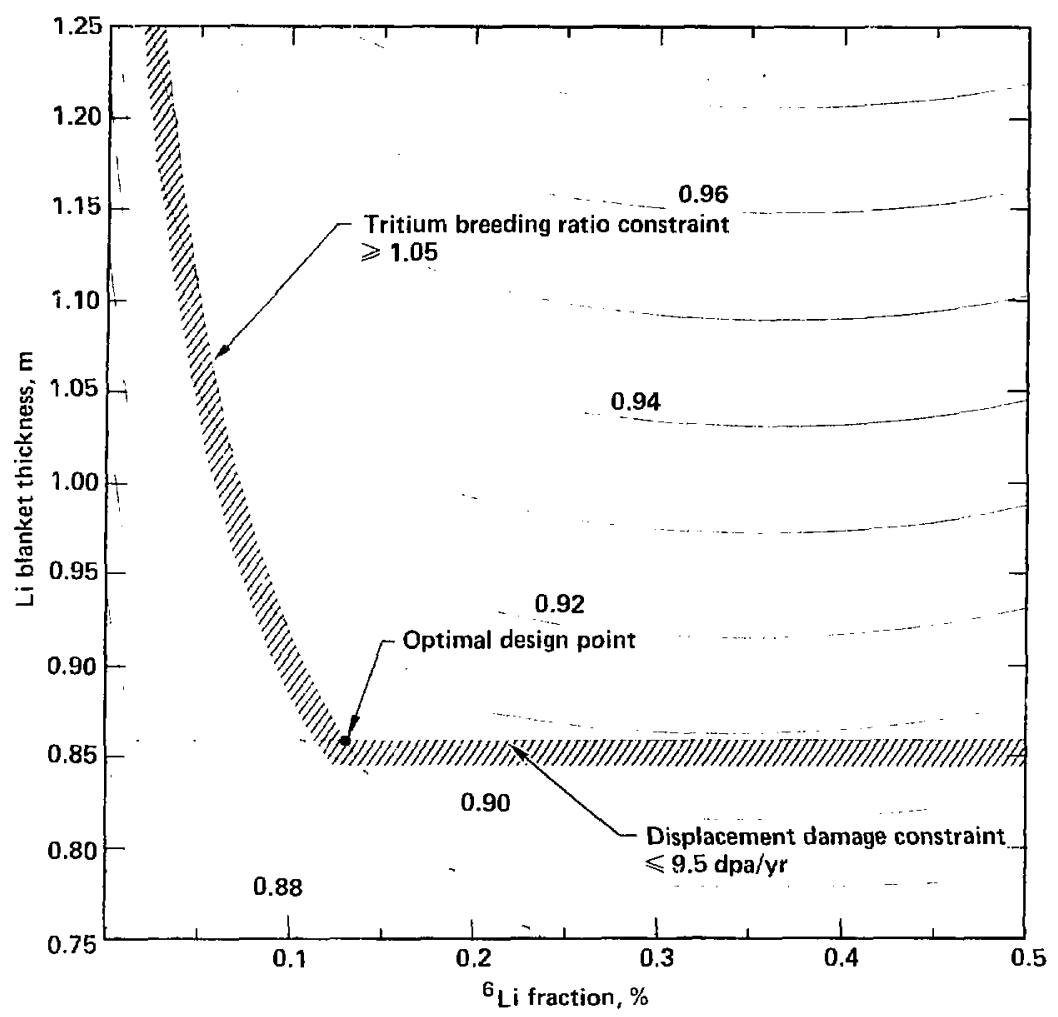

fig. 4.22 Third estimate of the location of the optimal design point. 
fraction did not add any ris: information relative to the damage rate.

To get an improved estimate of the displacement damage rate as a function of thickness requires additional transport calculations at an intermediate value of $x_{2}$. This is discussed in the next section.

\subsubsection{Using Three Point Interpolation on One Varlable.}

In this section the optimal design point 15 estimated using three point interpolations on $x_{2}$ followed by two point interpolations on $x_{1}$. Two new transport calculations were carried out with $x_{2}=1.00 \mathrm{~m}$; one with $x_{1}=0.07 \%$, and one with $x_{1}=0.5 \%$. The results at these points are given in Tables 4.10 and 4.11 .

Note that the number of ${ }^{6} L\{i n, T\} a$ reactions varies linearly with the LI blanket thickness in tinis range. Therefore T6 is estimated by a two point interpolation on $x_{1}$ between two linear expressions in $x_{2}$, one at $x_{1}=0.07 \%$ and one at $x_{1}=0.5 \%$. The energy deposition in ${ }^{6} L 1$ is also linear in $x_{2}$ and thus estimated in the same manner as T6.

As before $T 7, E 7$ and the displacement damage rate are independent of the ${ }^{6}{ }_{1}$ fraction at these low concentrations. Note that the variation in the displacement damage rate at $1.00 \mathrm{~m}$ is within the $6 \%$ standard deviation. The average values for $T 7, E 7$ and displacement damage rate at $1.0 \mathrm{~m}$ are $0.709,9.46 \mathrm{MeV}$ and $7.34 \mathrm{dpa} / \mathrm{yr}$. These, along with the values 11 sted in Table 4.9, serve as the reference points for three point interpolation on $x_{2}$. Also, the neutron balance method, Eq. 4.22, is used to calculate the energy deposition in structures. 


\section{Table 4.10}

Reaction rates and neutron damage rates for

$x_{1}=0.07$ and $0.50 \%$ with $x_{2}=1.00 \mathrm{~m}$

Reference Point

ELi Fraction, $\%$

Li Thickness, m
7

0.07

1.00
8

0.50

1.00

Reactions per DT reaction
$G_{L i}(n, T) \alpha$
0.366
$(1.5)^{\mathrm{a}}$
0.588
$(? .0)$
$T_{L I}\left(n, n^{\prime} T\right\} \alpha$
0.704
(1.3)
0.713
0.021
(1.3)
(1.2)
$T_{L+(n, Y)}$
0.325
(1.3)
0.009
$\operatorname{Mn}(n, Y)$
0.370
(1.2)
(1.0)
$F \in(n, Y)$
0.253
(2.5)
0.262
(2.3)

7.57

(6)

Oisplacement damage rateb

7.11

(6)
a) percent standard deviation.
b) dpa per full-power-year based on 2700 MW of fuston power. 


\section{Table 4.11}

Energy deposition for $x_{1}=0.07$ and $0.50 \%$ with $x_{2}=1.00 \mathrm{~m}$

$\begin{array}{lcc}\text { Reference Point } & 7 & 8 \\ \text { GL Fraction, \% } & 0.07 & 0.50 \\ \text { Li Thickness, m } & 1.00 & 1.00\end{array}$

Energy Depositiona

Target

1.83

$(0.4)^{b}$

1.82

1.75

$(1.5)$

9.52

(0.8)

0.96

(1.9)

4.81

(1.4)

0.81

3.52

23.20

22.65
a) MeV per DI reaction
b) percent standard deviation. 
The resulting figure of merit contour plot with constraints is shown in Fig. 4.23. In this case the predicted optimal design point is $x_{1}=0.09 \%$ and $x_{2}=0.91 \mathrm{~m}$. Note that the value of $x_{2}$ increased to lower the dpa rate as expected. The results of this final estimate are compared to the results of a transport calculation at this design point in the next section.

A transport calculation was carried out with a Li blanket thickness of $0.91 \mathrm{~m}$ and $\mathrm{a}^{6} \mathrm{Li}$ fraction of $0.09 \%$ in order to check the estimated results at the optimal design point..

The neutronic performance is compared in Table 4.12. All the results agree quite closely. The tritium breeding ratio is off by 0.5\%, the total energy deposition is within $1 \%$ of the transport calculation result, and the dpa rate is high by $\sim 0.5 \%$. The close agreement in the dpa rate is somewhat fortultous considering that the standard deviation in the result is $\sim 5 \%$.

Based on the agreement with the transport calculation the optimal design point of $0.09 \%^{6} \mathrm{Li}$ and a blanket thickness of $0.91 \mathrm{~m}$ is quite acceptable. 


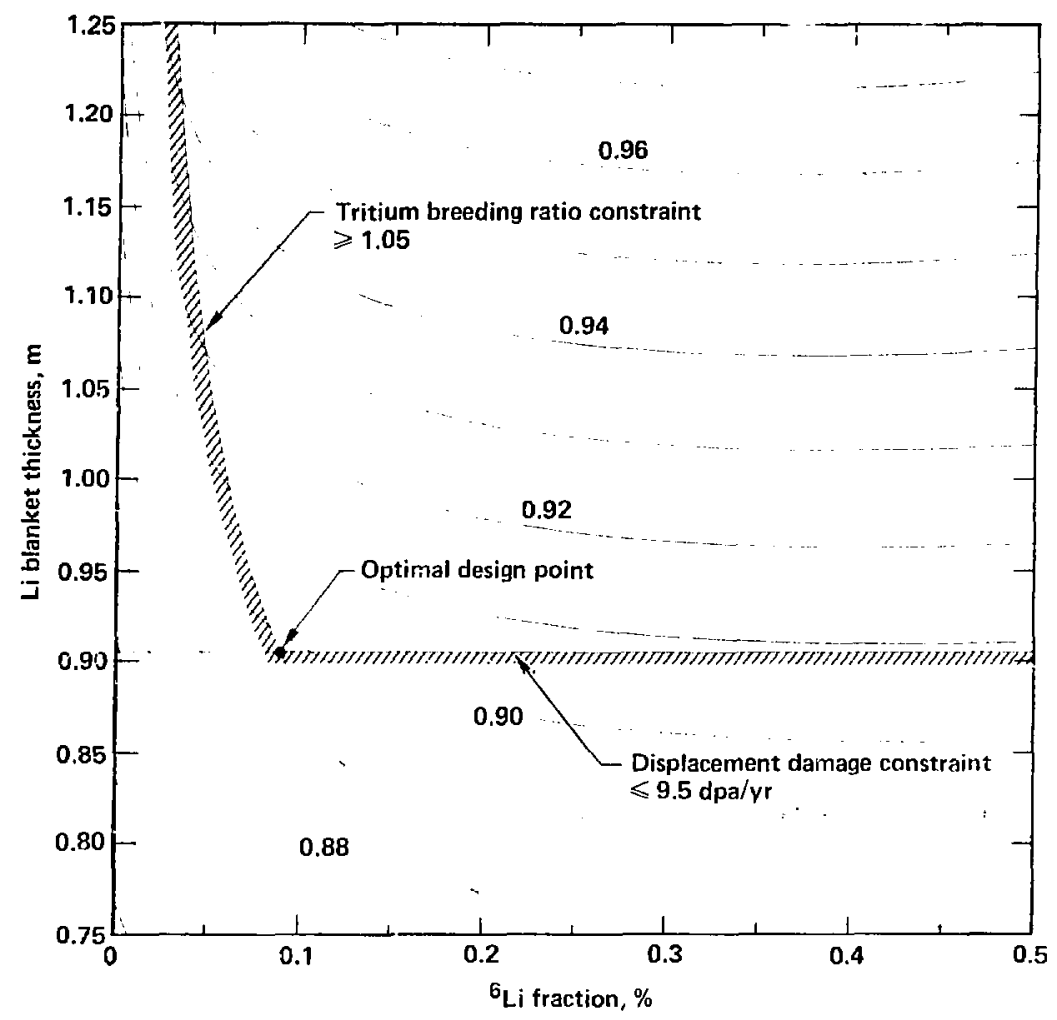

Fig. 4.23 Fourth estimate of the location of the optimal design point. 


\section{Table 4.12 \\ Comparison of TART and estimated results at $x_{1}=0.09 \%$ and $x_{2}=0.91 \mathrm{~m}$}

Reactions per OT reaction

TART

Estimated

$\begin{array}{lll}{ }^{6} \mathrm{Li}(n, T) a & 0.357(1.7)^{\mathrm{c}} & 0.350 \\ T_{\mathrm{Li}(n, T) \alpha} & \underline{0.698}(0.7) & \underline{0.700} \\ \mathrm{~T} & 1.055 & 1.050 \\ \gamma_{\mathrm{L} i(n, Y)} & 0.016(1.6) & 0.016 \\ \operatorname{Mn}(n, Y) & 0.353(1.5) & 0.353 \\ \mathrm{Fe}(n, Y) & 0.390(1.4) & 0.382\end{array}$

Energy depositiona

Target

6L1

$7_{\mathrm{L} 1}$

Structures

Mn decay

Alpha particle

TOTAL

Displacement damage rate ${ }^{b}$
$1.82(0.4)$

1.84

$1.67(1.7)$

1.70

$9.45(0.5)$

9.32

$6.17(1.5)$

0.89

$\underline{3.52}$

23.51

23.29

9.50
a) MeV per ot reaction.
b) dpa per fu11-power-year based on $2700 \mathrm{MH}$ of fusion power.
c) percent standard deviation. 


\subsection{SUMHARY OF OPTIMIZATIOH RESULTS.}

The plant parameters at the final optimal design point are

compared to the reference HYLIFE parameters in Table 4.13. With the modified design, the fusion energy multiplication factor is increased to 1.34 . As a result, the modified design produces $19.4 \%$ more electric power. The plant capital cost, however, is only $6.5 \%$ higher for an $10.8 \%$ reduction in the cost per kHe. To put this into perspective note that with the modified HYLIFE design the driver and target factory could cost $\$ 200 \mathrm{M}$ more (direct) for the same cost of electricity as from BYLIFE.

The various optimal design points described in this chapter are summarized in Table 4.14. 


\section{Table 4.13}

Comparison of HYLIFE and modified HYLIFE parameters at

$x_{1}=0.09 \%$ and $x_{2}=0.91 \mathrm{~m}$

\begin{tabular}{|c|c|c|}
\hline & HYLIFE & $\begin{array}{l}\text { Modiffied } \\
\text { HYLIfE }\end{array}$ \\
\hline Tritium breeding ratio & 1.75 & 1.05 \\
\hline Neutron energy deposition, MeV & 16.9 & $20.0^{\mathrm{a}}$ \\
\hline Fusion power, MW & 2700 & 2700 \\
\hline Fusion energy multiplication factor & 1.16 & 1.34 \\
\hline Therma 1 power, $\mathrm{MW}_{\mathrm{t}}$ & 3130 & 3607 \\
\hline Therma 1 conversion efficiency, $\%$ & 39 & 39 \\
\hline Gross electrical power, MWe & 1220 & 1407 \\
\hline Laser power consumption, MWe & 135 & 135 \\
\hline Auxillary power requirements, MWe & 75 & 75 \\
\hline Lithium pumping power, MWe & 30 & 27 \\
\hline Net electrical power, MWe & 980 & 1170 \\
\hline \multicolumn{3}{|l|}{ Direct capital costs, SM } \\
\hline Reactor & 960 & 1075 \\
\hline Lithium pumps & 160 & 146 \\
\hline Laser & 330 & 330 \\
\hline Target factory & 100 & 100 \\
\hline TOTAL & 1550 & 1651 \\
\hline
\end{tabular}

(a) based on results of transport calculation. 
Table 4.14

Summary of optimal design points discussed in Chapter 1

\begin{tabular}{|c|c|c|c|c|c|}
\hline Number & $\begin{array}{l}\text { Uptima i } \\
\times 1, \%\end{array}$ & $\begin{array}{l}\text { Point } \\
\times 2, \mathrm{~m}\end{array}$ & $\begin{array}{l}\text { Reference } \\
\times 1, \%\end{array}$ & $\begin{array}{l}\text { Points } \\
\times 2, \mathrm{~m}\end{array}$ & Method \\
\hline \multirow[t]{4}{*}{1} & 0.27 & 0.86 & 0.50 & 0.75 & Successive two \\
\hline & & & 0.50 & 1.25 & point interpolation \\
\hline & & & 7.42 & 0.75 & \\
\hline & & & 7.42 & 1.25 & \\
\hline 2 & 0.14 & 0.90 & 0.27 & 0.86 & $\begin{array}{l}\text { Taylor Sertes } \\
\text { about point } 1\end{array}$ \\
\hline \multirow[t]{4}{*}{3} & 0.13 & 0.86 & 0.07 & 0.75 & Successive two \\
\hline & & & 0.07 & 1.25 & point interpolation \\
\hline & & & 0.50 & 0.75 & \\
\hline & & & 0.50 & 1.25 & \\
\hline \multirow[t]{6}{*}{4} & 0.09 & 0.91 & 0.07 & 0.75 & Three point \\
\hline & & & 0.07 & 1.00 & interpolation on $x_{2}$ \\
\hline & & & 0.07 & 1.25 & Two point \\
\hline & & & 0.50 & 0.75 & interpolation on $x_{1}$ \\
\hline & & & 0.50 & 1.00 & \\
\hline & & & 0.50 & 1.25 & \\
\hline
\end{tabular}




\section{OPTIMIZATION OF THE CASCADE CHAMBER}

\subsection{DESCRIPTION OF THE PROBLEM}

\subsubsection{The Cascade Reactor Concept.}

The subject of the second optimization problem is another inertial confinement fusion reactor concept called Casrade. ${ }^{11,72}$ The primary feature of Cascade (see Fig. 5.1) is a rotating chamber in which a cascading blanket of solid lithium ceramí pebbles breeds tritium, acts as the heat transfer medium, and protects the chamber wall from the damaging effects of neutrons, $x$-rays and target debris. Pebbles are injected at each end of the chamber, and are held against the wall by centrifugal action. The pebbles cascade toward larger radil and exit through apertures into i stationary pebóle catcher. Heat and tritium are removed, and the pebbles are recirculated for reinjection into the chamber. This concept is currently under investigation at Lawrence Livermore National Laboratory, and researchers at GA Technologies are participating in the study under contract.

As reported in the literature, ${ }^{72}$ the solid breeding matertal used in Cascade is $\mathrm{Li}_{2} \mathrm{O}$. While $\mathrm{Li}_{2} \mathrm{O}$ is a good tritium breeding material, there are some concerns about the corrosive effects of $\mathrm{LiOH}$ which is formed from $\mathrm{Li}_{2} 0 .{ }^{73,74}$ From a compatibility standpoint, a more attractive ceramic tritium breeding material is $\mathrm{LAAOO}_{2} \cdot{ }^{75}$ Unfortunately, $\mathrm{LAAlO}_{2}$ w111 not give a tritium breeding ratio greater than one unless a neutron multiplier is placed between the fusion neutron source and the $\mathrm{LiAlO}_{2}$ breeding blanket. ${ }^{25}$ 


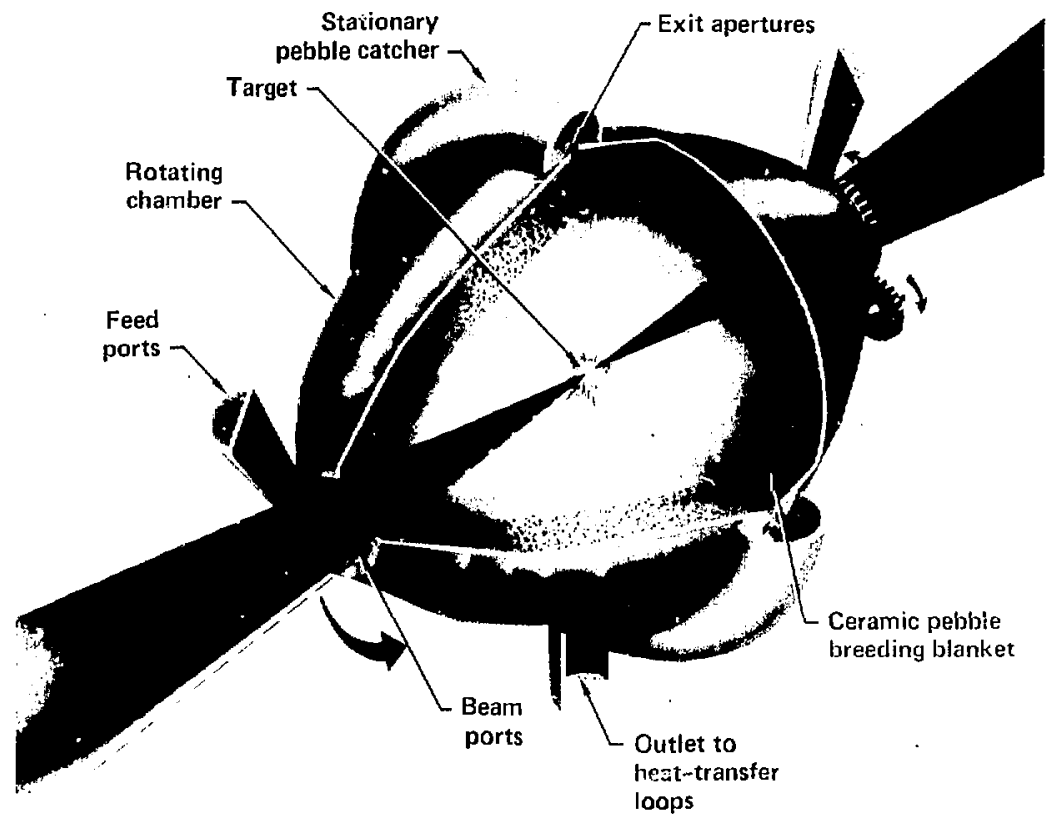

fig. 5.1 The Cascade chamber. 
In this optimization problem, a Cascade chamber using a $\mathrm{LiAlO}_{2}$ breeding blanket and a BeO neutron multiplier is investigated. Beryllium is an excellent neutron multiplier with a threshold of only $1.85 \mathrm{MeV} .^{76}$ Beryllium oxide 15 proposed here to aliou for high temperature operation. which is one of the goals of the Cascade concept. ${ }^{77,78}$

A flowing layer of BeO pebbles can be maintained on the surface of the LiAlO 2 blanket by fabricating the Beo larger and less dense than the $\mathrm{L} \mathrm{AlO}_{2}$ pebbles. ${ }^{79}$ The normal density of BeO is $3.01 \mathrm{~g} / \mathrm{cm}^{3}$, while Liarú 2 has a normal density of $2.55 \mathrm{~g} / \mathrm{cm}^{3}$. Therefore, the Be 0 pebbles must be fabricated at less than $85 \%$ normal density.

Three blanket design variables are considered in the Cascade optimization problem. They are

$$
\begin{aligned}
& x_{1}={ }^{6} L i \text { fraction in Li, } \\
& x_{2}=L^{2 A 2 O_{2}} \text { blanket thickness, m, and } \\
& x_{3}=\text { BeO multiplier thickness, } m .
\end{aligned}
$$

\subsection{2 figure of Merit tor Cascade.}

The figure of merit chosen for this design is simply the sum of the $\mathrm{LiAlO}_{2}$ blanket thickness and the BeO multiplier thickness.

That is, we seek to minimize

$$
f=x_{2}+x_{3}
$$

At this stage in the development of the cascade concept, it is not 
possible to optimize a more general system parameter, such as the cost of electricity, since cost estimates for the reactor plant have not yet been made. By minimizing the total blanket thickness (the multipliar is considered part of the blanket) the size of the rotating chamber can be minimized. This inner radius of the blanket is assumed to be fixed by the damaging effects (ablatien and vaporization) of the $x$-rays and target debris.

Pitts previously sought to minimize the size of the chamber from a mechanical and thermal perspective. ${ }^{80}$ In this problem, the neutronic perspective is considered.

\subsubsection{Constraints on the Design.}

Three constraints are imposed on the Cascade design. The first is a requirement for á tritium breeding ratio greater than 1.05 . This is the same constraint as used for the modtfied HYLIFE chamber optimization problem discussed in Chapter 4 . The constraint is expressed as,

$$
\mathbf{T} \geq 1.05 \text {. }
$$

The second constraint relates to the mechanical design of the Cascade chamber. GA Technologles recently proposed a concept where the rotating chamber is constructed of individual SiC panels held together by Al tendons. ${ }^{81}$ The Al tendons are actually a composite of $\mathrm{Al}$ and $\mathrm{SIC}$ fibers to increase tensile strength of Al. Based on a temperature $11 \mathrm{mit}$ of $400^{\circ} \mathrm{C}$ for the tendons, the heat generation rate in the tendons due to neutron and gamma heating must be less than $0.85 \mathrm{~W} / \mathrm{cmi}^{3}$. $^{81}$ The second canstraint is 


$$
\mathrm{G} \leq 0.85 \mathrm{w} / \mathrm{cm}^{3} \text {. }
$$

The heat rate in the tendons is calcuiated from,

$$
G=E_{t} P_{f} / 17.6 V_{t},
$$

where

$$
\begin{aligned}
E_{t}= & \text { energy deposited in the zone representing the Al/SiC } \\
& \text { tendons, MeV per DT reaction, } \\
P_{f}= & \text { the fusion power, } W \text {, and } \\
V_{t}= & \text { volume of the zone representing the tendons, } \mathrm{cm}^{3} .
\end{aligned}
$$

The value 17.6 is the total energy in MeV released per DT reaction. For Cascade, the fusion power is 3000 MW.

A third constraint is placed on the total neutron leakage rate from the Cascade chamber. This parameter gives an indication of the effectiveness of the blanket design in performing one of its primary functions, namely, capturing the fusion neutrons.

The beam ports at the ends of the Cascade chamber provide a direct leakage path from the chamber. The two ports subtend $1.25 \%$ of the total solid angle. The nestron leakage through the ports, hawever, will be greater than $1.25 \%$ of the fusion neutron source for two reasons. ${ }^{82}$ One is that neutrons entering the blanket can be scattered out through the ports. The second is tha! neutron multiplication in the BeO region will tend to increase the neutron leakage through the ports.

There will also be some neutron leakage through the $\mathrm{L}_{1 \mathrm{AlO}}$ blanket itself. The constraint on the total neutron leakage is set at 
0.1 neutrons per DT reaction. That is,

$$
L \leq 0.1
$$

The constraints given by Eqs. 5.2, 5.3 and 5.5 are evaluated as a function of the three design varlables using successive, two point varlational interpolation. As such, eight reference point transport calculations are required. The neutronlcs model for the cascade chamber is discussed in the next section. 


\subsection{REFERENCE POINT TRANSPORT CALCULATIONS}

\subsubsection{Neutronics Model for the Cascade Chamber.}

The neutronics model of the Cascade chamber is shown in Fig. 5.2 . The football shaped chamber (see Fig. 5.1) is approximated by a sphere. As in the neutronics model for the modified HYLIFE chamber, the 14.1 MeV neutron source is uniformly distributed throughout a region of DI compressed to a density-radius product of $3.0 \mathrm{~g} / \mathrm{cm}^{2}$. The target, zone 1 , is located at the center of the chamber. The region between the target and the blanket is void.

The innermost blanket region, zone 3 , contains the Be0 neutron multiplier. This zone $150.1 \mathrm{~m}$ thick and has an inner radius of $3.4 \mathrm{~m}$. The density of Be0 within zone 3 is varied to represent variations in the effective multiplier thickness, $x_{3}$.

The $\mathrm{L}^{\mathrm{AlO} \mathrm{O}_{2}}$ breeding blanket, zone 4 , extends from a radius of 3.5 to $4.5 \mathrm{~m}$. Again the material density is varied to represent variations in the breeding blanket thickness, $x_{2}$. The ${ }^{6}{ }_{L}$ fraction of lithium in this zone is the third design variable, $x_{1}$.

Outside the breeding blanket is a 2-cm-thick shell, zone 5 , of SiC representing the chamber wall. This is followed by a 2 -cm-thick region, zone 6, that contains the Al/SiC fiber composite and represents the tendons. The two beam ports are represented by cylindrical voids in the blanket. The radius of these holes is $0.72 \mathrm{~m}$ so that the solid angle fraction subtended at a radius of $4.5 \mathrm{~m}$ is $1.25 \%$.

The geometric characteristics are listed in Table 5.1. The volume of zone 6 is $5.09 \times 10^{6} \mathrm{~cm}^{3}$. Thus from Eq. 5.4, the heat rate in 


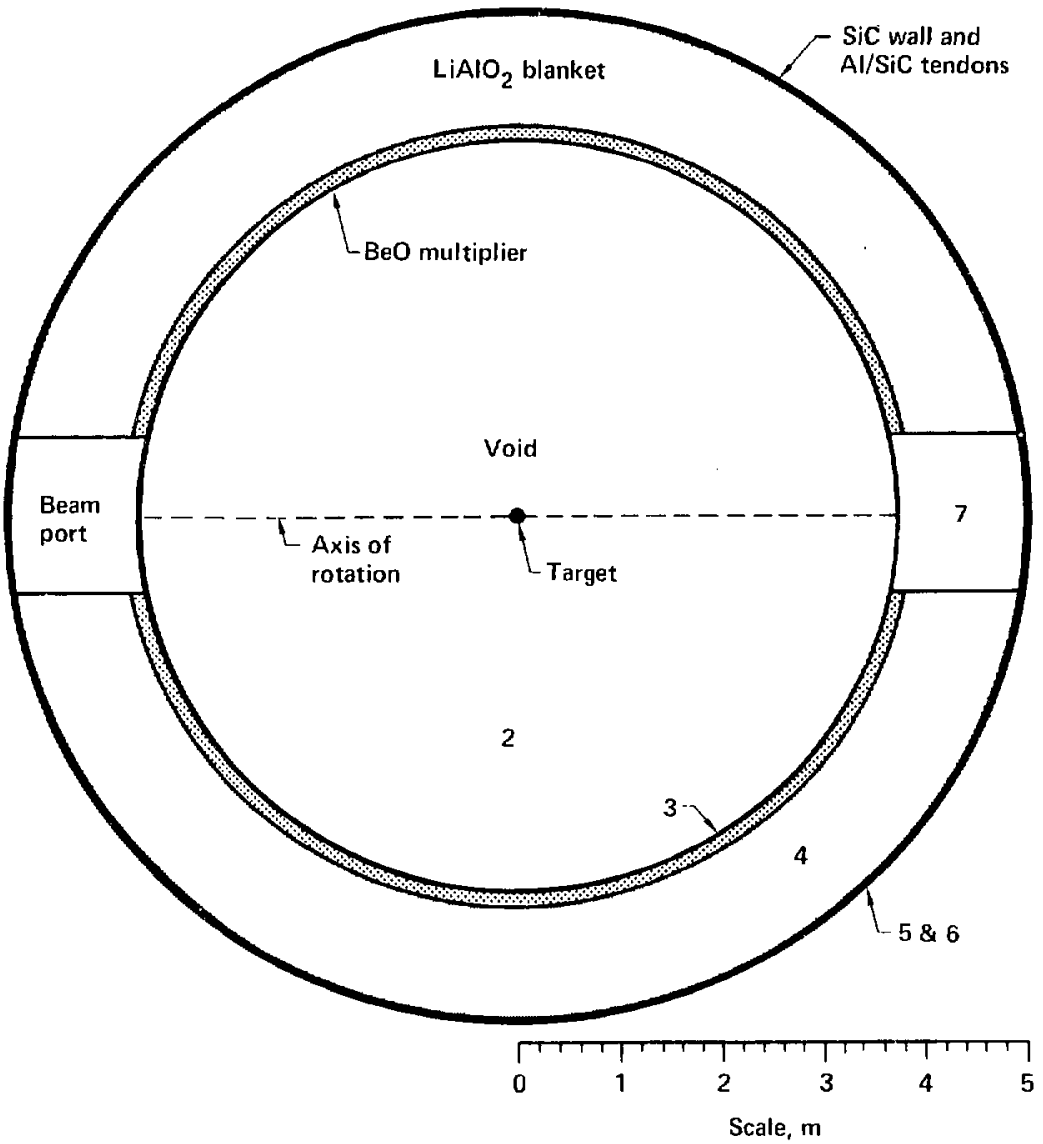

Fig. 5.2 Neutronics model of the Cascade chamber. 


\section{Table 5.1}

Geometric characteristics of the Cascade neutronics model.

\begin{tabular}{lllll} 
Zone & Description & $\begin{array}{c}\text { Inner } \\
\text { Radius } \\
\text { (cm) }\end{array}$ & $\begin{array}{c}\text { Outer } \\
\text { Radius } \\
\text { (cm) }\end{array}$ & Material \\
\hline & & & & \\
1 & Target & 0 & 0.03 & 1 \\
2 & Vacuum & 0 & 340 & Void \\
3 & Neutron multiplier & 340 & 350 & 2 \\
4 & Breeding blanket & 350 & 450 & 3 \\
5 & Chamber wall & 450 & 452 & 4 \\
6 & Tendons & 452 & 454 & 5 \\
\hline
\end{tabular}


the Al/SiC tendons for 3000 NW of fusion power is

$$
G=33.5 E_{t} \text {, }
$$

where

$$
E_{t}=\text { energy deposited in zone } 6 \text {, MeV per DT reaction. }
$$

The composition of the materials used in the neutronics calculations are 11sted in Table 5.2. The tendons are 65 vol\% A2 and 35 vol\% SiC fibers. These fibers contain $\mathrm{CO}$ and $\mathrm{SiO}_{2}$ impurities which gives rise to the indicated oxygen content. The fiber composition $1557 w t \% S 1,31$ wt\% C, and $12 w t \% 0$.

\subsubsection{Results of the eight inttial transport calculations.}

As previously stated, elght reference point transport calculations are required for the Cascade chamber optimization problem. The eight points are defined by the combinations of two values for each of the three design variables. The reference values for the design varlables are ${ }^{6} \mathrm{~L} 1$ fractions of 7.42 and $50 \%, \mathrm{LAlO}_{2}$ blanket thicknesses of 0.30 and $0.50 \mathrm{~m}$, and Be0 multiplier thicknesses of 0.05 and $0.15 \mathrm{~m}$.

The results are given in Tables 5.3-5.6. The reaction rates and the neutron balance for the four transport calculations with $0.05 \mathrm{~m}$ of Be 0 and $0.15 m$ of Be0 are given in Tables 5.3 and 5.5, respectively. The neutron balance gives the net neutron gain or loss in the varlous regtons of the chanber. The small remainder is the neutron capture in the SIC wall and AR/SiC tendons.

The energy deposition per DT reaction in each zone is given in Table 5.4 for the four cases with $0.05 \mathrm{~m}$ of Be0, and in Table 5.6 for the four cases with $0.15 \mathrm{~m}$ of Beo. The key number here is the energy 


\section{Table 5.2}

Composition of materials used in the Cascade neutronics calculations

Matertal

Density

$\left(\mathrm{g} / \mathrm{cm}^{3}\right)$

100

3.01

2.55

$3^{b}$

2.55

4

5 $3^{\mathrm{a}}$

1

2

(a)
3.20

2.60
Isotopic fractions

(X)
a) natural lithlum.
b) Vithium enriched to $50 \% 6 \mathrm{Li}$. 


\section{Table 5.3}

Reaction rates and neutron balance for transport calculations with $0.05 \mathrm{~m}$ of $\mathrm{BeO}$

Reference point

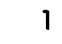

$\mathrm{LiAlO}_{2}$ thickness, Im

0.30

2

3

4

6 I fraction, $x$

7.42

0.30

0.50

0.50

Reactionsa

$\begin{array}{lllll}\sigma_{L I}(n, T) a & 0.797 & 0.948 & 0.999 & 1.100 \\ 7_{L I(n, n) T) \alpha} & (1.2)^{b} & (1.3) & (1.7) & (1.1) \\ & 0.070 & 0.038 & 0.075 & 0.040 \\ \operatorname{Be}(n, 2 n) & (0.9) & (1.0) & (1.5) & (1.9) \\ & 0.269 & 0.266 & 0.264 & 0.267 \\ & (1.6) & (i .4) & (i .1) & (0.9)\end{array}$

Neutron balance ${ }^{\mathrm{a}}$

\begin{tabular}{lrrrr} 
Target & 1.057 & 1.056 & 1.055 & 1.057 \\
Be0 & 0.189 & 0.188 & 0.187 & 0.184 \\
LiAlO2 $_{2}$ & -0.893 & -1.046 & -1.104 & -1.179 \\
Port leakage & -0.046 & -0.033 & -0.043 & -0.030 \\
& $(4.1)$ & $(3.5)$ & $(3.2)$ & $(8.6)$ \\
Blanket leakage & -0.303 & $-0.16)$ & -0.094 & $-0.03\}$ \\
& $(2.0)$ & $(2.5)$ & $(2.7)$ & $(3.1)$ \\
Remainder & 0.004 & 0.004 & 0.001 & 0.001 \\
\hline
\end{tabular}
a) per DT reaction.
b) percent standard deviation. 
Table 5.4

Energy deposition for the

transport calculations with $0.05 \mathrm{~m}$ of $\mathrm{BeO}$

\begin{tabular}{|c|c|c|c|c|}
\hline $\begin{array}{l}\text { Reference point } \\
\mathrm{LiAlO}_{2} \text { thickness, m } \\
6 \mathrm{Li} \text { fraction. } \%\end{array}$ & $\begin{array}{c}1 \\
0.30 \\
7.42\end{array}$ & $\begin{array}{l}2 \\
0.30 \\
50.00\end{array}$ & $\begin{array}{c}3 \\
0.50 \\
7.42\end{array}$ & $\begin{array}{c}4 \\
0.50 \\
50.00\end{array}$ \\
\hline \multicolumn{5}{|l|}{ Energy depositeda } \\
\hline Target & $\begin{array}{l}1.80 \\
(0.4)^{b}\end{array}$ & $\begin{array}{l}1.85 \\
(1.0)\end{array}$ & $\begin{array}{l}1.85 \\
(0.7)\end{array}$ & $\begin{array}{l}1.83 \\
(0.8)\end{array}$ \\
\hline $\mathrm{Be} 0$ & $\begin{array}{l}3.05 \\
(0.9)\end{array}$ & $\begin{array}{l}3.02 \\
(0.4)\end{array}$ & $\begin{array}{l}3.06 \\
\langle 1.0\rangle\end{array}$ & $\begin{array}{l}3.03 \\
(0.4)\end{array}$ \\
\hline $\mathrm{LiAlO}_{2}$ & $\begin{array}{l}9.79 \\
(0.7)\end{array}$ & $\begin{array}{l}9.98 \\
(0.7)\end{array}$ & $\begin{array}{l}10.77 \\
(1.1)\end{array}$ & $\begin{array}{l}11.28 \\
(0.8)\end{array}$ \\
\hline Sic wall & $\begin{array}{l}0.11 \\
(2.9)\end{array}$ & $\begin{array}{l}0.11 \\
(2.9)\end{array}$ & $\begin{array}{l}0.03 \\
(10.2)\end{array}$ & $\begin{array}{l}0.02 \\
(7.5)\end{array}$ \\
\hline Tendons & $\begin{array}{l}0.059 \\
(3.1)\end{array}$ & $\begin{array}{l}0.059 \\
(2.8)\end{array}$ & $\begin{array}{l}0.013 \\
(8.2)\end{array}$ & $\begin{array}{l}0.014 \\
(6.3)\end{array}$ \\
\hline Port leakage & $\begin{array}{l}0.20 \\
\langle 5.9\rangle\end{array}$ & $\begin{array}{l}0.20 \\
(7.5)\end{array}$ & $\begin{array}{l}0.19 \\
(7.7)\end{array}$ & $\begin{array}{l}0.18 \\
(8.8)\end{array}$ \\
\hline B Tanket leakage & $\begin{array}{l}0.66 \\
(3.7)\end{array}$ & $\begin{array}{l}0.65 \\
(2.7)\end{array}$ & $\begin{array}{l}0.14 \\
(7.4)\end{array}$ & $\begin{array}{l}0.73 \\
(7.6)\end{array}$ \\
\hline
\end{tabular}
a) MeV per or reaction.
b) percent standard devfation. 
Table 5.5

Reaction rates and neutron balance for transport calculations with $0.15 \mathrm{~m}$ of $8 \mathrm{eO}$

\begin{tabular}{|c|c|c|c|c|}
\hline Reference point & 5 & 6 & 7 & 8 \\
\hline $\mathrm{LAAlO}_{2}$ thickness, m & 0.30 & 0.30 & 0.50 & 0.50 \\
\hline $6_{\text {Li Fraction, }} \times$ & 7.42 & 50.00 & 7.42 & 50.00 \\
\hline \multicolumn{5}{|l|}{ Reactions ${ }^{a}$} \\
\hline $6_{L i(n, T) \alpha}$ & $\begin{array}{l}1.158 \\
(0.2)\end{array}$ & $\begin{array}{l}1.217 \\
(0.9)\end{array}$ & $\begin{array}{l}1.263 \\
(0.8)\end{array}$ & $\begin{array}{l}1.276 \\
(1.2)\end{array}$ \\
\hline$T_{L i\left(a, n^{\prime} T\right) \alpha}$ & $\begin{array}{l}0.023 \\
(<.6)\end{array}$ & $\begin{array}{l}0.012 \\
\langle 2.7\rangle\end{array}$ & $\begin{array}{l}0.023 \\
(3.2)\end{array}$ & $\begin{array}{l}0.012 \\
(3.0)\end{array}$ \\
\hline$B e(n, 2 n)$ & $\begin{array}{l}0.562 \\
(1.1)\end{array}$ & $\begin{array}{l}0.569 \\
(1.4)\end{array}$ & $\begin{array}{l}0.561 \\
\{1.1\}\end{array}$ & $\begin{array}{l}0.556 \\
(1.3)\end{array}$ \\
\hline
\end{tabular}

Neutron balance ${ }^{a}$

\begin{tabular}{lrrrr} 
Target & 1.052 & 1.051 & 1.061 & 1.057 \\
$\mathrm{Be} 0$ & 0.321 & 0.318 & 0.325 & 0.315 \\
$\mathrm{LiAlO}_{2}$ & -1.179 & -1.252 & -1.290 & -1.305 \\
Port leakage & -0.057 & -0.051 & -0.056 & -0.050 \\
& $(3.8)$ & $(4.6)$ & $(4.2)$ & $(6.4)$ \\
Blanket leakage & -0.136 & -0.065 & -0.039 & -0.016 \\
& $(1.9)$ & $(3.3)$ & $(5.3)$ & $(12.9)$ \\
Remainder & 0.001 & 0.001 & 0.001 & 0.001 \\
\hline
\end{tabular}
a) ner DT reaction.
b) percent standard deviation. 
Table 5.6

Energy deposition for the

transport calculations with $0.15 \mathrm{~m}$ of $\mathrm{BeO}$

\begin{tabular}{|c|c|c|c|c|}
\hline $\begin{array}{l}\text { Reference point } \\
\mathrm{LiAlO}_{2} \text { thickness, } \mathrm{m} \\
6 \mathrm{LI} \text { Fraction, } \mathrm{X}\end{array}$ & $\begin{array}{c}5 \\
0.30 \\
7.42\end{array}$ & $\begin{array}{c}6 \\
0.30 \\
50.00\end{array}$ & $\begin{array}{c}7 \\
0.50 \\
7.42\end{array}$ & $\begin{array}{c}8 \\
0.50 \\
50.00\end{array}$ \\
\hline \multicolumn{5}{|l|}{ Energy depositeda } \\
\hline Target & $\begin{array}{l}1.81 \\
(0.6)^{\mathrm{b}}\end{array}$ & $\begin{array}{l}1.83 \\
(0.7)\end{array}$ & $\begin{array}{l}1.84 \\
(0.8)\end{array}$ & $\begin{array}{l}1.83 \\
(0.5)\end{array}$ \\
\hline $\mathrm{Be} 0$ & $\begin{array}{l}6.89 \\
(0.6)\end{array}$ & $\begin{array}{l}6.82 \\
(0.9)\end{array}$ & $\begin{array}{l}6.94 \\
(0.5)\end{array}$ & $\begin{array}{l}6.82 \\
(0.9)\end{array}$ \\
\hline $\mathrm{LIARO}_{2}$ & $\begin{array}{l}7.77 \\
(0.9)\end{array}$ & $\begin{array}{l}7.91 \\
(0.7)\end{array}$ & $\begin{array}{l}8.36 \\
(1.0)\end{array}$ & $\begin{array}{l}8.38 \\
(1.2)\end{array}$ \\
\hline SiC wall & $\begin{array}{l}0.05 \\
(6.2)\end{array}$ & $\begin{array}{l}0.04 \\
(4.5)\end{array}$ & $\begin{array}{l}0.01 \\
(7.8)\end{array}$ & $\begin{array}{l}0.01 \\
(\dot{\theta} .0\rangle\end{array}$ \\
\hline Tendons & $\begin{array}{l}0.026 \\
(5.4)\end{array}$ & $\begin{array}{l}0.024 \\
(3.8)\end{array}$ & $\begin{array}{l}0.007 \\
(7.1)\end{array}$ & $\begin{array}{l}0.006 \\
(16.5)\end{array}$ \\
\hline Port leakage & $\begin{array}{l}0.21 \\
(8.0)\end{array}$ & $\begin{array}{l}0.20 \\
(6.5)\end{array}$ & $\begin{array}{l}0.18 \\
(6.3)\end{array}$ & $\begin{array}{l}0.19 \\
(3.1)\end{array}$ \\
\hline Blanket leakage & $\begin{array}{l}0.28 \\
(4.8)\end{array}$ & $\begin{array}{l}0.26 \\
(4.3)\end{array}$ & $\begin{array}{l}0.06 \\
(8.2)\end{array}$ & $\begin{array}{l}0.06 \\
(14.6)\end{array}$ \\
\hline
\end{tabular}
a) HeV per DT reaction.
b) percent standard deviation. 
deposition in the Al/SiC tendons. The other information is provided for completeness.

The results of the elght reference point transport calcuiations form the basis for estimating the neutronic performance as a function of the three design varlables. This is discussed in the next section. 


\subsection{INITIAL OPTIMIZATION RESULTS FOR CASCAOE}

\subsubsection{Estimated Neutronic Performance.}

The neutronic performance is estimated as a function of the three design variables by successive, two point variation interpolation. In particular, the constraints in the tritium breeding ratio, the tendon heat generation rate, and the total ne:tron leakage must be determined.

The tritium breeding ratio as a function of the ${ }^{6} \mathrm{~L} 1$ fraction and the $\mathrm{LiAlO}_{2}$ blanket thickness for the case of a 0.05-m-thick BeO multipiler is shown in Fig. 5.3. Note from Table 5.3 that the tritium breeding is dominated by the contribution from ${ }^{6} \mathrm{Li}$. A contour plot of the trittum breeding ratio with $0.5 \mathrm{~m}$ of BeO is shown in Fig. 5.4 . To meet the constraint of $\mathrm{T} \geq 1.05$ requires a $\mathrm{LiAlO}_{2}$ blanket thickness greater than $\sim 0.37 \mathrm{~m}$ if the $\mathrm{Li}$ is enriched to $\sim 40 \mathrm{X}^{6} \mathrm{Li}$.

Figures 5.5 and 5.6 show the tritium breeding ratio in the $\mathrm{LiAlO}_{2}$ blanket when a 015 -m-thick Be0 multiplier is used. Here the benefit multiplier is clear. The tritium breeding ratio exceeds the minimuril required value of 1.05 over the entire range of ${ }^{6} \mathrm{LI}$ fractions and $\mathrm{LiAlO}_{2}$ blanket thickness shown. The only exception is for thin blankets with denatured $L$, 1 .e., less than $\sim 3 K^{6} \mathrm{~L}$.

As seen in the previous four figures, the tritium breeding ratio shows the same trends as discussed for the modifted HYLIFE chamber. In particular, the breeding ratio increases with increasing ${ }^{6} \mathrm{Li}$ fraction and with increasing blanket thickness. The breeding ratios were calculates by interpolating on $x_{1}$ first, then on $x_{2}$ and finally on $x_{3}$.

As indicated in Tables 5.4 and 5.6 the energy deposition in the 


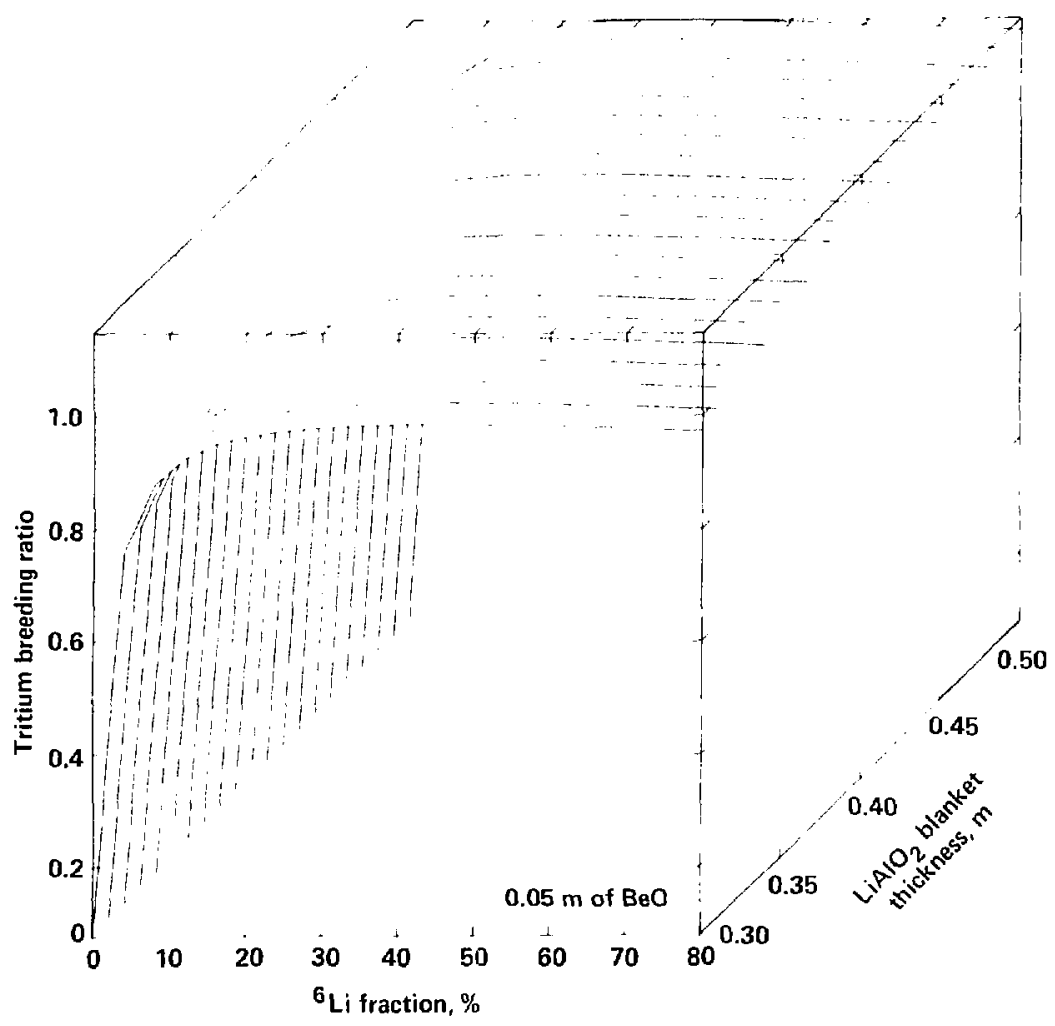

Fig. 5.3 Tritium breeding ratio as a function of $6 \mathrm{LI}$ fraction and $\mathrm{LALO}_{2}$ thickness with $0.05 \mathrm{~m}$ of $\mathrm{BeO}$. 


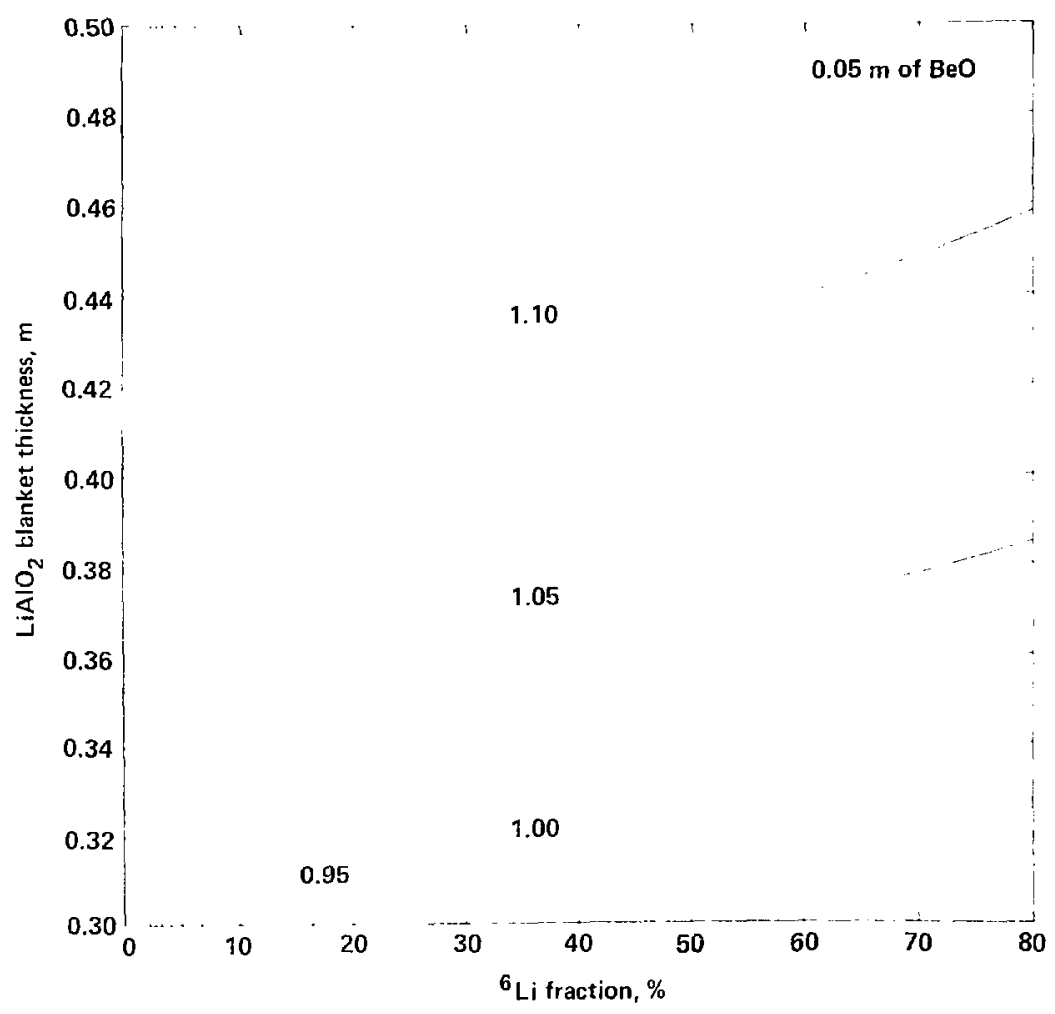

Fig. 5.4 Contour plot of tritlum breeding ratio with $0.05 \mathrm{~m}$ of Be0. The tritium breeding ratio must be greater than 1,05. 


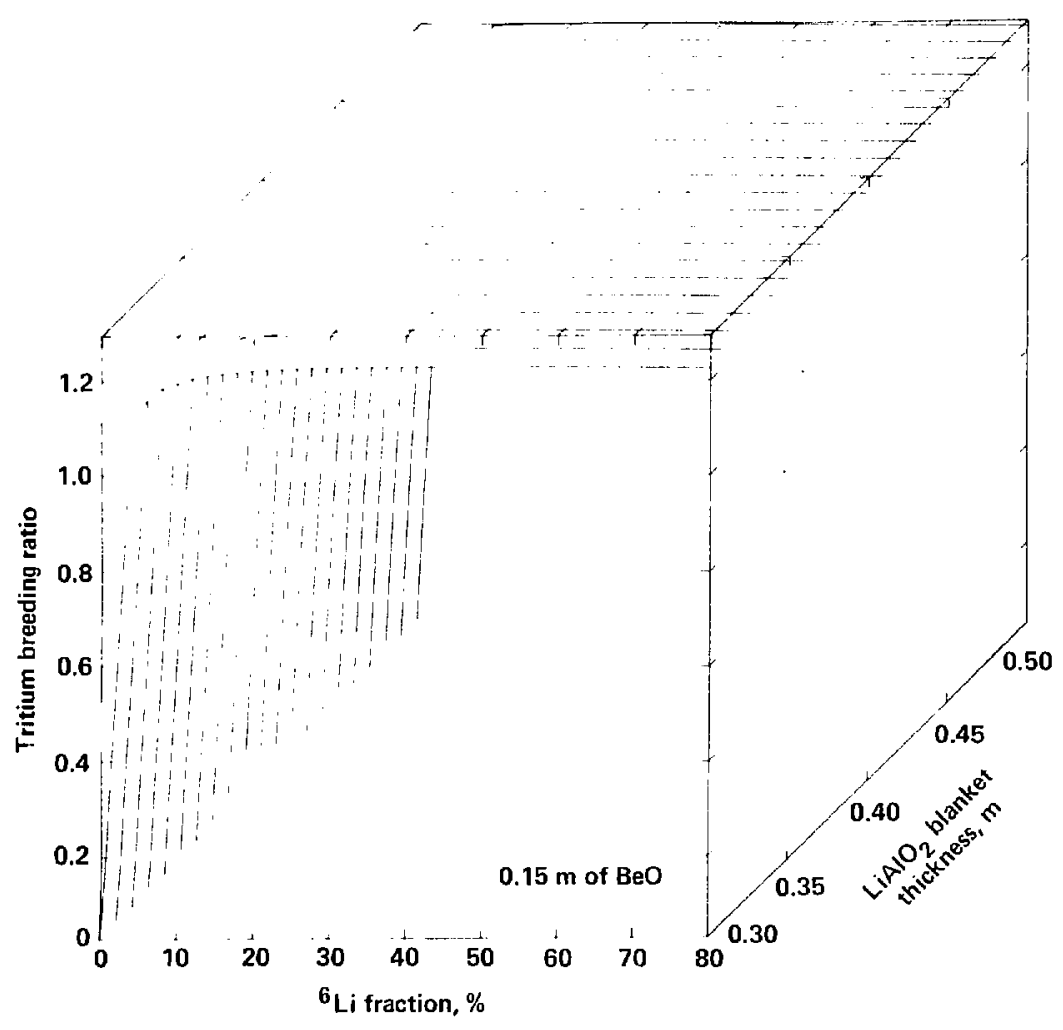

Fig. 5.5 Tritium breeding ratio as a function of ${ }^{6} \mathrm{~L}$ fraction and $\mathrm{LAlO}_{2}$ thickness with $0.15 \mathrm{~m}$ of BeO. 
$-155-$

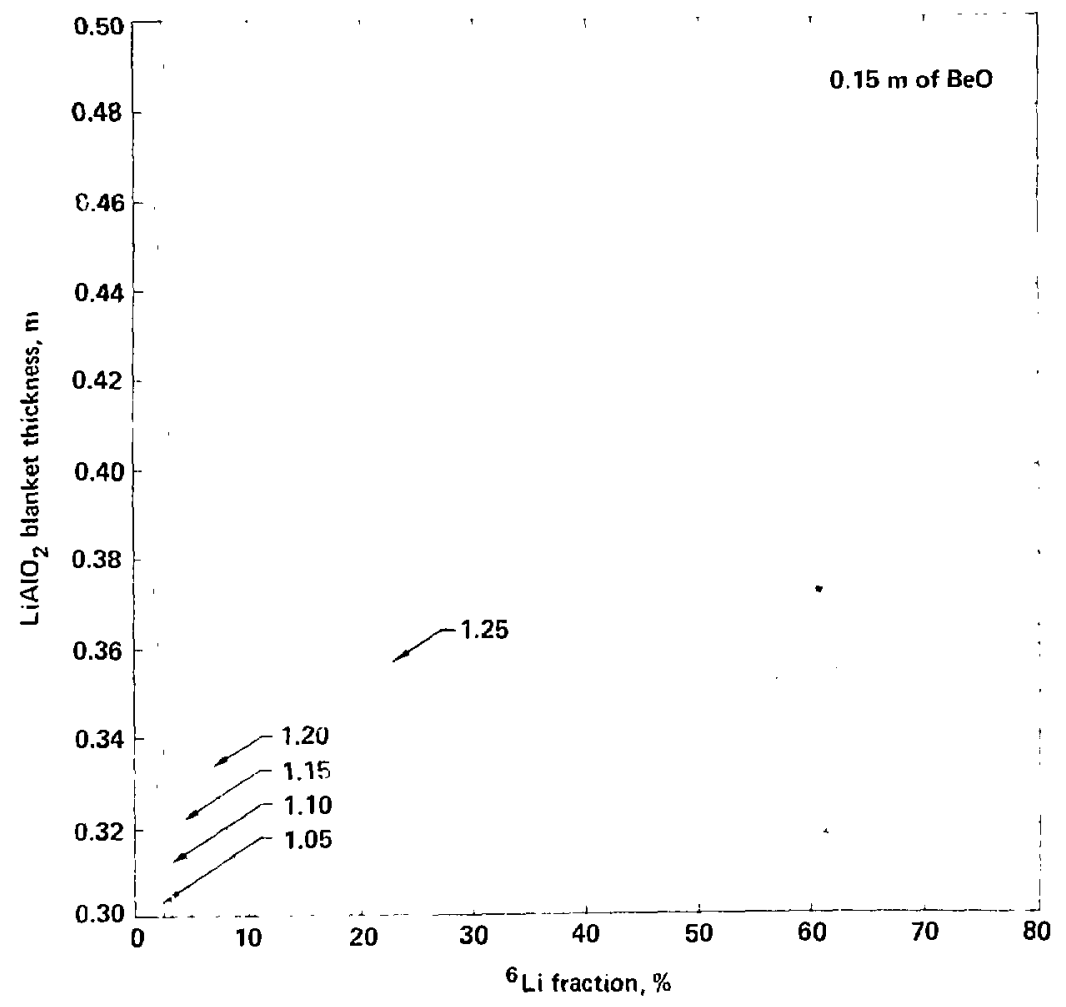

Fig. 5.6 Contour plot of tritium breeding ratio with $0.15 \mathrm{~m}$ of Be0. The tritium breeding rat 10 must be greater than 1.05 . 
Al/Sic tendons is independent of the ${ }^{6} \mathrm{Li}$ fraction. Figure 5.7 shows the heat generation rate $\left(W / \mathrm{cm}^{3}\right)$ in the tendons as a function of the BeO thickness and the $\mathrm{LiAlO}_{2}$ blanket thickness. As indicated, the heat generation rate decreases as the thickness of efther region increases.

A contour plot of the tendon heat rate is shown in Fig. 5.8. Rerall the heat rate must be $\leq 0.85 \mathrm{~W} / \mathrm{cm}^{3}$. In order to meet this constraint, the minimum required $\mathrm{LiAlO}_{2}$ thickness is $\sim 0.38 \mathrm{~m}$ with $0.05 \mathrm{~m}$ of Be0. The required thickness decreases with increasing Be0 thickness to $\sim 0.30 \mathrm{~m}$ with $0.15 \mathrm{~m}$ of Be0. The heat generation rate is calculated by first interpolating on $x_{2}$ and then on $x_{3}$.

The neutron leakage is calculated from a neutron balance with the net gain in the Be0 region and the net absorption in the $\mathrm{LiAlO}_{2}$ blanket being estimated by successive two point interpolation. That is

$$
L=1.056+N_{g}-N_{a},
$$

where

$$
\begin{aligned}
& N_{g}=\text { let neutron gain in BeO, and } \\
& N_{a}=\text { net neutron absorption in } \mathrm{L}^{1 A 2 O_{2}} .
\end{aligned}
$$

The factor of 1.056 is the number of neutrons emitted by the target per 01 reaction. It exceeds one because of $(n, 2 n)$ reactions with $D$ and $T$ in the compressed fuel zone.

The total neutron leakage as a function of the ${ }^{6} \mathrm{~L} 1$ fraction and $\mathrm{LiAlO}_{2}$ blanket thickness is shown in Figs. 5.9 and 5.10 for the case of a $0.05-m-t h i c k$ Be 0 multiplier. The leakage decreases with 


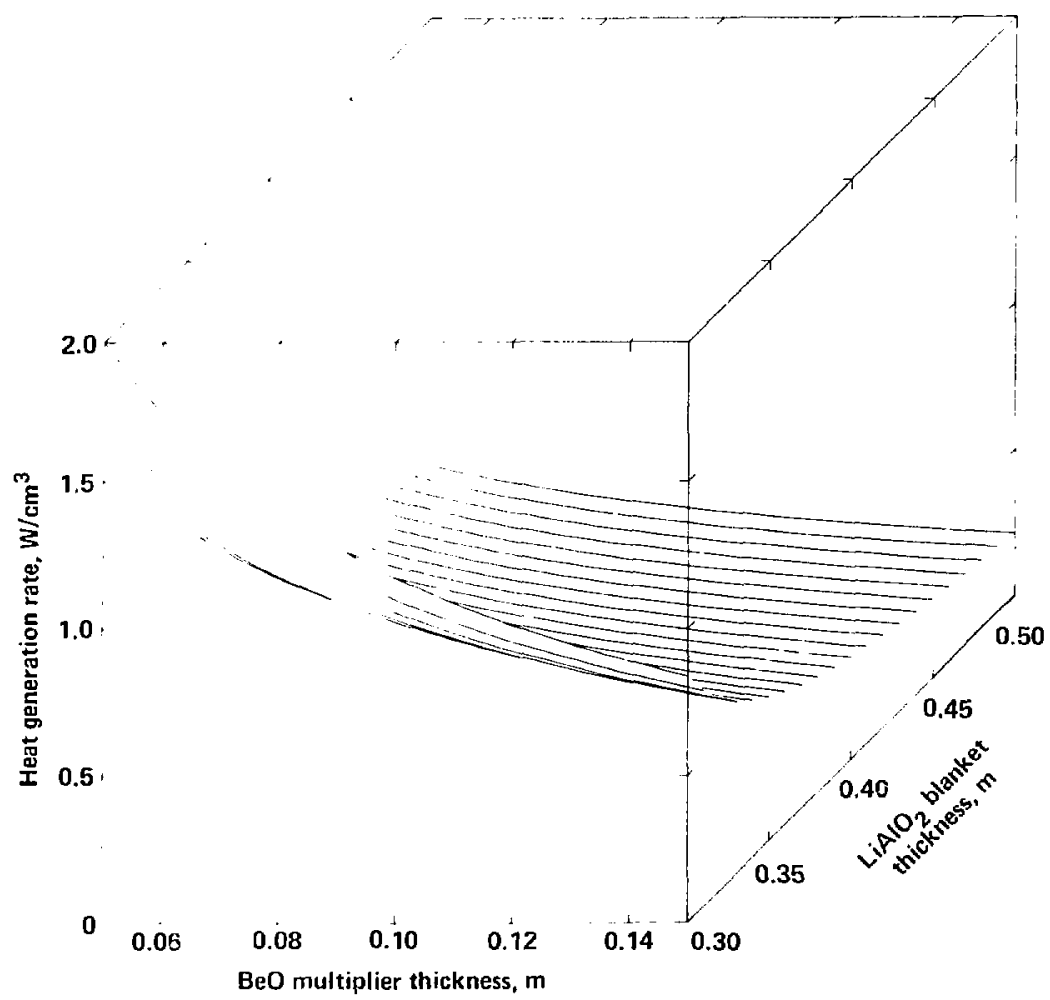

fig. 5.7 Heat generation rate in Al/SiC tendons as a function of BeO thickness and $\mathrm{LiAlO}_{2}$ thickness. The fusion power is $3000 \mathrm{MW}$. 


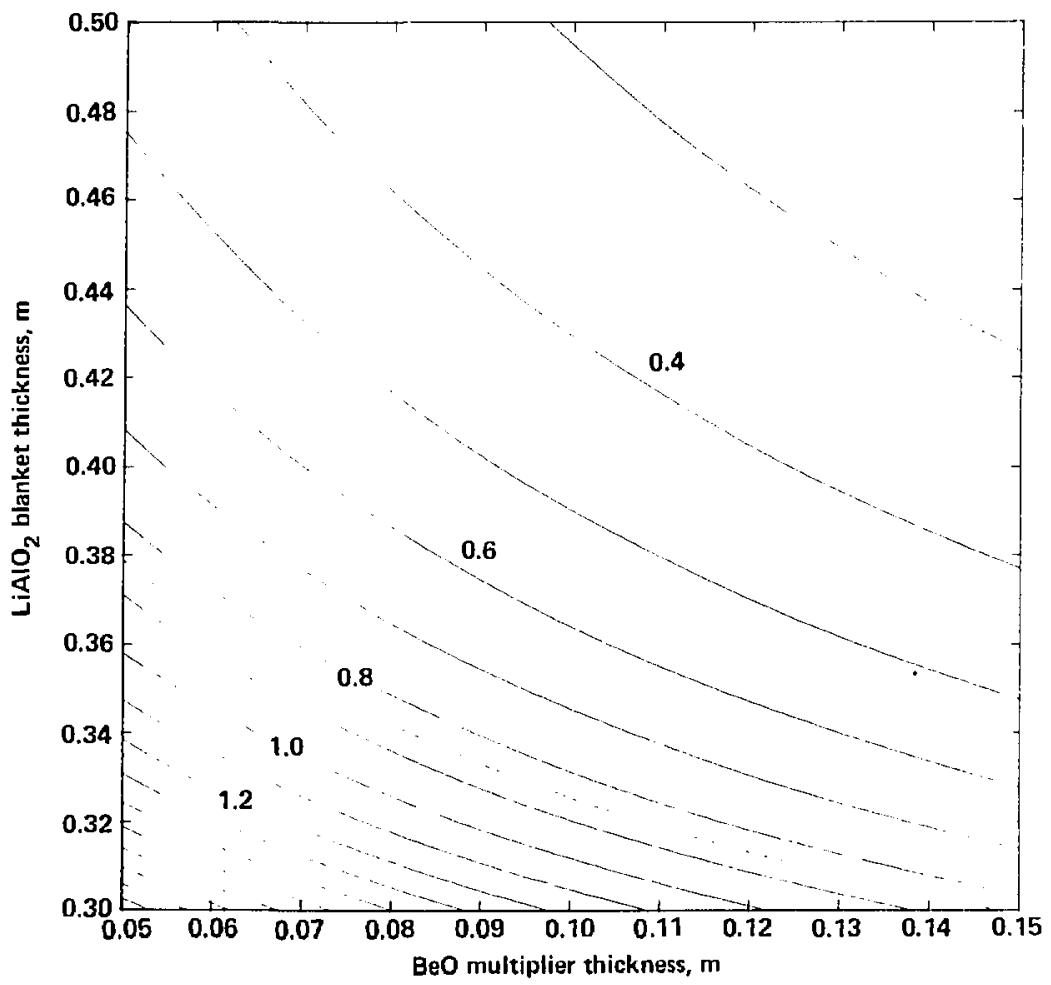

Fig. 5.d Contour plot of the heat generation rate in the tendons. The heat rate must be less than $0.85 \mathrm{~W} / \mathrm{cm}^{3}$. 


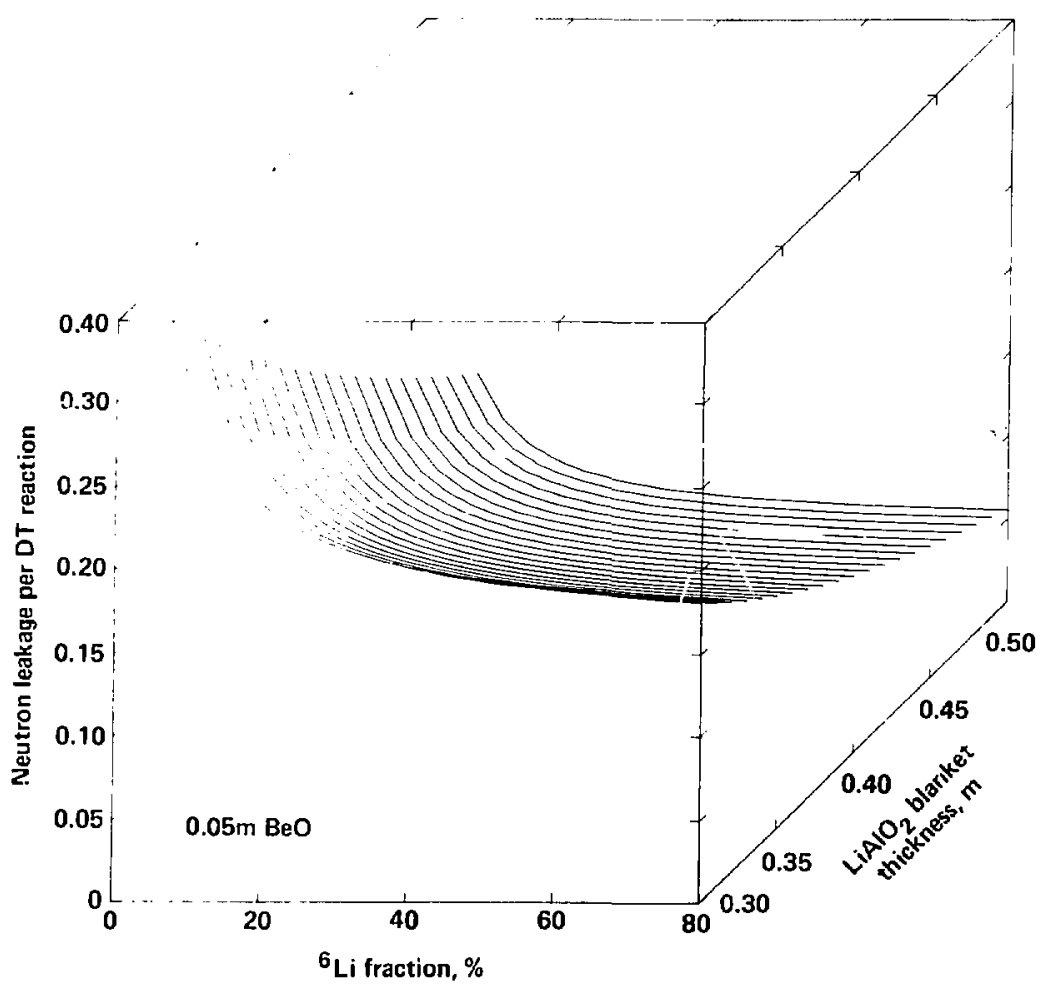

Fig. 5.9 Total neutron leakange per DT reaction as a function of ${ }_{L 1}$ fraction and $\mathrm{LARO}_{2}$ thickness with $0.05 \mathrm{~m}$ of BeO. 


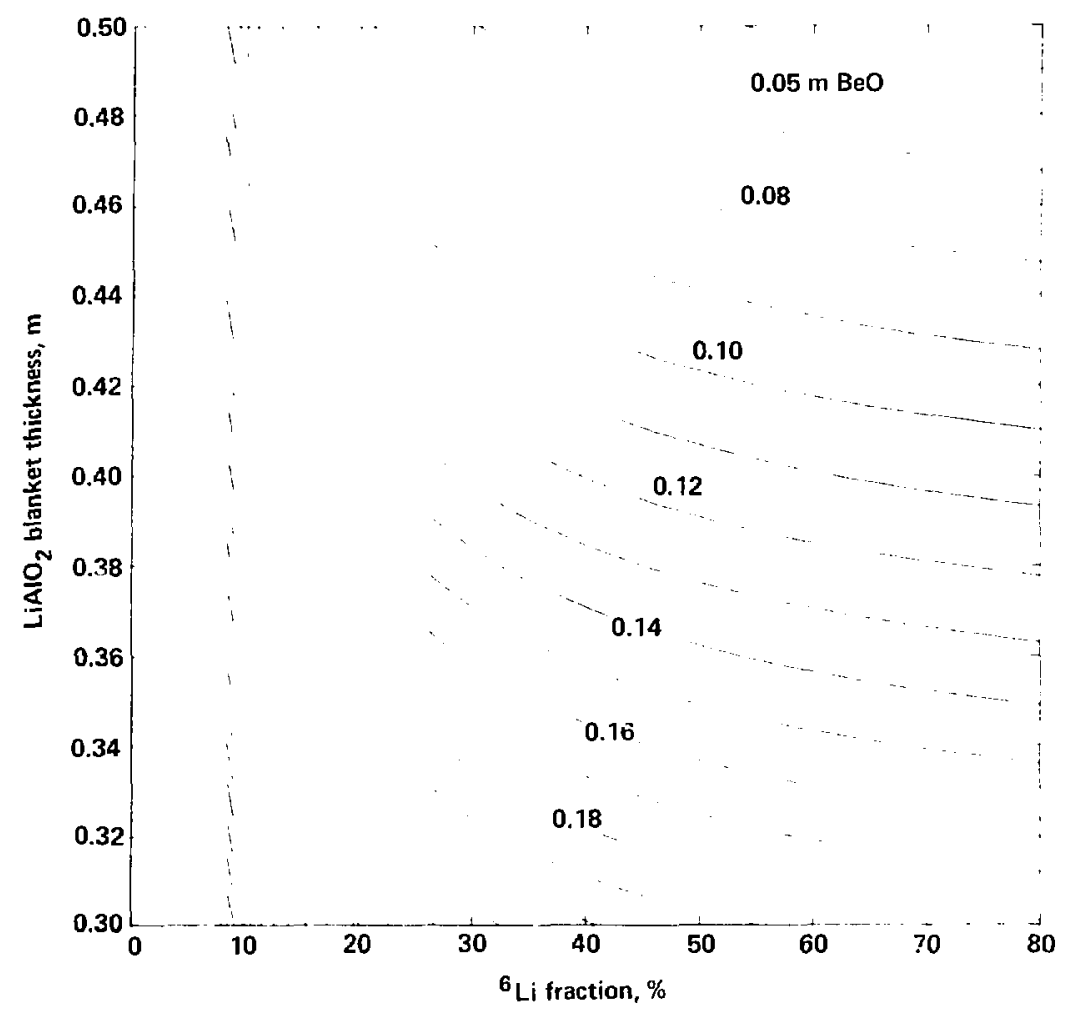

Fig. 5.10 Contour plot of neutron leakage with $0.05 \mathrm{~m}$ of Be0. The total neutron leakage is $11 \mathrm{mited}$ to 0.10 . 
increasing ${ }^{6}{ }_{L 1}$ fraction and with increasing blanket thickness since in both cases more neutrons are captured by ${ }^{6} L I$ as these varlables increase. The curves extend down to $7.42 \%{ }^{6} L 1,1 . e .$, natural 11thium. Note from Fig. 5.10, that even if the $L 1$ is enriched to $80 x$ in ${ }^{6}$ L1, a $0.41-m$-thick blanket is required to keep the neutron leakage below 0.1 per DT reaction.

Figures 5.11 and 5.12 show the neutron leakage as a function of the ${ }^{6}{ }_{\mathrm{L}}$ fraction and the $\mathrm{LIAlO}_{2}$ blanket thickness when a $0.15-m-t h i c k$ BeO multiplier is used. Note that the range of the vertical scule of Fig. 5.11 is about a factor of two smailer than in Fig. 5.9. In this case, the minimum required breeding blanket thickness decreases frum $-0.49 \mathrm{~m}$ with natural $\mathrm{Li}$ to $\sim 0.33 \mathrm{~m}$ with Li enriched to $80 \%{ }^{6} \mathrm{LI}$.

The three constraints, Eqs. $5.2,5.3$ and 5.5 are shown as a function of the ${ }^{6} \mathrm{~L} i$ fraction and the $\mathrm{L} \mathrm{AlO}_{2}$ blanket thickness for $0.05,0.10$, and $0.15 \mathrm{~m}$ of $8 \mathrm{eg}$ in Figs. 5.13,5.?4 and 5.15 , respectively. In each case it is desirable to find the minimum value of the $\mathrm{LiAlO}_{2}$ thickness such that the figure of mer $1 \mathrm{t}, \mathrm{x}_{2}+\mathrm{x}_{3}$, is minimized.

Comparing these three figures gives an indication of how the constraints vary as a function of the Be0 thickness. The minimum $\mathrm{LiAlO}_{2}$ blanket thickness set by the tritium breeding ratio constraint decreases with increasing Beo thickness. The same trend applies to the heat generation rate constraint.

Note that for the neutron leakage constraint, the minimum $\mathrm{LiARO}_{2}$ Dlanket thickness is greater at $0.10 \mathrm{~m}$ of $8 \mathrm{eO}$ than at 0.05 or $0.15 \mathrm{~m}$. This rise and fall in the required blanket thickness is 


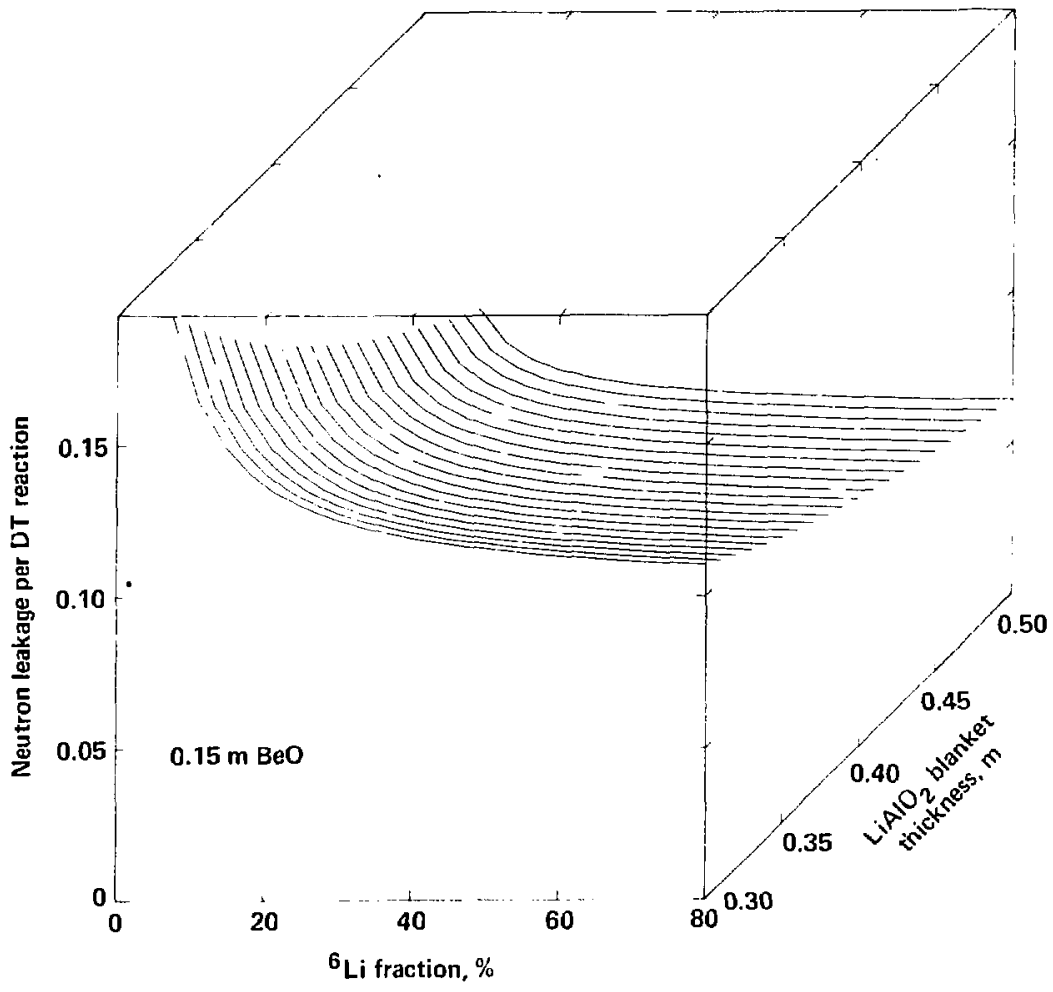

Fig. 5.11 Total neutron leakage per OT reaction as a function of ${ }^{6} \mathrm{~L}$ fraction and $\mathrm{LiAlO}_{2}$ thickness with $0.15 \mathrm{~m}$ of $\mathrm{BeO}$. 


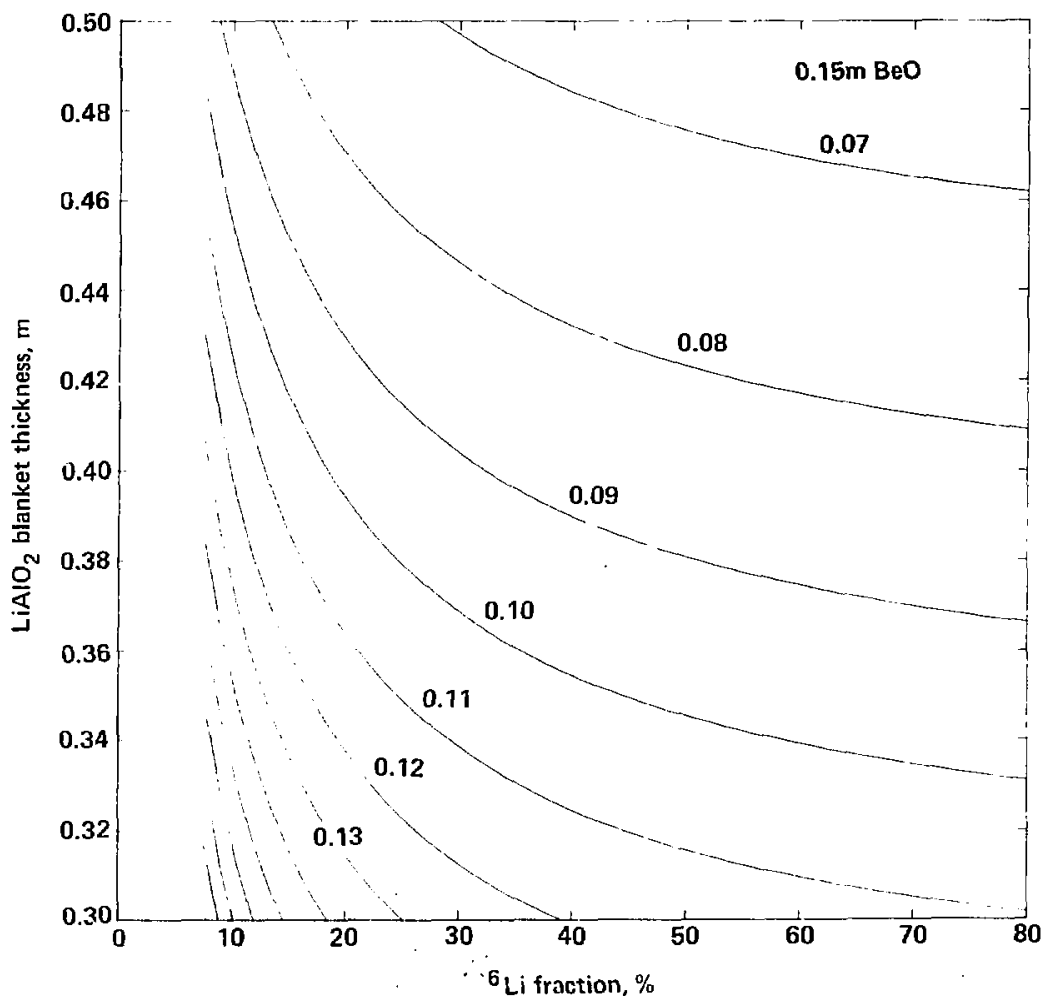

Fig. 5.12 Contour plot of neutron leakage with $0.15 \mathrm{~m}$ of Be0. The total neutron leakage is limited to 0.10 . 


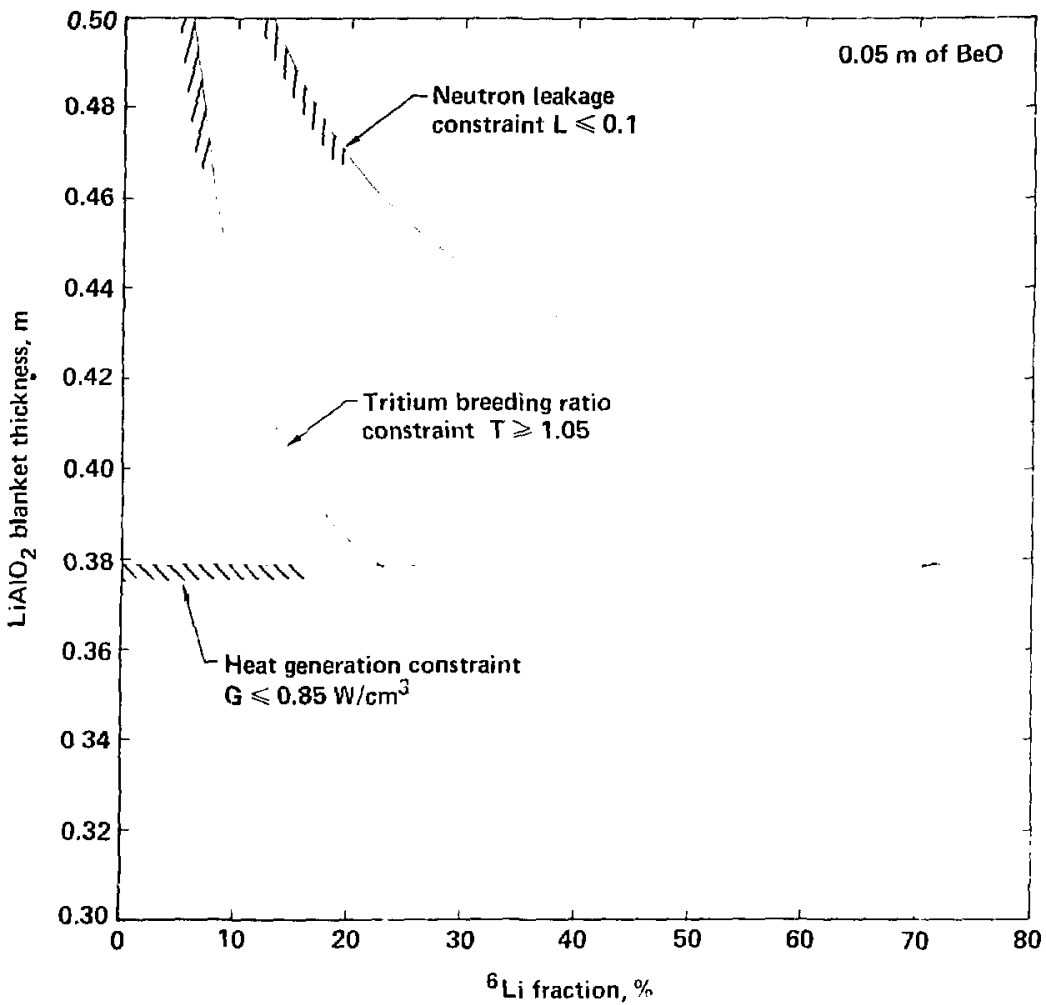

Fig. 5.13 Three constraints as a function of $6: 1$ fraction and $\mathrm{LARO}_{2}$ thickness with $0.05 \mathrm{~m}$ of BeO. 


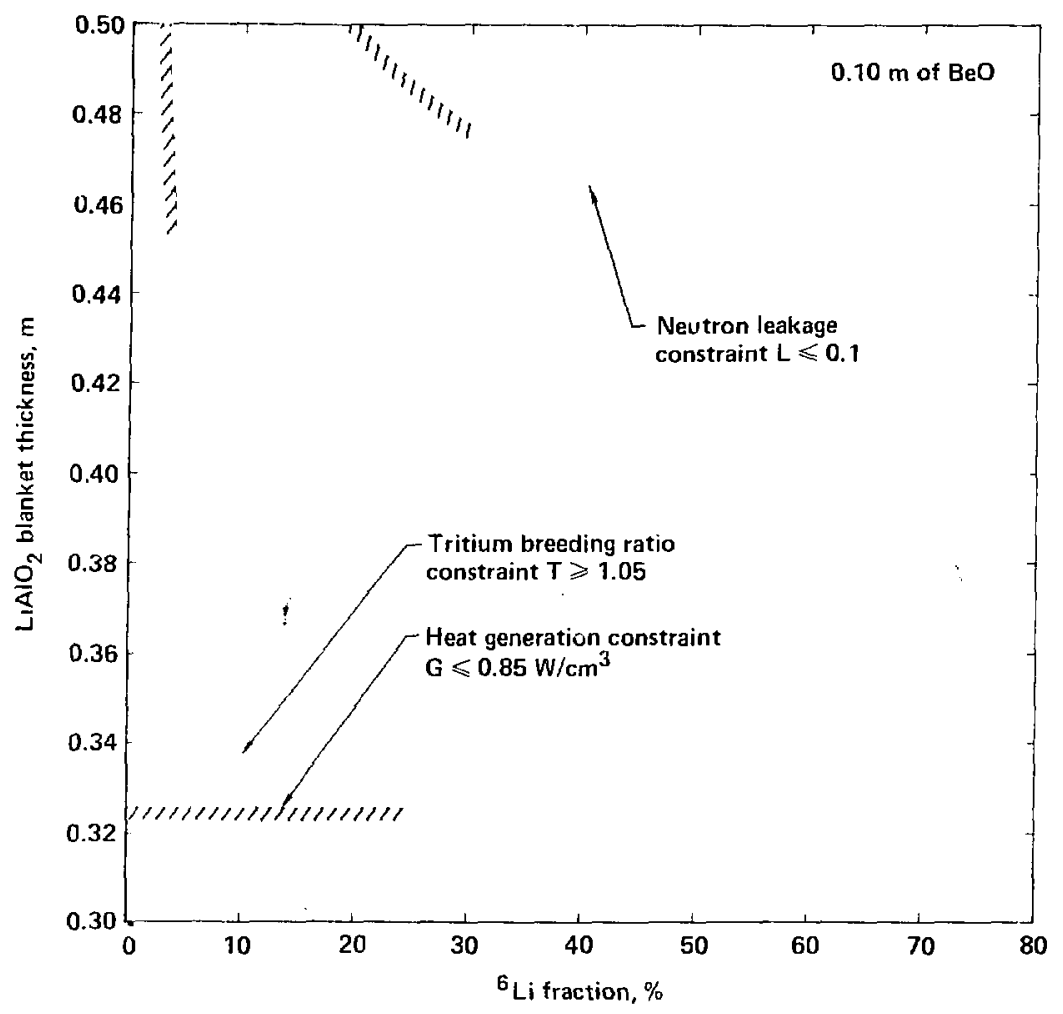

Fig. 5.14 Three constraints as a function of ${ }^{6} L$ fraction and $\mathrm{LARO}_{2}$ Lhickness with $0.10 \mathrm{~m}$ of BeO. 


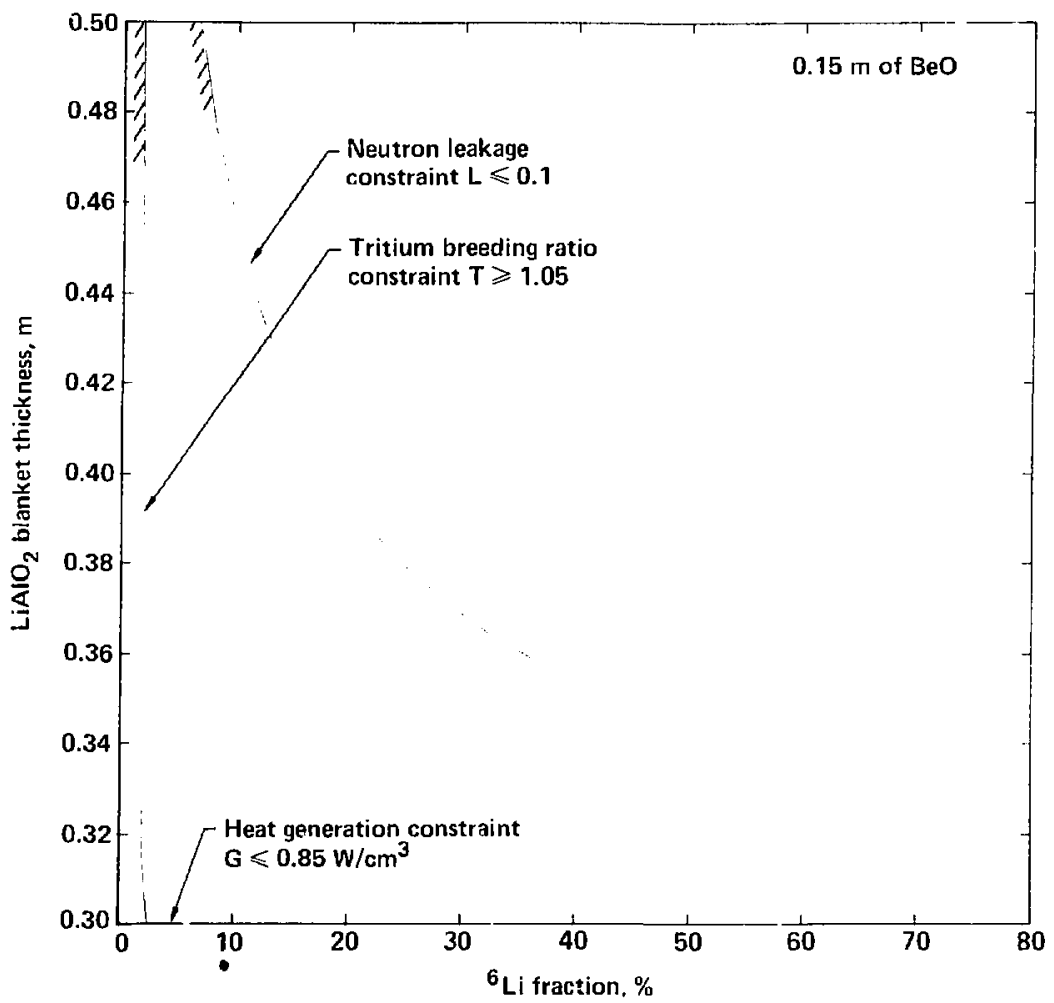

Fig. 5.15 inree constraints as a function of ${ }^{6} L$ fraction and $\mathrm{LiAlO}_{2}$ thickness with $0.15 \mathrm{~m}$ of BeO. 
related to the two modes of neutron leakage. As indicated in Tables 5.3 and 5.5, increasing the Beo thickness increases the neutron leakage through the ports and decreases the blankei leakage. For a blanket highly enriched in ${ }^{6} \mathrm{i}$, the increase in port leakage can exceed the decrease in blank:t Teakige. As a result a thicker breeding blanket is required to maintain a collstant total leakage rate of 0.1 per DT reaction.

In al) three figures the limiting constrint is the neutron leakage constraint. Assuming a upper $11 \mathrm{mit}$ of $80 \%$ on the ${ }^{6} \mathrm{Lt}_{1}$ enrichment, the minimum $\mathrm{L}_{1 \mathrm{AlO}}{ }_{2}$ blanket thicknesses are $0.41,0.44$, and $0.33 \mathrm{~m}$ fur the $0.05,0.10$, and $0.15 \mathrm{~m}$ thick Be0 cases, respectively.

\section{3 .2 Optimal Design Point.}

The direct search algorithm gives the optimal design point as $63.6 \%{ }^{6} \mathrm{Li}, 0.397 \mathrm{~m}$ of $\mathrm{LtAlO}_{2}$ and $0.040 \mathrm{~m}$ of $\mathrm{BeO}$. This result is shown graphically in figs. 5.16 and 5.17 . Figure 5.16 shows the minimum blanket thickness as set by the neutron leakage constraint and the heat generation constraint as a function of the Beo thickness. for less than $0.04 \mathrm{~m}$ of $3 \mathrm{e} 0$ the heat generation rate is the limiting constraints Between 0.04 and $0.16 \mathrm{~m}$ of Be0, neutron leakage is the limiting canstraint. Beyond $0.10 \mathrm{~m}$, the L1ARO $\mathrm{L}_{2}$ blanket thickness is again limited by the heat generation rate.

Also shown in Fig. 5.16 is the figure of merit, 1.e., the total blanket thickness. Note that there are two 'ocal minima, one at $0.04 \mathrm{~m}$ of $\mathrm{BeO}$ and the other at $0.16 \mathrm{~m}$. The minima at $0.04 \mathrm{~m}$ however, 15 the lower of the two.

The constraints as a function of the ${ }^{6} L 1$ fraction and the 


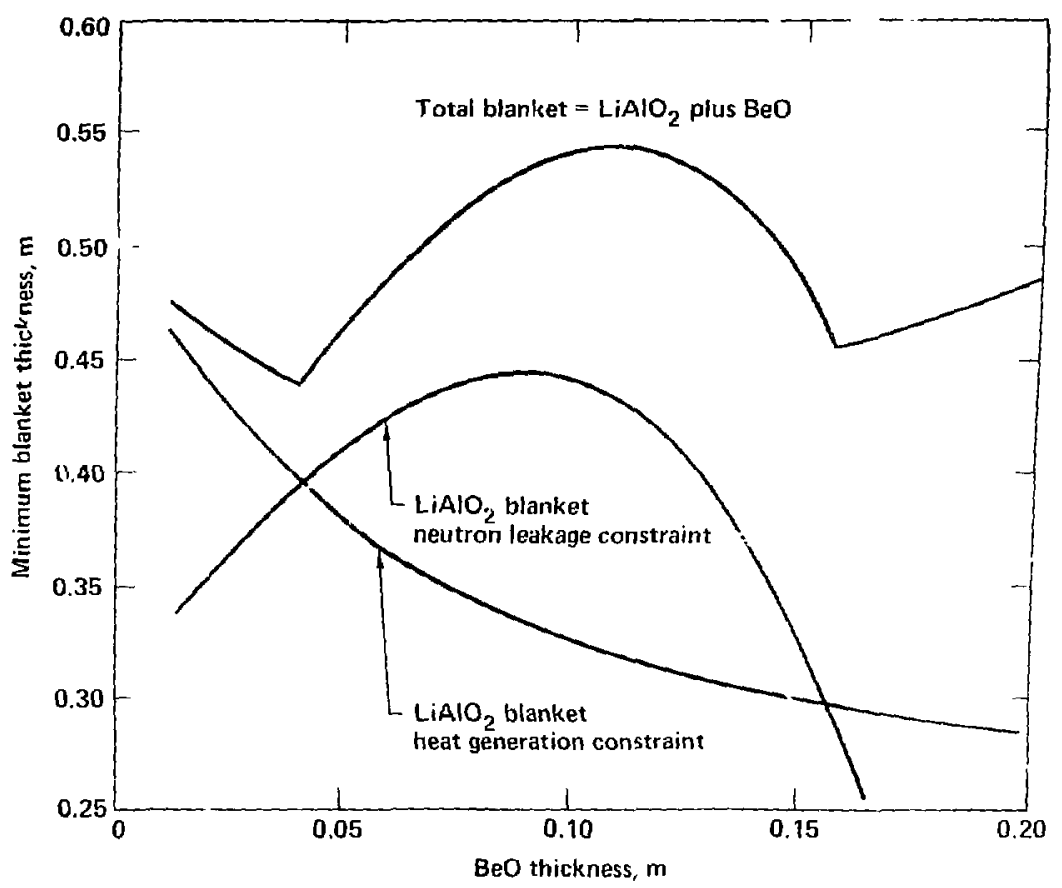

Fig. 5.16 Minimum blanket thickness as a function of Be0 thickness.

The lower curves show the minimun L $1 \mathrm{AlO}_{2}$ thickness as set by the neutron leakage anc heat rate constraints. The top curve is the total blanket thickness including the Beo thickness. 
$\mathrm{LiARO}_{2}$ thickness are shown in Fig. 5.17 for the optima $10.04 \mathrm{~m}$ of Beo. Note again how the optimal design point lies at the intersection of the neutron leakage and heat generation rate constraints. Clearly higher ${ }^{6} \mathrm{~L} f$ enrichments give the same minimum thickness since the heat rate is independent of this variable. The minimum acceptable ${ }^{6} \mathrm{~L}$ f fraction, 63.6X. is chosen from a resource consideration.

\subsubsection{Comparison to transport calculation at the optimal point.}

An additional neutron transport calculation was carried out at $63.6 \%{ }^{6} \mathrm{~L}, 0.40 \mathrm{~m}$ of $\mathrm{L}_{1.4 \mathrm{AlO}_{2}}$ and $0.04 \mathrm{~m}$ of $\mathrm{Be} 0$. The results are compared to the estimated results at the optimal point in rable 5.7. The estimated tritlum breeding ratio is $\sim 3 \%$ higher than the TART resuit and the estimated neutron leakage is low by $\sim 6 \%$. While these are acceptable differences, heat generation rate in the Al/SiC tendons is actually $22 \%$ ing gher than the estimated result.

In the next section an impraved estimate of the localion of the optimal design point is macis based on a new estimate o the tendon heat generation rate as a funcition of the $\mathrm{L}^{\mathrm{AlOO}} \mathrm{O}_{2}$ and BeO thickness. 


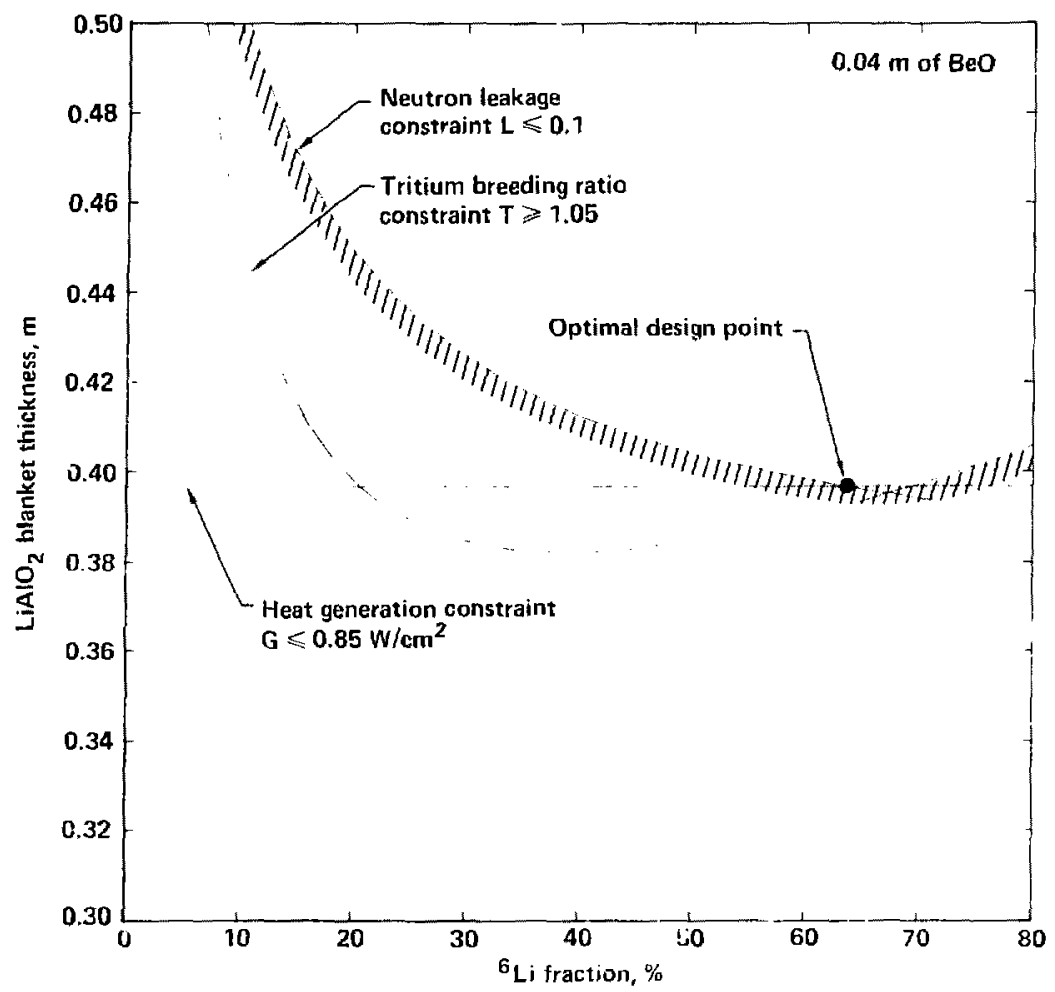

Fig. 5.17 First estimate of the location of the optimal design point. The point lies at the intersection of the neutron leakage and heat generation rate constraints. 


\section{Table 5.7}

Comparison of neutronic performance at $x_{1}=63.6 \%, x_{2}=0.40 \mathrm{~m}$, and $x_{3}=0.04 \mathrm{~m}$

\begin{tabular}{|c|c|c|}
\hline Parameter ${ }^{a}$ & TART & Estimated \\
\hline${ }^{6} L i(n, T) \alpha$ & $0.985(1.3)^{b}$ & 1.021 \\
\hline${ }^{7} L 1\left(n, n^{\prime} T\right) \alpha$ & $0.032(2.0)$ & 0.032 \\
\hline Tritium breeding ratio & 1.017 & 1.053 \\
\hline Total neutron leakage & $0.106(3.0)$ & 0.100 \\
\hline $\begin{array}{l}\text { Energy deposited in } \\
\text { tendons, MeV }\end{array}$ & $0.031(4.0)$ & 0.025 \\
\hline
\end{tabular}
a) per 0T reaction.
b) percent standard deviation. 


\subsection{IMPROVED ESTIMATE OF LOCATION OF OPTIMUM}

As indicated in the previous section, there is a significant difference between the estimated heat generation rate in ihe $\mathrm{Al} / \mathrm{SiC}$ tendons and the results of the neutron transport calcilation. It is postulated that this difference is largely due to the fact that a significant fraction of the energy deposited in the Al/SiC tendons is photon energy that originates in the $\mathrm{LiAlO}_{2}$ blanket. The break down is given in Tables 5.8 and 5.9. The variational interpolation formula used to predict the energy deposition in the tendons only accounts for variations in the neutron flux in that region. It does not arrount for variations in the photon source jyacents region and tı. ansport of those photons into the teridons.

An alternate approach is therefore used to estimate the heat rate in the tendons as a function of the $\mathrm{BeO}$ and $\mathrm{LiAlO}_{2}$ blanket thickresses. It is assumed that the heat generation rate deriecses exponentially with the thickness of $8 \mathrm{eO}$ and with the thickness of $\mathrm{L} \mathrm{AlOO}_{2}$. That is

$$
E=E_{0} \exp \left(-\mu_{2} x_{2}\right) \exp \left(-\mu_{3} x_{3}\right)
$$

there

$E=$ energy deposition in the $A 2 / S i C$ tendons, MeV, $E_{0}=$ energy deposition with no blanket, MeV, $\mu_{2}=$ attenuation coefficient for $L 1 . \mathrm{LO}_{2}$ thickness, $\mathrm{m}^{-1}$, and $\mu_{3}=$ attenuation coeffictent for Be0 thickness, $\mathrm{m}^{-1}$. Using the energy deposition results given in rables 5.4 and 5.6 


\section{Table 5.8}

Photon energy source and deposition in $\mathrm{Al} / \mathrm{S} I \mathrm{C}$ tendons with $0.05 \mathrm{~m}$ of Beo.

$\begin{array}{lcccc}\text { Reference point } & 1 & 2 & 3 & 4 \\ \mathrm{LIALO}_{2} \text { thickness, in } & n .30 & 0.30 & 0.50 & 0.50 \\ 6 \mathrm{~L} 1 \text { Fraction, } \% & 7.42 & 50.00 & 7.42 & 50.00\end{array}$

\begin{tabular}{|c|c|c|c|}
\hline Proton source ${ }^{a}$ & 0.028 & 0.039 & 0.006 \\
\hline
\end{tabular}

Photon deposition ${ }^{a}$

0.043

0.043

0.010

0.012

Photon/Total ${ }^{b}$

0.73

0.73

0.77

0.86
a) HeV per DT reaction.
b) Ratio of photon energy deposition to total energy deposition. Total deposition given in Table 5.4. 
Table 5.9

Photon energy source and deposition in

Al/SiC teidons with $0.15 \mathrm{~m}$ of $\mathrm{BeO}$.

$\begin{array}{lcccr}\text { Reference point } & 5 & 6 & 7 & 8 \\ \text { LiAlO }_{2} \text { thlckness, om } & 0.30 & 0.30 & 0.50 & 0.50 \\ 6_{\text {Li fraction, X }} & 7.42 & 50.00 & 7.42 & 50.00\end{array}$

Photon source ${ }^{a}$

0.013

0.007

0.006

0.003

Photon deposition

0.021

U. 019

0.006

0.005

Photon/Tota $1^{b}$

0.81

0.79

0.86

0.8 :

a) MeV per OT reaction.

b) Ratio of photon energy deposition to total energy deposition. Total deposition given in Table 5.6. 
the following system of equations can be written,

$$
\begin{aligned}
& 0.059=E_{0} \exp \left(-0.3 \mu_{2}\right) \exp \left(-0.05 r_{3}\right), \\
& 0.014=E_{0} \exp \left(-0.5 \mu_{2}\right) \exp \left(-0.05 \mu_{3}\right) . \\
& 0.025=E_{0} \exp \left(-0.3 \mu_{2}\right) \exp \left(-0.15 \mu_{3}\right) .
\end{aligned}
$$

Solving for the three unknowns and substituting into Eq. 5.8 gives

$$
E=0.827 \exp \left(-7.37 x_{2}\right) \exp \left(-8.59 x_{3}\right)
$$

Using this expression, the predicted energy deposition for the optimal design point of $x_{2}=0.40 \mathrm{~m}$ and $x_{3}=0.04 \mathrm{~m}$ is $0.031 \mathrm{MeV}$ or $1.03 \mathrm{~W} / \mathrm{cm}^{3}$. Hence at this particular point the new estimate is quite accurate.

The hedt generation rate in the tendon as a function of the BeO multiplier thickness and $\mathrm{LAAlO}_{2}$ thlckness is shown in Figs. 5.18 and 5.19. Note that the surface in Fig. 5.18 is somewhat flatter than the earlier estimate silown in Fig. 5.7.

The optimization problem was rerun, using the exponential estimate for tho ieat generation rate in the tendons. The optimal design point in this case is $34.2 \mathrm{X}^{6} \mathrm{~L} 1,0.124 \mathrm{~m}$ of $\mathrm{LAAlO}_{2}$, and $0.042 \mathrm{~m}$ of BeO. The constraints and location, ff the optimal design point for this case are shown in Fig. 5.20

A final transfort calculation was carried out at the new optimal point. The results are compared to the estimated results in. Table 5.10. In this case the agreement is close for all the relevant parameters. 


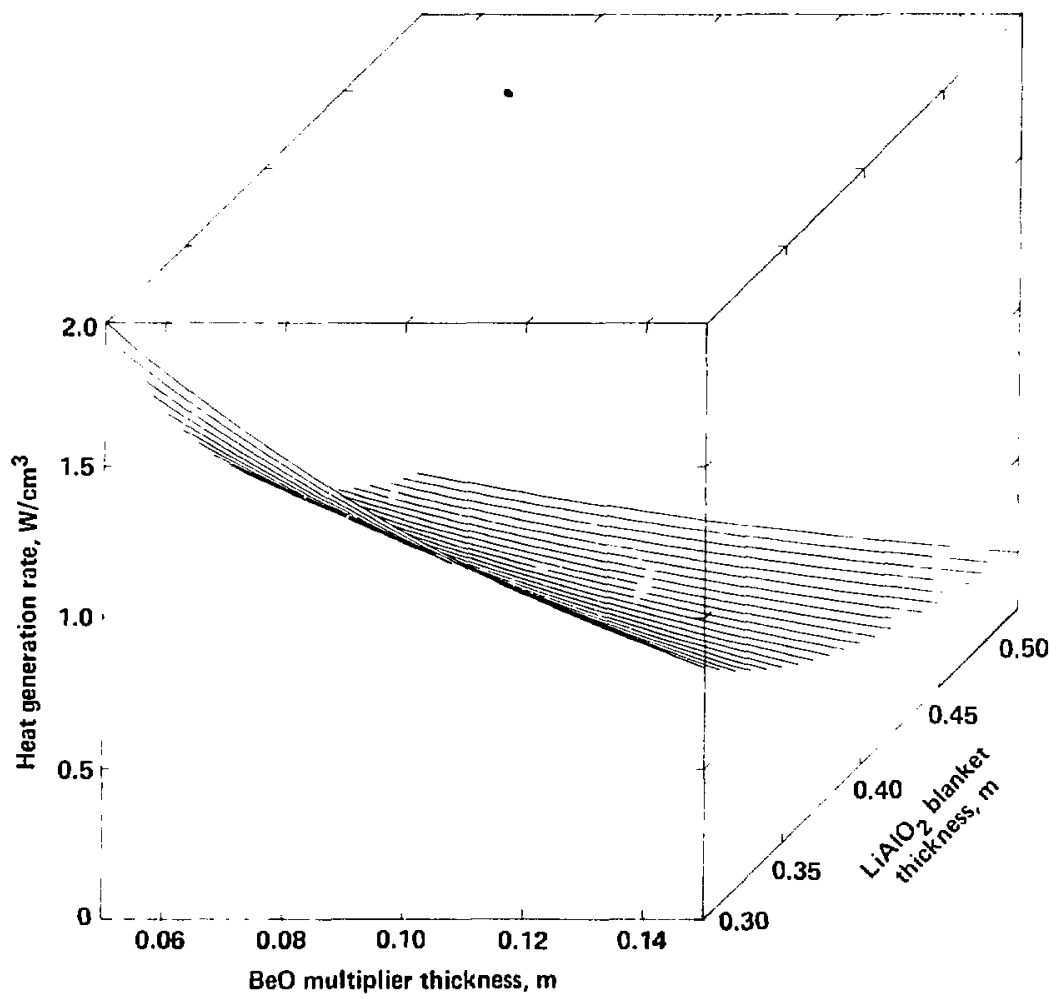

Fig. 5.18 New estimate of heat generation rate in Al/SiC tendons as a function of BeO thickness and $\mathrm{LiARO}_{2}$ thickness. 


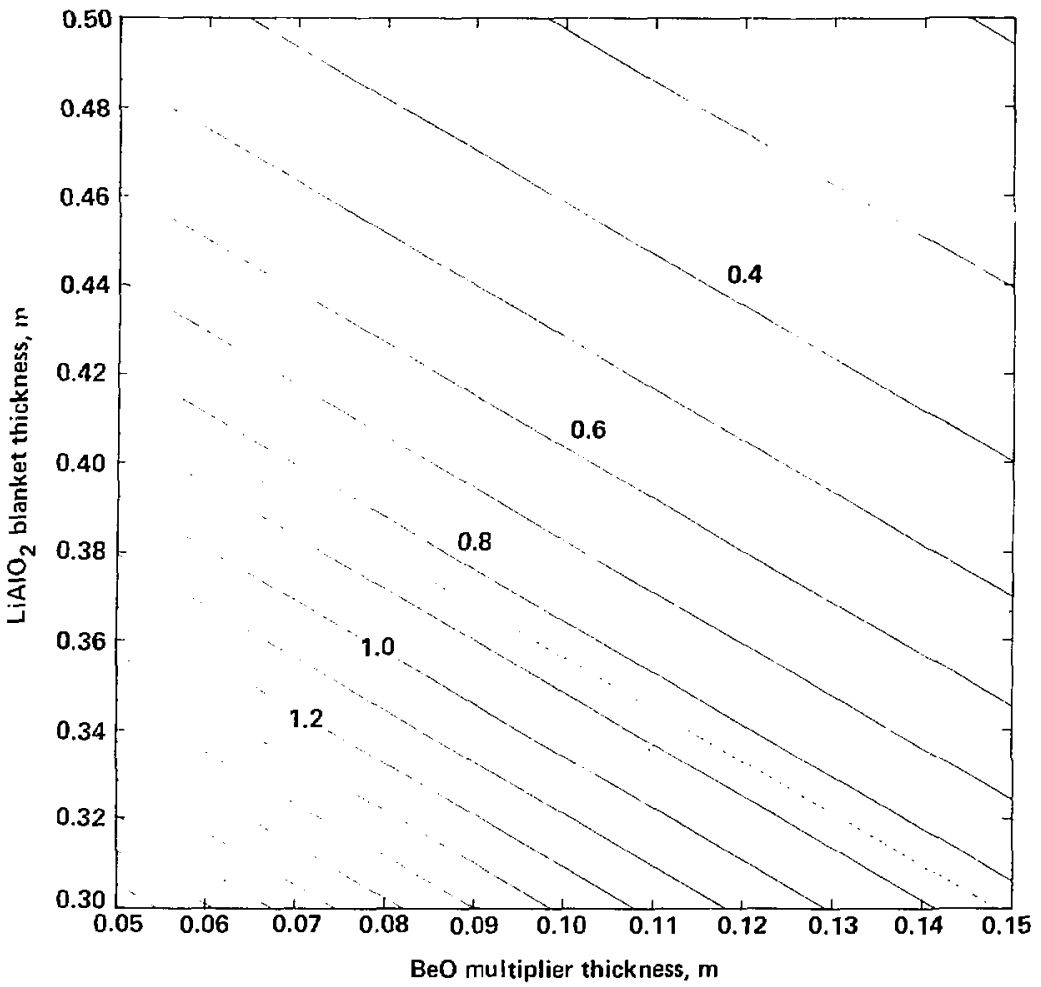

fig. 5.19 Contour plot of new heat generation rate. 


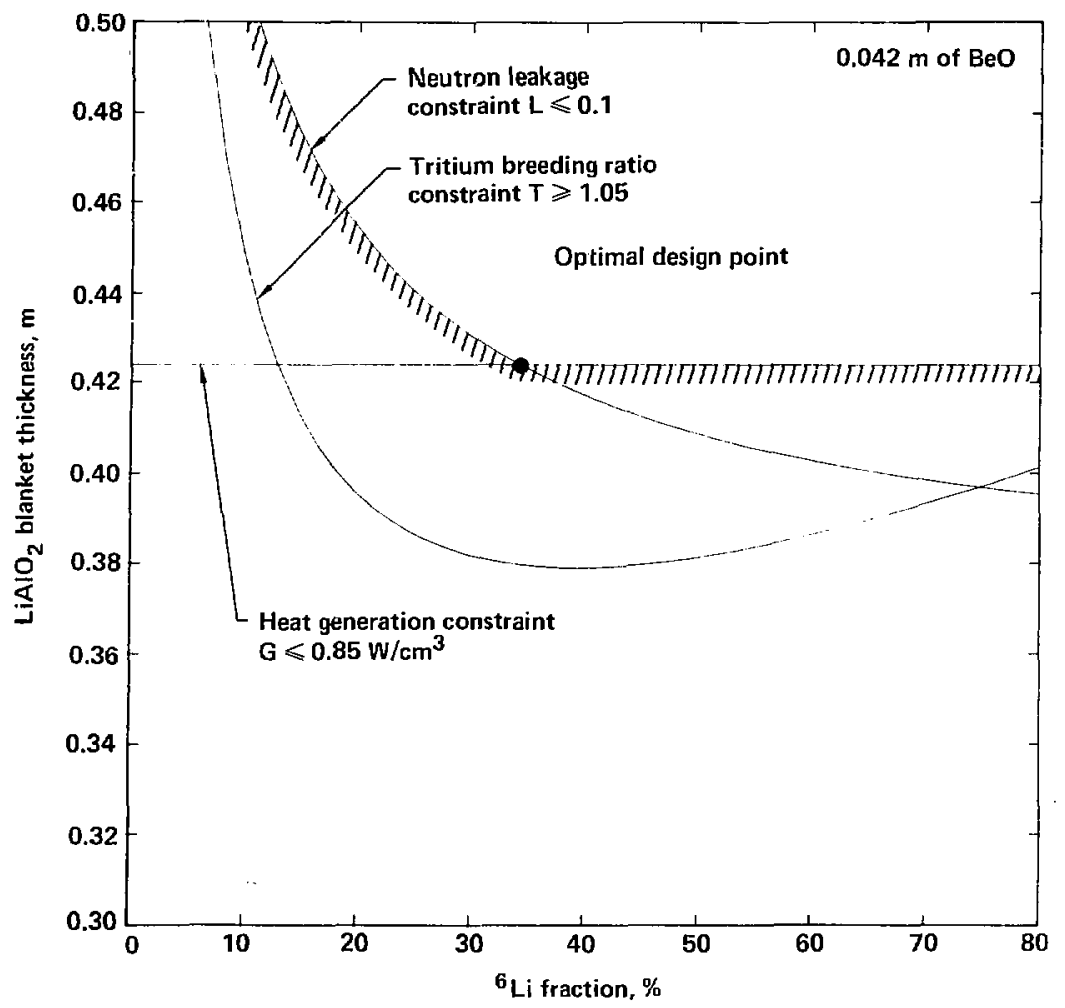

Fig. 5.2n Final estimate of location of optimal design point. 
Table 5.10

Comparison of neutronic performance at

$x_{1}=34.2 \%, x_{2}=0.424 \mathrm{~m}$, and $x_{3}=0.042 \mathrm{~m}$.

Parameter

TART

Estimated

$\left.{ }^{6} \operatorname{Lin}, T\right) \alpha$

$1.019(1.0)^{b}$

1.029

$T_{\operatorname{Li}\left(n, n^{\prime} T\right) \alpha}$

$0.040\langle 1.1\}$

0.057

Titium breeding ratio

1.059

1.086

Total neutron leakage

$0.097(3.7)$

0.100

Energy deposited in

$0.024(3.0)$

0.025

tendons, MeV
a) per ot reaction.
b) percent standard deviation. 


\subsection{SUMMARY}

In sumary, the Cascade chamber can be designed with a $\mathrm{LIAlO}_{2}$ breeding blanket if a Beo neutron multiplier is used. The configuration that minimized the total blanket thickness is $0.042 \mathrm{~m}$ of BeO followed by $0.424 \mathrm{~m}$ of $\mathrm{L}^{1 \mathrm{AlO}_{2}}$. The $\mathrm{L} 1$ must be enriched to at least $34.2 \%$ in ${ }^{6} \mathrm{Li}$.

Since the blanket is a pebble bed, the actual thickness is the erfective thickness divided by the pebble packing fraction. Assuming a 50\% packing fraction gives an actual tatal blanket thickness of $0.93 \mathrm{~m}$. 


\section{CONCLUSIONS AND RECOMMENDATIONS FOR FUTURE HORK}

\subsection{SUMMARY AND CONCLUSIONS}

Optimal blanket design is a key element in effective fusion reactor design. A methology has been developed to systematically optimize the blanket design as a function of several variables. The optimization proilem consists of four essential elements: the figure of merit for the particular reactor concept, a technique for estimating the neutronic performance as a function of the selected design varlables, constraints on both the design variables and the neutronic performance, and a method for optimizing the figure of merit subject to the constraints.

In the method presented, the neutronic performance is estimated using variational interpolation. By successive interpolations, the neutronic performance can be estimated as a function of several design variables based on a limited number of reference point, neutron transport calculations. Since only forward flux solutions are required for the interpolation, any number of neutronic characteristics can be estimated based on the same reference point transport calculations. The applicabllity of this approach has been demonstrated in the optimization of two inertial conficement fusion reactor concepts, one as a function of two variables and the second as a function of three variables.

The variational interpolation approach should not be used indiscriminately. If the reference point results vary linearly with one or more of the design varlables, it is senseless to use a 
nonlinear interpolation. Also, with the three point interpolation, care must be taken to check for singularitles within the range of interest. Where possible, it is advisable to relate the variational results to known boundary or continuity conditions. The neutron balance method is an example of this approach.

The optimization algorithm employed in this work is a direct search, nonlinear simplex method. The method seeks to rilnimize a figure of merit by comparing its value at several points and selecting a new point based on the results of the comparison. The method was found to work quite efficiently. Even with convergencs parameters $c=\delta=10^{-6}$, the optimum was generally found with less than 200 iterations. (To prevent the possiblity of an endless search, the maximum number of iterations is specifice in the input file.) Hundreds of iterations were typically completed in less thar. a second of CRAY-1 CPU time. In a typical problem, each iteration involved calculating several neutronic characteristics using successive variational interpolation, and then calculating a figure of merit that depends on the neutronic results.

It was found that graphical display of the constraints and figure of merit was very useful in understanding the factors determining to the location of the minimum. In addition, a visual display can reveal a nonunique minimum as in Fig. 5.20.

The optimization methodology was applied to two different ICF reactor concepts. The first optimization problem involved a modification to the HYLIFE concept. The object was to increase the fusion energy multiplication factor and thus reduce the plant capital cost per unit of net electric power. By reducing the tritlum breeding 
ratio and capturing more neutrons in a manganese stee 1 , the energy multiplication factor was increased by $22 \%$ and the plant cost per kWe reduced by $12 \%$.

The two design variables in this problem were the ${ }^{6} L$ fraction in lithium and the effective thickness of the lithium blanket. Constraints were imposed on the minimum tritium breeding ratio and a maximum displacement damage rate in the first structural wall. The optimal design point was found to be slightly less than $0.1 \%$ of ${ }^{6} 1$ in an $0.91-$ m-thick blanket.

The second optimization problem was based on the Cascade reactor concept. A version using a $\mathrm{LIAlO}_{2}$ breeding blanket with a BeO neutron multiplier was investigated. In this case the objective was to minimize the sum of the multiplier thickness and the breeding blanket thickness. Constraints were imposed on the minimum tritium breeding ratio, the maximum neutron leakage, and the maximum heat generation rate in the $A R / S i C$ tendons that wrap the chamber.

The Cascade chamber was optimized as a function of three design varlables: the Be0 multiplier thickness, the $6_{11}$ fraction and the LAAQO $_{2}$ blanket thickness. The optimal design point was found to lie at the intersection of the neutron leakage constraint and the heat generation rate constraint. The blanket parameters at this point were

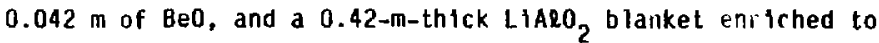
$34.2 \%^{6} \mathrm{Li}$. 


\subsection{RECOMMENDATIONS FOR FUTURE WORK}

It is hoped that the method developed and demonstrated here will be used in fisture conceptual reactor design studies for both inertial and magnetic confinement fusion. The exploratory nature of such studies is an ideal format for multivariable optimization. The study of fusion-fission hybrid blankets is another area for potential future application of this method for systematic optimization.

An interesting application of the techniques developed here would be to compare the optimal blanket designs for the same reactor but with various figures of merit. For the modified HYLIFE concept the blanket was optimized to reduce the cost per unit of not electric power. In doing so, Mn is activated, and the afterheat problem is thus heightened. If minimizing induced activity had been the figure of merit, a completely different blanket design would have emerged. Alternatively, a cost penalty proportional to the chamber's afterheat could be included in defining the figure of merit. The Cascade reactor concept should also be reexamined from an economic perspective once cost sraling relations are developed.

One final 1 recommendation for future work would be to automate and more closely couple the graphics with the definition of the figure of merit and constraints. As it now stands, the graphics are done separately. 


\subsection{A FINAL WORO}

In an optimization problem a complex decision involving the selection of values for a number of interrelated varlables, is made by focussing on a single figure of merit designed to quantify performance and measure the quality of the decision. This figure of merit is maximized or minimized subject to the constraints that may 1 imit the selection of decision variable values. Since all the complexities of the system being analyzed can not, in general, be fully represented in the model, optimization should be regarded as a tool of conceptualization and analysis rather than a principle yielding the true optimum. 83 The result is only as good as the model. A thorough understanding of the system one is dealing with, 1.e., being able to select an appropriate figure of merit, define the constraints, and model the system as accurately as possible, is, therefore, the first prerequistte to effective design optimization. 


\section{REFERENCES}

1. M. J. Monsler, et a1.. "An Overview of Inertiai Fuston Reactor Design," Nucl. Technol./Fusion, 1, p. 302 (July 1981).

2. C. C. Baker, et a1., "Trends and Developments in Magnet1c Fusion Reactor Concepts," Nucl. Technol./Fusion, 1, p. 5 (January 1981).

3. 3. A. Maniscalco, et al., "Recent Progress in Fusion-fission Hybrid Reactor Design Studies," Nucl. Technol./Fuston, 1, p. 419 (October 1981).

4. R. W. Werner, Synfuels from Fuston - Using the Tandem Mirror Reactor and a Thermochemical Cycle to Produce Hydrogen, Lawrence Livermore National Laboratory, Livermore, CA, Rept. UCID-19609 (November 1982).

5. M. A. Pralas, J. B. Romero, E. F. Pearson, "A Critical Review of Fusion Systens for Radtolytic Conversion of Inorgantcs to Gaseous Fuels," Nucl. Technol./Fuston, 2, p. 143 (Apri1 1982).

6. J. A. Maniscalco, et a 1., Civilian Applications of Laser Fuston, Lawrence Livermore National Laboratory, Livermore, CA, Rept. UCRL-52349 Rev. 1 (August 1978).

7. S. Glasstone and R. H. Lovberg, Controlled Thermonuclear Reactions (R. E. Krieger Publishing Co., Huntington, NY, 1960), p. 13 .

B. M. H. E1-Waki1, Nuclear Energy Conversion (Intext Educational Publishers, Scranton, PA, 1971) p. 548. 
9. E. F. Plechaty, et a1., Tabular and Graphical Presentation of 175 Neutron-Group Constants Derived from the LLL Evaluated-NuclearData Library (ENDL), Lawrence Livermore National Laboratory, Livermore, CA, Rept. UCRL-50400, Vol. 16, Rev. 2 (1978).

10. 3. D. Lee et a 1, "Fusion Reactor Nuc leonics: Status and Needs," in Proc. 4th Topical Meeting on the Technology of Controlled Nuclear Fusion (King of Prussia, PR, 0ct. 14-17, 1980) p. 367.

11. E. T. Cheng and R. W. Conn, "A Multipoint Interpolation Method Based on Variational Principles for Functionals of the Solution to Linear Equations," ]. Math, Phys., 17, (5) p. 683 (1976).

12. E. T. Cheng and R. W. Conn, "The Influence of Design Viarlations on Controlled Thermonuclear Reactor Blanket Neutronic Performance Using Variationa 1 Techniques," Nucl. Sc1., Eng., 62, p. 601 (1971).

13. G. R. Wa1sh, Methods of Optimization (John Wiley and Sons, London, England, 19771 p. 81.

14. J. A. Nelder and R. Mead, "A Simplex Method for Function Minimization," Computer Journal, I, p. 308 (1965).

15. D. Klein, "Optimization Considerations in the Design of a Tokamak Reactor," Irans. American Nuclear Society Summer Meeting (Chtcago, IL, June 10-14, 1973) p. 10.

16. D. S. Zuckerman and L. A. Carose?la, "Parametric Studies of an Inertial Confinement Fusion Reactor," Trans. American Nuclear Society Winter Meeting (San Francisco, CA, November 11-15, 1979) p. 54 . 
17. W. R. Meter, Cost-Performance Studtes of an Inertial-fusion Power Plant, Lawrence Lfvermore Natfonal Laboratory, Livermore, CA, Rept. UCRL-50021-79, p. 8-107, (1980).

18, D. H. Berwald and H. R. Meíer, Reactor Systems Modeling for ICF Hybrids," in Proc. 4th Topical Meeting on the Technology of Controlled Nuclear Fusion (King of Prussia, PA, October 14-17, 1980) p. 1487.

19. D. J. Bender, "Mirror Hybrid Reactor Optimization Studies," in Proc. Joint US-USSR Symposium on Fusion Fission Reactors (Livermore, CA, July 13, 1976) p. 37.

20. 0. S. Zuckerman and C. G. Bathke, "Optimization studies of a Commercial EBTR Power Plant," in Proc.9th Symposium on Engineering Problems of Fusion Research (Chicago, IL, October $26-29,1981)$ p. 1839.

21. S. A. W. Gerstl, "A Minimum-Thickness Blanket/Shield with Optimum Tritium Breeding and Shleld Effectiveness," in Proc. 3rd Topical Meeting on the Technology cf Controlled Nuclear Fusion (Sante Fe, NM, May 9-11, 1978) j. 269.

22. M. A. Abdou, "Nuclear Design of the B?ar,"et/Shield System for a Tokamak Esper imental Power Reactor," piuci. Technol. 29, p. 7 (Apri1 1976).

23. M. Z. Youssef, R. W. Conn, G. A. Moses, Neutronics Optimization Studies for a Proliferation Res 1stant ruel Assembly from the Fusion-Fission Fuel factory, SOLASE-H, University of wisconsin, WI, Rept. UWF OH. 263 (Oc tober 1378;. 
24. 0. S. Zuckerman, et al., "Impact of Blanket and Shield Materials on Cost of an EBT Fusion Power Plant", in Proc. 2nd Topical Meeting on Fusion Reactor Materials (Seattle, WA, August 9-12, $1981)$ p. 603.

25. Y. Gohar and M. A. Abdou, "Neutronic Optimization of Solid Breeder Blankets for STARFIRE Design," in Proc. 4th Topical Meeting on the Technology of Controlleg iuclear Fuston (King of Prussia, PA, October 14-17, 1980) p. 628.

26. L. J. Perkins and G. L. KuTcinski, "Economic Design Optimization of the LiPb Blanket for the Mirror Advanced Reactor (MARS)," Nuc1. Tehcnol./Fuston, 4, p. 1107. (Sept. 1983).

27. M. A. Abdou and C. W. Maynard, "Nuclear Design of the Magnet Shield for Fusion Reactors," in Proc. 1st Topical Heeting on the Technology of Cpntrolled Nuclear Fuston (San Diago, CA, Apr 11 $16-18,1974)$ p. 685 .

28. M. Kasai, S. An, S. Kondo, "Parametric Study and Optimization of CTR Engineering Design," in Proc. 5th Symposium on Engineering Problems of Fusion Research (Princeten, NJ, November 5-9, 1973) p. 257 .

29. W. W. Engle, Jr., and F. R. Mynatt, "A Shieid optimization Technique with Direct Utilization ef Transport Calculations," Is ans. American Nuclear Society Winter Meeting ISan Francisco, CA, November 30-December 4, 1969) p. 953.

30. G. ". Schwartz, An Optimization Method for the Design and Operation of Fusion-Fission Hybrid Breeder Reactors, M.S. thesis, Pennsyluania State University, Penn. (1982). 
31. E. Greenspan, A Method for the Optimization of Fuston Reactor Neutroonic Characteristics, Princeton University, Princeton, Rept. MATT-481 (1972).

32. E. Greenspan, W. G. Price, Jr., H. Fishman, SWAN: A Code for the Analys is and Optimization of Fusion Reactor Neucleonic Characteristics, Princeton University, Princeton, Rept. MATT-1008 (Nov. 1973).

33. W. M. Stacey, Jr., "Variational Estimates and Generalized Perturbation Theory for the Ratios of Linear and Bilinear Functiona1s," J. Math, Phys., 13, 8, p. 1119 (1972).

34. R. W Conn and W. M. Stacey, Jr., "Variations 1 Methods for Controlled Thermonuclear Reactor Blanket Studies," Nuc1. Fusion, 13, p. 185 (1973).

35. S. A. W. Gerst1 and W. M. Stacey, Jr., "A Class of Second-0rder Approximate Formulations of Deep Penetration Radiation Transport Problems," Nuc1. Sc1. Eng., 51, p. 339 (1973).

36. E. T. Cheng, "Application of Generalized Variational Principles to Controlled Thermonuc lear Reactor Neutronics Analysis," Nucl. Sct. Eng.: 74, p. 147 (1980).

37. W. M. Stacey, Jr., Variational Methods in Nuclear Reactor Phystcs, (Academic Press, Inc., New York, 1974).

38. E. T. Cheng and R. H. Conn, "Application of Variational Methods to Fuston Reactor Blanket Studies," Trans. American Nuclear Society Summer Meeting (Philadelphia, PA, June 23-27, 1974) p. 27.

39. G. I. Bell and S. Glasstone, Nuclear Reactor Theory, IVan Nostrand Reinhold Co., New York, 1970). 
40. R. Roussopoulos, "Methodes Varlationueles en Theories des Collistons," C. R. Acad. Sct., 236, p. 1858 (1953).

41. S. Giasstone and A. Sesonske, Muclear Reactor Engtneering KVan Nostrand Reinhold Co., New York, NY, 1967).

42. H. Spendley, G. R. Hext, F. R. Himsworth, "Sequential Applications of Simplex Designs in Optimization and Evolutionary Operation," Technometrics, 4, p. 441 \{1962).

43. D. B. Fox and J. S. Liebman, "A Discreie Nonlinear Method for Optimized Engineering Design," Engineering Optimization, $\underline{5}$. p. $129(1981)$.

44. J. M. Parkinson and 0. Hutschinson, "An Investigation into Efficlency of Variants on the Simplex Method, "Numerical Methods for Non-1inear Optimization (Academic Press, 1972) p. 115.

45. J. Trenholme, Lawrence Livermore National Latoratory, Livermore, CA, private communication (June, 1983).

46. 1978 Laser Program Annual Report, Lawrence Livermore National Laboratory, Livermore, Rept. UCRL-50021-78 (1979) section 9.

47. 1979 Laser Program Annual Report, Lawrence Livermore National Laboratory, Livermore, Rept. UCRL-50021-79 (1980) section 8 .

48. 1980 Laser Program Annual Report, Lawrence Livermore National Laboratory, Livermore, Rept. UCRL-50021-80 (1981) sect10í 9.

49. 1967 Laser Program Annual Report, Lawrence Livermore National Laboratory, Livermore, Rept. UCRL-50021-81 (1982) section 8.

50. M. Monsler et a1., "Electric Power from Laser Fusion: The HYLIFE Concept," in Proc. 13th IECEC Conf. (San Diego, CA, Aug. 1978), p. 2164 . 
51. M. J. Monsler and W. R. Meler, "A Conceptual Design Strategy for Liquid-Meta1-Wa11 Inertial Fusioń Reactors," Nuc1. Eng. Des., 63, p. 289 (1981).

52. H. R. Meler and W. B. Thompson, "Conceptual Design Considerations and Neutronics of Lithium Fall Laser Fusion Target Chambers," in Proc. Third Topical Meeting Technology of Controlled Nuc lear Fusion (Santa Fe, NM, May 9-11, 1978), CONF-780508, p. 297.

53 H. I. Avci and G. L. Kulcinski, "The Effect of Liquid-Metal Protection Schemes in Inertial Confinement Fusion Reactors," Nuc 1. Techno1., 44, 333 (1979).

54. W. R. Meier, "Two-Dimensional Neutronics Calculation for the HYLIFE Converter," Nuc1. Techno1., 52, 22 (198i).

55. Handbook of Chemistry and Physics (CRC Press, Inc., Boca Paton, $\mathrm{FL}$, 1982), 63rd ed.

56. R. T. Perry and C. W. Mynard, "A Reyiew of Neutronic Design Criteria." in Proc. Fourth Topical Meeting on Controlled Nuclear Fusion (King of Prussia, PA, 0ct. 14-17, 1980), p. 470.

57. J. Jung and $M$. Abdou, "Importance of Shield Design in Minimizing Radioactive Material Inventory in Tokamaks," in Proc. Fourth Topical Meeting on Controlied Nuclear Fuston (King of Prussia, PA, Oct. 14-17, 1980), P. 458.

58. Mirror Advanced Reactor Study Inter im Design Report, Lawr ence Livermore National Laboratory, Livermore, Rept. UCRL-53333 (Apr 11, 1983). 
59. E. E. Bloom, et a1., "Vanadium Alloys and Hodifled Steels for Low-Activation Fusion Reactor Design," in Iransactions American Nuc lear Society Winter Meeting (Washington, 0.C., Mov. 14-18, 19821 , p. 305 .

60. W. R. Mefer, "Tritium Breeding Management in the HYLIfE Chamber," Nuc 1. Technol., 52, p. 170 (1981).

67. G. L. Kulcinski, "Radiation Damage to Materials in DT Fuston Reactors," in Proc. of the Fifth Conference on Plasma Physics and Controlled Nuclear Fusion Research (Tokyo, Japan, Nov. 11-15, 19741.

62. F. A. Smidt, Jr., "Swelling Behavior of Commercial Ferritic Alloys, EM-12 and HT-9, as Assessed by Heavy Ion Bombardment," Irradiation Effects on the Microstructure and Properties of Metals, ASTH STP 611, 1976, pp. 227-241.

63. E. F. Bloum, "Candidate first Wall Materials for Fusion Reactors," in Proc. of the Tenth Symposium on Fusion Engineer ing (Phtladelphia, PA, Dec. 5-9, 1983).

64. H. E. Mooz, Cost Analysis of Light Water Reactors, Rand Corporation, Santa Monica, CA, Rept. R-203-00E (June 1978).

65. E. F. Plechaty and J. R. Kimlinger, TARTNP: A Couples: Neutron-Photoil Monte Carlo Transport Code, Lawrence Livermore National Laboratory, Livermore, Rept. UCRL-50400, Vol. 14 (1976). 66. J. R. Kimlinger, Lawrence Livermore National Laboratory, Livermore, private communication (0ct. 1983). 
67. 0. G. Doran, J. N. Graves, Meutron Oisplacement Damage Cross Sections for Structural Meta1s," Irradiation Effects on the Microstructure and Properties of Metais, ASTM STP 611, 1976, pp. 463-482.

68. D. G. Doran, "Neutron Displacement Cross Sections for Stainless Steel and Tantalum Based on a Lindhard Model," Nuc1. Sc1., Eng., 49, $130(1972)$.

69. D. G. Doran, "0isplacement Cross Sections for Iron, Nicke?, Stainless Stee1, and Tantalum," Nuc1. Sc1.,Eng.. 52, 398 (1973).

70. M. D. Greenberg, Foundations of Applied Mathematics, (Prentice-Ha11, Inc., Englewood Cliffs, NJ) 1978.

71. J. H. Pitts, "Cascade: A Centrifugal-Action Solid Breeder Reaction Chamber," Nuc1. Technol./Fusion, 4, p. 967 (1983).

72. J. H. Pitts, "Shock Propagation Through the Cascade ICF Reactor $\mathrm{Li}_{2} \mathrm{O}^{-P e b b i e ~ B l a n k e t, " ~ T r a n s . ~ A m e r i c a n ~ N u c l e a r ~ S o c i e t y ~}$ Winter Meeting (San Francisco, CA, Oct. 30-Nov. 3, 1983) p. 184.

73. C. E. Johnson, "Recent Advances in the Cevelopment of Solid Breeder Blanket Materials," to be published in Proc. on 3rd Top. Mtg. on fusion Reactor Materials (Albuquerque, NM, Sept. 19-22, $1983)$.

74. J. H. Norman and G. R. Hightower, "Measurements of the Activity Coefficient of $\mathrm{LiOH}$ Dissolved in $\mathrm{Li}_{2} \mathrm{O}(\mathrm{s})$ for an Evaluation of $\mathrm{Li}_{2} \mathrm{O}$ as a Tritium Breeder Material," to be published in Proc. on 3rd Top. Mtg. on Fusion Reactor Materlals (Albuquerque, NM, Sept. 19-22, 1983). 
75. P. A. Finn, et a 1, "Compatibility Study of Solid Ceramic Breeder Materials," in Proc. on 2nd Top. Mtg. on Fusion Reactor Materials (Seattle, WA, Aug. 9-12, 1981) p. 561.

76. F. J. Howerton, Thresholds of Nuclear Reactions Induced by Neutrons, Photons, Protons, Deuterons, Trittons, and Alpha Particles, Lawrence Livermore National Laboratory, Livermore, Rept. UCRL-50400, Vo1. 9 (Sept. 1970).

77. J. H. Pitts, et a1, A High-Temperature, Low-Activation Design for the Casuade Reactor, Lawrence Livermore National Laboratory, Livermore, Rept. UCRL-90199 Sum. (Jan. 1984). To be presented at the 1984 American Nuc lear Society Summer Heeting in New Orleans, June 3-8, 1984.

78. V. A. Murry and $M$ W. McDowe 11, Primary Heat Transfer Loop Design for the Cascade Inertial Confinement Fusion Reactor, Lawrence Livermore Nationa 1 Laboratory, Livermore, Rept. UCRL-15578 Sum. (Jan. 1984). To be presented at the 1984 American Nuclear Society Summer Meeting in New Or leans, June 3-8, 1984.

79. 0. R. Walton, Granular Flow Considerations in the Design of a Cascade Sol1d Breeder Reacton Chamber, Lawrence Livermore National Laboratory, Livermore, Rept. UCID-19903 (Oct. 1983).

80. J. H. Pitts, "Mechanical and Thermal Design of the Cascade Reactor," to be published in Proc. on 10th Symposium of fusion Engineering (Philadelphia, PA, December 5-9, 1983).

81. I. Maya, G. A. Technologies, San Diego, CA, private communication (March 1984). 
$-196-$

82. W. R. Meter, "Neutron Leakage Through Fusion Chambers Ports: A Comparison of Lithium and Lead-Lithium Blankets," Nucl.

Technol./Fuslon. 3. p. 385 (Hay 1983).

83. D. C. Luenberger, Introduction to Linear and Nonlinear Programing (Addision-Wesley, Reading, PA, 1973). 


\section{APPENOIX - I OERIVATIVE OF THE THREE POINT INTERPOLATION FORHULA} WITH $\Sigma(x)$ PROPORTIONAL TO $x$.

Consider the case where $\Sigma(x)$ is proportional to $x$. The three point interpolation formula, Eq. 2.64, becomes

$$
\begin{aligned}
R_{S I 3} & =x R_{a} / x_{a} \\
& -\left[\left(x-x_{a}\right) /\left(x_{c}-x_{a}\right)\right]\left[x_{c} R_{a} / x_{a}-R_{c}\right]\left[x R_{b} / x_{b}-x R_{a} / x_{a}\right] / 0,
\end{aligned}
$$

where

$$
\begin{aligned}
D= & {\left[\left(x-x_{b}\right) /\left(x_{c}-x_{b}\right)\right]\left[x_{c} R_{b} / x_{b}-R_{c}\right] } \\
& -\left[\left(x-x_{a}\right) /\left(x_{c}-x_{a}\right)\right]\left[x_{c} R_{a} / x_{a}-R_{c}\right] .
\end{aligned}
$$

Equation I. 1 can be rewritten as

$$
R_{S I 3}=x R_{a} / x_{a}-\left[\left(x-x_{a}\right) / x_{a}\right]\left[x R_{b} / x_{b}-x R_{a} / x_{a}\right] t_{a c} / 0,
$$

where

$$
\begin{aligned}
& 3=\left.\left\langle x-x_{b}\right)\right|_{b c} / x_{b}-\left.\left\langle x-x_{a}\right\rangle\right|_{a c} / x_{a}, \\
& 1_{a c}=\left(x_{c} R_{a}-x_{a} R_{c}\right) /\left(x_{c}-x_{a}\right),
\end{aligned}
$$

and

$$
1_{b c}=\left(x_{c} R_{b}-x_{b} R_{c}\right) /\left(x_{c}-x_{b}\right) .
$$

Note that $i_{\text {ac }}$ is the intercept on the R-axis of a straight line through the points $\left(x_{a}, R_{a}\right)$ and $\left(x_{c}, R_{c}\right)$. Likewtse, $i_{b c}$ is the intercept on the R.axis of a line through $\left(x_{b}, R_{b}\right)$ and $\left(x_{c}, R_{c}\right)$. Gathering terms, Eq. I.2 can be rewritten as 


$$
R_{S I 3}=x R_{a} / x_{a}-\left(C_{1} x^{2}-C_{2} x\right) /\left(C_{3} x+C_{4}\right),
$$

where

$$
\begin{aligned}
& c_{1}=1_{a c}\left(R_{b} / x_{b}-R_{a} / x_{a}\right) / x_{a}, \\
& c_{2}=1_{a c}\left(R_{b} / x_{b}-R_{a} / x_{a}\right), \\
& c_{3}=1_{b c} / x_{b}-1_{a c} / x_{a}, \text { and } \\
& c_{4}=1_{a c}-1_{b c} .
\end{aligned}
$$

The derivative of $\mathrm{R}_{\mathrm{SI} 3}$ with respect to $\times$ is then,

$$
R_{S I 3}^{\prime}=R_{a} / x_{a}-\left[\left(C_{3} x+C_{4}\right)\left(C_{1} x-C_{2}\right)-\left(C_{1} x^{2}-C_{2} x\right) C_{3}\right] / 0 .
$$

where

$$
v=\left(c_{3} x+c_{4}\right)^{2}
$$

The limit as $x$ approaches zero is

$$
\lim _{x \rightarrow 0} R_{S I 3}^{\prime}=R_{a} / x_{a}+C_{2} / C_{4} \text {. }
$$

To avold nega+ive values of $R$ as $x$ approaches zero, Eq. I. 5 must be greater than or equal to zero. That is,

$$
R_{a} / x_{a}-1_{a c}\left(R_{b} / x_{b}-R_{a} / x_{a}\right) /\left(1_{a c}-1_{b c}\right) \geq 0,
$$

or

$$
\left(1_{a c} R_{b} / x_{b}-q_{b c}{ }_{a} / x_{a}\right) /\left(1_{a c}-1_{b c}\right) \geq 0 .
$$




\section{APPENDIX II USER INFORMATION}

The fusion reactor blanket optimization code is available on the National Magnetic Fusion Energy Computer Center (NMFECC) system. To access the code type

FILEM RDS 3011 .FRBOPTC filelist

where "filelist" is one or more of the following filenames.

MVOHY = multivariable optimization program for the modified HYLIFE concept. It includes the figure of merit function and the successive interpolation functions. MVOHY reads INPUT, ca11s CREEP, and writes OUTFILE.

INPUT $=$ sample input file for MVOHY. This file allows the user to change the starting point of the search, the step size, the convergence criterion, and the maximum number of iterations without recompliting the program.

OUTFILE = sample output file from MVOHY. It incluces information written by CREEP.

CREEP = subroutine for the direct search, nonlinear simplex optimization algorithm. 
BCRP = bthary ftle of CREEP.

RVOHY3 = multivarlable opttmization program for the modified HYLIFE concept which includes three point interpolation for one of the variables.

MVOCS = multivariable optimization program for the Cascade reactor concept. This is a 3 variable problem.

Combining an Mvo program with the subroutine CREEP makes up the fusion reactor bianket optimization code. The code runs on CRAY-I machines with the CIVIC compiler.

The figure of merit function in MVG changes from problem to problem. Since the optimization algorithm, CREEP, does not change from problem to problem, the binary file BCRP can simply be passed to the lnader using a $L I B=$ specification in the CIVIC statement. Alternatively, the subroutine CREEP must be merged with the MVO program.

Many comment statements have been included in an at tempt to make the MVO and CREEP routines self explanatory. Questions that do arise can be referred to the author in care of Lawrence Livermore National Laboratory, Livermore, CA 94550. 